The Origin of Life

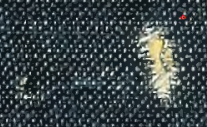

(3)

J. Butiler Bunke 


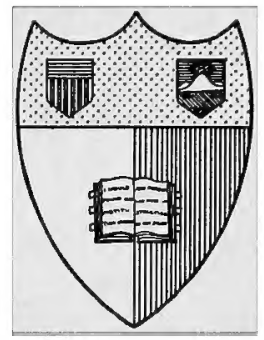

\section{Oarnell Alniturasity Fithrary}

Jtḩara, Nem 售axk

THE LIBRARY OF

\section{EMIL KUICHLING, C. E.}

ROCHESTER, NEW YORK

THE GIFT OF

SARAH L. KUICHLING

1919 
QH 325 Cornell University Library

The origin of life, its physical basis a

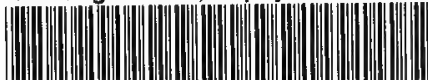

31924005006865 engr, anx 


\section{Cornell University Library}

The original of this book is in the Cornell University Library.

There are no known copyright restrictions in the United States on the use of the text. 
THE ORIGIN OF LIFE 



\title{
THE ORIGIN OF LIFE
}

Its Physical Basis and Definition

\author{
BY \\ JOHN BUTLER BURKE
}

NEW YORK

FREDERICK A. STOKES COMPANY

Publishers 
Richapd Clay and Bons, Limited, RREAD STHELT HILI, E.C., AND BUNGAY, SUFFOLK. 


\section{PREFACE}

IN presenting this work to the judgment of my critics, as the result in part of my studies for some years past, in some respects in outline whilst in others in detail, and more so perhaps than it was my intention at first to make it, two points should be borne in mind. In the first place, it is intended that the chapters which deal with phosphorescence may with advantage be omitted by those who are not particularly interested in such matters, since they may tend to divert the attention from the real points at issue, if the mind is not specially familiar with physical conceptions. The reader who does not wish to be burdened with detail is therefore recommended to omit them, at any rate on the first reading, if the book should prove of sufficient interest to demand his perusal for a second time. Those chapters of a purely physical and perhaps somewhat technical nature, which he thus may think it worth his while to pass over, have been introduced to illustrate the way in which the phenomenon which I have called physical metabolism admits of comparison with the highly 
complex biological effects in bringing out the essential features of the work. If therefore he passes over these he will find in the other chapters a résumé of the results which they contain. In the second place, it must not be supposed that the problem of the origin of life has been solved to the satisfaction of all parties or of any, even if a clue to its solution may be claimed in a suggestive form.

Since the days of the great controversy in which Tyndall and Huxley took so prominent a part, the interest in the question of spontaneous generation has scarcely surpassed, nor in some respects does it appear to have equalled, the enthusiasm which these experiments, whatever their ultimate bearing on the question, have aroused.

Although it is not the object of this book to lend support to the doctrine of abiogenesis, or the development, at the present day, of living from absolutely non-living matter, the more hopeful, though as it must be admitted less gratifying, view to take, is that we have arrived at a method of structural organic synthesis of artificial cells, which, if it does not give us natural organie life such as we see existing around us, gives us at least something which admits of being placerl in the gap, or, as it might preferably be called, the borderland, between living and dead matter, as familiarly understood.

Those who will approach the subject will, it is hoped, approach it with an open mind, and re- 
member also that great as has been the progress of science generally in the nineteenth century, we are after all merely at the dawn, so to speak, of that knowledge which is beginning to appear before us: that, in fact, in 2,500 years to comeif it is not too far ahead to think of, and it certainly ought not to be if we are to face the question in the proper light-people will doubtless look back to the work of this century in much the same fashion as we too are wont to look back, though it is to be hoped not down, upon the great efforts and marvellous speculations of the Greek mind of 2,500 years ago, in its brilliant attempts to unravel the problem which has puzzled humanity for ages: a problem which doubtless will continue to puzzle it to a considerable extent for many days to come. The why and the wherefore we may ask, but get no answer to; the how is our only consolation: and even in that do we need the most careful steering to avoid the pitfalls and precipices of error.

One word more I feel should preface the introduction to this book, and that is to express my indebtedness to the editor of the Fortnightly Review for his kindness in permitting me to reproduce here part of an article which has appeared in his Review, and to state also, how much the interest which this subject has evoked in England and in America is due to him and others mentioned in the text.

\section{JOHN BUTLER BURKE.}

Cambridge,

January, 1906. 



\section{CONTENTS}

\section{CHAPTER I}

INTRODUCTION-THE NATURE OF THE PROBLEM

Plan of the book-Relationship of natural phenomena-The continuity of vital processes-Historical-Aristotle, \&c.Life as a series of molecular changes-The gradual scale from the more complex to the simpler forms of molecular aggregation - Luminosity and metabolism - Phosphorescence and the simpler forms of life-Physical evidence of simple metabolism in fluorescent and in radio-active bodies -Pflïger's theory-Experiments with radium and bouillon - Borderland between mineral and vegetable kingdomsThe dawn of life . . . . . . . . . . . .

\section{CHAPTER II}

THE CONTINUITY OF VITAL PROCESSES

The properties of living matter-Life as conditioned by moisture and temperature-Metabolism and the intussusception of new matter or integration; and waste or disintegration by oxidation-The cyclic process-Chemical composition and protoplasm-Life and organisation-Bastian on protoplasm -Stimulation-Work-Herbert Spencer's definition of life -Fechner's views-The continuity of the animate and inanimate when clearly defined-Three stages that science has to pass : empirical, classificatory, theoretical ......

\section{CHAPTER III}

\section{CLASSIFICATION OF LIVING TYPES}

Reasons for extending the meaning of the word life to include a wider class of phenomena-Sciences not divided into watertight compartments, but their division largely arbitrarySurvival of living proteid-Definition of life-Life-stuffManner in which it may have at first arisen-Continuity of organic and inorganic matter-Biogenesis carried to its 
logical extreme-Haeckel and biogenesis-Cyclic process the test of life in the higher forms of matter-Whether a cell-wall is necessary in ultra-microscopic germs-Metabolic combination of two opposite processes-How they are effected-Formation of molecular aggregates-Many crystals may be fossilised remains of living matter-Classification should not be between organic and inorganic but between active and inert matter . . . . . . . . . . . . .

\section{CHAPTER IV}

\section{THE CORRELATION OF VITAI, PHENOMENA}

The object in view-Results outcome in part of researches originally started as to the phenomena of phosphorescenceObject to arrive at dynamical explanations-Luminosity result of metabolic actions, of a building up and breaking down of molecules-Fluorescence and phosphorescenceLuminosity of gases when an electric discharge passes through them-Theory of large chains of moleculesFluorescence and absorption-Inferences to be drawn from these-Luminous and non-luminous states of matter two different states-Catalytic actions-Enzymes and nucleiStable and unstable groups of molecules-Atoms may be elementary cells-Biogenesis carried to its logical extremeHuxley's scientific faith-Views of Johannes Müller-The unity and plurality in Nature everywhere combined, and constitute its continuity. . . . . . . . . . . .

\section{CHAPTER V}

\section{THE PHYSTCAL BABIS OF LIFE}

This correlation of Vital Phenomena opens up a new perspective -Life in its primitive state must have been different from anything now observed in Nature-According to Clerk Maxwell the number of atoms in the cell is not sufficient to account for its immense potentiality-This potentiality, with all-its: varieties, probably the result of perturbations in the particular motion which constitutes the principle of vital activity-How it may have arisen-Natural as distinct from artificial life-Radio-activity of living bodies, plants, and animals-Experiments of Tommasina-Origin of primitive radio-active bodies lost in same obscurity as that of primitive life

\section{OHAPTER VI}

EXPERIMENTS WITH RAUIUM AND CULTURE MEDIA

Experiments with glycerine and liquid air-Dr. Gladstone's glycerine crystals-Culture produced by radium salts in 
gelatin bouillon-Other globular bodies produced by gum

PAGE and gelatin-Reasons for supposing radiobes are not bacteria -Negative experiments with eyanogen-Pfluger's theoryNature of the cyanogen molecules and of the radium molecules-Dubois' vacuolides not radiobes-Sachs's theory of colloid bodies: that they are crystals asymmetrically arranged -Experiments of Leduc, Bütschli, and others-Discussion of Pasteur's results and their bearing on the present experiments-Radiobes and primitive life ...........

\section{CHAPTER VII}

\section{ON ARTIFICIAL CELLS, AND ARTIFICIAL LIFE}

Nature of the bodies produced by radium-von Schrön's petroblasts-Apparent life in young crystals-Bodies observed by Quincke-Foam-cells - Cellular protoplasm, how it may have been formed-Sir William Ramsay's helium bubbles - How these may be formed and what their behaviour. would be-M. Raphä̈l Dubois and mineral cultures or vacuolides produced by barium salts-Experiments with barium and other salts-The peculiar nature of uranium cultures-Whether it is radiu-activity that produces the effect and in what way-It is not the emitted rays $a, \beta$, or $\gamma$; but probably slow-moving rays-Structure of such artificial cells-Their sensitiveness to electrical and chemical stimuli - Their Parthenogenesis-Work of Loeb-Mode of subdivision probably similar . . . . . . . . .

\section{OHAPTER VIII}

ON THE STRUCTURE OF CELLS, NATURAL AND ARTIFICIAL, AND THE SOURCE OF THE ENERGY OF VITAL FLUX

Distinction between artificial and natural life-Morphology of cells-Vital process essentially a metabolism-Complexity of cell structure and potentiality of cell-The vital process as distinct from complexity of structure-The nucleus and Karyokinesis-Max Verworn on structure as result of metabolism - Whether his views may not be modified in the light of more recent ideas of the nature of solid and liquid bodies-Difficulties in studying structure of living cellCellular structure imparted by reagents-The ultimate or $n$th nucleus-Its probable nature, an aggregate of electrons like a radio-active element-Internal energy of living matter thus stored up in the rther-This may fit in as a physical and dynamical explanation of Sir Oliver Lodge's immaterial source of energy in living organisms, thus apparently independent of material connections, but really subject to the universal law of the conservation of Energy . . . . . 132 


\section{CHAPTER IX}

THE NUCLEUS AS A SOURCE OF ENERGY

Nucleus a source of energy-Possible mode of reconciliation between opposite schools of Haeckel and Lodge-Bioelements-Altmann's bioplasts-Dr. Charlton Bastian and the transmutation of species-Life-activity and radio-activity -Richter and Preyer's cosmoza-Bathybius and precipitates -The problem of the origin of life runs parallel with that of the origin of matter. . . . . . . . . . . .

\section{CHAPTER X}

\section{THE DESCENT OF LIVING PROTOPLASM}

Artificial cells in their relation to the mode in which life first made its appearance-Criticisms as to the nature of these cells-Preyer's theory-The small chance of the particular aggregations constituting a living cell being formed -Experiments with cyanogen and electric dischargeProbable structure of Haeckel's Monera-Fresh "speculation in their relation to biogenesis

\section{CHAPTER XI}

\section{SPONTANEOUS GENERATION}

Three states of electronic aggregation-Spontaneous generation a problem like that of perpetual motion cannot be demonstrated-Views of Pasteur and Weismann-Objections to Pasteur's results-Views of Bastian-J. Arthur Thomson -Haeckel-Bastian's heterogenesis-Method of filtration - Japp's views on asymmetric structures-Asynmetric structure of biogen-Origin of asymmetric structure as profound as that of life-Karl Pearson and FitzGerald on climate as a factor in producing asymmetry . . . . . . 191

\section{CHAPTER XII}

\section{THE MECHANISM OF LIFE}

Two opposing principles in vital processes; the constructive and the destructive-Mode in which metabolism is kept up in the cell in consequence of the electrical and radio-active properties of the nucleus-Artificial cells merely models, but yet give a clue to the nature of the mechanism in natural ones-Biogen hereditary substance-Nature of this substance-Biogen the transition stage between free electricity and condensed electricity or atomic matter-Astronomical analogue-Constituents of protoplasm the lightest elements-Bearing of this on the origin of protoplasmTwo kinds of biogens . . . . . . . . . . . . . . 


\section{CHAPTER XIII}

PHYSIOAL METABOLISM

The phenomenon of fluorescence-Discovered by HerschelChange of refrangibility discovered by Stokes-Work of Lommel--Change of absorption-Description of experiments on this-Views of C. E. Guillaume and A. CottonNegative results-The experiments of Nichols and Merritt - Relation between absorption and the intensity of fluorescence-Inference to be drawn from these observations and the change of refrangibility, the fluorescence being independent of the period of the exciting light-Fluorescence a building up and breaking down of molecules-Physical metabolism

\section{CHAPTER XIV}

\section{RADIATION AND MOLECULAR AGGREGATION}

Summarily the result of association and dissociation-Or more or less complex molecular groups-Radiation from flamesTyndall's experiments on the emissive and absorptive powers of gases -Spectra of oxygen-Repulsion between spheres of molecular dimensions whilst radiating intensely - How aggregates may preserve their identity-Catalytic actionEffect of glycerine and gelatin on aggregation in fluorescent bodies

\section{CHAPTER XV}

ON THE FORMATION OF AGGREGATES OF LARGE MIOLECULES

The effect of infra-red rays-Stokes' law reversed, or calorescence-The function of a nucleus in phosphorescent bodies -The effect of surface tension on aggregation-Influence of films-Chemical reaction in high vacua . . . . . . . . .

\section{CHAPTER XVI}

\section{PHOSPHORESCENCE AND MOLECULAR AGGREGATION}

Phosphorescence and catalytic action-Effect of molecular concentrations on freedom of corpuscles-Dependence of phosphorescence upon free-paths and velocity of corpuscles -Existence of separate phosphorescent molecules in liquids, and of separate active molecules in luminous gases-That separate large molecules exist in flames-The process of catalysis and metabolism once more . . . . . . . . . . 


\section{CHAPTER XVII}

\section{RADIO-ACTIVITY AND PHOSPHORESCENCE}

Molecular theory of phosphorescence and of radio-activityPAGT Analogy between phosphorescent molecules and those of radio-active emanation from thorium and radium compounds-Model of radio-active and phosphorescent molecules-Model of positive ion-The electric theory of matter

\section{CHAPTER XVIII}

\section{MODELS OF POSITIVE ION OR ATOMIC NUCLEUS}

Fluorescence of monatomic gases-Effect of specific inductive capacity on molecular aggregation-Difficulties in the kinetic theory-Nature of positive nucleus-Effect of approach of corpuscles on motion in nucleus-Balmer's law -Ramage's observations-Transmutation of the elements of same series-Aggregations produced by pressureModels of molecules in phosphorescent gases and in emanations.................

\section{CHAPTER XIX}

\section{MATTER AND "MIND-STUFF"}

Conclusions-Résumé of what has been said-Biogen is matter in process of becoming or being transformed from free electricity into condensed electricity, called atoms-Universal nature of physical metabolism-Matter a mode of motionMotion a complex perception or mode of thought-Two modes of thought, our own minds and matter are concomitant-Difficulty solved by Idealism--Berkeley and HumeTheir respective positions-Mind-stuff, how reconciled with Idealism-The permanent source of possible sensation . . 


\section{LIST OF ILLUSTRATIONS}

Test-tube containing Radium or other Salt, for Purpose of page Sterilisation . . . . . . . . . . . . 92

Test-tubes showing various Cultures . . . . . . . . . . . . 92

Developments during First Week . . . . . . . . . . . . . . 98

After a Fortnight . . . . . . . . . . . . . . . . . 100

Plates I., II., III., of Developments . . . . . . . . . . . 100, 102

Leduc's Cells . . . . . . . . . . . . . . . . . 104

Lehmann's Liquid Crystals . . . . . . . . . . . . . . 106

Nine Stages of Development of Radiobes . 108, 110, 112, 112(a), 112(b)

Lehmann Crystals . . . . . . . . . . . 118, 120

Sir Wm. Ramsay's Cells and their Effect on Nuclei . . $120(a)$ to (e)

M. Dubois' Vacuolides . . . . . . . . . . . . . . . . . 122

Deflection of Radiation in a Magnetic Field and other Properties of $a$-, $\beta$-, $\gamma$-Rays . . . . . . . . . . . . . . . . 126

Stoney's Diagram illustrating the Periodic Law . . . . . . . . 227

Stokes' Demonstration of his Law of Change of Refrangibility . 235

Method of Measuring Change of Absorption . . . . . . . . 239

Nichols and Merritt's Curve for Absorption and Intensity of Fluorescence . . . . . . . . . . . . . . 247

Phosphorescent Gas Experiments . . . . . . . . . . . . 285 



\title{
THE ORIGIN OF LIFE
}

\author{
CHAPTER I
}

INTRODUCTION.-THE NATURE OF THE PROBLEM

Plan of the book-Relationship of natural phenomena-The continuity of vital processes-Historical-Aristotle, \&c.Life as a series of molecular changes-The gradual scale from the more complex to the simpler forms of molecular aggregation - Luminosity and metabolism - Phosphorescence and the simpler forms of life-Physical evidence of simple metabolism in fluorescent and in radio-active bodies -Pflïger's theory_Experiments with radium and bouillon -Borderland between mineral and vegetable kingdomsThe dawn of life.

THE aspect of the question which it is the object of this essay to expound in as familiar and yet philosophic terms as the subject will itself admit of, is primarily twofold. That twofold aspect is that of actual knowledge and of speculation. For in its first origin as well as in its last end, life remains and doubtless for long ages, if not for ever, will remain a mystery to the intelligence of human beings. Between these two limits, however, there is much known and to be known. And the two means of attack may work together although 
quite independently, lest a false step on the part of the scout or guide should, to speak metaphorically, pull knowledge down or divert it from its true path of progress. This essay then is the embodiment of speculation and of experiment, the latter being the handmaid of that speculation that more than once it has pulled up and diverted in another course. Throughout, it is the author's wish that the work should be, and present itself to those who follow the line of reasoning mapped out in it as being, an effort in the pursuit of an object one does not profess to have attained, nor perhaps hopes ever to attain, but only to pursue. If it has added a few steps, or even only one, towards the solution of the problem, that step will not have been taken altogether in vain.

Theory and experiment must go hand in hand, and much depends on one as much as on the other, not merely upon its accuracy but also upon its nature. Hundreds of experiments may be made, which, however, notwithstanding their refinement and accuracy, contribute little to the march of human progress in the right direction; they may of course in ages count for much, but the chief thing is that the experiment should be of the right kind, and it is often desirable that as much time, if not even more time, should be spent in deciding upon the right thing to be done than in doing that thing itself. One bad theory is * often worse than ten bad experiments, because even if these are properly carried out, they may yet, if based upon false notions, add little or nothing, 


\section{INTRODUCTION}

if not to the store at least to the advancement of knowledge: and count almost for as little as the one bad experiment whether based upon theory or not.

Attention is therefore needed in the choice of the path to be pursued as well as in the pursuit itself. Now for our part we do not wish to affirm, nor strictly speaking even to suggest, that the theories herein hazarded and the experiments described to verify them, have been in all cases in the right direction; what may be affirmed, however, is that some trouble has been taken in deciding on them. No doubt the same end may be reached by divers paths.

The subject is thus approached, if one may venture to approach it so, from a different standpoint from that which the biologist, trained as he would be in another frame of mind, would naturally have started from. It is attacked from the standpoint of a physicist who endeavours to disclose in many of the phenomena, perhaps more familiar to physicists than to biologists, the striking resemblance between many physical and biological effects.

The object of this book then is to indicate, and it is hoped also to prove, so far as proof is possible, the continuity of vital processes; that the links between the organic and the inorganic, between living and dead matter form an unbroken and continuous chain, which connects biology with physics as closely as it unites the two with chemistry.

The doctrine of spontaneous generation was in the Middle Ages accepted as a fact: and those who may 


\section{THE ORIGIN OF LIFE}

affirm it now are not such heretics as might at first sight be imagined.

It was the accepted theory in Europe at an earlier period than the Middle Ages, and, in fact, for more than eighteen hundred years. Not till the seventeenth century does it appear to have been seriously questioned. Indeed, as Huxley reminds us, just two hundred and thirty-seven years ago a student, Francesco Redi, a native of the country which numbers amongst her sons so many illustrous names of the sixteenth and seventeenth centuries-whose studies have become associated for all time with the great work of laying the foundation of modern science -enunciated the hypothesis now known as biogenesis; that all living matter has sprung from pre-existing living matter. "The extreme simplicity of his experiments and the clearness of his arguments, gained for his views, and for their consequences, almost universal acceptance. He was a man of the widest knowledge and most versatile abilities, distinguished alike as scholar, poet, physician and naturalist. His work Esperienze intorno alla Generazione degl' Insetti went through five editions in twenty years"1: a record which in those days was considered quite exceptional. Now Father Needham, who was associated with Buffon, the great French naturalist, as a believer in what we should, at the present day, call abiogenesis, or the production of living from dead matter, produced experiments

${ }^{1}$ Biogenesis and Abiogenesis-Discourses, Biological and Geological. 


\section{INTRODUCTION}

which seemed to refute Redi's. The results of these, however, were not accurately supposed to prove abiogenesis; for Buffon assumed the existence of "organic molecules" of some substance possessing the inherent properties of life; the molecules of this substance being indestructible, and in modern nomenclature it might be regarded as an element endowed with the potential properties of life.

But Needham and Buffon were encountered by the destructive facts brought forward again by an Italian, the Abbé Spallanzani, who repeated Needham's experiments. He showed that if the tubes used in these experiments were subjected to the temperature of boiling water for three-quarters of an hour and the access of air eliminated by hermetically sealing the tubes, no sign of living forms or animalcules appeared. ${ }^{1}$ In these and all subsequent experiments -including those of Pasteur and of Tyndall as recently as thirty years ago-nothing was really proved: because when animalcules did appear the obvious explanation was that the sterilisation was imperfect; whilst when they did not appear after heating the still more obvious retort was that the process of sterilisation destroyed not merely previously existing life; but also the conditions by which life in ordinary circumstances could possibly have originated.

The only case which seems conclusive, then, is that when living forms arise which it could be proved would not have stood the temperature to which they had

1 See Huxley, loc. cit. 
been previously subjected. Or when by repeated heating and cooling they can be made to disappear and reappear again. If those which appear after the first sterilisation when two substances are brought together are entirely different from any which had previously existed therein before sterilisation was carried out, there can be little doubt that spontaneous generation in some form had actually taken place, or at any rate heterogenesis, for which Dr. Charlton Bastian has fought so persistently and for so many years.

Of this we propose to discourse in this book; whilst the results we have arrived at give us no small reason to believe that the continuity of living and not living substance, as familiarly understood, is a matter which cannot be passed over without pause.

The ancient philosophers like Aristotle believed that motion constituted life. And in regarding Life as mode of Motion, however inadequate that idea (in its ultimate simplicity) may really be, we have been guided by a somewhat similar conception, the notion kept before our mind being, not motion in all its simplicity, for the mere state of motion does not constitute life, but motion in some particular form. Life being, so to speak, a specialised motion, and all its manifestations accompanied by a particular kind, or kinds, of molecular interchange. It is a series of fermentations and thus also a series of catalytic actions and interactions, a catalytic action being a molecular change or series of chemical changes, brought about by the presence of some substance which apparently takes no part in the chemical 


\section{INTRODUCTION}

reactions, but only acts as the medium by which the process is set going and also carried out. This in itself, however, does not constitute the whole nature of the mechanism designated by vitality. The mechanical actions, if they may be so called, are throughout of the nature of a building up and breaking down of complex molecular aggregations ; and essentially of a dynamically unstable kind. This process of building up and of breaking down of such molecules is called metabolism. It is not confined to ordinary physiological processes, but in a gradually simplifying scale, it is to be found even in many purely chemical and physical phenomena. It can be detected even in some of the processes as manifested in the phenomena of radio-activity. Nay, it is not confined to these, for even in those phenomena in which we should least expect it, it appears to be the mechanism by which radiation in many cases, as, for instance, luminosity is almost invariably accomplished. 'That the luminosity of flames and that of phosphorescent and fluorescent bodies are of this nature, due to the building up and breaking down of such highly complex molecular agglomerations, though much simpler than those of proteids, there is ample reason from experimental evidence to think. In other words, that these too are of the nature, and come under the class of metabolic action, although, of course, it is simpler than that which takes part in living processes as familiarly understood. Still there does exist the gradual simplification of such interaction in Nature's scale of being ; and although we cannot go 
so far as to assert that luminous bodies like the flame of the candle, for instance, or an incandescent mantle, can be classified with living things, in their most elementary states, we may say that they at least partake in the process of metabolism; and if metabolism were the whole and the only thing that constituted vital action, they would, of course, be entitled to be included with such things. Flames, phosphorescent bodies, and probably luminous bodies generally, would thus come within the realm of biology, or, more accurately speaking, constitute a science in themselves such as Bio-Physics.

We must, however, before accepting this extension or this fusion of the two sciences, be careful that we are not altogether over sanguine. For does metabolism constitute the whole of vital actions, or should vital processes be confined to metabolic change? This is a question which will form the subject, or the subjects, of discussion in the chapters which are to follow.

The notion that all things are alive, and differ in this respect only in degree, is thus fraught, it should appear, with many advantages, and yet not without its disadvantages. We shall see then, with all due caution and reserve, which the subject naturally demands, how far the idea permits of an extension, if of an extension it admits at all.

It is of interest to note that the notion that luminous bodies are in some elementary sense alive was quite common to the ancients. Thus Hippocrates thought that flames were living things; whilst the 


\section{INTRODUCTION}

idea that the sun was the source not merely of light but of life, and that it is itself alive, is of very ancient origin; as ancient as that of the fire-worshippers themselves.

And, further back, Sûrruta, the author of probably the earliest Indian Manuscript upon the art of healing, the Yajueveda, regarded all moving bodies as living, and those at rest as dead. ${ }^{1}$ But these fantastic notions were never developed into any consistent and coherent whole, no systematic observations or speculations framed before Aristotle took up the study of the question, and it is all the more remarkable that with him it was allowed to drop. Some of his reflections in these matters, as in almost everything he dealt with, are remarkably astute. As the theory of the struggle for existence and survival of the fittest was most surprisingly taught by Empedocles (b. 504 B.c.), so Aristotle (384-322 B.c.) in his work, however erroneous in many ways, recorded a great number of interesting and for the time being important facts, and believed in the spontaneous development of life; but he also thought that eels and frogs were evolved by spontaneous generation. Auaximander believed in what was the equivalent of the nebular theory and he also assigned to life an origin in inorganic materials of primitive or pristine mud.

Through the minute study of living forms since the time of Harvey it has been generally assumed that the barrier between animate and inanimate

1 See Vernon's General Principles of Physiology, translated by Frederick S. Lee. 
nature is great and insurmountable, and still more so during the close of the nineteenth century has it been supposed, not without good reasons, that biology was sharply marked off from the a-biological sciences. The boundary between living and dead matter was supposed to be adequately defined, whereas we think it now appears it can no more be laid down than that between biology and psychology, or biology and sociology. Between biology and physics it seems to be indefinable. When we bear in mind the gradual and continued simplification as we descend from the most complex forms to the simplest atoms, it cannot fail to attract the attention of the acute observer that so also this continual dropping off of properties means something. That the process is in the limit continuous. This is the doctrine we propose to consider, and which we may in the end be forced, whether willingly or unwillingly, to accept as the most consistent and scientific one.

The processes we have to keep before our minds are not merely those of metabolism, but also those of continuity and continuous change.

It is therefore not inconsistent with the idea of biogenesis in its ultimate aspect, although it involves heterogenesis in an extended sense; or trans. mutation, admitting that complex forms can be evolved from simpler ones. Thus the theory of the universality of potential life in matter may be admitted without implying that such a change as that involved in abiogenesis has talken or is taking place. 
This is, however, altogether a matter for experiment. A highly complex organism may be quite incapable of being transformed after a few generations into other species, but after countless generations under varying surroundings Nature would doubtless promote those types which from accidental variations were most suited to it; and finally an organism largely, if not totally, different from its primitive ancestors may be the product of the long series of survivals in ever-changing environments. Thus we ourselves would not be regarded merely as the fittest to survive in our own environment, had that environment remained throughout unchanged, but rather as the descendants of the survivals in gradually changing surroundings, so that we are merely the remnants, so to speak, of all those that went before us, and have inherited many qualities perhaps not altogether the most suitable to our surroundings ; but nevertheless since we may possess on the whole counteracting qualities more suited to the present environment than the other progeny of our ancestors that have died away, our survival may possibly not be so surprising.

So also is it with microbes. They may differ widely, nay even inexplicably so, from primitive forms of life; which we hope in the sequel to have occasion to discuss. But in the long roll of ages such bodies as may now appear to be living, although the biologist may not be willing to admit it, because so much simpler than the simplest that he sees, these may still in countless ages have been the direct descendants of such like forms as 
those simpler ones to which the physicist can attract his notice as appearing quite spontaneously, even at this late hour in the history of the earth.

Till Faraday's discovery of electro-magnetism, which brought electricity and magnetism together, a doctrine not unlike that of biogenesis as it exists to-day might have been, or rather was, applied to magnetism. All magnets were produced from magnets. They could be broken up or subdivided into smaller ones; but these also were magnets, as much so as the originals. It was held to be ridiculous that magnets could be made except by or from previously existing magnets. To Faraday, things seemed different. He perceived unity and relation, where others saw nothing but diversity and plurality. He was convinced from his profound knowledge of Nature that electricity and magnetism were not merely allied phenomena but closely related effects. He observed that an electric current and a magnet reacted on each other; and that a current could induce magnetism temporarily in iron and permanently in steel. And conversely that a magnet by its motion could likewise induce a current in a neighbouring wire. Thus the connection between current electricity and magnetism was established, and the two ever afterwards must be looked upon as concomitant effects.

Turning, then, to the subject of biogenesis, what reason is there for supposing that purely physical and chemical processes cannot give rise to life? 


\section{INTRODUCTION}

None other surely than that hitherto they have not been satisfactorily shown to be capable of doing so. If Nature can prove it, surely reason must obey.

We have argued that the scale of living things varies continuously from the most complex molecular forms even to the simplest molecular and atomic groupings; and perhaps even the groupings of electrons within the atom itself. That such dynamically unstable types of aggregations showing metabolism are to be found in a gradually simplifying scale from the unit cell of the biologist, through complicated catalytic processes manifested in many chemical reactions, even in luminosity, phosphorescence and fluorescence, down to the processes of radio-activity taking place within the atom itself; all of which indicate the continuous building up and breaking down of groups of molecules and of atoms. The periods of time being aeons or seconds as the case may be, the greatness or smallness being only relative to our own perceptions; for truly is there nothing either great or small but thinking makes it so!

One of the most remarkable characteristics of these dynamically unstable aggregates is the large amount of energy which is stored up in them and which they give out in breaking up. The amount of this energy increases proportionately as the aggregates become smaller and smaller. The socalled vital energy of living matter is hardly comparable with that stored up in the atom of radium for instance. The compound which appeared 


\section{4 THE ORIGIN OF LIFE}

to the author to be midway between the organic and the inorganic was cyanogen, but since the results of his experiments upon this subject he has been inclined to regard the bodies he has observed as the products of radium and bouillon to be the nearest approach hitherto observed between visibly living and apparently not living nature. In a word, on the border-line between what we call living and that which we regard, or have regarded as dead.

They have been called radiobes, on account of their origin from radium and the many properties which they have in common with microbes.

An important portion of this work will be devoted to their method of production, properties and position as it seems to be, between the mineral and vegetable kingdoms.

The views which have led up to these experiments may be of interest to follow. They first originated in the theory of Professor Pfluger, of Bonn, that cyanogen was probably the origin of living things. By its chemical reactions, by the part it plays in vital actions, the striking resemblance of its chemical behaviour to that of living proteid, together with the fact that it is formed at a high temperature when primitive life may have originated, are all of themselves of intense interest and highly suggestive of the manner in which the elementary processes of life may have appeared. Not the least remarkable, once more, being the amount of internal energy which the unstable molecule of cyanogen has stored up in it and 
can give out by radiation. In many ways it seemed to be, as Pfliuger said, a "semi-living" thing. His theory has not been accepted by physiologists generally on the ground that, however interesting and suggestive, the evidence was insufficient. It thus fell the victim of a dull conservatism which dismissed what was not established as if it were not true, instead of taking the more philosophic course of procuring further evidence to decide whether it was really true or false.

It seemed most logical to think that if cyanogen is a living thing it would grow and multiply in culture media. Thus the experiment was tried whether, under varying conditions, it could be made to do so or not. The results did not afford evidence from which conclusions could be drawn, unless those conclusions were purely negative, the difficulties in the experiments will be pointed out elsewhere.

The physical analogy, on the other hand, between the instability of cyanogen and radium and the amount of energy stored up in them, although differing in the order of magnitude, led us to observe the results, if any, which radium could produce upon the same culture media. The results in this case were quite definite and distinctly positive. Their properties and minute behaviour were therefore studied with the closest care.

These bodies resembled bacteria in their appearance. They could grow, subdivide, and go through that cyclic process which is so often regarded as the criterion or the test of life. For after a while the 


\section{I6 THE ORIGIN OF LIFE}

properties that we associate with their vitality disappear, the objects themselves disintegrate, and ultimately appear as lifeless forms.

This was too important a matter to be passed over with indifference. Only the casual observer in his most thoughtless moods could have been guilty of so much inaptitude. And yet there were not wanting critics who would have abandoned them to crystallographers.

Well, then, they have not been abandoned, but investigated in divers ways to follow out their actual course; they have afforded ample material for reflection, and results which, to say the least of them, are, as we venture to think, not totally devoid in some instances of the highest interest and importance.

Such unstable aggregates like our

"Little systems have their day, They have their day and cease to be."

The dawn of life is thus not a question that need be abandoned in despair. It doubtless must have taken place, as Huxley said, in the remote prodigious vista of the past when the earth was passing through physical and chemical conditions that perhaps it can no more see again than man can recall his infancy; and the living types upon our planet at the present day are for the most part, at any rate, if not altogether, the descendants of a long series of ancestors extending from that remote past down to the present day. These types, however, produced by the means herein described, are far too elementary to be classified 
with already existing forms, and from the biological point of view should be regarded rather as suggestive and tentative than as dogmatically claiming citizenship with microbes of other kinds.

There is, as we think, strong evidence that they may be some elementary bacilli. The limits of temperature are very different from those of ordinary microbes. Probably none with such optimum temperature would ever have survived. The radiobe is soluble in warm water, and ordinary bacteria are likewise soluble at temperatures exceeding boiling point. Primitive forms of life may have been able to exist only at very low temperatures. They may have originated at the bottom of the sea, where the temperature is very low. The suggestion that they did so arise has often been proposed, and it seems in the light of these experiments that the idea is not at all impossible. At these temperatures such bodies would not necessarily be soluble.

But, granting the fact of solubility in water at temperatures somewhat higher than ordinary temperatures to be totally distinct from the dissolution of cells at comparatively high temperatures such as boiling point, what reason is there to suppose that such primitive forms of life if they could be obtained some day, supposing that they have not yet been found, should be insoluble at any particular temperatures? Such elementary types would doubtless not possess all the properties of the more highly organised types with which we are now familiar, and there is 
no reason to suppose, as will be seen, that solubility is not one of these properties. To assume the contrary would be to beg the question at issue.

The antiseptic property of radium has been supposed to be sufficient to prevent the appearance of life in substances exposed to its influence. Here again it may only be destructive of comparatively higher forms of life such as bacteria. We do not know upon what function of the microbe the injurious action of radium actually depends. Thus the absence of this function or the presence of some counteracting function may be sufficient to permit the survival of a living organism exposed to radio-activity. What is more, the fact that radium can produce an organism in organic bodies may in itself be sufficient to account for its destructive influence upon bacteria generally, such organisms as radiobes being sufficient to destroy all other living or apparently living things, by waging war, so to speak, upon the others; and proving themselves the fittest to survive.

Much stress has been laid upon the possibility of imperfect sterilisation in these experiments. But such criticism can only be the outcome of confusion of thought. If it is admitted that these forms we have obtained are soluble in warm water and if it is further admitted, as it must be, that they are not bacteria, how then can they have been the products of imperfect sterilisation? They surely have a less chance of surviving that process than bacteria themselves. And if they are totally different from such bacteria as we observed when sterilisation is incomplete, there 
remains no room for logic and common sense, but to infer the production of something new which had not previously existed therein.

The objection has also been raised that as the media in which these products have been developed were once living that consequently the origin of life remains as unsolved as it ever was before. This piece of criticism is quite sound. It must, however, be remembered that the culture media previous to the experiment, exhibited none of the properties of life, and the transformation, if it is a transformation, thus appears to have taken place by the reversal of the process of that which once was living and had become lifeless into a living form again, however simplified that living form may be.

The last traces of life as we know it did not and could not possibly have existed in such tubes. So that whatever way we view the matter the conclusion that some more elementary form of life than bacteria does exist is the least startling result that can be inferred from all these facts.

In that gradation we ascend the scale of being from the atom, through many unstable molecular forms, mineral, vegetable and animal, even unto Man, and in self conscious man himself reflect upon the mind-stuff of which he and all Nature are ultimately composed.

The notion that the material atom is a hard and tough thing with no property but that of exerting attractive or repulsive force upon its equally senseless 
neighbours, is gradually and steadily giving way to other and more recondite views as to its actual properties. It may yet prove, and we believe will yet prove, as immaterial in its nature as consciousness itself; nay, in some combination or other perhaps a most stable combination, the seat and the source of all consciousness. And why then this bugbear phantom apprehension of the dynamical or materialistic view of Nature? If by materialism we mean the explanation of all Nature by the properties of atoms: Thus sensibility, consciousness, intelligence, reason, nay, even the sense of morals, form part of one continuous scale of integration of unit elements of matter or mind-stuff. If consciousness, reason, will, the sense of responsibility, can be developed from the cell, as in truth we know they can, why should we stop there and not conclude that they may likewise have developed from the material atoms? For of the atom, or as it is now the electron, we know nothing except that it is a seat of force, of inertia and of motion, if it is to explain merely the physical properties of things. But if we find in the world around us not merely aggregates of the inactive and unconscious but also of active conscious things separated by the gulf between activity and inactivity, thought and thoughtlessness, and if we imagine all Nature to be made of units which can in their aggregation assume activity or apparent inactivity, motion or apparent rest, according to their particular form of motion, we are at a loss to find why in these units there should not also exist the elements 
not merely of motion but also of sensibility and of thought. That these same units should afford not merely the apparently unconscious properties of matter, but likewise what we know them to possess, its conscious functions too.

This is equivalent to the theory of matter which the late Professor Clifford designated as mind-stuff, that endows matter with the properties by which in certain of its states it can also manifest itself as Mind. If such aggregates in constituting a brain and nervous system can become self-conscious, the universe itself may, for anything we know now, be a still more complex aggregate and self-conscious too. This will involve the difficulty of selves within selves, a difficulty which we shall have to face and consider before entertaining the idea of a self-conscious world.

There is no necessary discontinuity between the animate and inanimate Nature as we have grown accustomed to regard it. This point is mentioned at the outset lest pious fears should be raised that the results of this work might be interpreted as destroying the foundations of Religion and of Morality. Rather do they tend, if our views be true, to break down the barrier between Religion and Irreligion and to show the continuity of Nature and of Mind as one harmonious and consistent whole.

We are not entering, nor should we care to enter, upon abstruse questions of metaphysics; but the Natural philosopher must be lopsided indeed, as we fear many such philosophers have been, when they attribute to matter the absence of any of the most 
elementary attributes of mind, when as a matter of fact we know that matter in its highest and most developed forms manifests complex organisation and that sensibility and thought itself are concomitant and run parallel with its most marvellous combinations. It is consistency that drives us to this conclusion. Most men, indeed, are willing to admit, perhaps only because they cannot possibly deny it, that we ourselves have once been microscopic germs, but they are unwilling to admit that these same germs may have once been merely atoms. There is the unconquerable prejudice no doubt that atoms are utterly devoid of even what might be called potential life, or potential sensibility. The prejudice is probably due to the fact that only those who concerned themselves with inanimate matter so-called ever troubled themselves about the properties of atoms; and since they were for the most part unfamiliar with the properties of Matter in its highly developed forms, differing largely as they might do from those in its simpler states, they likewise assumed a gulf between these two states. Rather should we pre-suppose that since Matter in its most complex states does reveal Mind, that Mind is an inherent property of Matter even in its most elementary form, and that sensibility in some rudimentary type is a property of the atom as much as motion and attraction or repulsive force.

The theory of spontaneous generation, by this we mean the evolution of what we have a right to think is living from that which we have hitherto had a right to think was not, is thus devoid of all such difficulties 
as inconsistent minds ascribe to it. It raises no obstacle whatsoever to Ethical or Religious thought; "For we are but parts of one stupendous whole," so that Consciousness, feeling, life itself thus appear as an attribute of matter varying only in degree. The physicist strictly speaking need not concern himself with this, but the Natural philosopher should and must. $\mathrm{He}$ is bound to study Nature as a whole and therefore cannot fail to observe that sensibility and life are as much properties of Matter as motion and force. And this he may discourse upon without being in the least sense metaphysical.

Of the ultimate nature of force and of motion it is not our intention here to speak, other than to note that to dwell upon them would be quite beyond our scope. In the closing chapters we shall venture to pass some remarks on the idealistic interpretation of Matter, an interpretation which appears to be the true one; we are, however, met by no contradiction, because though admitting as we do that Mind is a property of Matter in its higher and more complex states, the atoms of which Matter is composed are perceptions and therefore not merely elements of mind-stuff, but, strictly speaking, nothing else but Mind. We shall defer this question for the present until other matters far simpler are discussed.

The discussion of this subject, however, and its investigation from various points of view will always be a most fascinating occupation. We can claim for this work to have re-opened the subject 


\section{THE ORIGIN OF LIFE}

in a new light and to have added something to it, but by no means to have unravelled it. During our sojourn in this strange land, as Marcus Aurelius described life, only one side of Nature is open to our minds. We live, so to speak, in three dimensions, although there may be countless more. Not, indeed, until the veil of Isis has been lifted from our eyes shall it be ours to realise the meaning of the harmony of the things we live in; and of the beauty of the things we see.

The ultimate problem may remain unsolved, and the question: "whence have we come and whither are we going?" still continue to be asked again and again by thinking minds, as often as it had been asked before. The mind of Plato was as near the solution of the problem as the clearest minds of to-day. And with Tyndall the thought may perhaps be expressed that this great question will be considered by the noblest minds though probably with equal ineffectiveness, when, as with him, "like streaks of morning cloud," we too shall have melted into "the infinite azure of the past." 


\section{CHAPTER II}

\section{THE CONTINUITY OF VITAL PROCESSES}

The properties of living matter-Life as conditioned by moisture and temperature-Metabolism and the intus-seption of new matter or integration ; and waste or disintegration by oxidation-The cyclic process-Chemical composition and protoplasm-Life and organisation-Bastian on protoplasm -Stimulation-Work-Herbert Spencer's definition of life -Fechner's views-The continuity of the animate and inanimate when clearly defined-Three stages that science has to pass : empirical, classificatory, and theoretical.

BEFORE entering at length upon the subject of the origin of the simplest types of semi-living forms, it will be necessary to clear our minds at the outset as to what we mean, and what is generally meant, by living things. It will not be enough to regard radiobes as living because some authorities claim that even crystals should be included in that category.

By life we mean something more than mere static aggregations of molecules, even if they can grow and subdivide. Growth in such cases may be merely by accretion or accumulation of layers one over the other as it were, whilst subdivision may be merely by cleavage. Life means something more than this. It is an actual flux or continuous change of substance in a specialised unstable state of motion. Once this 
flux ceases, the organism as an organism may be considered to have lost the property of vitality, even if the constituent parts of which it is composed be living. The crystal may be made up of living particles, and yet as an organism it may be dead. What then are the points which must be considered in the definition of life? Here we must pause awhile; and reflect not merely upon that life around us, upon the qualities which are essential to it as life, and which we should expect to find associated with simpler types of life if they should be discovered; but upon those other qualities that, though essential to the simplest forms of life already known, may be merely accidents; and the result only of their relatively great complexity. We may formulate six points in the processes that generally constitute vitality.

(1) Living matter, it is generally supposed, must contain protoplasm. It invariably is composed of highly complex compounds of carbon, oxygen, hydrogen and nitrogen. It also contains sulphur, phosphorus, iron, aluminium and some other elements, constituting protein, only obtained from living imatter, whilst water is the chief constituent of protoplasm, likewise apparently universal in existing types.

(2) Metabolism is essentially a process taking place in all living as distinet from dead matter. This is more to the point if we are to deal with possible forms of life. The disintegration or decomposition which results from oxidation on the one hand with a waste product carbonic acid, together with re-integration by the intus-seption or absorption of new matter. 
In the healthy organism there is a balance between these two processes when maturity is attained. Previous to maturity intus-seption is greater than waste and the organism grows by the accumulation within itself of new matter from its environment, the matter which it assimilates being greater than that which it can get rid of. When, however, there is a balance between the two processes, the power of reproduction sets in, and when the process of disintegration exceeds that of re-integration there is degeneration, and death as a necessary consequence, in the course of time ensues.

The growth in crystals is due to the addition of layers of new matter; so that their growth is quite a different thing from that of animals and plants.

(3) There is the tendency to undergo a cyclic process. This includes not merely growth, but also decay. The evidence of internal energy is gradually lost. There is thus a continuous change of substance, together with a continual change of size and of form of the individual, and finally decay and death, whilst portions detached may also go through the same cyclic process as the parent source from which they originally sprung. So in an endless chain is the peculiar phenomenon we call life carried on.

(4) Such individuals possess a certain organisation or structure.

(5) They are largely dependent upon temperature and moisture.

(6) They are highly susceptible to external influences. 
This irritability is often considered a test of life, but not accurately so. All these properties imply a relationship between the internal processes in the individual and its external environment. In other words, as Herbert Spencer has put it, Life is the continuous adjustment between the internal relations of an individual or organism and its external relations with its environment: an idea which runs through the whole of his Biology and Sociology.

Although all the six conditions we have described are included in this definition, or, to put it more accurately, the definition includes all those processes we have mentioned in the six conditions of life, it may include many others without in any way affecting it. The definition is at once adequate and precise, and does not in the least imply more than is essential to vitality in elementary forms. We may also regard life from another but equivalent aspect, though more suitable to our purpose because more general. As Huxley has put it, living matter or protoplasm, and the products of its metamorphosis, may be regarded under four aspects :-

(1) It has a certain external and internal form, the latter being more usually called structure.

(2) It occupies a certain position in space and time.

(3) It is the subject of the operation of forces, in virtue of which it undergoes internal changes, modifies external objects, and is modified by them; and

(4) Its form, place and powers are the effects of certain causes. 


\section{CONTINUITY OF VITAL PROCESSES}

He of course regarded protoplasm as essential to life. This, however, although the substance of which all living matter that has survived upon our planet is composed, cannot be said to have been essential to such life as has not survived. It may be, and no doubt is, the most efficient substance for propagating the processes of vitality: but that it really is essential to vitality other than that which has survived and which we find naturally existing around us is an assumption for which there is no logical foundation. If the processes we call vital can be prepared without protoplasm in bodies which would otherwise be entitled to be called living, no course would be open to us but to admit that protoplasm is not essential to such simpler types of life. From our investigation it appears that such types are highly unstable and therefore could not possibly have survived.

The same point may be raised with regard to the part played by water and temperature. Supposing that an organism were to be found which could live and live only at very high temperatures. Would that prevent us, strictly speaking, from regarding them as living things?

So also as regards the effect of moisture. Radiobes are soluble in water at temperatures of about $25^{\circ} \mathrm{C}$, whereas some bacteria will resist for some minutes a temperature of $100^{\circ} \mathrm{C}$.

It therefore stands to reason that the former should not have been able to survive at high temperatures or even that of ordinary Summer. 
One hot day would kill them all : but they would again re-appear in cold weather, whilst if the radio-activity is very small it may never have a chance of asserting itself in the temperate zones. There are different limits of temperature for different types of life. And the fact that life exists here at particular temperatures is simply a result of survival of the fittest so as to suit the environment.

Simpler forms of life than those which have so survived doubtless did not possess all the properties of those comparatively higher types which have survived, and doubtless insolubility in water at such temperatures as we happen to live in has been one of these properties.

Similar remarks may apply to the actual composition of living bodies. Protoplasm may be the substance which at ordinary temperatures performs the processes of vitality with the greatest efficiency, and thus as living substance it is itself the fittest to thrive.

Bodies may be formed which should possess a definite structure, occupy a certain position in space, and go through a cyclic process in time, as also adjust themselves continuously to their environment by a continuous interchange of relation between their internal and external functions, and yet not necessarily, for anything we know, consist of protoplasm.

Similarly as to the presence of sulphur, iron, aluminium, phosphorus, \&c., these elements have 
been supposed to be essential to life as it is found in Nature to-day. But Dr. Charlton Bastian has conclusively shown that bacteria can grow and thrive in solutions of ammonium carbonate which contain only carbon, oxygen, hydrogen and nitrogen. These four, however, are considered essential to life. Upon this point all that can be said is that no form of life has ever yet been found which does not contain them.

There are authorities, however, who would not consider these elements strictly speaking as essential to life in its widest sense. Here we have at length come to really dangerous ground from a biological point of view.

And yet supposing bodies can be found that perform the processes laid down by Huxley; but which do not contain all or any of these elements, how then are we to regard them? If they integrate and disintegrate and can go through the cyclic process, are they on account of their chemical composition to be looked upon as dead, or rather as primitive forms of living matter which have long since been extinct? Would life at all times and in all places, not merely on this earth of ours but in the remotest worlds, consist essentially of carbon compounds? This is a query which of course we cannot answer without begging the whole question, and assuming a knowledge of the possible solutions of the problem as to the origin of life, which, alas! we do not yet possess.

So again, how are these types which show metabolism and a cyclic change to be distinguished from 
others that may show merely a cyclic change without metabolism, or simply metabolism without a cyclic change? The former might still come under Herbert Spencer's definition; the latter may not strictly speaking do so.

And yet if there is a continuous change of substance together with that integration and disintegration which we call metabolism : are we or are we not justified in regarding this as some elementary or primitive form of life?

The atoms of radio-active bodies are such subtances, and if they are found, by acting as a nucleus, as they have been found to give rise to more complex forms in organic substances, forms which undergo the cyclic changes and adjust themselves to their environments by internal and external interchanges, they then come under some definition of life in a higher sense; and would, I think, be regarded, and very rightly so, as elementary types of life. This may seem highly heterodox, but, for aught we know, may be true.

Life in its very simplest sense would consist of metabolic processes and cataly tic actions such as those that occur not merely in radioactive bodies, but in phosphorescent and luminous bodies generally.

Thus does there appear to be a continuity of vital actions, a gradual dropping off of properties and simplification of the process as we descend from higher organisms to smaller things down to the very atom itself ; and vice versâ a gradually increasing complexity as we mount the scale of being, with an 
equivalent increase in the complexity of molecular structure.

The simplest view of life then in this sense is a system of dynamically unstable groups of molecules, provided some principle is at work by which such molecules can be built up as well as broken down. The German philosopher, G. T. Fechner, in his work Einige Ideen zur Schöpfungs und Entwickelungs Geschichte der Organismen, takes a dynamical view of Nature and of the connection ketween organic and inorganic matter. There is a tendency to greater and greater stability, and for this reason he regards the inorganic as the final product of the organic, but in the later edition of his work, Fechner admits his conversion to the Darwinian theory of the evolution from the lower to higher forms of life, as he also doubtless would admit the development of organic from inorganic Nature.

Notwithstanding such a tendency towards greater and greater stability in the more elementary forms of matter, a counteracting process does no doubt exist. That is, a process of synthesis, as well as of decomposition; and the manner by which such aggregates are formed is less obvious than that by which they gradually break up. There can be no question that they are so formed. In some of the chapters which are to follow, we shall deal with the mechanism by which such changes are effected. There must be some method, as it appears at first sight, by which such synthesis can be brought about: and, granting this, there can be no doubt that the process can be kept 


\section{THE ORIGIN OF LIFE}

up, thus exhibiting the process which we call metabolism.

Life, using the word in the way defined, is thus a series of metabolic actions, which in a higher sense would constitute fermentations, and at the same time be most distinctly a specialised "mode of motion.

When we deal with catalytic actions we may be understood to use the term vitality in what may appear to be its most far-fetched and extended sense. Nobody would have been justified in regarding mere catalytic chemical reactions as processes equivalent to the most elementary life, unless such processes in some form or another could be found to give rise to higher or more complex reactions that exhibit some of the other properties which are associated with vitality. Thus, as in the case of radium and some other bodies which can produce in suitable chemical compounds bodies that undergo cyclic change, the evidence that they constituted some extremely elementary beginning of life is not so far-fetched as might at first be imagined. If biogenesis is strictly true, and if these forms are living things, then those simple metabolic changes are also logically vital actions in their simplest and most elementary sense. No argument more forcible need be adduced to emphasise the continuity of such actions. Life with all its complex interactions, if mechanical, is surely most obviously mechanical when thus stripped one by one of all, or most, of its mysterious properties, as we find them. Dropped one by one, till, having found the simplest reactions in their very lowest 


\section{CONTINUITY OF VITAL PROCESSES}

forms, the nature of life in its higher and even its highest manifestations may be realised more clearly and more vividly than by any other means that Nature or experiment has yet disclosed. To us it merely shows the continuity of vital actions, as of all performances that constitute the phenomena of Nature generally. To others they may seem repulsive, even should they be admitted to be true; whilst whichever way we look at it we shall find that the method of thus viewing the matter is both useful and inspiring.

As we say, the familiar notion of life amongst the orthodox to-day is that it is essentially a process of metabolism in proteids alone. But our answer is, that is true, undoubtedly true, of such types as have survived, and not necessarily so of such types which we should look for.

Many biologists pure and simple have fallen into a pitfall in their conception of the simplest life much in the same way as the chemist has done in his idea of the atom or the minutest particle of matter. That the chemical atom is the smallest thing which takes part in chemical reactions may be quite true; that it is the smallest particle of matter is untrue. That the "cell" of Virchow is that smallest aggregate of living matter which naturally and of its own accord has survived and still manifests the properties of living matter may be quite true; that it is the smallest aggregate of matter which can under any circumstances manifest vitality is, as we venture to think, when viewed from a broader standpoint, without any scientific foundation. 


\section{$3^{6}$ THE ORIGIN OF LIFE}

It is curious, is it not, how Science, or rather the history of Science, thus repeats itself? The same fallacies again and again due to the same misuse of words, to definitions inadequately expressed or based on insufficient evidence. It is due to certain facts, to the taking for granted as ultimate certain facts which, after all, are merely the farthest that our knowledge or experience has as yet reached.

To the savage mind everything is miraculous, and thus directly the intervention of a First Cause. The idea of causation in the scientific sense is altogether absent. Even to the great Malebranche the process of breaking an egg when it falls to the ground is due to the direct will of the Creator. He makes it fall and $\mathrm{He}$ breaks it. However true this may or may not be in the ultimate chain of causation, it certainly is not true that it is not performed by the intervention of a long chain of causes and effects. It is the want of recognition of this endless series of events that distinguishes the savage or untutored intelligence from the scientific and philosophic mind. It is so also even with scientists and philosophers when they forget themselves, and we have all of us something of the savage in us still. That detailed study of the many facts they have spun together with consistency in their own field of labour makes them forgetful of the many fields that lie beyond this little garden where they toil, and bids them fain to imagine, even though unconsciously, with characteristic inconsistency, that the farthest limit they have reached is now and for evermore the end. 
That the elements are the foundation-stones of Nature was the opinion of Clerk Maxwell. That they are merely groups of smaller atoms, systems which have survived on account of their stability, is the opinion of his successor, Professor J. J. Thomson. The electron is the atom of negative electricity. The positive atom may be, and probably is, something still smaller, but which for some reason has not yet been isolated from what is supposed to be the chemical atom. So is it with that grand survival of unstable matter, living proteid. We may, if we so think, regard it as beyond artificial synthesis at the present day; we may, if we so wish, regard it as indistinguishable in those phenomena we call vital, whether natural or artificial, if that were possible. As we have said, our studies in these matters have led us to form different opinions.

That the most elementary form of living matter which we see around us has always been and always will be the most elementary is the conclusion which some of us in moments of enthusiasm have not been inclined to doubt: but it is a conclusion for which we have failed to find the slightest particle of evidence.

No one can deny that proteids are the constituents of living matter which has been stable enough to survive, but this is altogether beside the point at issue. It is not less beside the point to suppose that the more elementary types of life in the continuous series we have outlined can be transformed one into another, although this may or may not be possible; 
the point insisted on being merely that there is such an approximately continuous series and that more elementary and more unstable forms of life than bacteria have once been and can to some extent at least again be brought about.

That there is actual transmutation is what we do not affirm, because it probably cannot and does not take place.

Having said thus much it must, however, be borne in mind that we do not plead for anything outrageous. It is a theory which, however expressed, has been held repeatedly by some of the clearest minds, as Tyndall has depicted, and the two objections which at present exist in many if not most men is to the transmutation of stable matter into the particular unstable types of organic matter which we call living proteid, and the other that anything not composed of living proteid ever could have been alive.

We must therefore, in presenting the aspect of this great and difficult question, more or less, in a new light, present also its intricacies, its many connecting and its many missing links, under a classification which, though by no means difficult to apprehend, is perhaps also at the same time new. The progress which has been made in our knowledge of Matter in its living and in its lifeless forms and equally so perhaps of Matter in that border-line between life and death, which more particularly forms the subject of our work, has enabled us to reconsider and to review, in outline as well as in detail, the many facts in this 


\section{CONTINUITY OF VITAL PROCESSES}

realm of Nature so to present them from a standpoint which at once enables us to see unity where there was once diversity and to grasp the meaning of that one grand principle which underlies all such phenomena in the evolution of Matter whether living or dead.

That in fact the division of all Nature into biological and a-biological is, strictly speaking, not correct, and that just as in the organic it has long been perceived that the inorganic plays a most important part, though that part should ever remain a closed book to us in its highest forms, so also in the inorganic are the same or similar processes to be found though in a more simplified and in a less marked degree.

That progress, as we say, is not chimerical but in a strict sense real, and has enabled us to bridge somehow over the gap that has so long and so wearily concealed the unity that exists between them. It is new, strictly speaking, and yet in a loose sense old, because the deep-rooted conviction that there is unity in organic and in inorganic matter has existed in certain minds for many ages past; it is new because the evidence for it has hitherto been insufficient, and because the evidence so long absent is now beginning to dawn upon the unweary worker in this day of progress.

There are three stages that every science must pass through, the Empirical, the Classificatory and the Theoretical. In the Empirical stage everything is higgledy-piggledy and the seeker for truth is merely groping in the dark. He sees many things, he knows their properties, he can relate their life history, he can 


\section{0

recall their presence in many districts of Nature and in many lands. He is familiar with all their doings; but they are strangers to him. They are old acquaintances, but they are not friends. Notwithstanding his long familiar knowledge of their ways, they are unintelligible to him. His very acquaintance with their behaviour merely helps to divert them from his comprehension, and to elude his grasp.

They are merely shadows, when he was wont to look upon them as realities. The fundamental principle is absent; and the connecting link cannot be found. Knowledge is bewilderment, and isolated scraps he once thought intelligible to him are merely the unworthy fragments of a something that he ought to but cannot understand.

But more advanced, with strange surprise, the mutual links at length commence to dawn upon him, and the things once hopelessly isolated, at length, one by one, begin to reveal the connections that exist between them: and the intellectual puzzle stands out before him as a related whole. He finds what seemed distant and unintelligible commence to stand out as entities in a system which is at once more intimate. The actual connections are absent but the common qualities are there.

We have then reached the Classificatory stage. But although we can perceive connections, we do not yet know what those connections are. Not until we can frame hypotheses or picture models which exhibit similar connections can it be said that we have 


\section{CONTINUITY OF VITAL PROCESSES $4^{1}$}

reached the Theoretical stage. This stage has three subdivisions: the purely hypothetical, when the connections are perceived as mere conjectures, the experimental, when the conjectures guide experiments, and the mathematical, where the phenomena are merely the results of certain laws by which they can be predicted when particular conditions are known.

Biology, although it has reached the Theoretical stage, is merely in the hypothetical subdivision of this stage. No general law has yet been found to prevail throughout the science of life. The survival of the fittest or natural selection is largely a truism, and another way of saying that Nature does what it does and cannot help doing. It, however, like many truisms, emphasises the fact that there is a continual struggle between an individual and its surroundings, and that only those that can withstand that struggle are the ones which can survive. There is selection because the unfit are eliminated.

It accounts for the presence of things we should otherwise see no reason for ; but it is not a theory in the strictest sense. We can explain phenomena, but we cannot predict them. It does not enable us to penetrate into the principle which underlies the struggle for existence between the individual and its environment. What it is that enables the individual to persist in certain circumstances and prevents it from doing so in others. As soon as we can frame theories which suggest experiments and obtain experimental results which enable us to frame 
theories which will predict phenomena that in time can be verified by experiment, biology will have become a branch, not merely of experimental, but of exact science.

Physiology, no doubt, is at present in the quasiexperimental stage. But its theories are more hypotheses than a consistent system of ideas: and until a dynamical basis can be arrived at for vitality or biological phenomena, even physiology, the most advanced branch of biology, will have no claim to an exact position in the Temple of Science. A place therein it no doubt is entitled to; but that place is shifty; now chemistry, now physics, or, forsooth, geology, points to some other corner in the temple where it should have its permanent abode.

We want to know not merely the facts of life and its laws, but the more general principles which can simplify them, and we want to know, if that knowledge can be attained, what life is, and what its nature and its origin.

As the late Professor Max Muller, ${ }^{1}$ dealing with another science, once remarked, "After the observer has collected his facts, and after the classifier has placed them in order, the student asks what is the origin and what is the meaning of all this? And he tries to soar, by means of induction, or sometimes even by divination, into regions not accessible to the mere collector. In this attempt the mind of man no doubt has frequently met with the fate of Phaeton; but undismayed by

1 Science of Language, vol, i., pp. 19-21. 


\section{CONTINUITY OF VITAL PROCESSES}

failure, he asks again and again for his father's steeds. It has been said that this so-called philosophy of Nature has never achieved anything; that it has done nothing but prove that things must be exactly as they had been found to be by the observer and collector. Physical science, however, would never have been what it is without the impulses which it received from the philosopher, nay, even from the poet. 'At the limits of exact knowledge,' said Humbolt, ' as from a lofty islandshore, the eye loves to glance towards distant regions. The images which it sees may be illusive; but like the illusive images which people imagined they had seen from the Canaries or the Azores long before the time of Columbus, they may lead to the discovery of a new world.'

"Copernicus, in his dedication of his work to Pope Paul III. (it was commenced in 1517, finished in 1530 , and published in 1543), confesses that he was brought to the discovery of the sun's central position, and of the diurnal motion of the earth, not by observation or analysis, but by what he calls the feeling of a want of symmetry in the Ptolemaic system.

"Truth is not found by addition and multiplication only. When speaking of Kepler, whose method of reasoning has been considered as unsafe and fantastic by his contemporaries as well as by later astronomers, Sir David Brewster remarks very truly ' that as an instrument of research, the influence of imagination has been much overlooked by those who have ventured to give laws to philosophy. 


\section{THE ORIGIN OF LIFE}

"The torch of imagination is as necessary to him who looks for truth, as the lamp of study, Kepler held both, and more than that, he had the star of faith to guide him in all things from darkness unto light." "

It is this combination of imagination and exactness, of knowledge and of speculation, that forms the basis of that principle which is to guide us in the discussions that are to come. 


\section{CHAPTER III}

\section{CLASSIFICATION OF LIVING TYPES}

Reasons for extending the meaning of the word life to include a wider class of phenomena-Sciences not divided into watertight compartments, but their division largely arbitrarySurvival of living proteid-Definition of life-Life-stuffManner in which it may have at first arisen-Continuity of organic and inorganic matter-Biogenesis carried to its logical extreme-Haeckel and biogenesis-Cyclic process the test of life in the higher forms of matter-Whether a cell-wall is necessary in ultra-microscopic germs-Metabolic combination of two opposite processes-How they are effected-Formation of molecular aggregates-Many crystals may be fossilised remains of living matter-Classification should not be between organic and inorganic but between active and inert matter.

THE method of classification which we venture to adopt is based upon the idea that simpler modes of life than the amoba have existed, though they may have long since perished, and that in many properties of matter we can trace the more elementary processes which have given, and can to some extent again give, occasion to produce them.

The classification is thus merely to emphasise not only the analogy between such types and the living forms around us like bacteria, but also to lay stress upon the equally striking differences between them. 


\section{THE ORIGIN OF LIFE}

Many phenomena take place which, although not, strictly speaking, lifeless, are nevertheless not sufficiently complex and organised to be regarded as living in the sense in which the word has hitherto been used by most biologists. For this reason there are ample grounds for extending the meaning of that word so as to include a wider class or classes of phenomena.

The method so much in vogue amongst many of us of regarding the sciences as divided into watertight compartments is in itself a great hindrance to the discussion of many problems that really come within the scope of two or more such branches of science.

For the division is arbitrary to a very large extent, and it should be borne in mind that the greatest problems of each are really those which lie in the borderland between them. If more progress is not made in this borderland it is, as we fear, of the awe and dread which, in these departments of knowledge, each professor entertains towards each. And the history of science is not without its reminders of the prejudices-often reasonable prejudices, no doubt—-that have stood in the way of progress.

Not merely in the battlefield does valour form a factor in success. Even the votaries of science need courage. And the dull conservatism of familiar notions, often of the generations which have gone before us, is one of the greatest hindrances to the development of new ideas. This opposition is not infrequently the result of misconception as to the 
real point at issue, and oftener than not the outcome of a silent fear that some cherished notion or wellestablished belief may be uprooted if the new ideas are true.

But these apprehensions are not always well founded, and the outcome of much controversy and overtaxed debate often results in the admission that had the parties understood each other at the beginning of the dispute they would have been of the one opinion all through.

In bringing in the assistance of the neighbouring sciences, we should be careful to bear in mind that they do not lead too hastily to conclusions which might prevent us from developing the subject sufficiently from our own special point of view when it seems necessary. Thus there is the great difficulty we are obliged to face: that of the intrusion of foreign ideas, to the bewilderment of our own. Yet these obstacles, much as we should guard against them, are not sufficient in themselves to prevent us from accepting whatever assistance the facts of Nature, outside our own arbitrary division of it, may afford.

The survival of living proteid as the one kind of Matter that has been able to persist, notwithstanding the vicissitudes which Matter is heir to by its own laws, is a question which needs careful consideration. The fact that it is the most stable substance which at the same time manifests the necessary instability.for life, is in itself one of the profoundest problems that Nature still presents. On the other hand, the continuous scale of descent of 
similar phenomena in a gradually diminishing or simplifying manner through various grades, although we do not see the change take place one into the other, is evidence of the same nature as that on which the Nebular Theory is actually based.

A nebula has never been seen to change from one stage into another; but different nebulæ are seen in different stages of development.

We say we do not see them change because no change has yet been seen from one such grade up to another, next it in the scale, by purely physical or chemical reactions; so also no change occurs from highly organic bodies not bacterial into bacteria. Such a change may require countless ages to be accomplished in. But changes have been found, however, which would entitle us to regard some of them as ancestors of others, and to regard the transformations actually obtained artificially, although highly unstable, as in a certain sense sufficient to fill the gap between the complex bacillus and the simpler bodies in the scale of chemical and physical effects.

The word Life is therefore used here in a sense which, if not necessarily a new one, is at least an extension, and perhaps a considerable extension, of that in which it is already employed. It is used in such a manner as to include within its scope many phenomena hitherto regarded as belonging to the lifeless world, but really of a kind which would entitle us to look upon them as similar, though simpler, phenomena in the scale of being. The unity underlying these is that for which we plead, and the 
results of our investigation go to show that the unity in that conception, or rather the conception of that unity, is to a considerable extent borne out by facts.

To clear our ideas then and base a definition upon a physical basis for the purposes of our classification; Life might be described as a specialised mode of motion, the specialised mode of motion being, that of a complex system of molecules in a dynamically unstable state, so that there is a continuous or continual change, or flux of its substance, between the individual aggregates of molecules and their surroundings.

This definition includes everything we understand by life from its physical basis and most general biological signification. But it is far more general than the definitions generally employed. It is more general even than Herbert Spencer's definition of the continuous adjustment of the internal and external relations of the individual to its environment. This may or may not include a radio-active atom, the former certainly does not exclude it. Whence the six apparent conditions laid down in the previous chapter can be satisfied by it, even if far more elementary phenomena are also included within its scope.

Thus the radio-active atom, the molecules of cyanogen, the complex molecular aggregate that takes part in many phosphorescent and other luminous effects, form examples of that specialised unsteady state of motion, which in some instances, when the environment in which it occurs is of a suitable nature, can give rise to aggregation in some manner at present 


\section{THE ORIGIN OF LIFE}

not quite understood. By this means, however, the cyclic process which is the test of vitality in its more developed forms is manifested.

Although, as we say, the artificial synthesis of a bacillus has never been, nor do we think ever will be, accomplished, any more than the artificial production of a man, there are still artificial types of vitality far simpler than the bacillus, that are entitled to claim relationship to their pedigreed fellow ereatures, with which they have so many and so distinctive properties in common.

The former is a creation of one generation, and may almost be designated as a self-made thing; whilst the bacillus can claim a long roll of ancestors back to the remote prodigious vista of the past, when life first made its appearance on this planet.

It is, therefore, too much to expect that the aristocratic creature should admit any relationship with its plebeian neighbour. Yet, if our definition is correct, the two are merely factors in the same field of Nature: one having had a history and the other not. And it is therefore to be expected, as a necessary consequence, that the bacillus should have some qualities, markedly developed, which the other has not. That, in fact, the bacillus, being the descendant of the most stable and persistent types, for the environment of our planet, has also the qualities adapted to the particular conditions of moisture and temperature which the other has not. What is more, the bacillus must have come into being under conditions of the precise nature of which we are totally 


\section{CLASSIFICATION OF LIVING TYPES $5^{\mathrm{I}}$}

ignorant, whilst the radiobe has been produced under conditions which are altogether artificial and could not possibly have existed at that remote period when pristine mud might have been a more likely culture medium than the constituents of fish broth or the essence of beef-tea.

For all that, however, the production is not unworthy of being admitted into the sacred precincts of biology, for even if it is like a hot-house plant, the product of artificial conditions, whilst the bacillus is the survival of Nature, the fact that it fits in with our idea of vitality is a sufficient reason for not refusing to regard it as a mode of life.

Granting then, as we feel compelled to do, that these radio-organic forms are living things in the sense in which we use the word, are we, or are we not, entitled to regard the bodies which give rise to them, the radium salt on the one hand and the sterilised bouillon on the other, as living or containing the elements of vitality? We should reply: the radium yes, but the bouillon no; at least, so far as we can at present judge. For one exhibits the particular state or mode of motion with which vitality is associated, but the organic colloid does not. Radium, therefore, may be regarded as the seed, if we may put it so, which grows in the bouillon soil. The constituents of protoplasm are in the bouillon, but the vital flux is in the radium. It is an interesting inference, therefore, that whilst inorganic bodies have been regarded as devoid of life, and organic bodies as the means of it, we are led to the conclusion that the vital principle 
is to be found in the inorganic, and that only in the organic has it the opportunity of thus becoming manifested. Life-stuff or bioplasm, as distinct from protoplasm, is inorganic and contains the germ and mode of motion of vitality. It is not a seed that grows in every soil, but only flourishes in the chosen environment of beef-jelly. This, however, does not detract in the least from the two points that on the one hand the products of radium and bouillon manifest vitality, and on the other that vitality in this particular case, and in the most general sense in which we use the word, is due to radium. The origin of life itself remains unsolved because we do not know what the substance and the environment were in which it first made its appearance. In ordinary soil it may have taken æons to assert or manifest itself even as a radiobe, or something similar in that scale of being, and æons still to develop as a bacillus, and this may have been the one favoured type which out of millions of varieties was most suited to survive. Upon these points there is scarcely need to dwell, because the actual manner in which life arose is beyond our present knowledge. In the laboratory we can demonstrate the production of varieties by natural selection, and can thus reason back as to the origin of species. So also from the fact that we cau produce artificial types of vital bodies are we enabled to carry our minds back in æons to the remote past when similar types, though certainly not the same, first appeared upon the surface of our globe.

When we turn our attention once again to the 


\section{CLASSIFICATION OF LIVING TYPES}

analogies between the mechanism in radio-active bodies and those of a more complex though less stable kind in other substances not radio-active, but nevertheless radiant, like phosphorescent and other bodies in a luminous state, we can perceive the presence of a somewhat similar unstable state of motion. It is, however, far more unsteady, but the phenomenon is of the same character and consists essentially of a series of metabolisms of an elementary kind, the radiation being merely the visible manifestation of the breaking down of these unstable molecular groups.

These aggregates do not persist for any length of time, but if we could imagine them to have sufficient stability and their number to be sufficiently great, the body which they compose would likewise be active like radium for an equally great length of time.

The sun itself thus comes under this apparently weird conception of primordial life, and the remotest stars like it, in their silent evolutions, in their turn develop out the first signs of that life which in the course of ages render them also the seat of many vital states, of many complex phenomena of life and death, the scenes of conflict and of quietude, of struggles, of survivals and defeats such as this earth of ours has passed through and has yet to pass.

This blending of the organic and the inorganic, of the world of animate and of inanimate things, has long since seemed to me to be the goal to which science may steadily be moving. But it must not be imagined that that goal has been reached until there is the strongest evidence that it has been reached: and the 


\section{THE ORIGIN OF LIFE}

absence of that full evidence must not, on the other hand, stand in the way of investigations in such directions as may appear to us most promising.

Now the reasons we have given for regarding the organic and the inorganic as one, for the development of vitality in its higher forms from the interaction of certain inorganic substances with complex colloid bodies, and its disappearance by the resolution of all these complex structures into their constituent elements, have forced on us the theory that they are equivalent to the integration and the disintegration of atoms. We cannot see why if life can disappear by disintegration it should not also have appeared by integration. Why, in a word, death should be natural, but birth unnatural. And I myself am loth to think that there is any reason to suppose that these effects should be purely the performance of Nature unless there is a real continuity between the organic and the inorganic, between the animate and the inanimate, between life and death.

This is biogenesis carried to its logical extreme. Naegeli, and Haeckel with him, maintains that "to reject abiogenesis is to admit a miracle"; our own view is that to reject biogenesis, if this term is to be applied to certain types of inorganic bodies, is to deny the continuity of Nature, and the unity of those performances which make the Universe a consistent whole. In other words, to presuppose a miracle.

Haeckel denies, if we understand him rightly, that there is a vital principle in inorganic Nature, but supposes it to develope into the organic; 


\section{CLASSIFICATION OF LIVING TYPES 55}

whereas the result of our work impresses upon us the continuity between them and gives to inorganic matter in certain of its states the property or quality of instability and decay in common with life in its highest forms, and impresses also upon us the fact that by the interaction of this kind of inorganic molecules with bodies of highly complex composition there can result others which not merely disintegrate and decay, but actually go through the cyclic process, by growth in the beginning and by subdivision in the end.

It is this cyclic process that is the test of life in the lower as well as in higher forms of matter. In the bacillus it is accompanied by reproduction. In the radiobe it is confined to growth, subdivision, and decay, and reproduction which is only degenerative. The products of the subdivision do not go through the same cyclic change as the parent, and as we go down lower in the scale, the instability is to be found throughout, and the consequent decay; and metabolisms which are performed in a considerable range of inorganic Nature.

We now come to the classification which it was our intention to propose. But it will be beyond the limits of this chapter to sketch much more than in outline the manner of demarcation which we desire to make.

All bodies which manifest vitality in any kind or form are supposed to be unstable, and to have a central nucleus visible or invisible. They may or may not possess an actual structure such as a cell-wall. In the higher grades of life the cell must contain a 


\section{THE ORIGIN OF LIFE}

wall; but in the elementary types which we are now considering, the precise nature of this boundary or even its presence cannot easily be discussed, if it can be discussed at all, for the simple reason that the bodies considered are too minute to come within our range of vision. Wiesmann encounters a similar difficulty, and doubts if spontaneous generation can ever be proved on account of the ultra-microscopic nature of elementary life. Is this cell-wall actually necessary, as a sharply defined boundary, or is it sufficient that it should be merely an envelope surrounding the minute body as an æether envelope is supposed to surround the atom? Within this ill-defined region like an atmosphere round the atom or particle, the diffusion somewhat similar, though not the same, as that which occurs in the more developed cell-wall of the higher organisms may be taking place.

Something similar to osmotic pressure, the result of the unequal diffusion of a liquid and a salt through what is called a semi-permeable membrane, may, or may not, be a factor in these elementary types of life. In other words the body may not assimilate from its surroundings and at the same time give to it. The diffusion may be all in the one direction, outwards, without any inward assimilation whatsoever, in the case of any particular particle at any particular time. There would in that case be a pressure outwards, as the diffusion is all that way. Where there is metabolism, however, there would be a building up as well as breaking down of aggregates, whether molecules, chemical atoms, or electrons. And 
where there is building up of them, there also is assimilation, if these constituent particles form part of an individual whole when that individual is in a stage of growth. But no diffusion occurs either way if the individual is in a perfectly steady state of motion or of rest. It is this diffusion of the constituent particles in a group when in an unsteady state of motion that constitutes the fundamental principle which, even in its most elementary state, we may associate with vital energy.

Metabolism is, therefore, a phenomenon of a higher order than mere disintegration, which forms a necessary part of it. It is, in fact, the actual combination in the same body or group of particles of two rival processes; of construction and destruction, or of growth and of decay. It is therefore the combination of two mutually contradictory effects; contradictory in so far as they occur in the same group or aggregate of particles, but not as actually occurring in the same individual particle at the same time. And as in the higher grades, in the radiobe for instance, the individual is the product of two different bodies, the gelatin on the one hand, and the radium on the other, so even in the simplest cases of metabolic action there are to be found the same, or similar, combinations of two totally different modes of molecular action. In one terminology, of association and dissociation : in another, nomenclature, of the building up and breaking down of little systems whether molecular or atomic. How then does it come to pass that these systems are built up? We can understand without much difficulty how it should be that, having 
once arisen, they should be more or less in a stable state; that as they part with their energy they ultimately reach a condition when they become highly unstable and finally break up; that this process may take place extremely slowly, as in the case of radio-active atoms; but how, in what manner do they actually come about, is what is not quite so easily explained. In the case of atoms it is by no means clear, nor is there the slightest clue as to how they have been formed, unless they have been the result of mutual attraction in the first instance, as solar systems have been formed; the more stable systems or configurations of atoms being the ones which have had the chance of persisting.

In the case of larger molecules the groupings may be brought about, since they are far more unstable, by the action of light or some ordinary electromagnetic disturbance, such as that due to the swift passage of a cathode ray or its impact upon bodies, or by its disruption from, or collision with, molecules and atoms.

The view which we have put forward that phosphorescence and fluorescence are but the visible manifestations of building up and breaking down of unstable molecular groups, is in accordance with the theory that such aggregations are formed by electromagnetic disturbances, which shatter, as it were, the individual particles, whether atoms or molecules, and enable them to get the opportunity of assuming the configurations which are most stable. In the course of time, that time may be hundreds or 


\section{CLASSIFICATION OF LIVING TYPES 59}

thousands of years or merely short fractions of a second, they begin to lose their stability on account of radiation, and thus break down again.

The building up may, however, be brought about in other ways, by the presence of a nucleus, which can give rise to aggregations, by coagulations, and catalytic actions, and by other means.

The method of the formation of these molecular aggregates will form the subject of a special chapter, and we need not for the present dwell upon it here with much more than a passing hint. It is doubtful if a clear understanding of the precise method by which it is effected can in all cases be formulated with precision: but it will then be, and it certainly now is, sufficient for our purpose to know that such integrations can, and do, take place. Whatever difficulties may arise, and in some cases such difficulties are sure to arise, in picturing to ourselves the actual manner by which such complex aggregates are built up, we shall for the present content ourselves and be pleased to assume that they can be formed. It is enough for our purpose at the present juncture. We know they can be formed, and are so formed. What more do we want for the purpose of classification?

Having thus started with the assumption that the vital principle is in bodies which grow and also in the course of time disintegrate, we can extend the limits of the conception of vital action to the simplest metabolism. The cyclic process of the self-integration and disintegration of the individual is a 
phenomenon in time for every individual particle. There are authorities like von Schrön, of Naples, who regard many stable bodies like crystals as forms of elementary life. No doubt they have many qualities in common with such bodies like bacteria, as are admittedly living; but for all that it seems to me that it may be said they have everything in common with microbes except the principle of vitality, and may be regarded as the final products of such elementary types of life as we have called radiobes. They have everything but life. That perpetual change of substance is absent, together with assimilation on the one hand and decay on the other. They thus appear to be nothing more than fossilised remains of what may once have been living types.

We therefore extend the rôle of life to all bodies which are at once self-constructive and destructive; whose parts can come together and form systems which are on the whole unstable, and thus separate again into the constituent elements from which they have been formed. If these bodies are like little solar systems with their constituent particles revolving round a centre, that central particle would form the nucleus and the little system itself the " cell."

We therefore regard all bodies in which metabolism occurs, whether by fermentation, catalysis, fluorescence, phosphorescence, or other types of luminosity or radio-activity, as manifesting the most elementary properties of vital activity-no doubt in its extreme sense. 


\section{CLASSIFICATION OF LIVING TYPES 6I}

The partial process of disintegration alone as in isolated radio-active bodies, as distinct from those placed in suitable surroundings, may be regarded as partaking in its last phase of disintegration of vital action. For purpose of classification, therefore, the line to take up is that of metabolic change, and to regard all bodies wherein it is absent'as absolutely lifeless and all those where it occurs as either actually living or possessing the elements or principle of vitality in its potential form.

The instability of comparatively stable aggregates whether of molecules, atoms, or electrons, would, therefore, if these aggregates have also the power of coming together as well as of separating, be the fundamental principle in vital actions, and the point from which the development of the subject starts.

According as aggregates of molecules, the molecules themselves, atoms, and electrons in their various combinations exhibit these qualities or their opposites, may they be regarded as possessing, or as lacking, the energy which leads to vitality; in that state from which matter may spring into life or fall into absolute inertness. There is extreme difficulty, no doubt often in deciding how far the elements in question are, or are not, to be dealt with in any particular system; but it is upon this point that subsequent discussion turns. We shall lay down the barrier between living and dead matter, not between the organic and inorganic, but between active and inert matter. This barrier, no doubt, is 
not absolute, for inertness is a relative term : and when we speak of inert matter it will be understood to be merely that matter which is inert, so far as we at present know it.

Thus, indeed, may all Nature be divided into the two great divisions. That containing a vast store of energy which it is displaying or about to display in virtue of its instability; and that which either forms similar stores of energy, but which is in a stable state which ordinary means cannot disturb, or does not possess that energy at all.

These are the two states of Matter that we have to deal with.

The barrier is not between the biological and abiological sciences as familiarly understood, but between those two fields of Nature which deal respectively with such dynamical and statical configurations.

Since the word Life has been used to exclude much that it really ought to include, and the problem of life has thus been abandoned to some semi-mystical obscurity, the attitude which we assume is that these are within the sphere of science as we know it to-day. Our opponents, as it seems, would have it relegated to phenomena not yet discovered and we to the phenomena we have already obtained. In truth

"Our path is in the fields we know And theirs in undiscovered lands." 


\section{CHAPTER IV}

\section{THE CORRELATION OF VITAL PHENOMENA}

The object in view-Results outcome in part of researches originally started as to the phenomena of phosphorescenceObject to arrive at dynamical explanations-Luminosity result of metabolic actions, of a building up and breaking down of molecules-Fluorescence and phosphorescenceLuminosity of gases when an electric discharge passes through them-Theory of large chains of moleculesFluorescence and absorption-Inferences to be drawn from these-Luminous and non-luminous states of matter two different states-Catalytic actions-Enzymes and nucleiStable and unstable groups of molecules-Atoms may be elementary cells-Biogenesis carried to its logical extremeHuxley's scientific faith-Views of Johannes Müller-The unity and plurality in Nature everywhere combined, and constitute its continuity.

IN dwelling upon so vast and so complicated a group of phenomena as that with which we have to deal, the object which should be kept in view is not so much that of dealing with the matter in an exhaustive fashion, which, it must be feared, would be as hopeless as it would be bewildering, but rather to present in outline, as far as possible, the results as well as the methods of some of the more or less recent investigations calculated to throw light 


\section{THE ORIGIN OF LIFE}

upon these phenomena, as also to expound the theories that may be advanced, and which in the present state of our knowledge seem to be best fitted to disentangle, the skein of facts in which these many phenomena appear to be enveloped.

It is not our desire, then, to hold out to the reader the hope-the illusory hope, as it may prove to bethat when the facts have been reviewed, and hypotheses put forward to explain their inner nature and relation with each other, he need expect much more than to have presented to his mind's eye a visual representation of the dynamical processes which underlie the facts that have been brought within his notice.

These hypotheses must be taken for what they are worth, and from the scientific standpoint, viewed merely as hypotheses, possessing perhaps the value only of conjectures, which may help us to discern new relations and new facts implied in such of them as shall have already come within our knowledge; but hypotheses or conjectures we must be ever ready to dismiss, if new facts come to light antagonistic to them-that is, provided we are certain that they are facts; for apparent facts that contradict hypotheses otherwise well founded, require to be carefully considered before they are accepted as truths.

These results, the outcome in part of some years of study and research, curiously enough, as to the cause of the phenomena embraced by the term phosphorescence, give in the outline the substance of an inquiry originally undertaken with 


\section{CORRELATION OF PHENOMENA 65}

the hope of arriving, sooner or later, at some consistent explanation-for there would be little doubt that such an explanation does exist-of these manifold, and indeed in some cases apparently mysterious phenomena.

Fluoreseence and phosphorescence are, to our mind, connected with all these, whilst the class of effects almost invariably associated with them, being of a more persistent type than other modes of luminosity, form in many instances a more powerful, and in most cases a more tangible, means of research.

It is, therefore, a definite object which should be kept in view in such matters, that of reaching, if it can be reached, a comprehensive dynamical theory, and commencing with the construction of mechanical models, to illustrate the principles involved in the facts, although, as we shall find, such facts do not always admit of simple dynamical representation, except by the stepping-stones, as it were, of a molecular theory, before such mechanical analogies as we may hope to arrive at can be constructed.

Luminosity, which to the ancients, like Hippocrates, was a form of life, is to us a manifestation, however modified, of the simplest forms of metabolism, of, we may say, a continual and continuous change, of the building up and breaking down of complex molecular agglomerations, although of a far simpler kind than those which in a similar manner constitute the vital processes of the organic world. Here, however, we come within the realm of analogy rather than that of hypothesis. But, whatever we 
may call it, it affords us, as we may venture to think, the true keynote of the vast field which we are compelled to cover: that instability of molecular structure, disintegration, and decay, as concomitants' of their opposites, constitute, however simplified, the fundamental principles of luminosity not less than those of life; "a continuous adjustment of internal to external relations," when, as in the case of fluorescence, the external environment is that of similar but smaller particles; the violet and ultraviolet radiations giving rise to the formation of these unstable molecular groups, which, in their turn, disintegrate, radiating all the while intensely the energy which was stored up in their formation.

The æether must be considered part of the environment, else we should find ourselves dealing with only one aspect of the question, or with one part of Nature. The absorption of radiant energy of one period and the emission of that of another are accompanied by a molecular shuffing, of a catalytic nature, as in the case of metabolic transmutations.

It is when we come to deal with flame that the presence of catalytic actions will be most apparent: whilst the facts which relate to luminous, or phosphorescent plants, insects, and bacteria will serve to make the analogy almost complete. But not altogether so. For the luminosity of gases, highly rarefied, presents many difficulties, which are not so easily to be surmounted; and, therefore, whilst following in detail the great work of the last ten years, of ionisation in such media, we must point 


\section{CORRELATION OF PHENOMENA 67}

out that this work scarcely touches the ground which we propose to traverse, of its relation with luminosity. Nay more, it seems as though the tendency of the work of these few recent years has been almost to ignore the views of the decade that preceded them; although some of these views or hypotheses do not appear to have ever been disproved, and it is to them that the facts and speculations in this essay give a signal but perhaps a qualified support.

We do not refer to the ultra-atomic; but what may be called the mega-molecular theories of the discharge of electricity through gases.

The former theory, by which the corpuscle is supposed, under the influence of the electric field, to acquire sufficient energy, in moving through its free path, to break up, or ionise, the molecules with which it comes into collision, admirable as it is in affording a simple explanation of many, if not most, of the facts connected with the discharge of electricity in gases, does not in itself give a clue to some residual effects. The small potential difference in the positive column, together with the intense luminosity in this part of the discharge, favours, as it would appear, a return to the older hypothesis of chains of molecules in transmitting the current, and at the same time giving rise to striæ, and the brilliant glow; not the phosphorescent after-glow-although this also, as we shall see, affords much evidence of great molecular agglomerations at low pressure-but that positive glow, which, though not persistent, is the 
chief luminous phenomenon in the passage of the discharge.

Two difficulties, however, at once present themselves in connection with these long chains and gigantic groups of molecules. In the first place, it is not altogether obvious how they could, or should, arise; and in the second place, how, having so arisen, they could manage to persist.

There appears to be no evidence, from experiments on viscosity, or otherwise, of the existence of these large aggregates at ordinary pressures; and, indeed, the great frequency of collisions in such circumstances would seem to be sufficient to hinder any possibility of their formation.

But it has been urged that, even at low pressures and high vacua, the bombardment to which they would be subjected should still be sufficient to prevent them from having an opportunity of being formed, or, if formed, of lasting for any appreciable length of time.

Such considerations, however, do not appear to be well founded. The molecular aggregates may be sufficiently stable, or, what amounts to the same thing, the molecular forces brought into play may be sufficiently large to hold the group together for some time, against the bombardment to which it is exposed; whilst the persistence of the glow as in phosphorescence, in some cases, shows, as will be seen, that such unstable aggregates in gases at low pressures are not only not impossible, but found actually to occur, whilst the presence of the radiation 


\section{CORRELATION OF PHENOMENA 69}

from these would be sufficient to enable them to preserve their identity for a considerable time. ${ }^{1}$

Granting, for the present, that they do so withstand the presence of surrounding molecules, how then is their formation to be accounted for? We may, I think, attribute it to the radiation which is set up when the electrons or corpuscles are stopped by collision with molecules. These "pulses" would behave like ultra-violet light, which, as we know from the experiments of C. T. R. Wilson, can produce such condensations; whilst the intensity of the radiation within molecular distances should be sufficient to bring these aggregations we are in search of into being. What is more, the influence of a spark on particles of dust is well known as the readiest method of bringing down such particles. And what is this due to, but to the formation of great aggregates of dust, by electrical cohesion, much in the same fashion as we have supposed the molecules themselves to do?

The experiments of Hertz on the pressure due to the discharge itself, indicate a great increase of that pressure in the luminous column close to the positive electrode. And is not this what we should expect from the condensations in this region?

It seems, therefore, that the phenomena of light, produced directly by the discharge of electricity through gases, can be brought into harmony with the

1 This may be inferred from Poynting's calculation of the repulsion between radiating spheres the size of molecules. Phil. Trans., 1904. 
types of luminosity we have described; and that, although perhaps in many instances our theory is far simpler than others, they may help to give us some material with which to test it, when other facts we shall come in contact with may fail by their complexity to give us that support in all the entirety that might be wished for.

In no instance is this theory more approximately true than in the case of fluorescence, which for a long time has been regarded as a simple dynamical phenomenon, which Stokes illustrated by a model consisting of a number of pellets fastened to a string, as we shall have occasion to discuss. This elegant model, although illustrating the change of refrangibility, does not give a clue to some of the other facts which accompany or are associated with the phenomena of fluorescence ; and therefore, useful though it is, so far as it goes (in its own way), there can be no question that, whilst explaining roughly the change of frequency, from higher to lower, it yet gives no satisfactory explanation of the true nature of the phenomenon of fluorescence itself.

For this means not merely a change of refrangibility, but also a change of absorption; the exception to Kirchhoff's law which was assumed to exist in these phenomena being by no means justified by facts. If fluorescence is merely a disturbance which has been aroused in previously existing modes of vibration, it can be shown, without difficulty, that the absorption of light of the same period must be independent of the amplitudes of the vibrations, and 


\section{CORRELATION OF PHENOMENA 7I}

therefore of the intensity of the fluorescent light itself; so that the absorption ought to be the same whether this fluorescent body is fluorescing or inactive. This, however, is by no means true.

The absorption depends upon the fluorescence, and can be explained, as we shall endeavour to show, only on the assumption of a discontinuity in the structure of the body, so that new periods are produced which last merely during the time of fluorescence. These new periods appear to be due to the formation of new molecules, which last during the fluorescence and to which the fluorescence is due. Thus the luminosity may be said to be but the manifestation of a molecular process, of building up and breaking down of aggregates or groups of molecules. And this applies not merely to fluorescence and phosphorescence, but to the phenomena of luminosity generally. A process analogous to metabolism and essentially catalytic in its nature being that which forms the basis of the facts of light as well as of life around us.

For the time being the luminous body may be said to be different from its non-luminous preceding state, to which it gradually returns when the source of energy which influences it is once more removed.

Thus these various kinds of luminosity, in the many fields of physics which we shall traverse, indicate that molecular interactions underlie the more elementary, as well as the more complicated, facts of observation; and that the "molecular shufflings" and "unstable aggregations," whether chemical or semi-chemical changes of an ephemeral 
kind, are manifested whenever the phenomena of luminosity present themselves in Nature.

There appears also to be evidence that such large agglomerations of molecules do carry charges, large relatively to the electron or unit charge of electricity, and that they may be looked upon as electrified particles rather than as ions; that they can be regarded as centres of force of considerable magnitude, relatively to the ordinary molecular attractions, or repulsions, considered in the ordinary kinetic theory.

In the case of solids and liquids the aggregates are more persistent than in that of gases, the phenomenon of phosphorescence being of more frequent occurrence in the former than in the latter; whilst in the case of flames, which ought to be regarded as different states of matter from any of these threea luminous gas and a non-luminous gas being really two distinct states, as it is the object of this work to prove-the chemical interactions are more intense than in the case of phosphorescence, and more obviously of the nature of catalytic interactions. The existence of these aggregates facilitates the formation of flames, and performs an important part in their luminosity. The interactions are analogous to that of platinum upon combustible mixtures of gases; to the decomposition of hydrogen peroxide by metals and oxides; or to the action of dilute acids, or enzymes on starch, or of sulphuric acid in the formation of ether: all of these being the result of catalytic performances, the differences being merely 


\section{CORRELATION OF PHENOMENA 73}

a matter of degree. It is by the presence of a subatance which acts as a nucleus that these changes are brought about, without the nucleus apparently partaking in the actual combinations of the process, whilst the last state of the nucleus is neither better nor worse, but the same as the first! Thus, as in the case of catalytic phenomena, the influence of impurities forms a very important part in the production of phosphorescence, as also does the presence of nuclei, and their behaviour is like that of enzymes in more complicated molecular interactions. The extraordinary behaviour of solid solutions in exhibiting phosphorescences and thermo-luminescences, gives at the outset a clue which cannot be ignored as to the probable catalytic nature of these phenomena. ${ }^{1}$

That a nucleus takes part in the process of luminosity, and that it resembles in many ways, in its behaviour, the part played by enzymes in highly complex organic and vital processes, is a point of very great importance in the correlation of these facts.

We shall, in conclusion, have to deal with experiments on the influence of radium and other substances on gelatin and other colloid bodies, and to dwell upon the remarkable effects thus produced, of the organic bodies spontaneously developed in such media, notwithstanding all previous sterilisation and re-sterilisation.

The unstable nature of the radium emanation resembles in many ways the behaviour of unstable

1 Electrician, 26 Sept. 1902. Brit. Assoc. Rep., Belfast, 1902. See also Phil. Mag., March and April, 1901. 


\section{THE ORIGIN OF LIFE}

phosphorescent molecules on the one hand, and the molecular instability and vast store of energy in the molecules of cyanogen and its polymers on the other, as also of albuminoids and other highly complicated colloidal organic compounds which coagulate at high temperatures, as we suppose flames to do.

Are, then, these unstable molecules and atoms only simpler forms of living things? It is largely a matter of definition, but if we accept vital process to be "a continuous adjustment of internal to external relations," then there seems no reason to suppose that that "continuous adjustment" should not be extended to the "internal and external relations" between corpuscles and material objects, particularly as that instability of molecular interactions is found to be the striking feature in one as well as in the other.

The processes of radiation and absorption of matter are thus a part of these relations; so that if we find they are not reckoned with, the continuity between the socalled living matter and the dead breaks down, and we may find sufficient grounds for our attempts to reconsider the definition of the vital processes which biologists have hitherto maintained. Our own opinion is, as we have said elsewhere, ${ }^{1}$ that " the atom preserves its identity in the same manner as the cell does, and bears the same relation to the latter that this does to a living organism. The barrier, apparently insuperable, which the biologist holds to exist between living and

1 "The Radio-activity of Matter," Monthly Review, Nov. 1903. 


\section{CORRELATION OF PHENOMENA 75}

so-called dead matter would thus pass away as a false distinction, and all Nature appear as a manifestation of Life; this being the play of units of we know not what, save that it is what we call electricity. Atoms and molecules would thus be merely elementary living cells, possessing some of the properties, but not all, of the more highly organised cell, the unit with which the biologist has to deal. These, indeed, are not idle thoughts, heterodox, or orthodox; they are to us the logical outcome of all that we have had to say."

It is then towards molecular and atomic groupings and the grouping of electrons that thought ere long will doubtless move ; and although the facts already obtained are few, yet new fields of investigation have been opened up, as promising to the man of science as the discovery of a new continent, nay, of a new world, is to the explorer ; to what results they may lead us, he would be rash, indeed, who should venture to predict. They will, no doubt, in time, bring with them results of practical value, and they will most assuredly expand in no small degree our ideas of this world around us; and it now seems as though such investigations were at least to give us a clue as to the ultimate constitution, perhaps also as to the ultimate destiny, not only of Life as we know it, but of a simpler Life, that of Matter, too. Thus, indeed, are we led, not by imagination alone, but by the clearest analysis, to this generalisation, which to me, and, I trust, to the reader, too, shall ere long have reached the stage of an 
assurance; since in truth experiment and knowledge teach it, that, whilst life and death are only one so far as our experience goes, the process of the universe is continuous and complete.

It will be evident from these few remarks that our object is to indicate that the molecular processes which manifest themselves by luminosity are of the nature of a building up and breaking down of groups of molecules, so that the analogy with vital processes, though not enough to identify the two, is yet more than plausible.

Still, the barrier between the living and the dead, if by the living we mean the organised cell which to the biologist is the ultimate unit of living things, this barrier, we must admit, remains where it was before: although the fact that the natural cell apparently cannot be produced artificially from other and simpler forms of "unstable" or living matter does not draw a sharp distinction between them, any more than that radium cannot be synthesised from its constituent products is a proof or even a reason for regarding it as belonging to an entirely different branch of science from those which deal with the simpler elements.

The fact, we say, that a bacterium cannot be produced artificially, because it is too highly organised, will not prevent the hope of producing the next best thing to it, a molecular aggregation of a highly complex matter, an organic or colloidal body which possesses the $(n-1)$ properties of the $n$ properties of the living bacillus-things which would grow and 


\section{CORRELATION OF PHENOMENA 77}

divide, and to some extent, however slightly, reproduce in subcultures. We have called these "radiobes," as indicating their characteristic properties as well as their origin. We can say perhaps that we are witnesses at last to the first beginnings of life in its higher sense: but though apparently a case of abiogenesis, to our mind it seems to be a case of biogenesis, from the view of matter which we take, of biogenesis indeed carried to its logical extreme.

The radium atom may thus act as a nucleus which, in the suitable surrounding medium containing the constituents of protoplasm, assumes in the molecules around it the definite and unstable forms which are associated with living things. The properties we call "vital" appear to be associated with the radium emanation which, in the water from springs, or in the earth itself, may have been the cause "through the prodigious vista of the past" of the commencement of life upon our planet. Even Huxley, who denied biogenesis at the present day, has said that if it were given to him to look beyond the abyss of geologically recorded time to the still more remote period when the earth was passing through physical and chemical conditions which it can no more see again than a man can recall his infancy, he would expect to be a witness of the evolution of living protoplasm from non-living matter. He would have expected to see it appear under forms of great simplicity, endowed, like existing fungi, with the power of determining the formation of new protoplasm from such matters as ammonium carbonates, 
oxalates, and tartrates, alkaline and earthy phosphates, and water, without the aid of light. Such was the expectation to which analogical reasoning led him; but he begged of us once more to recollect that he had no right to call his opinion anything but an act of philosophic faith.

It is that unstable condition of inorganic matter possessing an apparently inexplicable source of energy that we have been in need of, and which has at last reached us in the form of radio-active bodies, that leads us once more to think that we have, perhaps, at length reached this dream of the evolution of living from non-living matter.

One of the great objections to the theory of "vital force"-which strictly speaking was not a force at all, but a particular condition of matter-was that it apparently contradicted the principle of the conservation of energy, as the energy of radium seems to do: but, of course, in reality cannot do.

There is apparently a source of energy in living things which is not included in their chemico-physical relations, and this property appears at last to have been detected in inorganic matter, by the discovery of such peculiar unstable systems as we have discoursed upon. The old philosophers, like the great physiologist Johannes Müller, would once more have called it "vital force," and they would not really have been far out if they merely meant vital energy.

If these conceptions be correct, then in the "vital putrefaction of the dust" have the first elements of life originated, and thus most assuredly would it be 


\section{CORRELATION OF PHENOMENA 79}

true that as from the dust of the earth they have arisen so to that dust they will with like assurance yet return. And Science, in her dismal corner of the Universe of knowledge, once more may proclaim that dust and ashes are really all that is! And yet if we do not know what dust and ashes are, if atoms and electrons are only elements of mind stuff, why then should we object if we once more return to that mind in which and from which we also have had our origin, the cradle of our birth, that great ocean of thought in which we live and move and have our being? Whether that great ocean is itself conscious of itself, we cannot say : but our own deep conviction is that in that selfconsciousness alone would its unity exist as a reality. Whether we too, dim units that we are, shall persist self-conscious in that great ocean independently of all time, science again cannot answer. Many men will say yes. Not because they think it ; but because they feel it must be so. The old answer is the same as that which Plato had to give more than 2,500 years ago, although he cannot have been blind to its inadequacy: that if Goodness and Love, like truth, be realities, whatever atoms may really be, that which delights in virtue must be happy, and in harmony with the totality of things. In the correlation of vital phenomena are that unity and that plurality at once rendered a continuous whole. 


\section{CHAPTER V}

\section{THE PHYSICAL BASIS OF LIFE}

This correlation of Vital Phenomena opens up a new perspective - Life in its primitive state must have been different from anything now observed in Nature-According to Clerk Maxwell the number of atoms in the cell is not sufficient to account for its immense potentiality-This potentiality, with all its varieties, probably the result of perturbations in the particular motion which constitutes the principle of vital activity-How it may have arisen-Natural as distinct from artificial life-Radio-activity of living bodies, plants, and animals-Experiments of Tommasina-Origin of primitive radio-active bodies lost in same obscurity as that of primitive life.

THE correlation of Vital Phenomena, when extended, as we have thus ventured to extend it, so as to include many physical and chemical effects not generally regarded as living, opens up a new perspective of the whole question as to how life in its primitive state may have originated.

We have seen that many types of life may have been, and most probably have been, entirely different from any of its forms now naturally existing around us. These are the strongest and most stable specimens of life; that after countless ages and in the most 


\section{THE PHYSICAL BASIS OF LIFE 8I}

unfavourable conditions, notwithstanding the most adverse circumstances, have managed to persist. How different, then, should we expect them to be from anything that may now arise, by comparatively simple processes? This is a point that cannot be too strongly emphasised. And if we are in search of the first beginnings of life to-day, it must be in such elementary reactions as some of those which we have endeavoured to depict.

To expect to make a full-blown bacillus at the present day would not be more absurd than to try to manufacture a man! The actual potentiality in the bacillus must overpower the imagination even of the most imaginative minds. Clerk Maxwell estimated that the living cell cannot contain much more than two million atoms, and he did not think that all the variety we see in Nature could be adequately accounted for by the arrangements of this comparatively small number of units. To some minds it seems as if, with the possible combinations of that number of units, it ought to be possible to do and to produce anything. But when we bear in mind that it is not all possible combinations, but only those which are necessarily confined to the particular accidental changes that may arise in protoplasm-the atoms constituting it being already arranged in certain groups with these limitations and restrictions-then the immense variety of living types in Nature, and the still greater number of varied qualities amongst these types themselves, become so amazing. But this is not all. The types 
we see around us constitute after all a fraction, perhaps an infinitesimally small fraction, of the vast numbers of such types that have once existed and have long since perished. Whilst in that arena wherein life has played so conspicuous and so persistent a part throughout the history of the earth, in the struggle for existence against the more inanimate forces of Nature, there are once more to be found in a still greater variety the elements, so to speak, of that which was the source of those higher forms or survivals of living matter.

This almost indefinite variety of combination in organic and inorganic matter, these weird though simple instances of metabolic aggregations and of even simpler states, give the clue to the first signs of life. Amidst this vast variety a few possessed the qualities which enabled them to perform the functions of transmitting their kind, and a still smaller number of transmitting the kind which would persist in the surroundings which Nature had laid out for them ; till at length, as if against all opposition, "a race was formed with conscience enough to know that it was vile, and intelligence enough to know that it was insignificant"; this race itself, no doubt, like the individuals which constitute it, in turn will die. "And the uneasy consciousness, which for a brief time had in this obscure corner broken the silence of the Universe, will then be at rest. Imperishable monuments and immortal deeds, death itself, and love stronger than death, will be as though they never had been." Nor does it appear from these considera- 


\section{THE PHYSICAL BASIS OF LIFE $8_{3}$}

tions alone "that anything should be better or be worse for all that the labour, genius, devotion, and suffering of Man have striven through countless generations to effect." I In this conflict of stress and storm, in this wild struggle between organised. and unorganised matter, when extended through an almost indefinite time, opportunities arose for an almost indefinite variation of its combinations. And a few such varieties, amongst the many which have long since perished, possessed the qualities which enabled them to persist in the warfare against the brute forces of Nature. In that primitive aggregation may we seek the first beginnings and the immense varieties of life. Was it as complicated then as it now is? Apparently it must have been entirely different. A human being cannot have sprung spontaneously into existence; and if life did arise as we have supposed, doubtless there was a continuous chain of development from that time till now.

The question is, how these varieties are possible with such a comparatively small number of atoms? Well, the atoms are made up of electrons, and we do not yet know if the electrons are not made up of something else. Nay, more, whilst an atom as a unit has certain physical and chemical properties which enable us to ascribe unity to it, it may yet possess many slight variations which should not affect its physical or chemical properties when we have to deal with aggregates, or even with the single 1 Right Hon. A. J. Balfour, Foundations of Belief. 
atom itself as an individual whole. And yet, notwithstanding all this, it seems as if all these varieties must be sought, not in the particular types of aggregations of molecular atoms and electrons or what not, but in variations in that something else, that particular and specialised state of motion, upon which life itself depends. That something else, as we have seen, it is not easy to define, nor is it ours to explain its precise nature in all cases, even in its simplest state, nor the variations of which it may admit. We have endeavoured to describe the manner in which that instability of motion in certain syntheses which can give rise to it, can afford the so-called vital principle or energy in such reactions. We have also suggested that it might explain all the phenomena of life and death, of growth, of subdivision, reproduction, and decay. But, just as the motions of aggregates of electrons, that we call atoms, can give rise to the immense numbers and varieties of spectra, so might it be expected that the flux as well as the aggregates which constitute the principles in vital actions admit of endless varieties of motions and configurations which only become manifest by their subsequent developments, in which such variations in the internal properties of germs, or whatever we may call them, once more become decisively distinct.

We may expect that the minutest differences in living things, like the variations in animals from the same parents, or even in those of the same species, are to be accounted for in some such way. 


\section{THE PHYSICAL BASIS OF LIFE 85}

But it is not merely variations which present difficulties. The almost indefinite variety of qualities which are obviously stored up in the atom are just as embarrassing. These, like the variations themselves, can, as it seems, be accounted for in the same way. Minute perturbation in the motion of these aggregates might be sufficient to give rise to marked qualities in the fully developed organism. A pugnose or red hair may be handed down from generation to generation as some slight disturbance or perturbation in the configuration of a particular third motion in some comparatively stable and important group.

We thus perceive the vast complexity of these unintelligible germs. How very different must they be from anything that we should now produce even by the most complex of artificial means !

The incalculable conditions under which they, and, still more so, their remotest ancestors, have had to exist, leave a blank which no scientific facts can unravel nor speculative thought can penetrate. The most that can be hazarded is that, as to-day we can see taking place under our eyes the development of certain primitive or elementary germs, under certain conditions purely artificial, in the laboratory, as the hot-house produces a plant with which all Nature cannot vie, so may we reason backwards in thought to the time when some unknown conditions should have given rise to something somewhat similar, but, as we must admit, still different from those microorganisms that as by some wild guess we have succeeded amidst many failures in producing to-day. 
This is not all that counts for our contention, unsatisfactory in some ways as it yet may be. In the correlation of the vast fields of such phenomena as we see around us, we can perceive, as we say, the principle of some intrinsic power which runs throughout one type of matter which we call active, and is absent in the other, which we call inert. And in a milder form even this too, with its slight instability in countless ages, as it seems, may in its turn join issue in the great struggle for life. When this instability becomes apparent, the first signs of vitality may be admitted to have at length set in. And, whatever differences there may still be between this primordial type or vital energy and the immeasurably more complex types in which it may yet occur, the mode of action is, as we have endeavoured to depict, the same.

Having made it clear to ourselves that spontaneous generation in the past, and spontaneous generation at the present day, may not be expected to give rise to the same kind of germs, the conditions being quite different, and that, as we plead, due allowance should be made for such differences as may then be observed : it would, we fear, be the height of presumption to assert that, because these artificial products have not all the qualities of that living matter which Nature has handed down to us, or rather has been unable to destroy, therefore life in some simpler form, or in some different form, cannot actually arise artificially, even when there is indisputable evidence of its actual presence by such means. 


\section{THE PHYSICAL BASIS OF LIFE 87}

If some investigator in the distant future had at length arrived at the conditions by which highly developed life could be produced : let us suppose, for the sake of argument, that he found vertebrates under certain circumstances to be artificially generated, and that he set out to manufacture a man, but only managed to produce a donkey: what inference would it be possible to draw from such an achievement? Well, if he was too ambitious, we might admit he was sadly disappointed; but if his object was merely to attain what was possible, and neither more nor less, we might have thought his efforts eminently successful. His failure would have been in not having produced a man, even if intellectually it should approximate to some of them; but his success would have been in having manufactured an animal, which as an animal was not much worse than man. So likewise is it with the products that we now call vital. They are not bacteria, not more bacteria than donkeys are men; but, as we have endeavoured to emphasise, they possess most of the qualities which are observed in bacteria, and though not all of them, at least enough of them to enable us to identify, or rather to classify, them with the living things we see. We have made clear, then, what we consider our position in the matter is. We cannot claim that in all our observations there is the slightest evidence of anything which is the same as natural life. What is produced artificially is essentially artificial life, and is no more to be identified with the natural survivals which have been handed 
down to us, than new wine is like old, or than the new-born baby is like the veteran of three score and ten.

In reference to these artificial cells it may in passing be remarked that the recent experiments of Professor Tommasina of Geneva, as described at the recent International Congress of Radiology at Liége, on the radio-activity of animals and plants, small though this activity may be in living bodies are indeed remarkable, and quite in accordance with the views which we have all along maintained. It is measurable as much as, if not more so than, the now well ascertained radio-activity of metals generally, and of many other substances, and is much larger than that which would be passed over with indifference or escape the attention of any acute observer. Now if in the first instance life arose by the spontaneous action of some radio-active bodies upon certain media possessing the ingredients of protoplasm, it might be expected that the radio-active nucleus would remain attached to the living body and that radio-activity would be one of its properties. Considerable induced radio-activity would also exist in the substances which diffused outwards from the nucleus, this induced radio-activity disappearing altogether with time, and being renewed again by the circulation or diffusion of fresh substances. The life of the radio-active atom, however, is something of the order of a thousand years, and if life originated in this way, it is not easy to see how living things could still retain their radio-activity, nor indeed how 


\section{THE PHYSICAL BASIS OF LIFE 89}

radio-activity could still exist. The idea is, and the evidence is very strong indeed, that radium is the direct descendant of uranium; that, in fact, uranium is slowly being converted into radium. Most probably, too, uranium is the descendant of something else, or of a series of such elements that have long since become extinct. The first appearance of radio-active bodies is thus lost in obscurity not unlike that of the first beginnings of life. But it must not be imagined that, because the life of each radio-active substance is so short, therefore, it is not to be found still in such living bodies as may have originated contemporaneously with the remote ancestors of radium, so that whatever the radio-active substance is, its descendant would no doubt appear in some form and even at the present day persist. 


\section{CHAPTER VI}

\section{EXPERIMENTS WITH RADIUM AND CULTURE MEDIA}

Experiments with glycerine and liquid air-Dr. Gladstone's glycerine crystals-Culture produced by radium salts in gelatin bouillon-Other globular bodies produced by gum and gelatin-Reasons for supposing radiobes are not bacteria -Negative experiments with cyanogen-Pflüger's theoryNature of the cyanogen molecules and of the radium molecules-Dubois' vacuolides not radiobes-Sachs's theory of colloid bodies: that they are crystals asymmetrically arranged-Experiments of Leduc, Bütschli, and othersDiscussion of Pasteur's results and their bearing on the present experiments-Radiobes and primitive life.

In the course of my previous work on phosphorescence I was induced to try whether the molecular groupings which, it was supposed, were formed during phosphorescence, by exciting sources, could also be produced in other organic bodies, whether they become luminous or not, so long as they are similarly acted upon. The precise reasons for this hypothesis will appear when we come to deal with the phenomena of phosphorescence and fluorescence.

The first attempt was to bring about the con- 


\section{EXPERIMENTS WITH RADIUM 9I}

densation or formation of a complex aggregate round a nucleus, itself the seat of an electromagnetic disturbance, as in radio-active particles that might set up an aggregation of molecules, probably of an unstable kind, in its vicinity.

The most promising step to take appeared to be to introduce some radium salt into a tube containing glycerine, and then suddenly to cool the liquid, which would thus have every opportunity of condensing round the ions from the radium embedded in the glycerine; and perhaps also the aggregates contemplated would have a similar opportunity of being formed by the intense electromagnetic pulses set up, or possibly by some catalytic actions. Crystals of glycerine were thus produced, but it was found that the radium was not necessary, the low temperature being sufficient to enable them to form. On being removed from the cooling chamber and allowed to stand at the ordinary temperature of the room, they rapidly disappeared in about five minutes or so. Dr. J. H. Gladstone exhibited to the Chemical Society, 1866, some crystals of glycerine which were found in a tun from Vienna. Several generations of these have been obtained and preserved in various laboratories. The manner in which they first appeared is not known. They were quite different from those obtained by liquid air, and this experiment was also made with gelatin. Microscopic crystals were thus easily produced by immersion in liquid air, and the outward appear- 
ance of the colloid was greatly altered, as it became intensely opaque.

Bouillon, which was carefully sterilised, under pressure, with radium at a temperature from $130^{\circ}$ to $140^{\circ}$ cent., for about thirty minutes at a time, was also tried. It was found in this case that after two days a culture grew on the surface of the gelatin. Moreover, on repeating the experiment it was observed that the culture, if it might be so called, was still formed, even when the tube was not frozen.

This was most remarkable, but the obvious explanation appeared to be that the cultures were contaminations and the result of imperfect sterilisation. So the experiment was repeated with controls. The result was precisely the same as before obtained in the tube containing radium, whilst the control tube showed no sign whatever of contamination. The radium was mixed with the gelatin medium in most of the experiments; in some, however, it was contained in another and smaller tube close to the surface of the gelatin, or in a side tube. In all the experiments which may be regarded as reliable, actual contact seemed to be necessary, although at first it seemed as though the a-rays were sufficient. In all such cases some of the radium actually reached the gelatin during the process of sterilisation.

In the earlier experiments the salt used was the chloride. It was sprinkled on a narrow glass slide over which a thin layer of gum was spread. 


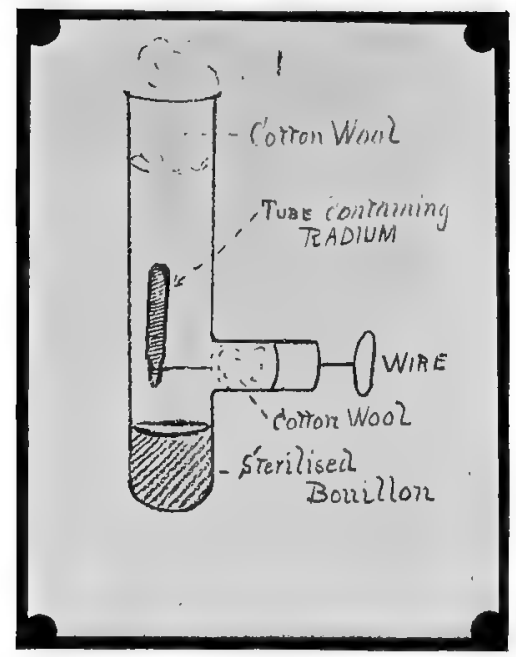

T'ent-tube carticining radium or other salt, for purpuse of sterilisation.
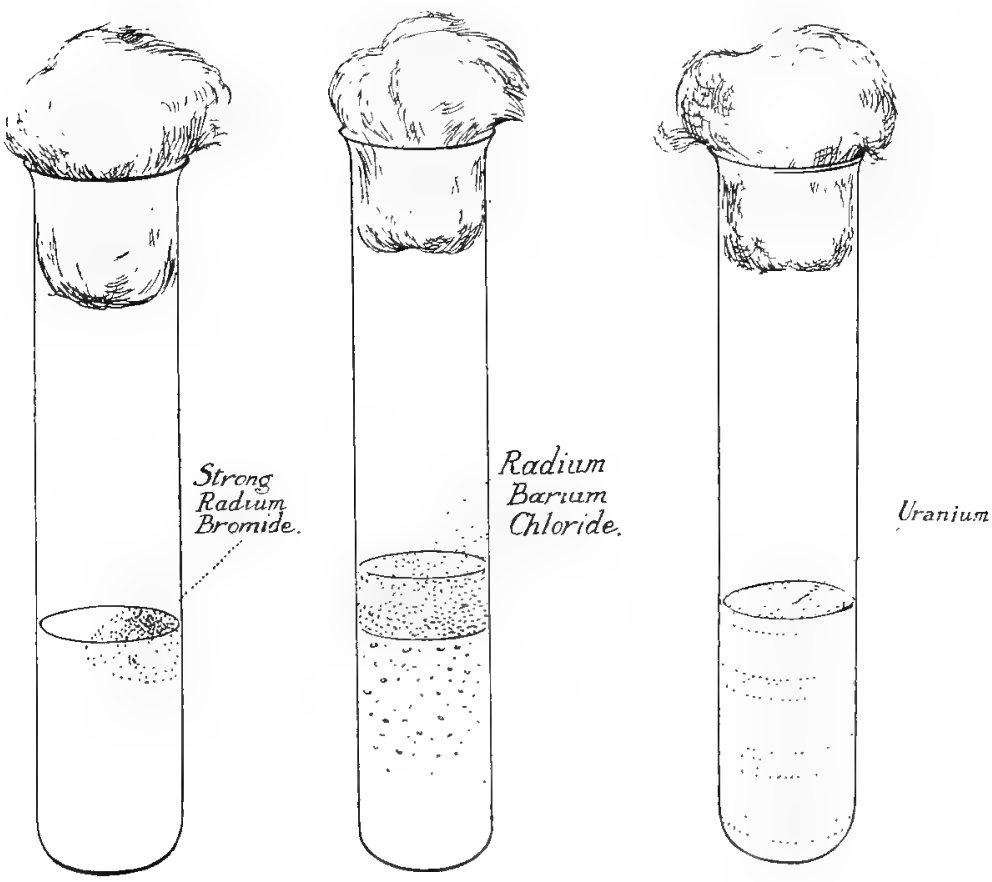

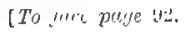





\section{EXPERIMENTS WITH RADIUM 93}

The cultures were obtained only when the edge of the glass slide came in contact with the gelatin.

In looking through some of the literature of the subject, I found that it was a well-known fact that gum acted on gelatin in such a manner as to produce oily drops. ${ }^{1}$ Controls with gum alone, however, proved that the two effects were entirely different, the gum globules being confined chiefly to the surface, and disappearing altogether after some days, whilst the radium effect increased.

Thus it seemed quite clear from these control experiments that the gum was not the cause of the culture-like appearances, whilst subsequent experiments with pure radium salts proved this beyond doubt.

The next step was to get sub-cultures by inoculation in fresh media. The sub-cultures did not show the slightest signs of growth for nearly six weeks. They then, however, did manifest some tendency towards development, but only to a very small extent.

It was at once evident that the original cultures were not bacteria.

When working some time ago at the phosphorescent glow in gases, I was led from various considerations to infer that the luminosity was the result of great complex molecular agglomerations produced by the spark. The duration of the life-period of those molecular groups, if they might be so called,

1 Article "Gum," Encyclopadia Britannica, ninth edition. 


\section{THE ORIGIN OF LIFE}

is greatly increased by letting them diffuse into another tube through which the spark had not previously been sent. ${ }^{1}$

The effect of glycerine and gelatin on phosphorescent liquids is also known to increase the duration of the luminosity, and this is probably due to the diminution in the number of collisions.

I thus endeavoured to observe the effect upon the phosphorescent molecules by introducing glycerine or gelatin into a vacuum tube, immediately after sending a discharge of electricity through it, whilst the phosphorescent glow lasted.

If the glycerine or gelatin on being introduced is shaken inside the tube, some of the phosphorescent molecules would be caught by the liquid, which in turn should become phosphorescent. The cyanogen molecules, it was thought, would do this, particularly on account of their persistent nature after the passage of the discharge. Bouillon, which had been sterilised with the tube itself before being introduced, was also among the substances employed. The vapour, however, from these substances when in the liquid state was enough to prevent the phosphorescent molecules, which could exist at low pressure, from persisting, and thus the experiments for the time were dropped.

It seemed as if the complex molecules of paracyanogen, unstable, but at the same time persistent, and yielding a vast store of energy in their disintegration, might act as nuclei, which would in

1 Philosophical Magazine, March, 1901. 


\section{EXPERIMENTS WITH RADIUM 95}

suitable media set up catalytic actions, and thus act as a means of synthesising complex organic compounds: a method not bitherto employed. It was for this reason that bouillon, of the composition used in the experiments with radium, was used, since it contained all the constituents of protoplasm, and it seemed at the time quite possible, not to say probable, that the physical properties of the cyanogen molecule, as well as its chemical properties, justified the very shrewd conception of Pfliuger, that the molecule of cyanogen is a semi-living thing.

The fundamental difference between living proteid as it constitutes living substance, and dead proteid as it occurs in egg albumen, is in the selfdecomposition of the former and the stable constitution of the latter.

As Verworn ${ }^{1}$ remarks:- "The starting point for further consideration is afforded by the fact that of the heterogeneous decomposition products of living proteid, such as uric acid, creatin, and, moreover, the nuclein bases, guanin, anthin, hypoxanthin, and adenin, a part contains cyanogen as a radical, and a part like urea, the most important of all the decomposition products of living proteid, can be produced artificially from cyanogen compounds by a rearrangement of the atoms. This points strongly," he thinks, "to the probability that living proteid contains the radical cyanogen, and thus differs fundamentally from dead or food proteid." Thus, according to Pflüger, "in the formation of

${ }_{1}$ Loc. cit. p. 306. 


\section{6}

\section{THE ORIGIN OF LIFE}

cell substance, i.e., of living proteid, out of food proteid, a change in the latter takes place, the atoms of nitrogen going into a cyanogen-like relation with the atoms of carbon, probably with the absorption of a considerable amount of heat." Cyanogen is a radical which contains a vast amount of energy, and although not to be compared with that of radium compounds, nevertheless its potential store is very great, as appears from thermal investigations.

And again, "the idea that it is the cyanogen which confers upon the living proteid molecule its characteristic properties is supported especially by many analogies that exist between living proteid and its compounds." This product of the oxidation of cyanogen, cyanic acid HCNO, possesses great similarity to living proteid.

Pfluger calls attention to the following interesting points of comparison :-

1. "Both bodies grow by polymerisation in combining chemically similar molecules like chains into masses; the growth of living substance takes place thus, and in this way also the polymeric $\mathrm{H}_{n} \mathrm{C}_{n} \mathrm{~N}_{n} \mathrm{O}_{n}$ comes from cyanic acid HCNO.

2. "Further, both bodies in the presence of water are spontaneously decomposed into carbonic acid and ammonia.

3. "Both afford urea by dissociation, i.e., by intra-molecular rearrangement, not by direct oxidation.

4. "Finally, both are liquid and transparent 


\section{EXPERIMENTS WITH RADIUM 97}

at low temperatures and coagulate at higher ones; cyanic acid earlier, living proteid later. Their similarity," says Pflüger, "is so great that I might term cyanic acid a half-living molecule."

Pfliger's analyses, to say the least of them, have not met with widespread recognition, further experimental confirmation being doubtless necessary before they could be ranked as theory.

The dynamical nature of the cyanogen molecule, however, together with the large store of potential energy which it contains, constitutes the resemblance, from a physical point of view, between it and radium compounds. Still it must be borne in mind that the internal energy thus manifested by the molecular disintegration is of an entirely different order of magnitude. Nevertheless there is a sufficient resemblance between the two from a physical point of view to utilise either of them for the purpose of the experiments we have in view. The molecule in either case might act as a nucleus that by catalysis, or some other means, should set up dynamically unstable groups, which, though not living in the sense that they possessed the $n$ qualities of living proteid, might, as we have said, by possessing $n-1$ of those qualities be regarded as a mode of life in the sense in which many philosophers have used the word. If cyanogen is a half-living thing, as Pflüger supposed for the reasons given, it is only natural to try if it would form growths in culture media, and the use of bouillon in my experiments was merely the logical outcome of this conception. 
It was at the beginning of the Michaelmas term, October, 1904, that we exhibited to a host of people at the Cavendish and Pathological Laboratories at Cambridge these first experiments made on the action of radium salts on sterilised bouillon. The bodies thus observed were very curious indeed, and some of their properties very remarkable.

M. R. Dubois stated in an inaugural address at Lyons, shortly afterwards, in November, a somewhat similar result. Claims to priority are always distasteful. It is therefore not our intention to enter into controversy upon such matters, but merely to tell the story of our own doings in our own way. The proceedings of the laboratory in which we worked constitute in themselves publicity and an exhibition of our experiments to those outside it still more so; whilst the idea which led to those experiments was outlined in the Monthly Review, Nov., 1903. M. Dubois' vacuolides, which are also produced by other means than by radium, as, for instance, by barium and manganese salts, are not radiobes, but only like one of the products of the reactions with bouillon. They are so much larger, and resemble the globules produced by gum and other bodies. Of this more elsewhere anon.

The pièce de résistance is the sterilisation, and upon this point M. Dubois says practically nothing; except that his culture medium was rendered "aseptic" in the usual way. No doubt his precautions have been carefully carried out and it must be 

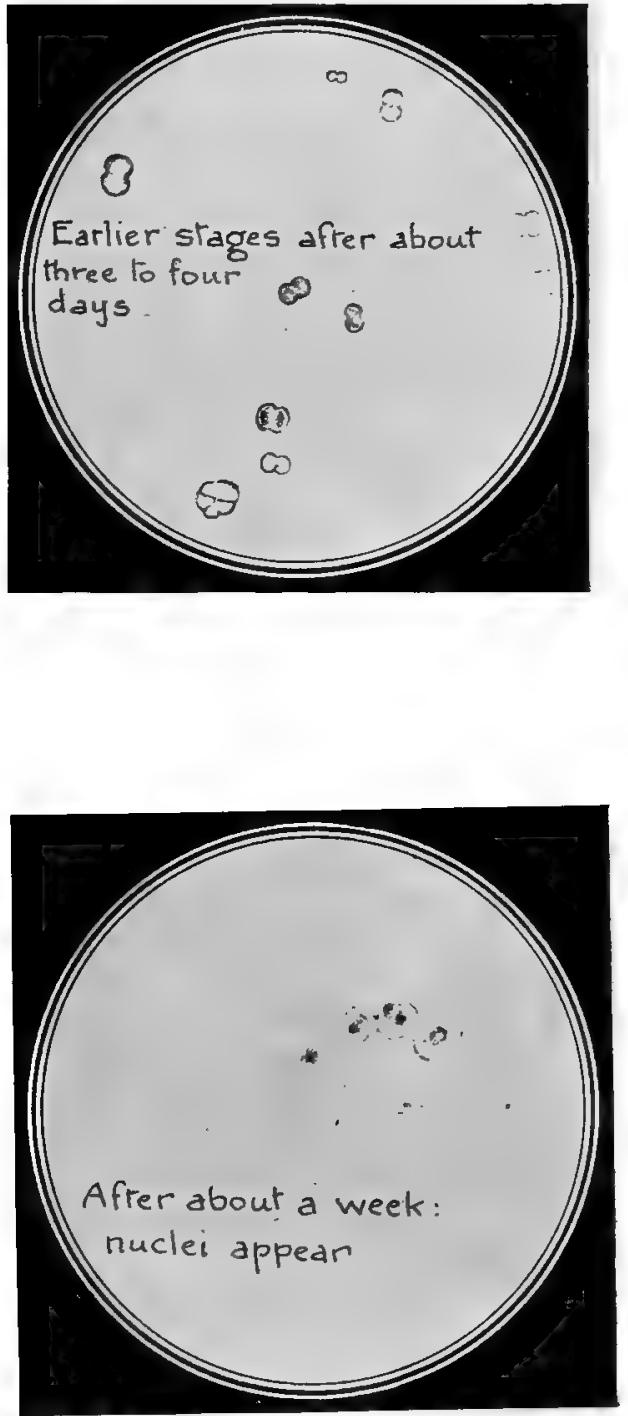

[To face page 98. 



\section{EXPERIMENTS WITH RADIUM 99}

remembered that the salts themselves are antiseptics: but as the artificial production of bodies apparently alive has been repeatedly asserted, as it has been again and again disputed and denied; the production of such bodies by radium and other salts is not more remarkable than their production by other means, unless it can be shown that when extreme precautions are taken it is by this method, and this method alone, that such bodies are, notwithstanding their prevention, still produced. If the tubes were opened to insert the salt after sterilisation, the experiment is inconclusive, because the growths may emanate from other parts of the surface of the gelatin, when the parts on which the salt fell cannot be identified.

We do not claim to have produced spontaneous generation, for by this is meant the development of what is living from that which was supposed not to be. No doubt inorganic substance may contain embedded in it some germ or germs till hitherto unknown and of a nature quite distinct from any we have yet had reason to regard as living; the substances employed may by their very nature, as it is here suggested, have the principle of vital process in an elementary form. ${ }^{1}$ It is so with the dynamically unstable substances which of their own account manifest radio-activity. These dynamically unstable bodies disintegrate and decay in their manifestations of that activity : but although

I "The Radio-activity of Matter," Monthly Review, loc. cit. 
this is merely analogy, and we must remember, as the great Darwin has well said, "analogy is a deceitful guide," still, if that analogy has prescribed or suggested results which have since been verified, its utility should have a claim to our attention before it is explained.

The first experiments were repeated with radium bromide. A minute quantity of the salt contained in a small glass tube, one end of which was drawn out to a fine point, was introduced into an ordinary test-tube containing bouillon. The test-tube was plugged with cotton wool in the usual way with such experiments, and then sterilised at a temperature of $130^{\circ} \mathrm{C}$. for about thirty minutes at a time. On cooling, as soon as the liquid had coagulated, the fine end of the inner tube containing the radium was broken by means of a wire hook in a side tube. The salt was thus allowed to drop on the surface of the gelatin. After twentyfour hours signs of growth were already visible; and on opening the tube and examining the culture microscopically the results were as those previously obtained.

Their appearance is indeed most striking. It is curious, however, that with bromide the cultures, although produced more rapidly, did not spread far into the interior of the gelatin, as did those due to the chloride, but the cultures after six weeks or so were even more remarkable and resembled the cultures of tuberculosis.

Slides were made in the usual way. The appearance was that shown in Plate I. It is noteworthy 

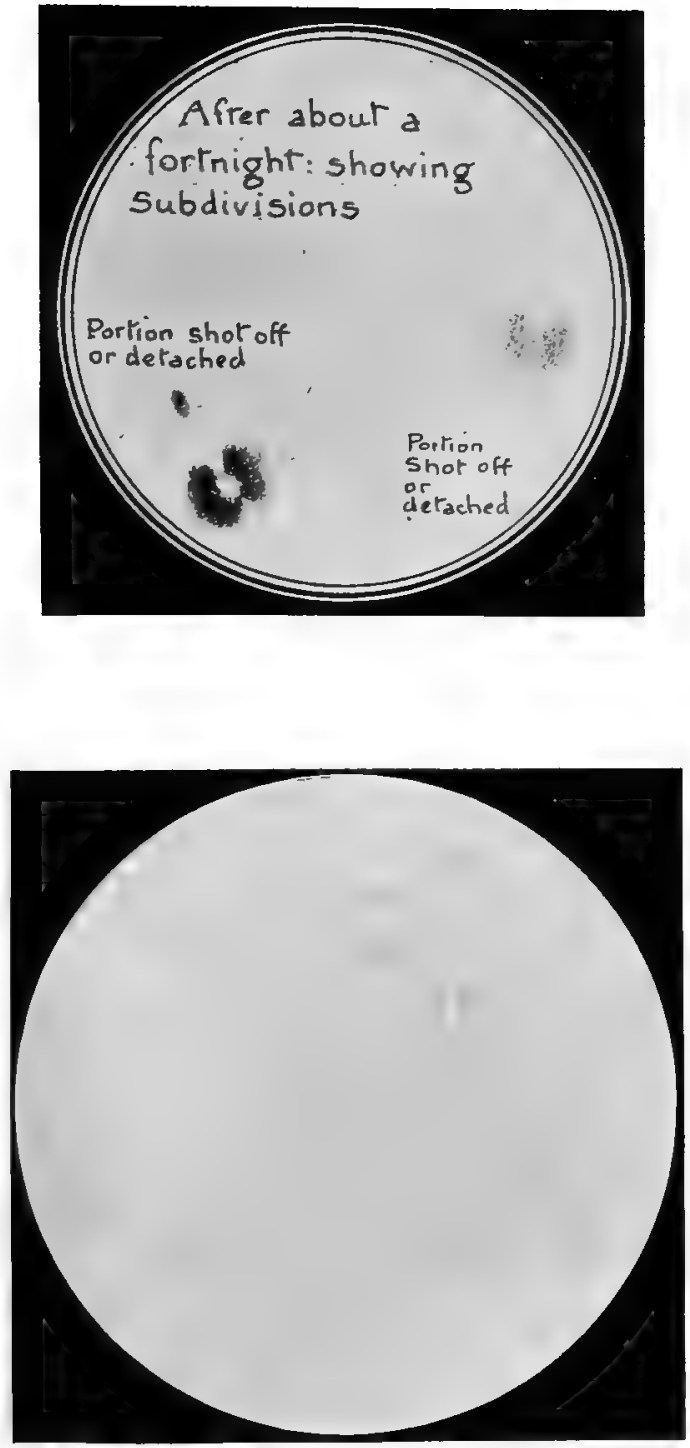

I.

[To jace page 100. 



\section{EXPERIMENTS WITH RADIUM IOI}

that the consistency with which they appear and their form at each stage of development are not the least striking features of their many characteristics. At first their appearance is that of diplococci; yet it will be observed that they are not all of the same size, but vary considerably through a wide range from mere specks as seen in $\frac{1}{12}$-ine' oil immersion power. There is an indication of growth and of their having originated from ultramicroscopic particles, but they do not grow beyond a certain size.

At first they looked like calculi of carbonate of lime precipitated from viscid solutions of gum, albumen or even glycerine, but these are so very much larger and visible with much lower powers. The latter are insoluble, whilst the former are soluble in warm water; so that the two cannot be identified. They might have been soluble phosphates, but the considerations which follow indicate that they are highly complicated structures and more like organisms.

The polariscope does not give the figures and changes of colour which are the characteristic features of a crystal. There is, however, a lefthanded rotation imparted to the gelatin, and one which can easily be detected when the culture has penetrated some distance into the interior, the rotation amounting to several degrees in a centimetre thickness. Thus they appear to be more of the nature of colloidal bodies, but, like bacteria, with an asymmetric structure.

The very minute quantity which could be experi- 


\section{IO2 THE ORIGIN OF LIFE}

mented with rendered it extremely difficult to investigate their chemical composition; but the method of prolonged observation, like the astronomical method in matters over which we have no control, enables us to study their structure and behaviour, and to decide the question as to whether they are crystalline or organised and living forms.

Upon this point, however, it is necessary that the use of the word "crystal" should stand for some definite thing. By a crystal we mean an aggregate of symmetrically arranged groups of molecules. Such aggregates are known to grow by piling up, as it were, one on to another. They grow by accretion, not by assimilation, from their environment. Sachs ${ }^{1}$ regarded protoplasm as made up of minute crystals, but he seems to have used the word in, perhaps, a somewhat elastic sense, by thus including protoplasm, a colloidal substance, amongst crystalline bodies.

If colloidal bodies are aggregates of minute crystals, they are, however, not symmetrically arranged crystals, and the aggregate is not isomorphous with the constituent crystals, but on the whole amorphous.

An organism has a structure, a nucleus, and an external boundary or cell-wall, and its vitality may be described as being a continuous process of adjustment between its internal and its external relations.

1 Physiology of Plants, pp. 206-7. 


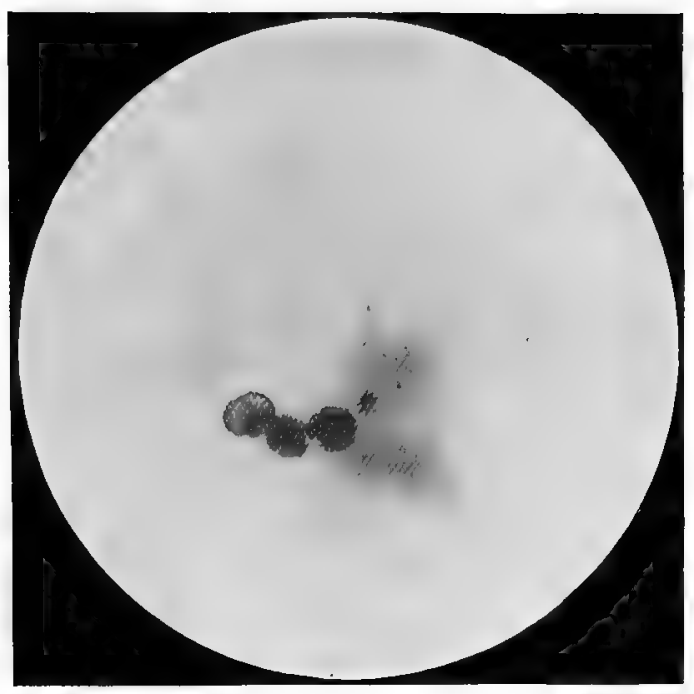

II.

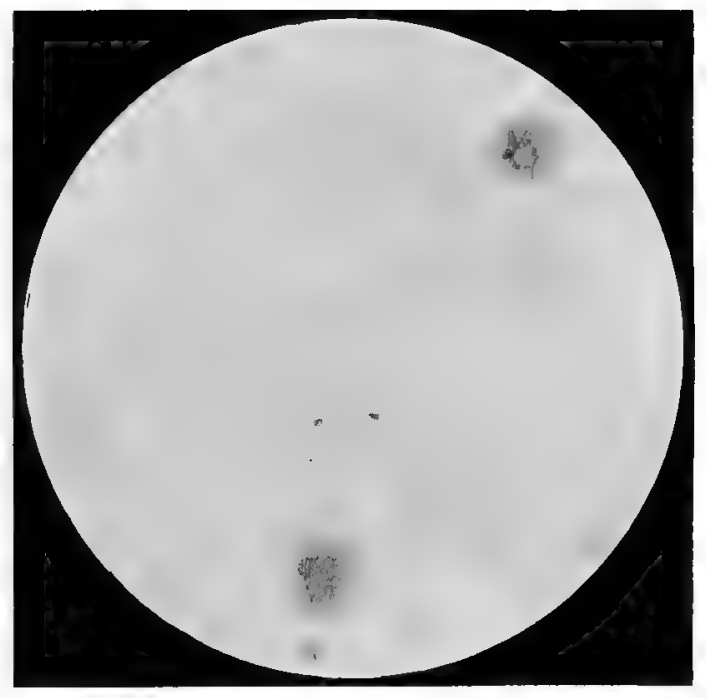

III.

[To face paye $10 \%$. 



\section{EXPERIMENTS WITH RADIUM $1{ }_{3}$}

Now a clear examination of the bodies produced by the action of radium on culture media will enable us to decide under which of these two heads these bodies come.

Plate I. does not reveal any structure, but Plate II. distinctly shows the existence of a nucleus of a highly organised body, whilst later, in Plate III., the particular segregation effects of growth and development, which it would appear rule crystals out of court, is evidenced.

This subdivision is the most striking thing about them, and a clear idea of its actual nature cannot be derived fully from the photographs. When the size of the body exceeds this there is a tendency for it to divide up as in Plate IV., and to lead a separate existence.

These products of radio-active bodies thus manifest not merely instability and decay but growth, subdivision, reproduction, and, as it were, adjustment of their internal functions to their surroundings; a circumstance which may be found to be equivalent to nutrition. Whether we are to regard these products, strictly speaking, as living things is the point which remains to be decided. We have to define their properties as we have defined life.

Thus by the action of radium upon sterilised bouillon microscopic bodies appear, of which the micro-plates give a clear and a definite idea.

In the first instance they are not, as microorganisms would be, of the same size so long as 


\section{THE ORIGIN OF LIFE}

they are of the same kind; ordinary bacilli, provided they are of the same type, are found to be also of the same dimensions. These do not show signs which indicate that they have one and all sprung in a process of continuous growth from ultra-microscopic forms. But this is one of the characteristic features of the products now produced by radium. There can be no question that in each case they have sprung from the invisible and grown to such a magnitude as to be seen. We find no such indication with ordinary bacteria. But the radiobes undergo many developments. After six or seven days, and at times even less, they develop nuclei; and later still they cease to grow and then begin to segregate and multiply. The manner in which they do this has led us to suppose that they are assimilative and automatic, and not altogether, strictly speaking, lifeless things.

Their growth is no indication of vitality, for crystals not merely grow, but grow to such dimensions that in this point no living microscopic organism has any chance to rival them; crystals, however, do stop growing at some stage or another, else we should have, as someone has insisted, diamonds as large as Mount Etna or the Himalayas. This, however, does not seem to be, the point; when crystals reach their maximum dimensions do they throw off their superfluous particles and disintegrate themselves? In other words, do crystals go through the cyclic process, pass into higher forms, and then decay, which is so 


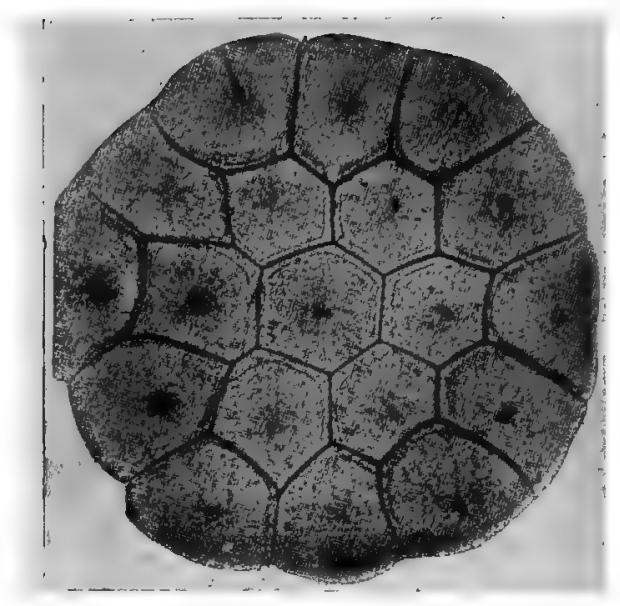

Artificial licuid cells produced in a solution of sorlium chloride, coloured with china ink in distillerl water (Lerluc).

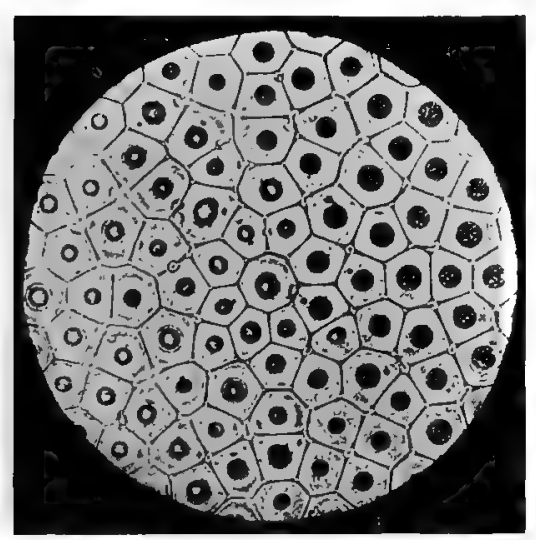

Artificial cells produced by potassium ferrocyanide and gelatin (Leduc). 



\section{EXPERIMENTS WITH RADIUM 105}

often regarded as a test of life? The passage into higher forms, or rather development in size and shape, is not the test; but only when subsequent decay ensues. The passage through the cyclic process in time is indeed the test of life. It is the stoppage of growth at a particular size and of reproduction by fission or subdivision, and then the total disintegration of the cell, or whatever we may choose to call it, after its steady regular growth up to that point, that is suggestive of vitality. The subdivision, or fission, which accompanies the cessation of development even in the mechanism of adding to its size, shows the stage when there is a balance between the accumulation of energy and its expenditure. The bodies obtained by M. Stephane Leduc in 1902 , by the action of potassium ferrocyanide on gelatin, or by allowing metallic salts to crystallise in gelatin and other colloidal solutions without sterilisation, do not exhibit all these primary or elementary properties of living things. They do not, in fact, manifest more than a resemblance in appearance to the cells or unit forms of life. Their properties are not sufficient to justify the inference that they are even approximately living things, nor even that they possess to any marked extent the qualities that are associated with organic matter as we. have described.

On the other hand, it has been suggested that if radiobes are crystals, they subdivide by cleavage under the influence of internal strain, as, for instance, South African diamonds are found. 


\section{THE ORIGIN OF LIFE}

occasionally to do. It all depends upon the nature of the segregation whether it is like a fission or a cleavage. The photographs show this most distinctly as it occurs within fourteen days or so, the subdivision being clearly not of the nature of a cleavage. These subdivisions do not resemble those obtained by Professor Bütschli, of Heidelberg, by the action on soluble salts of such substances as olive oil: the bodies obtained by emulsion of these bodies in water behave much as if they were elementary forms of living things. But here again it is upon the nature of the subdivisions that we must rest our assurance as to what these subdivisions mean. These subdivisions are quite different from anything we should expect mere surface tension to effect.

A close examination of the mode of segregation at once shows that the "cell," if we may call it so, becomes divided into segments, much in the same way as ordinary yeast cells are well known to do. Sharp corners, which are not unusual in the part so segregated, seem incompatible with the proposed theory of some overbalance in the force of surface-tension over the internal forces which tend to keep the body intact. Many minute bodies subdivide, but they thus subdivide in different ways: and the manner in which they are found to do this is, we venture to think, as important, if not far more so, than the mere fact that they do so actually divide. In this way it may again be urged that there are many microscopic particles which are known to pass through some of 


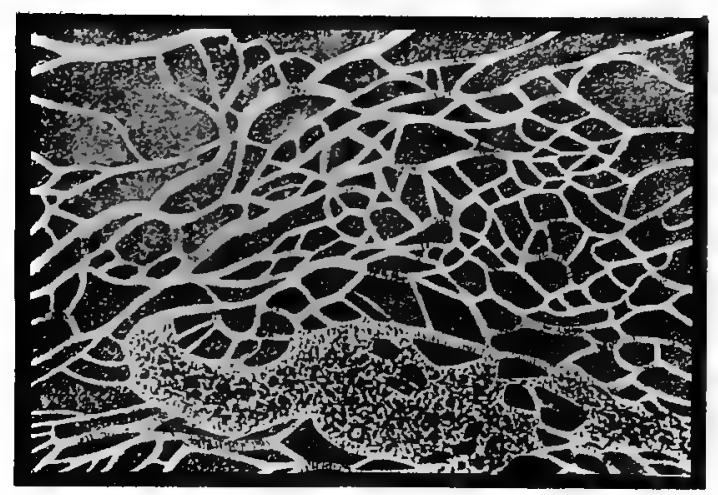

I.

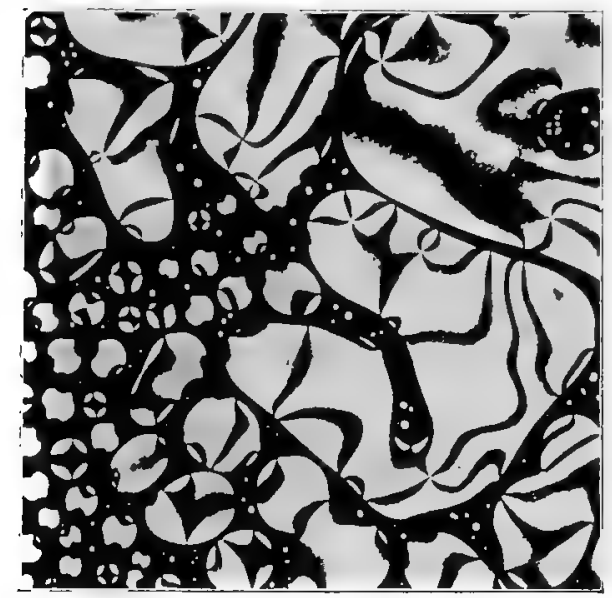

II.

Lehmann's liquid crystals.

Reproducod hore, with the kind permission of Herr Wilhelm Engelmann, of Leipzig, from Schenck's work, loc. cit. 



\section{EXPERIMENTS WITH RADIUM 107}

the stages which these bodies also do; but we have no knowledge of any bodies which can perform the cyclic process so completely. It has been suggested that the products of radium and bouillon are like the microscopic crystals described by those already mentioned, and also by Schenck in his admirable little work which has just recently been published. ${ }^{1}$ We have never thought of classifying or identifying the bodies therein described with the "plastide particles" in bouillon, some of which have been so many times observed. The two indeed are totally distinct, the smaller ones behaving like bubbles or more accurately like oily drops, possessing no indication whatsoever of an internal structure other than that which we may associate with crystalline forms; whilst the larger ones are much too large, and show no signs of disintegration, but give the beautiful characteristic figures as in crystals under the polariscope. Even the comparatively small ones exhibit, to some extent at least, some slight polariscope effects. But they are obviously, to anybody who has seen them, quite different from those which are brought about in the culture medium under the influence of radium. They do not stain-at least they have not been found to do so-as the radium bodies do, and they do not manifest the properties which have so attracted our attention with the latter; the two, so far as can be judged, are totally distinct, as distinct as coal is from potatoes.

It will be urged-in fact it has been urged-that

1 Kristallinische Flussigkeiten und Flüssige Kristalle. 


\section{IO8 THE ORIGIN OF LIFE}

these bodies, if living, must be the result of imperfect sterilisations, and that the experiments of Pasteur completely proved that when sterilisations are properly carried out, life does not spring from lifeless matter. These experiments have really no bearing on the question as to whether radio-activity can afford the internal energy of vital processes. Pasteur's experiments were on sterilised media not acted upon by sources of activity such as those which now form the subject of discussion, and they have nothing whatsoever to do with the questions as to whether radio-activity can afford that energy in dynamically unstable groupings placed in suitable surroundings, which might afford in more complex aggregations the $f u x$, so to speak, which constitutes the principle of life. It may be said without fear or hesitation that whatever is the aspect we should take of this conception, it is a matter about which we may feel confident that Pasteur, Tyndall, and Huxley would have thought as strongly as ourselves that their experiments had no bearing whatsoever on the point at issue. Nay, more, since all bodies are now supposed to be radio-active to a slight degree, even Pasteur's experiments should yet yield the same result; although it would take aeons to produce in this way the aggregations brought about by radium in a few days.

The growth is from the minutest visible specks, which develop into two dots, then into a dumbbell shaped appearance, later a biscuit-shape, and later still more like frog's spawn, through various 


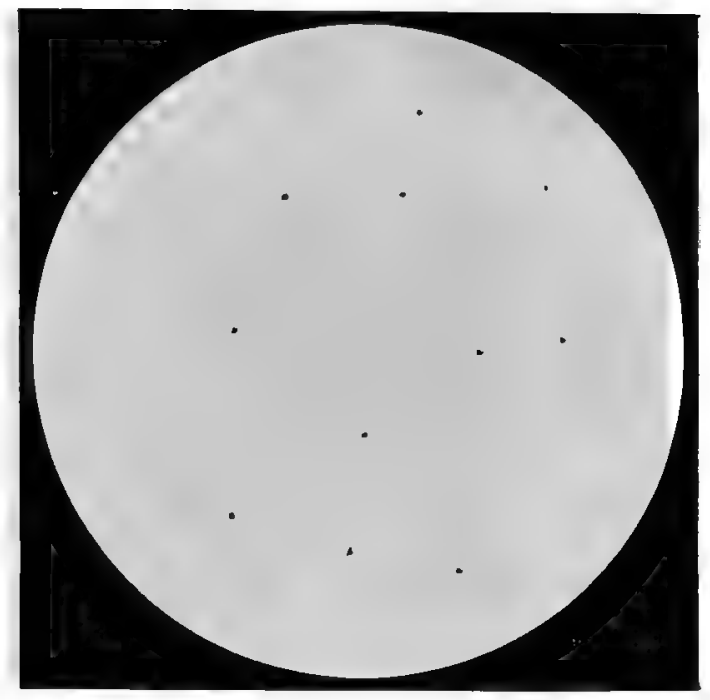

I.

First signs of Radiobes.

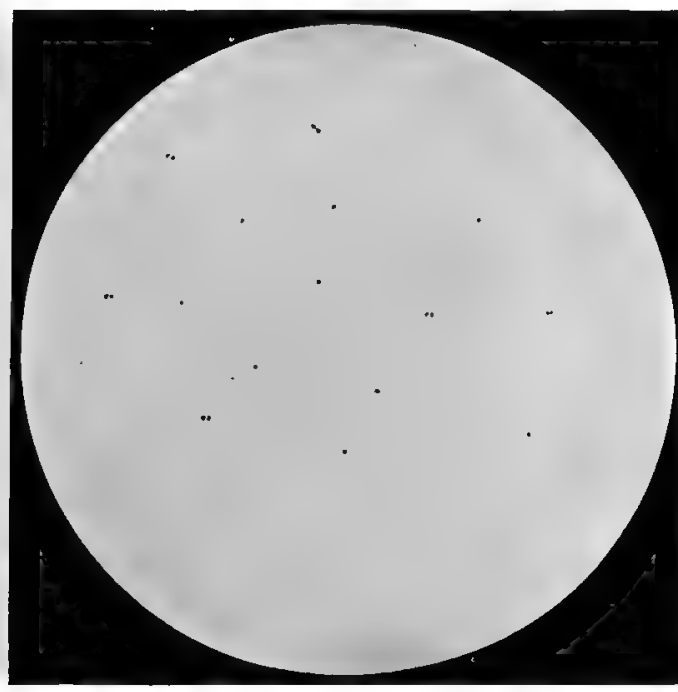

II.

Second_stage.

[To face page 108. 



\section{EXPERIMENTS WITH RADIUM 109}

stages, as in the figures, until a shape is reached different from its previous forms, when it divides and loses its individuality, and ultimately becomes resolved into minute crystals. This is a development which no crystal has yet been known to make, and forces upon the mind the idea that these bodies must be organisms; the fact, however, that they are soluble in water seems, on the other hand, to disprove the suggestion that they can be bacteria. But the stoppage of growth at a certain stage of development, together with the particular subdivision, is a clear indication of the continuous adjustment of internal to external relations, and thus suggests vitality.

The continuity of structure, assimilation and growth, and then the particular subdivision, together with the nucleated structure as shown in a few of the best specimens in Plate II., indicate a process like vitality, whether we call these forms bacteria or not. There is further a subdivision of the nucleus, as in karyokinesis, which will be discussed later on.

As they do not possess all the properties of bacteria they are not what are understood by this name, and obviously lie altogether outside the beaten track of living things. This, however, will not prevent such bodies from coming within the realm of biology; and, in fact, they appear to possess many of the qualities and properties which enable them to be placed in the borderland, so to speak, between crystals and bacteria-organisms in the sense in which we have employed the word, and possibly 
the missing link between the animate and inanimate. May they not also be something like the germs which, after countless generations, under gradually changing forms and in suitable environments, had at length evolved into a bacillus, at which we gaze with hopeless wonder and amazement each time we view them in the microscope to-day? Upon this point we are at liberty to have our own personal opinions without forcing them upon others. It is mere speculation.

For our own part the gap, apparently insuperable, between the organic and the inorganic world, seems, however roughly, to be bridged over by the presence of these radio-organic organisms which at least may give a clue as to the beginning and the end of life.

The mode of development, or the life-history of these bodies is, then, their most remarkable characteristic, and it is curious to note that, although in their living or semi-living states they may differ widely from crystals, yet the final products are nothing more than these. Can they still be crystals in disguise? Not more so surely than protoplasm, which, as Sachs in his Physiology of Plants maintains, is really composed of crystals. Such aggregates, however, are by no means to be identified with crystals, their properties being quite different - as different as those of a highly complex molecule is from its constituent atoms. Their properties are quite different, although the substances be the same. The constituent crystals of protoplasm are 


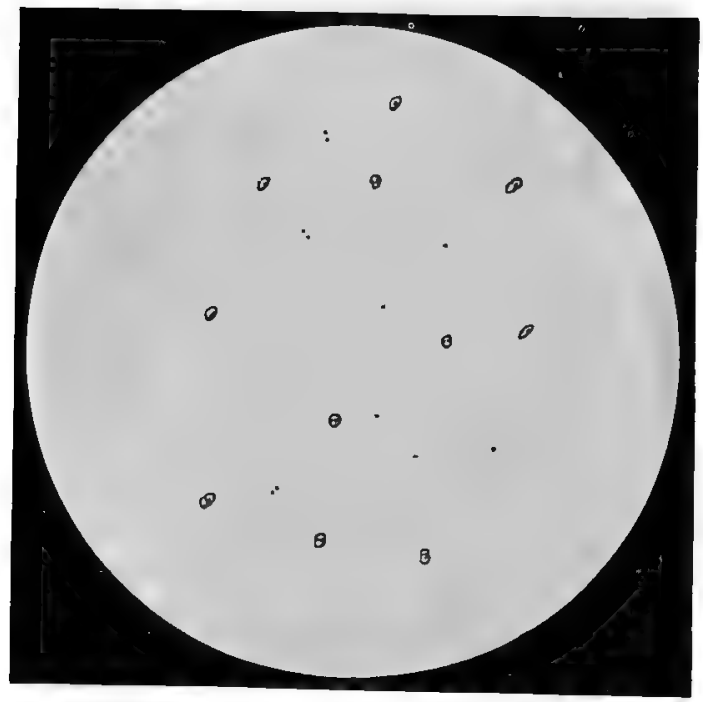

III.

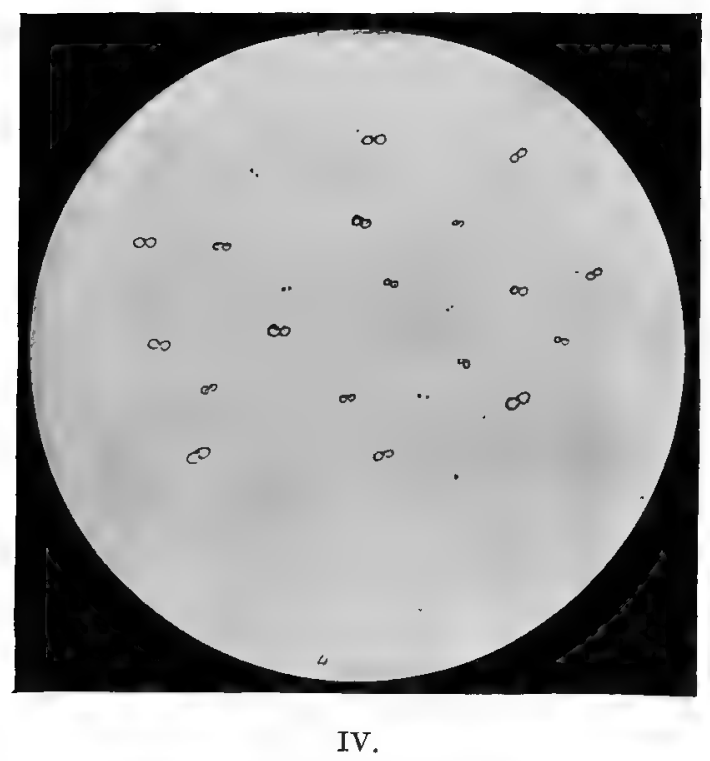

Third and fourth stages.

[To face page 110. 



\section{EXPERIMENTS WITH RADIUM III}

therefore arranged in an entirely different way from isomorphous groups; so that the ultimate crystalline nature of the constituent bodies has little if anything to do with the plastide nature of the amorphous substance which they constitute.

Sach's view was that protoplasm is an organised substance consisting of crystalline, doubly refracting molecules (Micellae). This view is "now generally accepted. In the moist state each of them (Micellae) is surrounded with an envelope of water in consequence of its powerful attraction for them. In their dry state they are supposed to be in mutual contact. This theory of the internal structure of the organised bodies was propounded by Naegeli.

Now the idea that minute crystalline bodies do take part in vital actions is not to be dismissed without the fullest consideration, and the fact that radiobes are ultimately resolved into minute crystalline forms does not justify the inference that the aggregate body is itself also crystalline. It is, as a whole, a colloid, not a crystal, and the behaviour of such bodies shows that there is a difference, and that upon that difference so much depends-

"That little more and how much it is, That little less and what worlds away!"

as someone who understood the question so appropriately remarked.

"That little more" is what in each step upwards in the scale of being, as if by added parts, finally 


\section{I12 THE ORIGIN OF LIFE}

imparts the actual character and meaning to the individual as a living whole.

Granting then, as there can be little doubt we should grant, that these radio-organisms are in reality aggregates of crystals and yet not crystalline because the constituent crystals are not isomorphously arranged, we are induced to look upon whatever properties they possess when acting individually as distinct from crystals in their separate states. This difference, we are induced to think, is of such a nature that, in whatever light crystals may be looked upon, radiobes and living proteid generally are not crystals whether composed of them or not.

These bodies, as we have said, are neither crystalline nor colloid in disguise, though colloids, as aggregates, but something more: and crystals in their constituent parts. The point which distinguishes them from both of these is perhaps the fundamental principle which marks them out at once as possessing the elements of vitality in a primitive and most undeveloped state. 


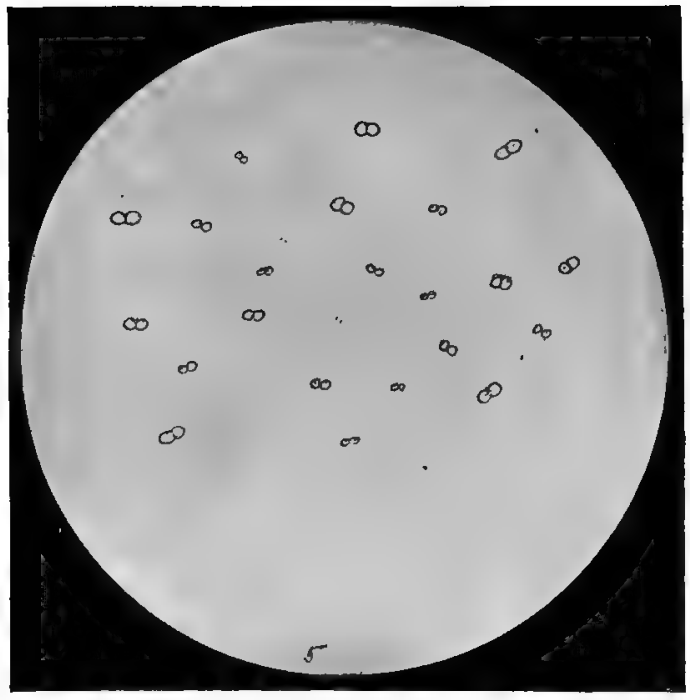

V.

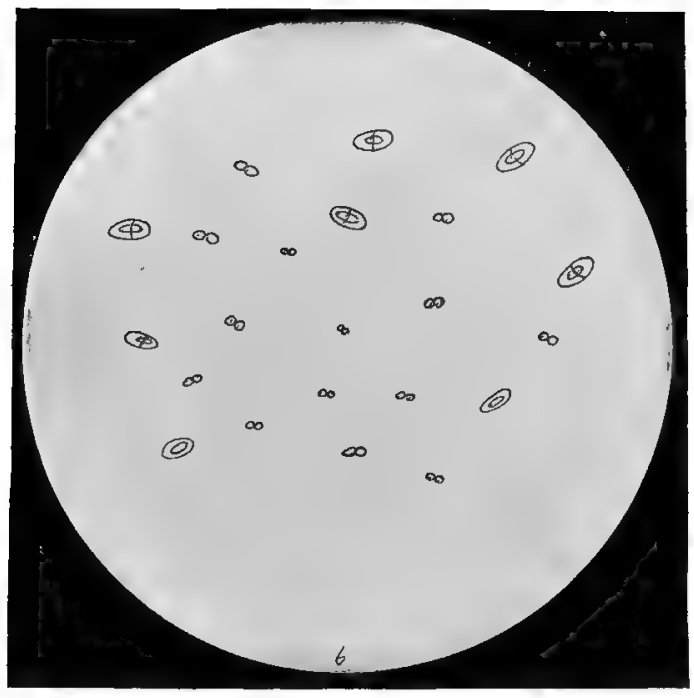

VI.

[To face page 112. 



$$
8
$$





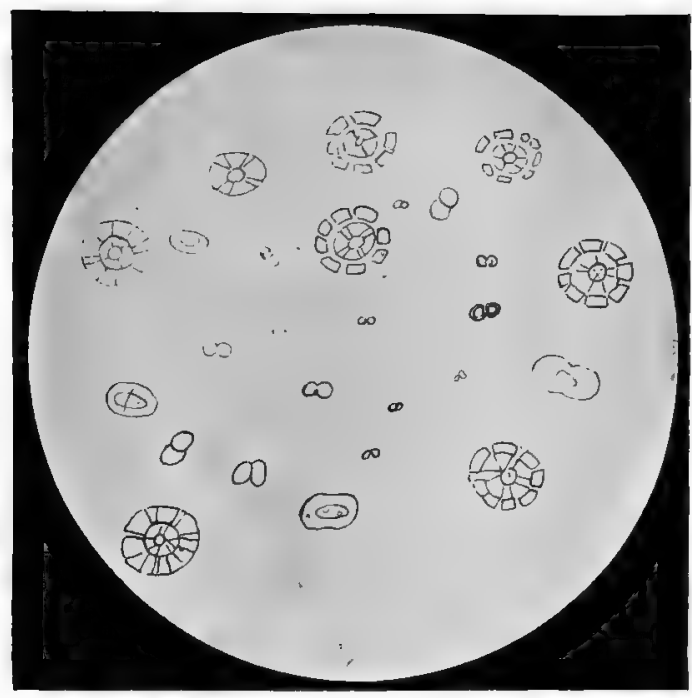

IX.

Last stage of Radiobes.

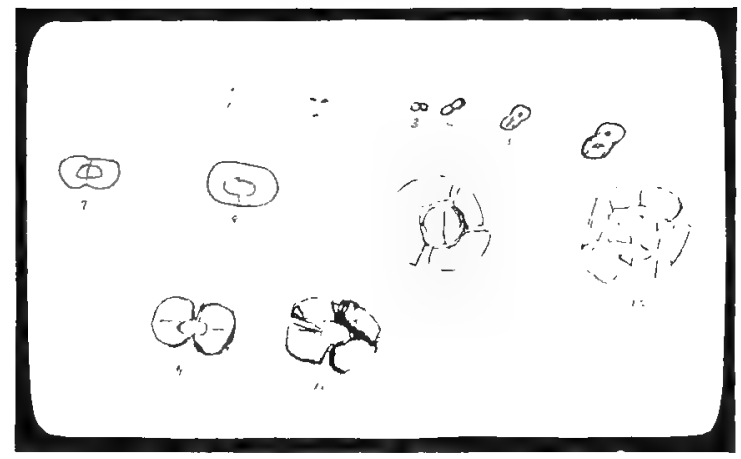

Various stages of development of Rarliobes, from (1) to (12). 



\section{CHAPTER VII}

\section{ON ARTIFICIAL CELLS AND ARTIFICIAL LIFE.}

Nature of the bodies produced by radium-ron Schrön's petroblasts-Apparent life in young crystals-Bodies observed by Quincke-Foam-cells_Cellular protoplasm, how it may have been formed-Sir William Ramsay's helium bubbles - How these may be formed and what their behaviour would be-M. Raphaël Dubois and mineral cultures or vacuolides produced by barium salts-Experiments with barium and other salts-The peculiar nature of uranium cultures-Whether it is radio-activity that produces the effect and in what way-It is not the emitted rays $\alpha, \beta$, or $\gamma$; but probably slow-moving rays-Structure of such artificial cells-Their sensitiveness to electrical and cbemical stimuli -Their parthenogenesis-Work of Loeb-Mode of subdivision probably similar.

IN discussing the results thus obtained by the action of the salts of radium upon bouillon, many interesting points present themselves; many questions naturally arise as to the precise nature of these bodies and the actual processes by which they are produced. The interest attached to them has been such that the brief note communicated to Nature, May 25th, 1905, and the few words uttered to a representative of the Daily Chronicle, June 20th, and in a short article on June 29th, 1905, have resounded from the remotest corners of the earth to an extent quite beyond the expectation even of my most apprehensive friends. 


\section{4 THE ORIGIN OF LIFE}

However, it is the actual result that concerns us, and not by how many it may have been discussed.

Numerous effects have been observed by the action of salts on gelatinous substances, but the precise nature of the bodies thus produced is a point which requires the most careful consideration. In the case of non-radio-active bodies it seems as if there can be little doubt that these bodies are crystalline in most cases. Whether even here the crystalline structure is the final or fossilised stage of a something analogous to living things which have become extinct is a point that remains to be considered. And in giving in outline the summary of this work, so far as it bears upon the point at issue, we are forced to recognise that this aspect of the question is not one that we should pass over without pause.

The remarkable researches of von Schrön, of the Pathological Institute of the University of Naples, have added much to our knowledge of the generation and behaviour of crystals. According to him, everything in Nature either lives or has lived. $\mathrm{He}$ thoroughly maintains that "young crystals" are living things, just as he denies vitality for old ones in the fossilised state. His assertion that the vital phenomena take place in crystals, even if they do not unite all the periods of their existence, is very a propos. Some of his photographs, of which he has taken a great many, are magnified 


\section{ON ARTIFICIAL CELLS}

about 800,000 times. This means, however, only about 900 diameters.

Amongst the secretion products of bacteria there are some formed by albumins which crystallise, and, according to him, these crystals in their earlier stages present many, if not all, the characteristics of living matter; whilst he asserts that similar observations with inorganic crystals, minerals, and igneous rocks have led him to a similar conclusion. Whether the bodies when thus manifesting vitality are really crystals is what remains to be decided. From our observations, if the processes are similar, we should be inclined to think that in the initial stages something more than crystalline bodies are observed.

Von Schrön has given the name petroblasts to these minute bodies which are formed just as crystallisation occurs or is about to occur in a salt solution. These bodies go, as we have said, through something similar to the cyclic process which radiobes undergo, and finally become resolved into what may appropriately be designated as crystals. Whether in the first instance in his experiment, when they are just in the stage of initial formation, they are also crystalline, is a point upon which there does not appear to be sufficient evidence to decide. And yet it seems a highly important one; since, if the contention is true, there can be no doubt that crystals are really the final products of disintegration in a process vastly more complicated than that which occurs in the subsequent process of crystallisation.

The question as to whether the young crystal is, 


\section{6 THE ORIGIN OF LIFE}

or is not, the seat of vital action leaves upon our minds a doubt which we cannot attempt to remove when such unstable bodies last only for a short time. But when their life period can be prolonged, the method of studying their behaviour is so largely increased that operations can be observed with considerable precision.

It is this preliminary stage that von Schrön regards as the period during which vitality can be ascribed to it. Only when that vitality has ceased is this organism converted into a crystal. But of the actual process which takes place during that unstable state little or nothing is known, so much so that it seems not improbable that the bodies thus formed are really different from those produced when the aggregates are, comparatively speaking, stable, as when produced by the action of radio-active bodies on organic media.

Not unlike these crystalline aggregates are the peculiar bodies which Quincke has investigated and described as occurring in solutions of silicic acid, glue, or other colloids, when evaporated. They form thin films on gelatinous masses, and their behaviour is very remarkable, as the bodies develop fissures. Quincke has shown that thin, viscous, oily films of more concentrated solution exist in a less concentrated solution of the same substance, and form folds, straight and twisted tubes, cylinders or cones, spheres and bubbles, open and closed foam-cells with visible and invisible foam-walls; and he has recently observed the formation of such "cells" even in 
ice, which, as he points out, is also a "liquid jelly."

Whether, the "oily" films form tubes or bubbles, and foam-cells joining on to one another, depends on the viscosity of the oily liquid.

By an "oily" liquid he means one which has surface-tension in the common surface with other liquids with which it may be in contact. Thus a solution of any salt in comparison with pure water, or a weaker solution, may be called an oily liquid. "Foam-cells" are thus formed, and if these cells are very small and their walls very thin, the whole is called a liquid jelly. The mutual inclination of the foam-walls, and their surface-tensions, change with the concentration of the oily liquid.

Now these foam-cells, in a liquid jelly immersed in water, apparently grow or diminish in size by the diffusion of water inwards and outwards. And liquid jelly can, by the presence of these cells, for the time being, become doubly refracting when the cells of their walls are expanded or contracted, thus behaving like crystalline bodies.

The very beautiful work of Lehmann, moreover, illustrates the optical effects produced in a somewhat similar way. But it is a matter of some difficulty to decide whether these doubly refracting bodies are really crystalline or merely of the nature of the foamcells just described. In any case they are not, it would appear, in any sense alive, and not even like the active petroblasts of von Schrön.

Their appearance on the whole suggests that they 


\section{8 THE ORIGIN OF LIFE}

are not cells, but rather crystalline in structure; and they doubtless belong to the class of organic crystalloids, frequently observed when gelatinous bodies are allowed to dry.

The bodies investigated by Lehmann which he has called liquid-crystals are extremely curious indeed, and may possibly come under the classification of Quincke's foam-cells, which, as we have said, are at times doubly refracting : but really more cellular than crystalline in their structure, as well as in their behaviour.

These illustrations are as worthy of examination as they are beautiful to look upon. To the uninitiated eye, however, in the absence of the polariscope they might easily be mistaken for mere globules, as frequently they are quite spherical, or at any rate smooth and curvilinear in their boundary: and this might lead one to suppose that they are merely bubbles. But to one who has seen much of them, they can be distinguished from mere bubbles or ordinary globules almost at a glance.

Whether, indeed, the primitive cell of protoplasm was formed by some simple means it, of course, cannot be shown; but to my mind, and to the minds of many, it seems tolerably clear that if cellular life originated by purely physical processes, -as there is very little reason to doubt, - such a process as that which we see taking place in a much simpler way in the formation of these artificial cells was a factor of the highest importance in their formation. 


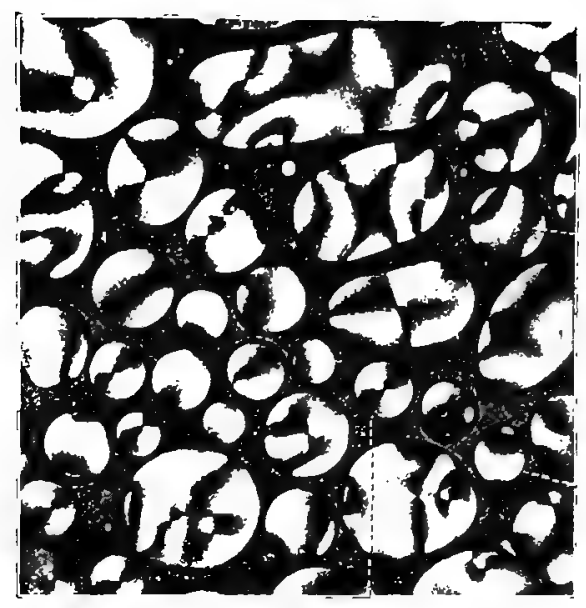

III.

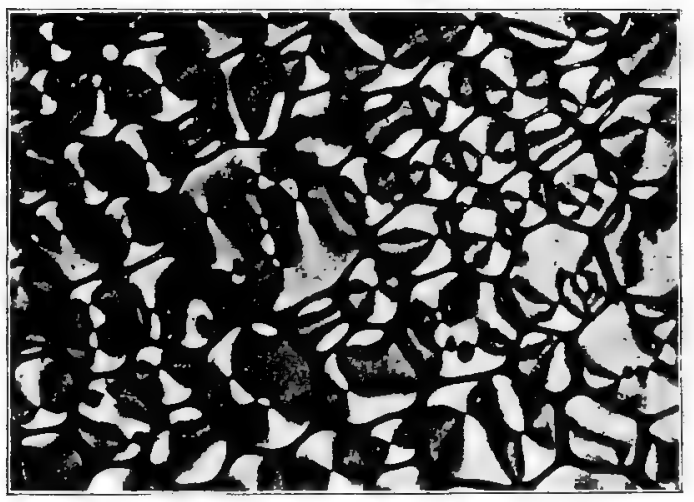

IV.

Lehmann's liquid erystals.

(See page 106.) 



\section{ON ARTIFICIAL CELLS}

Now there is another type of cell which is nothing more than a bubble, and yet it would seem should appear different from ordinary air bubbles, and that is what Sir William Ramsay has suggested should be one of the effects produced by the action of radium emanation upon gelatinous media. He was inclined to think that radiobes were really of this description. But, as we have shown, their properties would not be the same, and although it seems possible, and even highly probable, that such bodies should be produced by the action of radium on bouillon, their behaviour, as we hope to show, would be quite different from those other products that have already been observed.

Thus, when radium emanation acts on albuminous bodies, the layer acted upon is coagulated, and if a particle of radium salt is embedded in a gelatinous medium this emanation given off will thus form a cell-wall round it, the contents being ultimately converted into helium. Strietly speaking, the emanation electrolyses the water in the gelatin, and the nascent oxygen and hydrogen coagulate the albuminoids: probably by the action of the positive ions in the freshly electrolysed gas. The water diffuses through the boundary membrane or cell-wall, and the gases formed within the cell will go on increasing: thus the cell will expand or apparently grow. Now, as the tension in some parts of the cell-wall will most probably be less than at others, the gas in the course of time will force its way through the wall; and thus, apparently, the cell will bud and 
finally a new cell will be formed, which in turn will go through the same cyclic process as the parent: and ultimately, when the emanation ceases to be formed, even if that should take a thousand years, the cell will degenerate, and collapse.

In these respects the whole process resembles life. The continuous adjustment of internal to external relations of the individual with its environment: of assimilation or nutrition as well as of growth, of reproduction and decay.

However simple and intelligible the process, it fits in with the most elementary and most mechanical conception of life that we possess. And yet how few are there who would look upon so elementary a piece of mechanism, as it might well be called, as anything more than a purely physical analogy of that higher and vastly more complicated mechanism which we call organic life!

There is no metabolism, unless the cyclic process which the cell itself goes through in a period of a thousand, or more probably two thousand years, can be considered as its equivalent. But however interesting the formation of these cells may be, and however like and yet distinct from organic life, they are not the same as radiobes. The mode of division of the cells in the two cases is totally different. The radiobes divide up much in the same fashion as yeastcells are well known to do. That is, they divide into clearly cut segments or sections, with angular edges, which cells or bubbles whose boundary is under the 


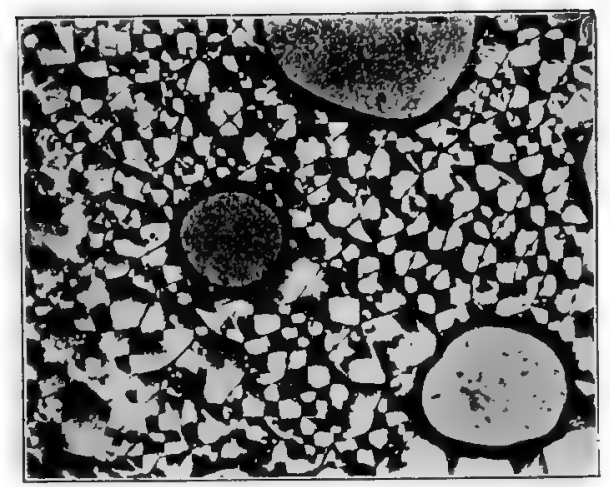

V.

Lehmann's liquid crystals.

(See page 106.)

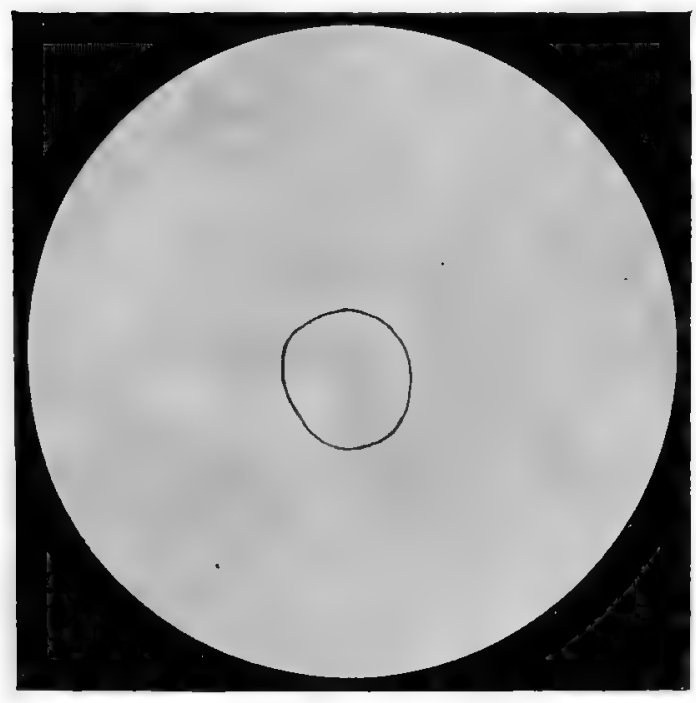

I.

Sir William Ramsay's artificial helium cells.

Way in which they would be expected to behave; and which we suppose to be the process in the $n^{\text {th }}$ or ultimate nucleus.

[To face prife 120 . 



$$
8
$$





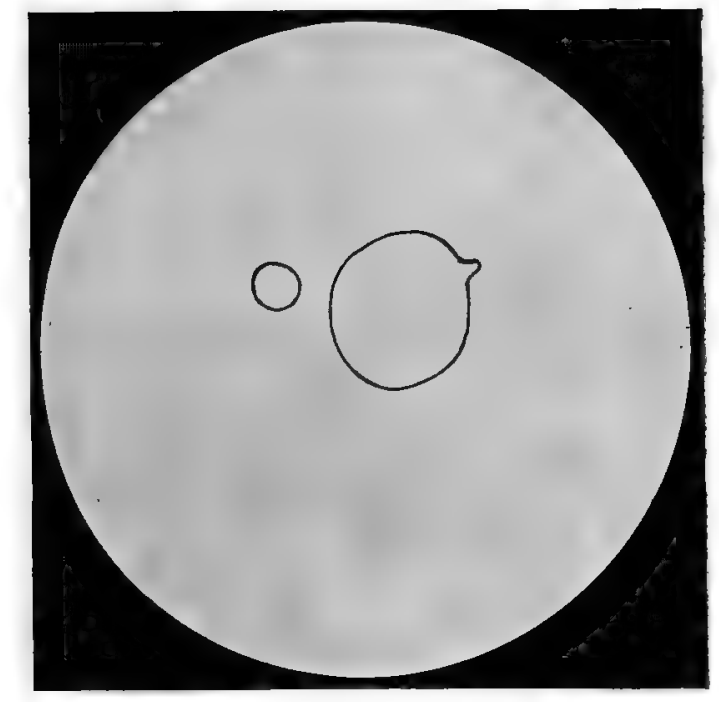

IV.

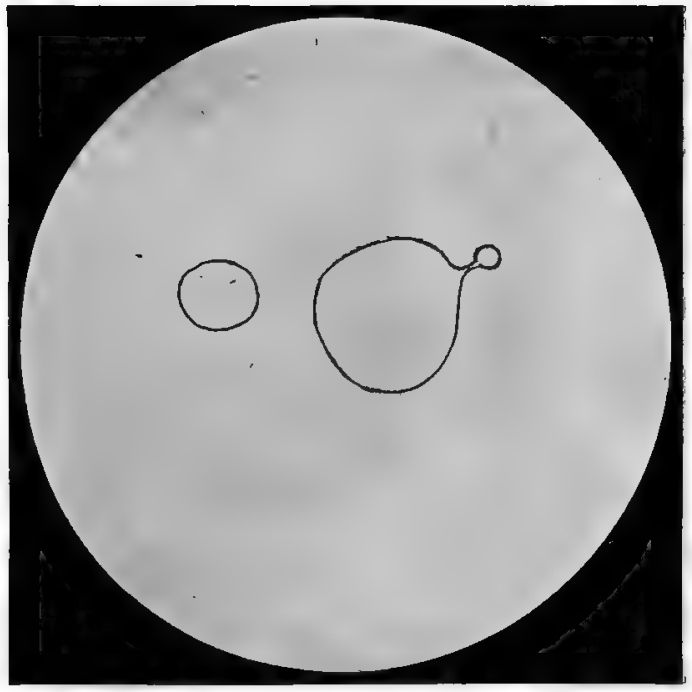

V.

[To face page 120(b)» 



$$
8
$$





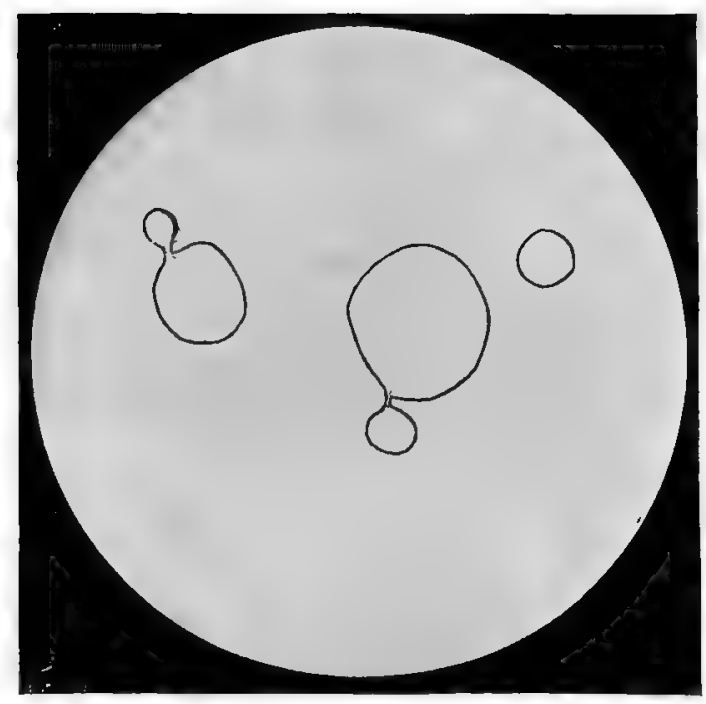

VIII

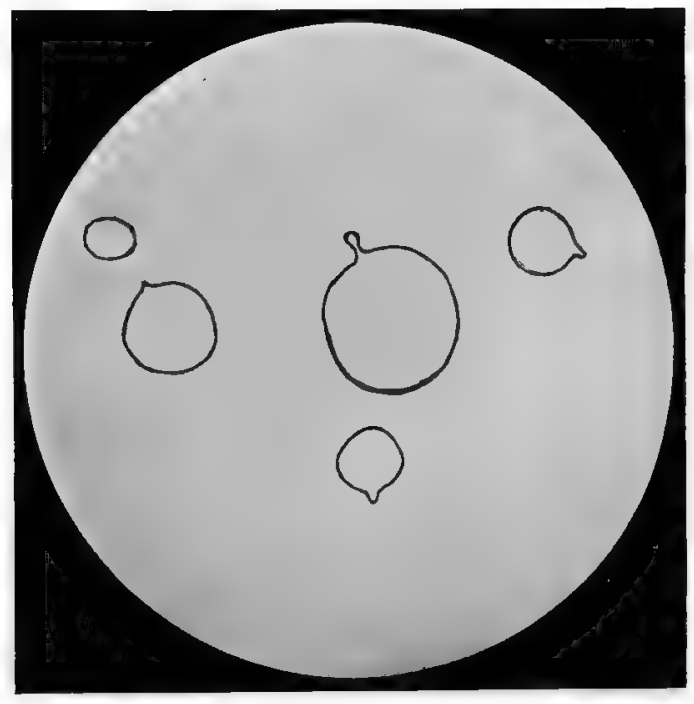

I.I.

[To fuce page $120($ (i) $)$. 



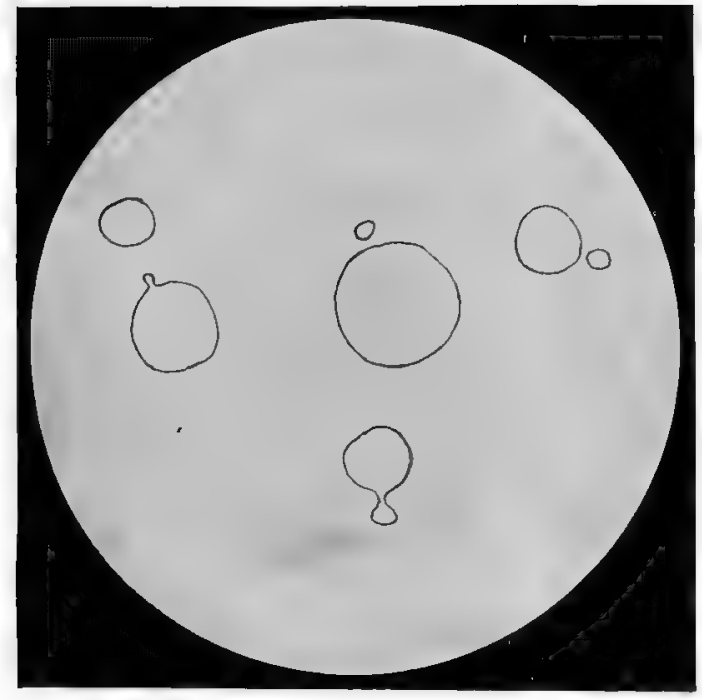

X.

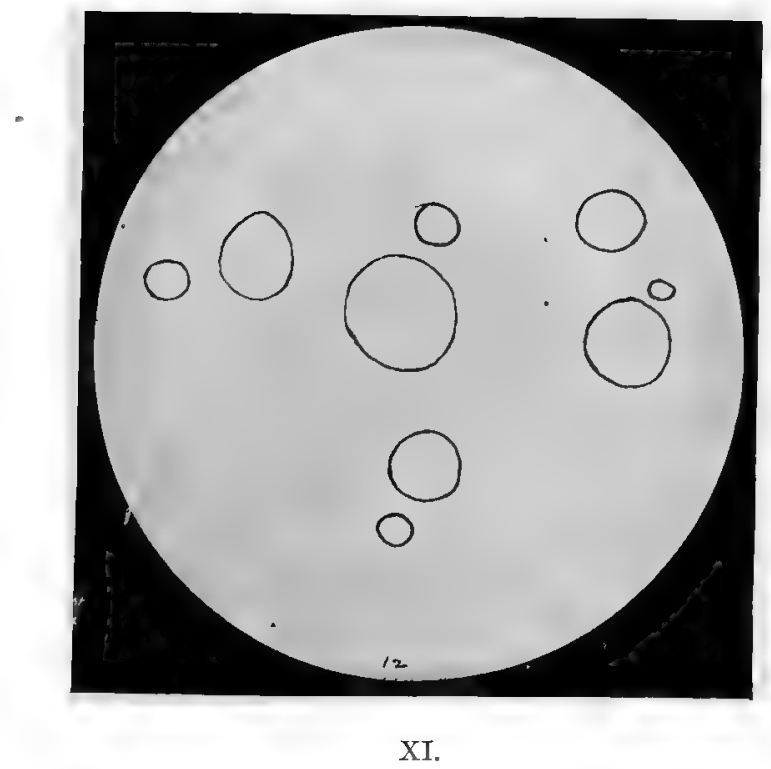

[To face page 1:20(e). 

stress of surface-tension cannot, as it seems to us, possibly do. The mode of subdivision or reproduction of a gas-cell would thus be entirely different from that of the other products of radium and bouillon. Although the helium cells differ from ordinary bubbles, on account of the comparatively thick boundary walls their mode of division would be of a somewhat similar nature.

The budding may not necessarily take place from a single point, but from a curve or surface of least resistance. There would be surface-tension in all cases, but sharp corners would not remain.

Thus the objection to identifying radiobes with such cells, would be of the same nature as the objection to supposing them to be ordinary bubbles. All the objections based upon the effects obtained by Buitschli of Heidelberg, already referred to, by the action of olive oil on soluble salts by the action of emulsion in water on such salts, which have been ruled out of court, would similarly apply to helium-cells.

It is, therefore, a matter of importance that some other explanation should be forthcoming of the nature of radio-organic organisms.

The work of M. Raphaël Dubois of Lyons is of special interest in this matter, although the bodies which he has investigated are, on the face of it, quite different from the ones we have observed.

In a note communicated to the Société de Biologie, May, 1904, he described what are called mineral 
cultures produced by the action of salts on organic media. Amongst the salts employed were the chlorides of radium, barium, and manganese. Dubois placed a small crystal of chloride of barium and radium on a gelatinous culture for luminous microbes, and observed that in the nutritive and colloidal jelly a number of small corpuscles appeared which grew downwards in the gelatin, and at the same time increased in volume. The appearance of these granules or larger vacuolides is shown in the adjoining figure, taken from M. Dubois's paper in the Revue des Idées, March 15th, 1905, where a summary of his lecture at Lyons in November, 1904, is given. The opinion of M. Laveran, of the Pasteur Institute, was that they seemed to him to be like contaminations; whilst that of M. Henneguy, Professor of Cytology at the College de France, Paris, was that they were like the eggs of a frog in process of segmentation. M. Dubois affirms, however, that they were not contaminations, but large vacuolides, which in their more developed states were in the process of segmentation or subdivision.

Similiar effects were produced with ordinary barium chloride: "If one continues to follow the evolution of these corpuscles they are seen to change gradually into crystals. The cycle of changes in these "synthetic vacuolides," organic mineralbodies, is from birth, nourishment, growth, division, and death in assuming crystalline forms.

It is important to note that barium salts, whether bromides or chlorides, give the same bodies as the similar salts of barium and radium, perhaps even 


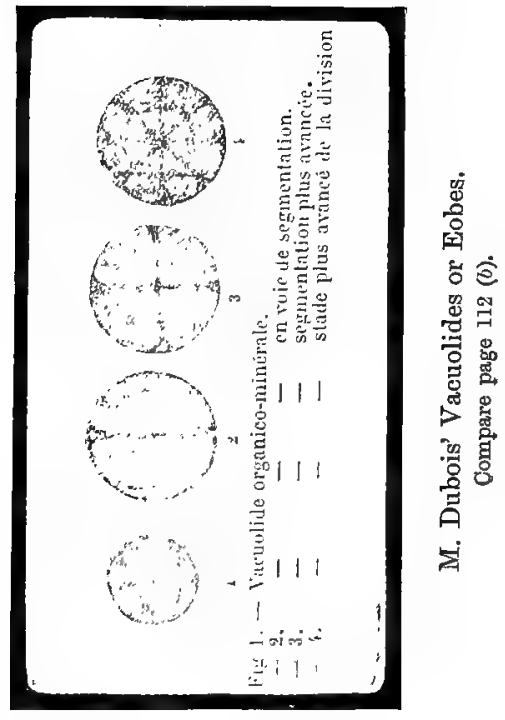

[To face page 122. 



\section{ON ARTIFICIAL CELLS}

with greater facility, thus suggesting that it is the barium and not the radium that produces them, and that the presence of radium tends if anything to retard their growth.

The bodies in question can, as I have observed, be seen with comparatively low powers, whereas those I have called radiobes are only visible with the highest powers, and so do not grow beyond that order of magnitude, although they make their appearance as mere specks. Mr. Rudge (Nature, Oct. 26th, 1905) has found that the soluble salts of barium, strontium, and calcium, as also those of lead, produce these large granules, whilst the insoluble salts do not. He has, however, since found that the precipitate of sulphates which was insoluble was what he observed.

The granules, however, are quite visible to the naked eye, and are at first sight at least like the globules obtained by the action of many soluble salts on gelatin, but they do slowly subdivide as in the figure.

M. Dubois and his friends, on the other hand, have said strong things about my claims to priority in this discovery. As it is, he has not noticed the bodies which I bave observed. The radiobes cannot be described as "grosse vacuolides" in any sense of the word, and their claim to priority, though distasteful, may, it is to be hoped, lose half its evil when thus deprived of all its "grossness" ? The two are totally distinct, as distinct, as we have said before, as coal is from potato. The vacuolides, or eobes, as Dubois has since called them, have 


\section{24 THE ORIGIN OF LIFE}

undoubtedly, like some crystalloids, the power of assimilating from their surroundings, and thus may, like radiobes, approximate more closely to living types than any crystalline or colloid bodies hitherto observed. They appear to come more directly within the sphere of the cytologist than that of the crystallographer, or the organic chemist, and to possess more in common with a living organism than any artificial cells that have as yet been obtained.

M. Dubois has suggested that barium may be nothing more than an allotropic form of radium. This suggestion is most probably correct, in so far as they belong to the same series; but it may also be one of the disintegration products of radium, just as this is a disintegration product of uranium.

Uranium, according to Strutt and Boltwood, is gradually transformed into radium, which later on, as Rutherford has shown, goes through various stages, and finally becomes converted, as Ramsay and Soddy have found, into inert helium. It may be that barium is one of the stages through which the emanation has to pass.

It is of importance in this matter to bear in mind that cultures of uranium consist of several horizontal layers or strata which are totally distinct from each other and several millimetres apart; such internal growths within the medium itself I would account for as the necessary result of the transformation-as the uranium diffuses down.into the medium, of barium into radium and other culture-producing bodies.

It is all the more remarkable, as the transforming 


\section{ON ARTIFICIAL CELLS}

substance obviously passes through states which are inactive.

The formation of these growths may not dependand, in fact, it seems does not depend-upon the intensity of the radio-activity, but probably upon the process upon which radio-activity depends. Thus the intensity of this so rests upon the nature, number, and velocity of the ions emitted by the body; whereas the power of producing molecular agglomerations may, and most probably does, depend upon the nature of the ions emitted far more so than upon their number and velocity. And most bodies seem to be radio-active, to however small an extent, as le Bon and others have shown.

Now, the radiation consists of four types, namely, the $a_{-}, \beta-, \gamma^{-}$, and $\delta$-rays, the $a^{-}$being positively electrified particles, the $\beta$-and $\delta$-negatively, whilst the $\gamma$-rays do not appear to carry a charge. These radiations themselves, however, do not seem to produce the aggregations in question when the radio-active salt is placed at a slight distance, a millimetre or so, from the surface of the gelatinous body, possibly on account of their great velocity. But when the salt is actually in contact with the culture medium the agglomerations, which are limited in size, result.

Ions do tend to produce aggregations, the positive far more so than the negative; so that, provided their speed is not too great, the required aggregate should result, and nowhere more so than round the atom itself, as it remains electrified owing 


\section{26 THE ORIGIN OF LIFE}

to the unequal emission of positive and negative electricity, whilst it remains fixed. The growth of the aggregate would then depend upon the length of time during which the electrified and self-electrifying atom has been in contact with the medium. When the atom ceases to be radio-active, this growth would stop and the nucleus losing its charge, the aggregate would begin to disintegrate. The power of the nucleus in bringing about this cyclically changing aggregate would thus depend on the difference in the number of positively and negatively charged rays emitted. The more intense the radiation and the less the difference between these two emissions the shorter the life period, and the smaller in size would the aggregates be, because of the transformation which is taking place in the nucleus itself.

The construction of an artificial cell which should behave as if it were alive would thus be possible. As the $a$-rays are not penetrating they would be stopped by the gelatin, and a shell of positively electrified matter would thus be formed round the central atom, serving as the boundary of the nucleus. The subdivision may be started by some such process as Sir William Ramsay has depicted, but within the nucleus itself and of such a nature as to force the division of the cell by subdividing the nucleus: since the newly formed parts will act as a rival, as it were, of the parent nucleus and thus tend to start on its own by breaking up the cell and taking some of the material with it.

A cell so formed would be highly sensitive to elec- 


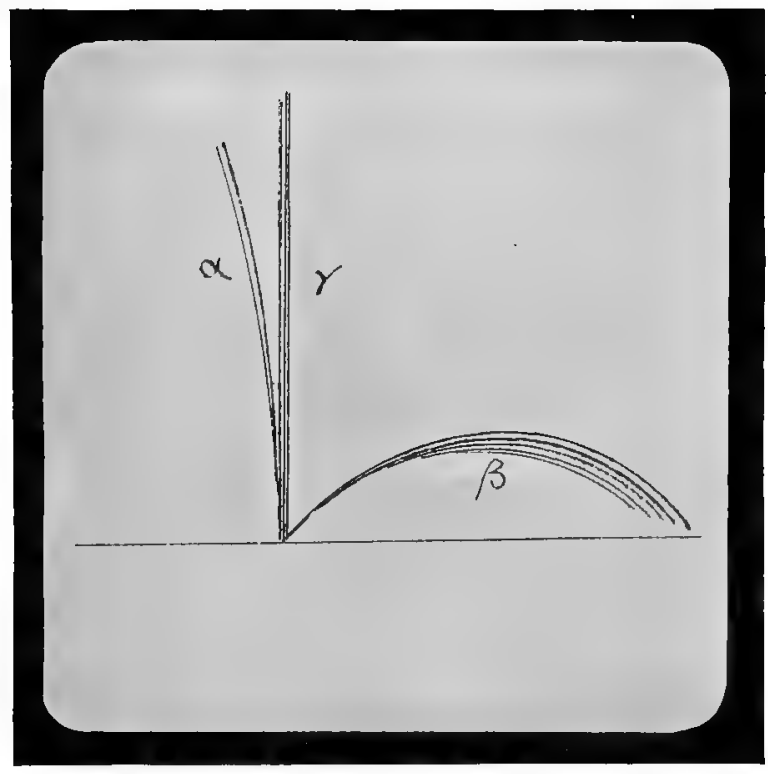

I.

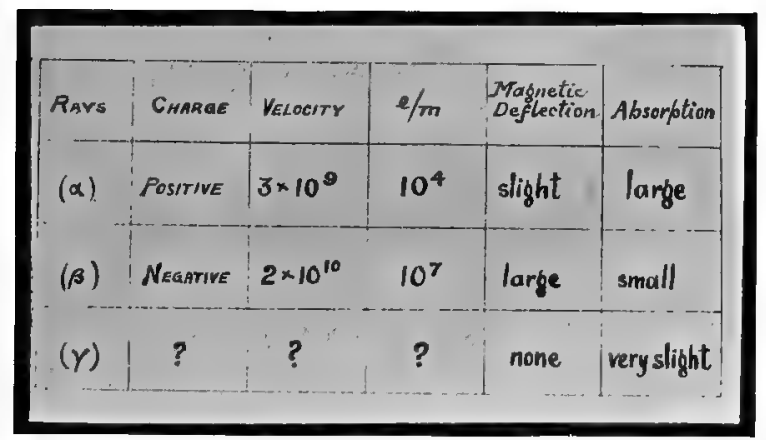

II.

[To face page 126. 

trical stimuli, as well as to acid and alkaline reactions; and would thus possess another of those physiological qualities which we ascribe to living matter by the action of positive and negative ions.

We should, by means of such a model, have obtained a cell which illustrated, if it did not actually perform, the process of parthenogenesis.

This brings us at once to the work of Professor Loeb, of California, who by experiments on the artificial fertilisation of the eggs of a sea-urchin has succeeded in getting what virtually amounts to artificial parthenogenesis or cell-division in the egg.

It was known that subdivision of the egg could be started by immersing it in a strong salt solution. Natural fertilisation is, of course, accomplished by the sperm of the sea-urchin, which forms a thin membrane round the egg when the cell-division commences. Professor Loeb found that, by immersing the egg in concentrated salt solution, the film was similarly formed, although the subdivided cells did not live anything like the length of time that those naturally fertilised by the sperm did, so that the artificial subdivisions were degenerated forms, lacking the vigour of the naturally fertilised cells, but nevertheless capable of living for some time. These subdivided eggs developed into larvæ which were mobile, and exhibited all the characteristics of living things in their self-action.

The self-movement does not perhaps mean very much in any case, and it has always seemed to me 


\section{28 THE ORIGIN OF LIFE}

that this self-movement in microscopic bodies is merely the result of slight variations in the surfacetension due to the secretions from these bodies and an effect not connected with vitality but capable of taking place without it: as in fact we know it can take place by the solution of small particles of camphor in water.

The vitality of the newly formed eggs in Loeb's experiments was, as it seems, unquestioned, and the accuracy of the observations likewise demonstrated by the use of controls. Needless to say, the observer himself is a sufficient guarantee of this.

Under the action of the salt solution the albuminoids coagulate, probably by the action of free ions, and this wall or membrane being semi-permeable allows the diffusion of water into the cell. By pressure, or some other means, the nucleus subdivides, and also in due course forces the division of the cell with it. It thus looks as if the action of the sperm is primarily that of some secretion it emits, which, by its power of coagulating a layer on the surface of the egg, thus indirectly brings about its subdivision.

The artificially subdivided cells are, as we say, lacking in the vigour of the naturally fertilised ones, thus showing that the sperm has not taken the full part in the process.

Apart, however, from any such considerations it does not seem probable on the face of it that artificial parthenogenesis, possible though it is, can be of any real importance in propagating the 
species; and the offsprings thus produced are abnormal and degenerate forms that cannot last.

The possibility of thus effecting reproduction of some sort artificially, and the fact also that artificial cells of protoplasmic substances can be formed by such processes as we have described, show that the mechanism in these phenomena is of a much simpler physical nature than might at first sight be imagined.

Now the problem which presents itself to us is that of endeavouring to fill in the gap-futile though it may seem to be to endeavour to do so perfectly -between living and dead matter.

We see around us the disappearance, not merely of living types, but even the disappearance of inorganic ones; we see the death of worlds and the death of atoms; we can carry our minds backwards to the time, perhaps not so very long ago, when the elements were more numerous than they now are; when some radio-active matters, now extinct, played a part in the phenomena of Nature, which we can no more picture to ourselves than recall events of which we have neither the record nor the memory. In the disappearance of such types of organic and of inorganic matter, we can conceive also the disappearance of the links which once connected them together. We can realise, perhaps more vividly than might at first be possible, how it was that in time the sifting out of the unstable and the unfit could give rise to those anomalies and apparent breaks in the continuity of Nature which now seem so unintelligible. 


\section{30 THE ORIGIN OF LIFE}

We can perceive also that in the inorganic world the survival of the fittest holds good as much as in the organic world, and that the gap between these two, however insuperable it may seem to be, is also the consequence of the same law: of the elimination of primordial or primitive types between living and dead matter, which once gave rise to the types that now survive, but were unfitted to survive themselves. Perhaps they were not the ancestors of these at all, but only the links between them and the rest of things. It is in this way that life as we see it to-day undoubtedly had its origin. And in trying to unravel the problem of that origin, at the present day, the only direction as it seems to us in which progress can be made is in that which may give a clue as to the nature of those eliminated forms themselves. In other words, in trying to fill in the gaps by producing artificially such of them as have long since ceased to be. To do this in every case would be altogether beyond hope; but to do it in some instances, in determining the possibilities of the combination and admixtures of organic and of inorganic matter, that is the goal towards which we can only beckon: the promised land which it may never be our lot to enter, and which we may only view as from a lonely and far distant standpoint. In imagination at least wo can picture to our mind's eye the detailed structure, and the minute construction of their many parts. But our eyes are dimmed, and the images that wo 


\section{ON ARTIFICIAL CELLS}

seek are blurred and indistinct; the creatures that we think have been are more the creatures of our own fancy than the actual bodies that many of us would now give the whole world to see.

Those things that once have been have left the gaps that science has to fill. But fill them it never will. It may supply the missing links in a few instances, though produce them in full it cannot do; for most of those links we would look for are lost for ever in that world that is past.

We have to try, then, in endeavouring to approximate to a solution of the problem of the origin of life, to determine some method of manufacturing, or more accurately of synthesising, artificial cells of such substances as those of which protoplasm itself is composed; and of obtaining by such artificial processes bodies which shall have some of the qualities or properties of living things as they have been handed down to us by Nature. The most that we can hope to do is to synthesise cells which, like radiobes, and such others as have been described, can go through some of the processes of vitality. Cells which would possess, perhaps, $(n-1),(n-2)$, or $(n-4)$ of the properties of living protoplasm. Such bodies would not have survived on account of their inability to overcome the opposing or contending forces of their surroundings. But it is by this means that we may hope to mount the scale and approximate, though we should never hope to reach, that structure which we call living matter. 


\section{CHAPTER VIII}

ON THE STRUCTURE OF CELLS, NATURAL AND ARTIFICIAL, AND THE SOURCE OF THE ENERGY OF VITAL FLUX

Distinction between artificial and natural life-Morphology of cells-Vital process essentially a metabolism-Complexity of cell structure and potentiality of cell-The vital process as distinct from complexity of structure-The nucleus and karyokinesis-Max Verworn on structure as result of metabolism-Whether his views may not be modified in the light of more recent ideas of the nature of solid and liquid bodies-Difficulties in studying structure of living cell-Cellular structure imparted by reagents-The ultimate or $n$th nucleus-Its probable nature, an aggregate of electrons like a radio-active element-Internal energy of living matter thus stored up in the æther-This may fit in as a physical and dynamical explanation of Sir Oliver Lodge's immaterial source of energy in living. organisms, thus apparently independent of material connections, but really subject to the universal law of the conservation of energy.

WIтH the reservations which have been made it is sufficiently clear at this stage that the vital processes in the radiobe and other such bodies constitute merely artificial life, as distinct from that natural life we see around us, and which it is beyond our wildest hopes to imitate, much less to create. 
The natural cell has most probably a highly complicated structure, vastly more complicated than anything that by artificial synthesis we can endeavour to obtain. It is interesting, however, to try to approximate to this highly organised state of matter, even if, as we think, that final stage should never be attained. To come nearer and nearer to it, as the curve of the hyperbola approaches to its asymptote, is it seems the most that by scientific investigation we can hope to arrive at.

The structure and composition of such artificial cells is sufficient to enable them to perform the functions of organic life, as distinct from such simpler forms of vitality which we at first supposed inorganic matter to possess. Thus they can assimilate, grow, pass into higher types, subdivide, multiply, and finally, having gone through the whole cyclic process, disintegrate and lose their structure in the course of time, being sensitive all the while to external stimulation, both electrical and chemical, in various degrees.

Now the morphology, if we may call it so, of these artificial cells presents to us their structure as another function of their close resemblance to the actual things in Nature, and enables us to realise that the vast complexity of the latter structures, when judged by the results which in some instances give rise to highly developed forms of life, is not so much the function upon which vitality depends, as that to which its subsequent development is due. The actual process of life, even if the cell does admit of 


\section{I34 THE ORIGIN OF LIFE}

such development, is something really simpler; as much so as life in the Amoeba and life in Man are very much the same although the potentialities, the developments of which they admit, are in the two cases totally distinct. This is a point upon which too much stress cannot be laid: that the potentiality and consequent complexity of the natural cell as distinct from the artificial one is not that which distinguishes the vital process in them, for this seems to be far simpler than is at first imagined, when distinguished from the developments to which it can subsequently give rise. It is the single assimilation and secretion, the peculiar flux within a comparatively simple structure, that constitutes the vitality: quite distinct from the potential properties of the cell itself, which is due, no doubt, to the finer structures of which it is finally composed.

We imagine, then, life to be the simpler process by which these complex structures are ultimately able to develop. It is the mode of change of substance by which the growth or expansion of the cell is accomplished in such a manner as to develop its innate powers.

A cell which can subsequently develop into an animal must indeed have a structure of the most complicated kind. And those potentialities, innate qualities, it is difficult to imagine, can be due to nothing else than to the structure of the germ itself which can give rise to them.

That complex structure we can never hope to imitate. Not even in its simplest examples, as in the 


\section{ON THE STRUCTURE OF CELLS I 35}

amœba, can we attempt to construct anything that will even approximate to it. But the vital process in that which we can and that which we cannot bring about is found to be ultimately the same.

In both cases the organism is, whether natural or artificial, "a nucleated mass of protoplasm," as Max Schultze defined a cell; and in both cases this nucleated mass of protoplasm can go through the various processes which are associated with vitality in the organised mass. Thus it is not so much upon the process of vitality itself, as upon the minutest and ultra-microscopic structure of the cell in which vitality occurs, that the actual differences in the subsequent development of the cell depend. The morphology of the artificial cell is simple enough; that of the natural cell may be, and in most cases certainly is, vastly more complicated. But in outline it is the same; and the actual process by which the vital actions are maintained, it would appear, are in the outline, too, pretty much the same.

It is generally supposed that chlorophyll is the substance in the nucleus by which the process of vitality is performed. But in the artificial cell there is no chlorophyll. This, however, is merely one of the many points in which, as we say, they differ. The points in which they do agree seem to be those which constitute some type of vitality, even if the method by which these are actually accomplished may be different. It is, however, a question of a somewhat debatable nature as to whether chlorophyll 


\section{I36 THE ORIGIN OF LIFE}

does actually play so important a part in vital actions.

The gaps have to be filled up; they may never be filled up; but it is by such methods as these in filling in some of those gaps that an insight into the nature of the inner mechanism of the cell may be attained.

The amount of work that has been done on cell structure is amazing, and it is not improbable that in that vast complexity the actual mechanism by which the vitality in the cell is carried out has possibly been lost sight of; or indeed that the principles upon which that mechanism depends were not within the reach of investigators till quite recently.

Now it is upon the nature of the nucleus that the whole mystery, so far as it is a mystery, depends; and the phenomenon of karyokinesis, or mode of subdivision of the inner portions of the nucleus, or nucleosus, the centrosome as it is more commonly called, can be imitated in the artificial radio-active cells. The karyokinesis of the centrosome is shown in the figures. It precedes the subdivision of the cell itself.

The protoplasm between the nucleus and the cell wall is familiarly called the cytoplasm ; and authorities disagree as to whether the subdivision is due to stimulus in the cytoplasm, the nucleus, or the more obscure part, the centrosome. But it is generally admitted that it is upon the latter that the subdivision really depends. Boveri postulates another source of the phenomenon in the centrosome to its vicinity, which he calls the archoplasm. He has 


\section{ON THE STRUCTURE OF CELLS I 37}

made many beautiful experiments on the importance of the nucleus, and still more of the centrosome or centrosphere. Thus in one instance he fertilised the non-nucleated portion of the ova of echinoderms of one species by the spermatozoids of another, and found that larvæ resulted which resembled the male parent in all cases; whilst, when the nucleated portion of the egg was fertilised the larvæ had intermediate characters between the two parents. The process of mytosis, as the multiplication of the chromosome is called, is thus of especial importance in the morphology of the cell, and we hope to enter further into the subject in the sequel. There is another aspect of the question, of not less, but probably of even greater moment, and that is the physiological one. It is frequently complained that too much stress is laid upon the morphology of cells, and that the metabolism which occurs in them has not received the same degree of attention. Max Verworn lays particular stress upon this point. To him it appears that all the vital phenomena of an organism are only different expressions of its metabolism, and that all the form changes which it undergoes as a part and characteristic of its vital process are merely the outcome of its own characteristic metabolism. "The remarkable fact," as he says, "that this evident truth has been so little taken into consideration, can only be accounted for by the difficulty of combining the two groups of phenomena-metabolism and organic formation." He goes on to add, however, that "metabolism is practically inconceivable without a 


\section{38 THE ORIGIN OF LIFE}

fluid condition of the substance undergoing change, while, on the other hand, the idea of a definite form involuntarily suggests a fixed position of the particles of matter of which the organism is composed. This difficulty, however, is merely superficial and vanishes as soon as we examine the two seemingly irreconcilable facts. A fluid substance is certainly a requisite of metabolism. In the words of the ancient alchemists, corpora non agunt nisi humida. Only gases or dissolved matter can enter into the chemical relations required in the metabolism of an organism."

Upon this point recent physical and chemical work seems to show that that fluidity of state can, to a certain extent, exist even in solid bodies, and that metabolism is in a more minute degree a phenomenon which can take place even in solids. We shall see in a later chapter that there is considerable evidence of such metabolism in phosphorescent and other solid bodies.

Max Verworn, however, does admit that there can be no doubt that protoplasm, which, as he thinks, is essentially a fluid, does contain some more solid and firm elements in it; that it is a compound of substances of various constituents, and that those who hold the opposite view base it solely on the examination of dead and preserved objects. It is, however, held by many, as he admits, that the protoplasm and the nucleus is a sponge-like network or a thread-like structure, composed of numberless fibres. He then asks, "What are we to consider as actually living in 


\section{ON THE STRUCTURE OF CELLS I 39}

living matter?" And the answer is that, "we have but one criterion to assist us to a decision, and that is metabolism; only when there is metabolism there is life. This is the A B C of physiology. Thus the starch granule in the plant cell, the glycogen particle in the animal cell, so long as they remain without chemical change, as reserve material in the protolasm, are not living. They only become living when, decomposed and dissolved, they take part in metabolism .... Given unchanging outward conditions, the form depends wholly on the unchanging character and direction of the metabolism. In the fountain or gas-jet, although the particles are in a constant movement, not one of them retaining the same position for a moment, the entire jet retains its characteristic form as long as it is subject to the same conditions. A cell, in spite of its active metabolism, appears to us to be in repose. It gives us the impression of immovability, just as a gas or water jet conveys the same impression, although each particle is in rapid and incessant movement." Living and dead protoplasm may be illustrated by the gases or materials in a flame, they may be said to represent two different states of matter, even though the chemical composition be the same.

We shall see that even solids such as phosphorescent bodies can thus exist in two different states, although the ultimate chemical composition is the same in the two cases. Metabolism is a process of building up and breaking down of molecules. It is difficult to see how this process 


\section{THE ORIGIN OF LIFE}

of chemical reactions can be kept up, and the continual flow of matter which is a characteristic property of the cell can be maintained, unless the cell has a definite structure which controls the direction of the flow. For Verworn and many other physiologists believe that the structure is the result of the directive flow of the molecules of the substance constituting the cell; so that their entrance and exit always take place in the same direction. It is not easy to see how the flux could be kept up in this way in bodies so large as a cell, relatively to the size of the constituent molecules, the smallest cell visible being about 1,000 times the diameter of a molecule. With membranes, however, which serve as semi-permeable walls, it is easy to see how it might be directed, even if there is no actual clue as to the manner in which the circulation or flux is maintained.

It is supposed that the fact that a cell, from which a portion has been cut off, if the nucleus has not been also removed, can again acquire its original form, necessitates the structure should depend upon the flux and not the flux upon the structure. It is no doubt true that the flux does depend upon the nucleus, but that the structure of the cell should also depend upon the flux, even if it also depended on the nucleus, is that which it is so difficult to see the need of.

The enormous potentiality of the cell involves a highly complicated structure, and no doubt something more; and it is upon this something more that 


\section{ON THE STRUCTURE OF CELLS I4I}

everything depends. Its varieties of motion seem to depend more upon the structure than the structure does upon them.

In this respect, however, so eminent a physiologist as Max Verworn protests against the view that the egg cell in the higher animals must have a more complicated molecular structure than that of other cells (quite a different thing). "Because a highly complicated organism results from the microscopical egg cell, it is thought that the molecular structure of the latter must be highly complicated. I do not doubt that it is complicated, but I deny the assumption that it is more complicated than the molecular structure of any other cell. We have only to imagine that the metabolism in the egg cell is continually changing, never remaining the same for two consecutive moments, so that each condition causes the following condition, and is itself the outcome of the one preceding it."

Considering how close is the connection between metabolism and change of form, each change in the metabolic exigencies of the developing organism must be responded to by a further and more complicated structural change. The assumption of greater complication of the molecular structure of the original egg cell is thus entirely superfluous, he adds, "These processes, however, are only brought about because each atom, or group of atoms or molecules, attracts, by chemical affinity, other atoms, groups of atoms or molecules, in a certain direction. This causes a continual flow of matter, some atoms or 


\section{THE ORIGIN OF LIFE}

groups of atoms being withdrawn and others taking their places. If these atoms and groups of atoms are always of the same kind, and if their substance and exit always take place in the same manner and direction, as must be the case so long as the metabolism of the whole remains unaltered, a certain altering of the particles results, which we must call structure; although the whole substance is in motion, in a continual flow."

It is only in this way he supposes that the reconstruction of the cell can result when a portion is removed. It must, however, be borne in mind that the same phenomenon of reconstruction of a damaged part can take place in crystals, when metabolism in the sense in which he uses the word does not occur. The structure of the cell does not appear to be a particular state of motion of the metabolic flow, it seems to consist of surfaces wherein the molecular aggregation and consequent flow are the same. The larger structures for a time remain unchanged even when the flow has ceased, although the more minute structures may or may not depend upon the flow itself.

The formation of very minute cell structures dependent upon instability in the physical and chemical conditions of the flow is, however, possible when we bear in mind that our ideas of the solid and liquid states have been largely, if not completely, altered by the discovery of what are called liquid crystals, which may give a cellular structure to a substance in the ill-definable state between a 


\section{ON THE STRUCTURE OF CELLS 143}

liquid and a solid, by the formation of some type or types of liquid crystals and foam-cells such as have been described.

This cellular structure would be a highly sensitive one and dependent upon many conditions, and may in turn be a factor by which the metabolism is kept up. It is not improbable that it is due in part to the metabolism too, and that the two react upon each other. There can be little doubt, however, that the potentiality of the cell does depend upon the minute structure rather than upon the metabolism itself, which it does not appear that physical or chemical laws within our knowledge are sufficient to explain. The directive force we should prefer to ascribe to the minute structure of the cell, than to any mystical and directive force which may be ascribed to the metabolism. It is true, no doubt, that the countless variations and the indefinite potentialities of which it admits are still difficult to explain, on account of the number of atoms which the cell contains, as Clerk Maxwell has pointed out: the number of combinations being limited to a comparatively small number owing to the nature of the compounds formed. By giving a cell a minute cellular structure, however, and by assuming certain definite and permanent or stable motions to be thus associated with such structures, the potentialities may be almost indefinitely increased.

Such structures and specialised modes of motion should be largely dependent upon the metabolism, and yet not be said to form part of them: 


\section{I44 THE ORIGIN OF LIFE}

for the simple reason that they do not consist of chemical changes but of physical effects.

The minute cellular membrane would then be the result of physical effects which could be handed on from generation to generation, owing to the particular structure and type of motion in the nucleus. One great obstacle in the way of studying the structure of living cells is that, by fixing or staining, that structure may be, and most probably is, altered. The dead cell has been studied so minutely, that the living cell, which is, after all, what we wish to know most about, has been sadly neglected. In fact, as Fisher has pointed out, some of the reagents used for studying the structure of protoplasm can actually give rise to structures, as in the experiments of Bütschli, already referred to ; so that instead of really studying the minute structure of the cell we should merely be studying the structure we had chosen to give it by the methods of our own choice. Just as if one were to form an idea of what another man's house was like by sending somebody in to turn everything in it upside down or inside out, and then entering it oneself and inferring that it must certainly be most disorderly.

It is not easy to see how the minute structure of the living cell can be properly studied except by improvements in our optical arrangements, such as increased resolving and magnifying power.

No doubt there are some reagents which can retain some of the larger structures without adding 


\section{ON THE STRUCTURE OF CELLS I 45}

others which were not previously visible. The structure which has been observed has been generally supposed to consist of a "network of threads embedded in a homogeneous substance." But this so-called substance might itself be seen to consist of a highly complicated structure if the sensitiveness and acuteness of our vision were greater than they are. Bütschli regarded it as made up of finely divided structures.

When small drops of a mixture of finely powdered potash and oil placed in water are observed, an emulsion is formed which has the structure of the foam-cells described by Quincke, and very possibly to some extent of the nature of the liquid crystals described by Lehmann. Such structures, however, have what are called vacuoles or internal spaces filled with liquid, as distinct from the outer and more solid-like substance which corresponds to the cytoplasm; the vacuole corresponds to the centrosome. The structure of living protoplasm, as investigated by the method of staining, is naturally viewed with considerable doubt by many students of the subject.

Again the element phosphorus enters largely into the compounds of which the nucleus is made up, chiefly in the substance called nuclein, and it doubtless plays an important part in the process of metabolism ; for phosphorus is highly phosphorescent, and, as will be shown, this phenomenon appears to be due to the simplest types of metabolism, resulting from the building up and breaking down of molecules: 


\section{I46 THE ORIGIN OF LIFE}

the building up being the result of some catalytic action of a semi-chemical nature; and the breaking down the consequence of the unstable nature of the molecular aggregates formed: the luminosity being the immediate consequence of the radiation which is given out by the breaking down of these unstable groups.

It is in this way that substances which compose the nuclei that exist within nuclei should ultimately be found to behave; the ultimate nucleus, however, being the fountain, so to speak, of the vital energy, that sets and maintains the whole mass going-something similar to the radio-active atom, which, for a long range of time, is apparently the source of inexhaustible energy; something which would behave like the molecule of cyanogen, a comparatively stable, and yet really an unstable group, which in losing its stability, like the atom of radium, gives out at the same time the vast store of energy that results from the mutual attraction of its parts.

This substance need not be, and most probably is not, cyanogen nor radium, but some other which possesses this quality in a marked degree. The nucleus would not consist of a single such molecule, but of a vast number of them like a gas, or the emanation from radium, and the multiplication of the primitive or ultimate nucleus would be very much the same.

The process of karyokinesis in the visible nucleus and nucleolus would be the result of strains set up 


\section{ON THE STRUCTURE OF CELLS I 47}

in the substance within the nucleus itself in consequence of the multiplication of the ultimate $n$ thnucleus; and the whole process of subdivision, the result of the separation of these two ultimate $n$ thnuclei from each other; or when the multiplication is a case of reproduction, of the separation of the $n$ th-nuclei from their parent source.

The problem, then, would appear to depend largely upon the source of energy in this primitive or $n$ th-nucleus; though of course there are many other questions involved. This ultimate nucleus is the fountain and the source of life, and the energy which emanates from it is analogous to but vastly more complicated than that which is manifested in the infra-atomic aggregations of electrons, as in radioactive bodies, amongst which, as it now appears, all the elements may be included.

This internal energy of matter, which is really stored up in the æther, may be something equivalent to the energy that is stored in the ultimate nucleus, and seems to spring in such a fashion as Sir Oliver Lodge and others maintain-if we understand them rightly - that is, that all living energy springs from ultra-materialistic sources, notably in such a highly developed organism as Man.

Life in its ultimate form would then appear to be the consequence of an aggregation of æthereal units or electrons, the units of electricity of which all matter, too, is ultimately composed. This ultimate unit aggregate or ultimate life nucleus might be something equivalent to Needham and Buffon's 


\section{THE ORIGIN OF LIFE}

indestructible organic molecules, which have not as yet been actually isolated; an element of a higher and more unstable type than any as yet known, and of whose physical and chemical properties we can only form the faintest guess; an element or organic compound which would possess some of the physical properties of comparatively stable and yet really unstable aggregations of æether units like the atoms of uranium, thorium, and radium themselves. Their energy would seem to spring from some immaterial source, although, strictly speaking, it would form a part of the connected totality of things, and be subject likewise in its final aspect to the same laws which regulate the universal whole. Such vital units would of course be physical units too. The idea which runs throughout this book is that such vital units are of the nature of elements, probably more unstable than the so-called dead elements of inanimate matter, although these, too, possess that quality of instability in a less marked degree, and are the aggregates of æthereal units or electrons, centres of vast quantities of energy stored up in the all-pervading æther.

These vital units would themselves differ in many ways from each other. It is to them that we should look for the vast multiplicity in organic types. They would, in fact, be the directing factor in each case upon which the subsequent development of the cell depends-clements, or, if we prefer to call them, as it is best to do, substances, which have been preserved only by the nuclear boundaries and 


\section{ON THE STRUCTURE OF CELLS I 49}

handed on from cell to cell by the subdivision of the ultimate nucleus; something equivalent to the emanation in the case of radio-active elements, which, as we have seen, when acting as the substance of the nucleus in artificial cells, can give rise to their reproduction or multiplication almost without limit.

From the action of radio-active bodies on organic media we can form some conception as to the action of such more complex vital units on the organic cell. The analogy is too striking to be passed over by one who has followed and entered into the minute study of the two classes of phenomena.

The source of energy in vital actions which Sir Oliver Lodge would ascribe to something immaterial would thus be stored up in such vital units in the æther itself, and seem to spring from ultra-material sources, not subject at first sight, nor indeed directly, to its material connections, although of course ultimately resolvable to the dynamical laws of Nature, much in the same way as the source of energy in the atom of radium can be traced to dynamical laws by the motion of aggregates of electrons.

Even in the most developed organisms, as in Man, there would be this ultra-material source of energy, which was part of the vital energy of the parent, and which may survive the material dissolution of the individual organism. This vital substance, element or unit, this source of energy, may be all of us that survives when we have shuffled off this mortal coil!

This unit, too, will no doubt disintegrate in time. 


\section{50 THE ORIGIN OF LIFE}

But its period of duration would be of a different order of magnitude from that of the material aggregate with which, for a comparatively brief interval, it was associated.

Some of that vital substance is inherited from ancestors; some of it goes down to posterity; that part of it which remains with the individual is severed from the material organism and, like the other elements of which that organism was composed, survives. In this respect it is of interest then to note the assumption which we make of the existence of such vital units. It gives us a clue to such phenomena as that of rhythm, which prevails throughout the organic and inorganic worlds, which appeals in so inexplicable a fashion to the inmost depths of the very soul itself!

Most curiously the rhythm in the structure of the elements applies to that of the planets and of the cells too, as it is in a singular degree applicable to music, poetry, and architecture.

It is by rhythmic disturbances that the flow of energy of the ultimate source or the vital unit would be affected; the connection between rhythm and the flow of vital energy in very many physiological phenomena being most remarkable. It may have a bearing upon the ultimate source of vital energy when it is borne in mind that such rhythmic laws prevail in the aggregates of the elements and in the formation of cells.

In an original and most interesting note in the Athenoeum, 30th April, 1904, Mr. Newman Howard 


\section{ON THE STRUCTURE OF CELLS I 5 I}

pointed out the strange analogy which exists between rhythmic relations in the case of many phenomena in Nature. Harmonic relations in the numbers 3,4 , and 5, appear in a most striking manner in the grouping of electrons as in the distances of the planets, and the harmonic relations as in music.

There are relations in the geometrical figures which for a long time have attracted the attention of many people. Upon these points we shall discourse in a later chapter.

The extraordinary effect of rhythm as a stimulus to vital actions has been regarded as one of the most remarkable phenomena associated with life and with psychological effects; it plays a most important part, for instance, in music, in poetry, and in prose. Mr. Theodore Watts-Dunton in discussing rhythm has remarked, and we think quite rightly, that "deeper than the rhythm of Art is that rhythm which Art would fain eatch, the rhythm of Nature, for the rhythm of Nature is the rhythm of life itself." In fact the amount of energy in the vital flux in the $n$th or ultimate nucleus should admit of being increased or diminished by its response to external stimuli of certain periods. As the energy of vibrations of light can be taken up and absorbed by the vibrations of the electrons within the atom itself, so too in a similar fashion would such vital units as we have postulated, possessing as they would similar dynamical structure, behave in a similar fashion. The response may of course be excited in many ways; and although these methods 


\section{I52 THE ORIGIN OF LIFE}

differ widely, they would in all cases, directly or indirectly, transmit high frequency vibration to the ultimate unit itself.

To return, then, to the relation between the nucleus and the cell: it must be borne in mind that there are some minute forms of life which seem to have no nuclei, as, for example, the Monera of Haeckel, which seem to be single bits of protoplasm. The answer has been given, however, that they probably consist entirely of nucleus and there is no cytoplasm visible. This seems to be most probable. However, there is reason to believe that the inner nuclei may not always be visible by ordinary means. That there are such nuclei it seems scarcely necessary to question.

It is upon this nucleus and these nuclei that we suppose the vitality of the cell depends. The flow of energy is doubtless continuous and independent in its ultimate course from the mechanism with which it may be associated. In the relation between this vital unit and the organism to which it may be attached, rests the whole question of living organism. As we have seen, such effects can be imitated by the action of certain minerals on organic media. They appear in each case to possess the striking qualities which are associated with vitality, and to support the hypothesis which has been put forward that such a nucleus as we have supposed can give rise to aggregations wherein a continuous flow of energy as well as of matter is maintained. 


\section{CHAPTER IX}

\section{THE NUCLEUS AS A SOURCE OF ENERGY}

Nucleus as a source of energy-Possible mode of reconciliation between opposite schools of Haeckel and Lodge-Bioelements-Altmann's bioplasts-Dr. Charlton Bastian and the transmutation of species-Life-activity and radio. activity-Richter and Preyer's cosmoza-Bathybius and precipitates-The problem of the origin of life equivalent to or parallel with that of the origin of matter.

$W_{E}$ have now discoursed upon the internal energy of which the nucleus is the seat, and have seen that a striking analogy exists between the behaviour of nuclei in natural and artificial cells. This view leads to a possible mode of reconciliation between the two apparently antagonistic doctrines held by Haeckel and by Lodge. According to one the vital energy is the result of purely molecular atomic interactions; whilst according to the other there is some other transcendental ultra-physical source. If we regard the nucleus in the manner so described, as constituting the seat of infra-atomic motion, we can conceive how it is that sources of energy which at first sight may appear not to come under the law of the conservation of energy, may in reality be reconciled with that law 


\section{THE ORIGIN OF LIFE}

and be found to be derived from sources purely physical. Such a phenomenon is already familiar to us in the case of radio-active bodies, the amount of energy stored up in the atom being very great indeed. Only when the stability of motion of the electrons is lost is the energy radiated intensely. Such energy as we know is of such a magnitude that that of the most powerful explosives cannot compare with it. The atom may remain thousands of years in perfectly stable equilibrium, but when the stability is lost that rearrangement of the electrons takes place which is accompanied by a vast amount of radiation.

It is in this manner that we have imagined the nucleus of the cell to behave, and it is conceivable that that nucleus in its ultimate aspect may prove to be nothing more than an agglomeration or aggregate of electrons in an unstable state, highly complicated no doubt by the vast number of electrons which compose it; but capable however of behaving somewhat as the unstable elements themselves. In fact, as radium is the descendant of uranium, so uranium too may be, and most probably is, the descendant, direct or indirect, of other and more unstable elements, of whose actual properties we have at present not the faintest knowledge.

The nucleus may contain many million corpuscles, and most probably far more, so that such a system when slightly disturbed would admit of many qualities which ordinary atoms would not be expected to possess. Assimilation, the power of replacing electrons which have been emitted, may be one of these pro- 


\section{NUCLEUS AS SOURCE OF ENERGY I 55}

perties. So that its substance would be in a state of perpetual change. It may be that such a substance as we have been led to postulate, is a polymeric form of carbon, just as Verworn postulates biogenes or units of life, and that in following the line of reasoning here suggested we should be led to regard such units rather as vital elements than compounds. For we see that it is most probable that the energy which may at first sight appear to be ultra-materialistic is in fact stored up in the æther as internal atomic energy. Life activity and radio-activity should admit of continuity. We may venture to call such vital units bio-elements, being regarded as active and unstable polymeric forms of carbon, just as radium is probably a polymeric form of barium; polymeric, however, in its newest and most recently accepted sense, as being similar in its ultimate electronic constitution and occupying a similar place in the periodic law.

The reasons which lead us to adopt this view are based of course on analogy. The part played by carbon in vital processes is the most remarkable fact in connection with the phenomena of life. The fact that artificial cells can be synthesised and that they can behave, though remotely, as if they were alive leads us to suppose that by a process of extrapolation we should reach the elements which in turn should give rise to the analogous or vastly more complicated phenomena of life itself.

In this way the problem of the origin of life becomes in part at least entwined with the problem of 


\section{56 THE ORIGIN OF LIFE}

the origin of matter. The origin, however, of organic matter, which, as we know, cannot exist at a very high temperature, becomes reduced to the development of organic cells by such methods as unstable nuclei are capable of originating. The real difference between natural and artificial cells is in the greater complexity of the nth or ultimate nucleus; whilst the mode of subdivision of the nucleus in the manner we have described gives rise to assimilation, growth, and reproduction.

It takes no great stretch of imagination to comprehend the vast possibilities of which this notion really admits, and there may be a great variety of types of such ultimate vital units or aggregates of electrons. A great variety of types of nuclei is possible, and the subsequent complexity of the organism becomes more intelligible when it is borne in mind that almost an indefinite series of them may now exist or may have existed in the past. This conception is particularly fruitful, especially as it gives us a clue as to the origin, not merely of life itself, but of the many types in which it has appeared.

As we have said before, of the vast number of varieties which have thus been formed only a small proportion have been sufficiently stable to counteract the opposing circumstances in which they had been placed, and thus the illimitable gap between living and dead matter, as we see them to-day, may have been in the course of æons finally established.

In this way then, and in this way alone, 


\section{NUCLEUS AS SOURCE OF ENERGY I 57}

does it appear that the missing links between the organic and the inorganic are to be accounted for. Haeckel has regarded the Monera-or rather a particular type of Monera, called Cromacea-as the most primitive of all organisms known to us. They are, as we have said, supposed to be structureless organisms, and to have no visible organisation or composition from different organs. These cells without nuclei have, as he points out, been ignored and neglected by most biologists. But. the existence of cells without nuclei is considered extremely doubtful, and although they may appear to be quite structureless it is more than probable that the structure has merely escaped our notice owing to imperfections either in the methods of staining or in the optical arrangements. As has been suggested already, the cell may be a nucleus itself without any cytoplasm.

The view herein put forward, however, is that they constitute merely one of the many missing links we are in search of, and that they are far more complicated than any artificial types which we can endeavour to produce. In these gaps there exist, between the organic plasma products and inorganic crystals, types called bio-crystals which are formed by the interaction of mineral matter and plasm. Amongst these we may mention the crystalline flint and chalk skeletons of the sponges and corals, and, as Haeckel points out, it is also in the flinty shells of the diatoms and radiolaria. His idea, however, like that of Schleiden and Schwann, that crystals are also types of elementary 


\section{58 THE ORIGIN OF LIFE}

cells, is not altogether satisfactory unless there exists during the formation of a crystal such a process as that which Schön supposes. There are, however, types of organic crystals and bio-crystals which seem to have the power of intussusception, or of taking in new matter into their interior. As we have seen, the organisms or organic cells produced by radium and other salts do possess that power of metabolic action to some extent.

Now the process of intussusception may be produced by very elementary physical processes, for a colloid globule immersed in a salt solution, provided it does not dissolve, may grow by assimilation; in other words, the process of nutrition may be imitated physically. It therefore seems that those processes which are associated with vitality, even in its highest sense, may be reproduced if the various conditions which, as we have seen, can be produced artificially could also be made to coexist. Even metabolism can take place without the combination of the other processes, whilst its coexistence with the other functions would thus give rise to cellular life in its highest sense.

All these bio-crystals or organic crystals and colloid bodies under certain circumstances, as with a nucleus with a considerable source of energy stored up in it, may possess the power of growth or nutrition by its intussusception, as well as reproduction; the secret of the reproduction being in the peculiar nature of the nucleus itself, which, strictly speaking, is a cell within another cell, and the substance 


\section{NUCLEUS AS SOURCE OF ENERGY I 59}

containing that cell, like the radium and the emanation, would be capable in a newly formed cell of performing the same processes as in the original.

If, then, the primitive substance in the nucleus consists of an element or substance possessing a store of energy like the emanation from radium, even if that substance be not radium but some other substance possessing similar qualities, perhaps different chemical qualities more allied to those of carbon, such a substance would, we think, admit of performing the processes which are associated with vitality.

In every combination of organic and inorganic matter there is some resemblance between the animate and inanimate. And it is only a question of degree whether we should regard such results as approximating more or less closely to the animate or to the inanimate kingdoms of Nature.

In every case, as we say, there can be perceived the properties of one as well as of the other. And it is from this gradual scale of increment of living qualities that we feel justified in inferring that by an extrapolation we should ultimately reach the phenomenon of natural life itself.

The nth nucleus or bio-element is of course invisible, and probably of molecular dimensions; particularly so if it is of the nature we suppose it to be-namely, an element possessing many of the chemical properties of carbon and the radio-active properties of the more unstable elements.

Altmann had a theory that all living matter is made up of very minute bodies which be called 


\section{I60 THE ORIGIN OF LIFE}

bioplasts. His view, however, was that the globular particles or granules, such as the secretory pigments and fats, are also amongst the bioplasts: and, as Haeckel remarks, his granular theory is now generally rejected. Altmann's visible granules, like many other theories which attribute the elements of life to visible structures, are likely to lead little further than we have already arrived at. That the first beginnings of life should in any way have anything to do with our range of vision can only be entertained in moments of enthusiasm when we are inclined to take ourselves too seriously. The smallest visible organism is doubtless a highly complicated body, and the atoms of which it is composed bear the same relation to it that it does to a highly complex living organism such as a plant or animal. In every case we have to deal with the relative aspect of life rather than with the ultimate type. Once more there is nothing great or small but thinking makes it so. The elements themselves may be distinct species of atoms, which resemble each other much in the same fashion as organisms of the same species do. Their general properties are the same and enable them to be classified together, but there is plenty of room for differences in non-essential points; non-essential so far as these do not apply to the particular properties upon which the classification is based. And we may so regard the atoms of the same element as differing in many non-chemical properties: for it is only in their chemical properties that their identity obtains. 


\section{NUCLEUS AS SOURCE OF ENERGY I6I}

In some such way do we suppose the bio-elements or bio-carbons, if we may call them such, to differ and to agree.

No doubt one would expect such radio-carbons to stand high temperatures, and when living organisms containing them are sterilised in culture media the presence of these elements would in turn give rise to some type of artificial cells, however different from the original.

Thus some of the results obtained by Dr. Charlton Bastian may be accounted for in this way. What the phenomenon really amounts to is this, that in the process of sterilisation there remain some particles with the vital principle unaltered, and although the cellular organic structure is destroyed, a new structure, totally different no doubt, admits of being re-formed. Such a process would no doubt be nothing else than heterogenesis. But we might expect the newly formed cells to be simpler as the conditions under which they are produced are simpler too.

Of the work of Dr. Charlton Bastian we hope to be able to discourse in a subsequent chapter. His experiments on heterogenesis, and particularly on the transformation of the eggs of a rotifer into ciliated infusoria, are indeed most remarkable. An account of the nature of these experiments has recently been published in the proceedings of the Royal Society. There can be no doubt that, however startling the results, they are at least worthy of the 


\section{I62 THE ORIGIN OF LIFE}

most careful consideration. His observations will no doubt give rise to a great deal of controversy, and whether they are accepted as final or not, there can be no question that the track which he has followed is also the one on which progress is before long destined to be made, for there is much circumstantial evidence of the transformation or heterogenesis of living types in the remote past. We cannot imagine that types have always been what they are; although natural selection has played a most conspicuous part in bringing about such changes, the change from one such type to another, or rather the transmutation of species, is scarcely to be unexpected.

As in the case of the chemical elements, such analogous transformation was not believed in on direct evidence till very recently; indeed, not till Sir William Ramsay and Mr. Soddy found that radium emanation is converted into helium, although there is much circumstantial evidence that transmutations of the elements did at one time occur.

So also the transmutation or heterogenesis of species is at the present day not at all unlikely, and we fear that it would be the height of presumption on the part of any thinker, sacred or profane, to assent dogmatically that the principle which has been violated, even in the case of the elements, where the distinctive features seem so marked, should not also have been violated in the case of the biological elements, if they might be so called, of 


\section{NUCLEUS AS SOURCE OF ENERGY I $6_{3}$}

living species. It was not so very long ago that the chemist proudly proclaimed that the atoms were sacred structures, and that same proclamation is to-day the catch-word of the orthodox biologist in regard to the organic cells with which he has to deal so far as they are vital units. Clerk Maxwell regarded the elements as the foundation-stones of nature, but in the same manner as Virchow and other eminent biologists of the present period regard the corresponding units of life. Such types are, we think, only approximately distinet, and circumstances may be brought about by which they should be made, or enabled, to change one into the other. These circumstances may be extremely difficult to ascertain, and in fact they may be largely if not altogether accidental. But as in the case of radioactive substances the transformations are spontaneous, so may it be that with particular types of living things in certain circumstances similar transmutations should occur.

We have made it clear, we hope, that there is no a priori reason to suppose that such changes or transformations of stable types should not also occur in the organic as well as in the inorganic world. We may then pass on for the present without entering into the details of Dr. Bastian's work. We have simply seen that the heterogenesis is the most probable result of our hypothesis, that the nucleus of the natural cell is composed in its ultimate aspect of a substance which might be described as a bioradio-carbon element: and that when such a cell 


\section{I64 THE ORIGIN OF LIFE}

is sterilised or destroyed by heat in a gelatinous culture medium, if this $n$th nucleus survives the heat, as in the case of radium, a new cell would be formed which would differ largely from the original and more appropriately admit of being styled an artificial cell; a revival, in fact, of the life which was destroyed, but only an artificial imitation, so to speak, and more like radiobes than natural life, with that impassable gulf which separates the natural from the artificial.

This is the most we can expect, and we may call it spontaneous generation if we please, or heterogenesis, but the results are as far from natural life as the artificial products of the laboratory can be.

What we have chosen to call bio-carbon, then, would form the physical basis of life. Such an element, or compound as it may appear from the complexity of its nature, whilst possessing the chemical properties of carbon, would also possess a considerable store of energy, which, strictly speaking, would be energy stored up in the æther and apparently at least independent of physical forces, but in reality forming a part of the dynamical connections of the universe.

This secret source of vital energy may perhaps satisfy those philosophers who maintain that vital actions are guided by some immaterial source. Sir Oliver Lodge, although belonging to this class of thinkers, admits that even in such cases the conservation of energy is still valid. The hypothesis which we venture to put forward seems 


\section{NUCLEUS AS SOURCE OF ENERGY I 65}

to fit in with the two apparently diametrically opposite points of view and to reconcile the material with the immaterial aspects of the question, by showing that they are both the consequences of the energy which is stored up in the æther which admits of various modes of transformation. Furthermore, it helps to give us a consistent and harmonious view of the continuity of nature and therefore also a Monistic theory of the material and immaterial parts of which it consists.

By material, of course, we mean the atomic and by immaterial the infra-non-atomic phenomena of æther: the former being more ephemeral, the latter, which we are to some extent justified in regarding as the immaterial, or spiritual if we wish to call it so, being more permanent perhaps than material phenomena.

It may, of course, be objected that all these phenomena are, strictly speaking, material in so far as they are subject to the physical laws of nature, and that therefore such distinctions are only a matter of words. The objection is scarcely sound, unless we mean by matter anything which is subject to physical law. But by matter as it is generally understood we mean that matter which manifests the ordinary physical and chemical phenomena of nature as distinct from those others which have recently been found to owe their origin to an ultra-atomic source and such others, known as spiritual, which may yet be found.

We have no desire to confine the use of the 


\section{I66 THE ORIGIN OF LIFE}

word material within these limitations, but all that we wish to emphasise is that beyond the phenomena of nature with which we have been till recently acquainted there exist other phenomena, which in turn are subject to laws, but which at first sight at least seem to be independent of the older and more familiar effects. The attempt is therefore an effort to include the so-called immaterial phenomena within the ordinary course of nature; the two classes of effects being apparently independent of each other, but really closely interwound and capable of being transformed one into the other. That must be our earnest endeavour to prove; for the conviction that Monism in its ultimate form is the correct view of the world is as deeply rooted in our minds at the present day as in that of Haeckel, or for that in the mind of Spinoza. It is only a question as to where the dividing line is to be drawn; though that line does not really separate the two or destroy the continuity between them wherever it is drawn.

Life-activity is a phenomenon of matter as much as radio-activity, although really of a more complex kind, and the manner in which the energy is stored up in the ultimate nucleus is probably pretty much the same. Such nuclei may have existed, like the chemical elements themselves, throughout the universe for an almost indefinite time. To account for their formation 


\section{NUCLEUS AS SOURCE OF ENERGY 167}

would be the same as to account for the formation of the elements. These may have been constituents like the other elements of the nebula of which the planet once consisted; or they may have been carried to our planet by meteors, as Lord Kelvin and von Helmholtz imagined that life originally appeared amongst us.

In our hypothesis, however, we do not suppose that ordinary germs appeared thus; for the high temperature to which they must have been subjected, at some time during their history before reaching the surface of the earth, would have been sufficient to destroy them. What we suppose to have been sufficiently permanent and stable was the ultimate nucleus; which might have been formed at, or at any rate which might have resisted, the high temperature through which it should at one time have had to pass; whilst the formation of cellular life as we see it to-day was the result of the subsequent interaction of this radioor bio-element with organic compounds in such a manner as has been suggested. Reasoning, then, by analogy from the behaviour of the artificial cells, it was in this way, we think, that the most efficient types of cells were formed, and in virtue of their efficiency some of them have been able to survive.

Professor Pflüger, of Bonn, regarded cyanogen as the substance which thus gave rise to the formation of proteids. Cyanogen does resemble in physical structure the hypothetical substances which 
we have dwelt upon, although it is not an element.

All that is required really is a nucleus which would possess the properties as above described. Whether it is an element or not it is impossible to say; it is probable that it would possess the properties of an element, but it may be a compound. This hypothetical substance, bio-carbon, may be nothing more than cyanogen, although we think it is probably something else, since it is doubtful if the energy stored in this compound is sufficiently large.

It may be that the element whose existence we postulate does not possess the chemical properties of carbon, but those of cyanogen. But we may regard life as a property of matter as much as radio-activity or electricity, of which matter is ultimately composed; life-activity being, from the considerations which we have given, nothing more than a particular kind of instability in the substance which composes the $n$ th, or ultimate nucleus; and that instability can give rise to the subsequent behaviour of cells when it occurs in a substance embedded in organic media, the mode of producing these cells in such media being a mere process of structural organic synthesis.

The mere production of complicated compounds is not the only factor in the synthesis of organic life, but also the formation of cells composed of these substances. And in fact even the precipitate which may be produced by the action of a salt 


\section{NUCLEUS AS SOURCE OF ENERGY i 69}

on gelatin would in its initial stage be of interest to follow, just as in the case of the formation of crystals it is the initial stage, as von Schrön has pointed out, that is of real importance. In the case of precipitates in organic media the amount of salt used, if large, is sufficient to obliterate any cellular effects which may be produced initially, so that only an agglomerated mass results, without the structures, a crystal or two of the salt being sufficient to produce the cellular structure which forms the subject of so many developments in the colloid medium, whereas if a bucketful of salt is thrown in the effect is merely that of an ordinary precipitate. It will be remembered in this connection that our old friend Bathybius turned out to be a mineral precipitate from muddy sea-water mixed with alcohol. Now whether such globules did or did not possess a kind of structure which should have enabled us to regard them as a certain type of cells we cannot at present say. It is evident, however, that in sufficient quantities such globules, whether cells or not, would aggregate and present all the outward appearance of an ordinary precipitate.

Similarly as regards the cells produced by the active minerals upon organic compounds. The bio-carbon compound, or element as it may be, would to some extent correspond to Richter and Preyer's theory of cosmoza, the idea being that these are merely particles, or, strictly speaking, germs possessing vital properties. If such germs coming from other heavenly bodies find suitable surroundings 


\section{I70 THE ORIGIN OF LIFE}

here they then would begin to develop and start the formation of organisms. Richter and Preyer regarded organic life, strictly speaking, as never having originated, but as having existed from all eternity, like the elements of matter. The hypothesis put forward here is that the substance which forms the ultimate nucleus in cellular life possesses some such properties and may in a similar manner have existed for a very great period like the elements. Recent work shows that even these are the results of more or less stable types that have survived in the course of the evolution or formation of matter. So that the problem of the origin of life resolves itself into the problem of the origin of matter, and in particular of the origin of unstable matter, like the radio-active elements. Formation of a cell is thus the result of the formation of a particular type of growth and resembles the growth of a plant from its seed. As the seed is the nucleus on a larger scale by which the elements carbon, oxygen, hydrogen, nitrogen, sulphur, phosphorus and iron, are assimilated from the soil, so the element bio-carbon, acting on the soil in certain circumstances which we do not at present know, the conditions being probably most complicated, may also in the remote past have given rise to such cellular structures as we see to-day, and which we see produced artificially in the laboratory in such forms as have been described, notably in the case of radio-organic bodies.

Just as the lighter elements appear, in view of 


\section{NUCLEUS AS SOURCE OF ENERGY I7I}

recent work, to be merely the more stable survivals of aggregates of electrons of which all matter is composed, and to be the inert products of unstable radio-active bodies which differ from them only in being more complicated, so, too, does it appear that the elementary substance to which life is due is largely the result of a peculiar combination of electrons, vastly more complicated than anything which inorganic matter at the present day may have to show us. We have explained, or tried to explain, how the union of an inorganic substance with organic compounds can give rise to active and structural forms. The manner in which the descent of such types may have taken place is what we have to deal with in what follows. 


\section{CHAPTER X}

\section{THE DESCENT OF LIVING PROTOPLASM}

Artificial cells in their relation to the mode in which life first made its appearance-Criticisms as to the nature of these cells-Preyer's theory-The small chance of the particular aggregates constituting a living cell being found -Experiments with cyanogen and electric dischargeProbable structure of Haeckel's Monera-Fresh speculation in their relation to biogenesis.

By this time it is no doubt apparent that the dawn of life in the remote past was the result of a process very closely allied to the formation of artificial cells, as we see them develop to-day in the laboratory, by the action of various salts upon gelatin media, or more accurately of gelatinous bodies containing the constituents of protoplasm. Those gelatinous substances, however, cannot have existed in that remote past as they do to-day, and it is therefore to be inferred that the formation of cells of protoplasm in the first instance was the result of the interaction of a particular substance or substances, composed of the bio-elements thus postulated, with other organic bodies. It is most probable that the conditions under which they were formed were totally different from those within our 
power to bring about at the present day. Reference may once more be made to the suggestion which has been offered, that artificial cells are nothing more than precipitates. Such a view can only betray the most profound ignorance of the subject. Bacterial cultures will give precipitates when treated in a similar manner. Moreover, the precipitates are insoluble, whilst the cellular structures are soluble in warm water. This solubility is not merely apparent, as might easily be supposed when the quantity of the salt used is very small. Such an effect might delude one when the observations are made with the naked eye or with magnifying powers which are insufficient to serve the minute bodies themselves, which it must be remarked do not exceed a certain size. These bodies can be seen with twelve-inch oil immersion objectives; with lower powers they are scarcely visible, and their solubility can only be tested by such microscopic examination. There can be no doubt that they are cellular and soluble, being more like the bodies obtained by Quincke than the results of such crude and superficial observations as some, for instance, have so inaptly imagined. No doubt, in using a large quantity of salt, one can destroy the cellular structure by producing coalescence; as has been said before, if a bucketful of the salt be thrown in a few other bucketsful of gelatin, we should no doubt obtain a great precipitate. It will in fact be the best way of not getting the results. 


\section{THE ORIGIN OF LIFE}

The minute bodies visible under the microscope would, if they are insoluble, continue to be visible on warming the slide. Whilst the bodies produced by barium, strontium, and lead are of a different order of magnitude, and it does not seem that the insolubility of the sulphates has after all so very much to do with the formation of cells such as those which have been observed. It can be suggested that, although there may be a cellular structure in all such cases, that structure is due to desiccation, or perhaps liquefaction of the gelatinous medium round the precipitated particle, leaving a vacuole which would collapse on melting, so that the solid particle of precipitate being so small might easily escape notice. But this is just what does not happen, for the precipitate aggregates, and provided the observations are made on the same microscopic slide, there does not appear to be any reason to confuse the two effects. The suggestion is intelligible if one has not seen the bodies that have been described, but only larger groupings of precipitated particles in excess of salt.

The action of light on those bodies is equally remarkable, as by exposing them for some hours to strong daylight they completely disappear, but reappear again if kept in the dark for a day or two. This would not happen to an ordinary precipitate.

The bodies obtained by Rainey by precipitating carbonate of lime in viscid solutions of glue or gelatin, although also of a different order of magni- 
tude, resemble the products of radium and gelatin more closely, but only in appearance, for they too are insoluble in water. Dr. Bastian in his $\mathrm{Be}$ ginnings of Life, published some thirty years ago, describes many similar effects. It is difficult to say how far they are cellular in each particular case, and $I$ am inclined to think that in many instances they are probably crystalline forms. Then again, Herrera of Mexico, Künstler of Bordeaux, Leduc of Nantes and Debois of Lyons, have obtained many types of bodies which seem to be distinctly cellular; whilst Bütschli, Quincke, Lehmann, and Schenck have observed and experimented upon many similar bodies which might also be described as cellular. The vital principle, however, is what is absent. In all cases it is possible to regard them as corresponding to types which have been eliminated owing to their inability to carry on the cyclic process from generation to generation. In fact, for this reason, if for this reason alone, the biologist would not admit they were alive. But in trying to fill in the gaps, however largely they may differ from the actual thing we call living protoplasm, such phenomena are nevertheless of interest and utility to those who would make a comparative study of the effects which resemble vitality in the remotest degree throughout Nature.

We have impressed this point more than once before, for it cannot be too clearly emphasised in considering the probable descent of living matter 


\section{I76 THE ORIGIN OF LIFE}

in its highest sense from primitive elements. It is, indeed, essentially a case of a survival of the fittest, in the particular case, of a substance which can reproduce its own type to a perfect degree. And, therefore, that degree of perfection, although one instance amongst millions that have failed, by the operation of purely physical forces, stands out today as the wonder of all civilised minds.

We look upon the continuity throughout nature as complete, notwithstanding the presence of many gaps. It does not matter whether we regard the organic as the product of the inorganic or the inorganic as the inactive remnants of the organic. The latter was the view put forward by Fechner and by Preyer, who abandoned Richter's theory of cosmozoc and regarded the universe as a huge organism of which inorganic nature is the ultimate product, the elements being merely the more stable types which result from the gradual disintegration of this agglomerated mass. Even the sun itself was regarded as an organism, and the elements as precipitates.

"In accordance with these considerations," says Verworn, "he sketches the picture of the derivation of life upon the earth. Originally the whole molten mass of the earth's body was a single giant organism. The powerful movement that its substance possessed was its life. When the earth's body began to cool, the substances that could no longer remain in the liquid state at that temperature, e.g., the heavy metals, were separated out as 


\section{THE DESCENT OF PROTOPLASM I 77}

solid masses, and, since they no longer had a share in the vital movements of the whole, formed dead, inorganic substance. Thus arose the first inorganic masses. This process continued. It is remembered that at first hot, molten masses represented the life of the earth. .. When in the course of time these compounds became solidified upon the surface of the globe, or, in other words, died, compounds of the elements that had thus far remained still gaseous and liquid appeared, and these became gradually more and more like protoplasm, the basis of the living substance of the present day. With the decrease of temperature and the lessened dissociations there must constantly have appeared more complex compounds, chemical substitutions, denser bodies, and more involved and correlated movements of the parts which were being massed more closely together. Thus, the first forms of plants and animals, resembling one another and made possible by advancing differentiation, were able to exist.

"We do not say, therefore, that protoplasm as such existed from the beginning of the earth's formation; or that without beginning it wandered as such from elsewhere out of space to the cooled earth; or, still less, that without life it became compounded upon the planets out of inorganic bodies, as spontaneous generation would have it; but we maintain that the movement that exists in the universe without beginning is life, and that, after the bodies now termed inorganic had been separated out upon the cooling surface of the 


\section{I78 THE ORIGIN OF LIFE}

incandescent planet by its intense vital activity, and were not able to return again into the hot liquids which gradually decreased in quantity because of the progressive decrease in temperature of the earth's crust-we maintain that after this had occurred, protoplasm must necessarily have remained over. The heavy metals, once organic elements, no longer melted, and did not return into the circulation from which they had been cast out. They are the signs of the rigor mortis of the gigantic, cooling, primeval organisms, whose breath perchance was luminous iron-vapour, whose blood was liquid metal, and whose food was meteorites."

It is at this juncture that we may begin to realise the bearing of physical forces upon this state of matter. For although Preyer's statements may appear now, as they did at the time he made them, somewhat fantastic and crude by adverse critics; yet from the views herein expressed, they appear to be quite in harmony with the physical theory of metabolism in inorganic as well as in organic substances. The phenomena of catalysis seem to take part in such simpler reactions as in the phenomena of flames, and in those of fluorescence and phosphorescence. These phenomena are distinctly of the nature of a building up and breaking down of more or less unstable molecular groups. So that it may be said that here at last we have metabolic action in its simplest form; each little aggregate acting as an individual for a time, and then, having played its part in the process, dis- 
integrating and becoming absorbed into the constituents which composed it. This is a physical process which is not merely analogous to, but essentially of the same kind as, even if incomparably simpler than, organic metabolism. The mechanism in each case does differ in complexity, as the simplest chemical or even infra-atomic actions differ from the vast and complicated reactions of an incandescent nebula or of the sun itself. But if we so choose we might prefer to call it not organic but physical life. Such peculiar types of atomic and of interatomic systems, when acting in concert with highly complicated organic compounds, can give rise to further molecular actions which, partaking as they do of their metabolism, and forming larger individual aggregates, can assume the distinctive cellular structures that, according to the circumstances in which they have been formed, may be regarded as types of more or less organic forms of physical and even of organic life.

Even in the production of artificial cells, like those we have described, there is still the possibility that even amongst the bodies thus produced there may be, if the number of trials be sufficient, one or two amongst millions or billions of such individuals; one or two cells which should possess the structure that would enable them to multiply or reproduce to an indefinitely recurring period.

This is the great difficulty which all experiments on spontaneous generation present. Negative results, however numerous, may be merely the most 


\section{I80 THE ORIGIN OF LIFE}

probable but accidental failures, using the word probability in its mathematical signification. If this theory be correct it would still appear that, even with the proper combination, the probability of getting a living cell in any particular experiment may be one in millions or perhaps millions of millions. It seems far more probable indeed that we have not yet obtained that combination, and that we shall not guess what that combination should be for a considerable time to come.

Out of the fortuitous combination of electrons in the evolution of matter only a very small number would have attained a stable state, the most stable of these being the elements; while it seems extremely probable that the substance of which a body like the sun is composed consists largely of primordial elements or electrons rather than of the stable aggregates or systems which these in turn are in the long run capable of forming; so that the elements are merely the precipitated aggregations, so to speak, of that gaseous fluid of electricity. In other words, instead of looking at the sun as composed chiefly of chemical elements, we should regard it as composed essentially of corpuscles gathered into it from all space, and which in the course of time condense into stable and unstable systems. It is among the unstable ones that we may hope to find the initial conditions by which the formation of highly complicated metabolic actions can result.

The same process or processes no doubt took 


\section{THE DESCENT OF PROTOPLASM I 8 I}

place at one time on this earth, and with compounds as well as elements, the simplest being water. By the passage of an electric discharge, or, what comes to the same thing, by the swift passage of electrons of opposite kinds through a mixture of oxygen and hydrogen, the aggregation we call water is produced. Now the properties of water are entirely different from those of its constituent elements oxygen and hydrogen. They are as different, in fact, as the properties of living protoplasm are from those of its constituent elements. So much so that we have been led in following this line of thought, and in reasoning from Pflüger's analogies, to try to mix it with various types of organic substances by sending a discharge of electricity through cyanogen whilst the gas is in a highly unstable phosphorescent state, and amongst these substances sterilised bouillon was introduced in the vacuum tube in which the electric discharge had passed through the cyanogen, the discharge being preferably of the electrodeless type.

The figure shows the kind of apparatus used, and although the results were unsatisfactory and negative, and still remain somewhat inconclusive, hope still lingers that further experiments in this direction may lead to more definite results. As has been said, it is largely a matter of chance whether the particular mode of grouping occurs, and the probability that this should take place may be extremely small. Negative results should not be regarded as conclusive against the possibility of 


\section{THE ORIGIN OF LIFE}

such formations, but rather treated with the same scepticism as positive results would have been had they been obtained.

It is curious, is it not, bow willing people are to acquiesce in negative results, since to prove a negative is not much easier than to prove a positive? People who are always willing to rest content with negative results seldom come across anything new. The mental processes of perceiving identities and differences must work together, lest we should imagine things which are the same to be quite different, or things different to be the same. Now, since there are reasons for supposing that the attainment of positive results is a matter which depends largely upon accidental circumstances in these experiments, and, as we have pointed out, it is only one out of perhaps many million molecules that is successful in producing the necessary aggregation, we can see how it is that the attainment of the positive result should be so difficult. In these circumstances, then, the development, or, if we choose to call it so, the spontaneous generation of that which we regard as living from that which apparently was not, may have taken place in æons past, having had many such opportunities in which to occur; just as these opportunities are so small when in the short intervals of time the conditions are repeated in the laboratory. It is interesting to note in this connection that Crosse more than fifty years ago thought he had succeeded in producing animal life by sending an electric 


\section{THE DESCENT OF PROTOPLASM I $8_{3}$}

current through a gas. His results created intense excitement at the time, and brought down upon him the wrath of many divines. The bodies thus obtained had the appearance of animalcules, but the results were doubtless due to imperfect sterilisation, as they have never been confirmed. Lewis, in his History of Philosophy, refers to these interesting experiments. We were not aware of them when our own with cyanogen and bouillon were commenced some three years ago. The mere passage of a discharge through gas would not afford any reason to suppose that anything of the kind should result; but if the discharge takes place in a medium containing all the necessary constituents, it is quite possible indeed, not to say probable, that amongst the many complicated aggregations formed, a few may be of the nature of living protoplasm. It seems not unlikely that cyanogen should form a nucleus of the type of which we have been in search. Although the living types which thus result differ from those we see around us, they would still most probably possess many properties in common. In this way, it was hoped that successful results might be obtained which should resemble organic forms, but unfortunately the results were negative, and if such methods ever do yield the required result, it will doubtless be after many failures, unless the experimenter is particularly lucky.

The most that can be done is to reason from analogy: and from the results obtained, by various 


\section{THE ORIGIN OF LIFE}

methods, and from every fact that we can get a hold of, arrive at some comprehension of the manner in which probably the highest organisms also arose.

As we have seen from Pflüger's analogies, cyanogen or its compounds are the essential constituents of which living matter is composed, and the production of that substance and of these compounds also necessitates intense heat. As Verworn remarks, "When water was precipitated in the form of liquid upon the earth's surface, these compounds entered into chemical relations with the water that dissolves salts and gases, and thus originated living proteids, that is to say, extremely labile compounds like other compounds containing the cyanogen radical, and distinguished by their tendency to decomposition and polymerisation, which form the essential constituent of living protoplasm. The first living substance which may be formed spontaneously out of lifeless matter is very simple and showed no differentiations. It is very probable that, if it did not have the morphological structure of the cells, that is, that its mass was not yet separated into different substances such as nucleus and protoplasm, it was homogeneous in all its parts, as Haeckel assumes for his Monera."

Although we agree with him that cyanogen did play a most important part in the formation of proteids, we nevertheless doubt that the most elementary types of life were absolutely structureless, as he supposes the Monera to be. Indeed, we 


\section{THE DESCENT OF PROTOPLASM I 85}

question the fact that Monera are really structureless, and, as was suggested in the previous chapter, it seems probable that there is a series of nuclei one within the other, even though our optical arrangements do not enable us to follow them. As in the case of the Monera, the structure may be too fine to admit of staining by ordinary means.

In discussing the descent of living matter this point is not of so much importance. We regard such matter as the direct descendant, including the Monera, of probably much simpler types. Just as successive variations in each generation have been sufficient to provide the most varied types and amongst these a few which have been suitable to their surroundings: so also there may have been others which, instead of adding to their complexity by successive variations, have become simpler and simpler; and even amongst these there could have been some' types which, whilst being sufficiently adapted to their environment, and by possessing the power of reproduction in an indefinite series, have also been able to survive. It seems not unlikely that the Monera belong to this type, and that, simple as they are, they differ, if not as largely at any rate largely, from the original types as many of the higher organisms themselves. There is no need to enter here into the evidence for the development of the various species, as for instance from palæontology, comparative anatomy, and embryology. We are more chiefly concerned with the evolution of that 
matter which constitutes them and its descent according to similar laws from primordial substance composed of electrons or the electric fluid. In the almost infinite combinations which have taken place amongst these there were a few stable enough to survive, and at length the chemical elements themselves in a similar way appeared.

From the considerations given in the other chapters, it is preferable to regard the substance of which the ultimate nucleus is composed as nothing more than a highly unstable element or perhaps compound, like cyanogen, with a considerable store of energy. The mechanism which on this hypothesis would constitute cellular life we have already sketched; and we should now proceed to develop more in detail.

A point to bear in mind is that living protoplasm is the survivor in the struggle for existence against the forces of its environment, which has been gradually changing, so that there has been also a certain amount of natural selection in promoting slight variations in the substance. In this way, the gap between living and not-living things has gradually become more and more marked; till many types corresponding to those produced artificially in the laboratory very rapidly became extinct or eliminated in the struggle for existence with their environment.

As we have said, for anything we know there is no such thing as really dead matter, and there may be in all matter a certain amount of energy stored up 


\section{THE DESCENT OF PROTOPLASM $\quad 187$}

which would entitle it to be regarded as possessing a certain amount of potential life. Of this little is known, but analogical reasoning leads us to suppose that it is so. The line of argument we have followed, and the illustrations obtained of the forms generated in the course of experiments showing their behaviour in their development, growth, multiplication and decay, suggests that living matter itself was most probably a distant relative of other types less obviously animate, and that it was produced by some similar process through the unstable aggregations of matter similar to but not the same as the unstable aggregations which produce radio-activity, and which in turn radio-activity produces in highly complex media. Forms we have obtained are analogous to living types and may, as we say, be called artificial forms of life, but they are not the same as life as we know it to-day; they may help, however, to fill in some of the gaps between living and dead matter.

The principle of biogenesis supported and almost conclusively established, though not completely so, by Pasteur and Tyndall, the principle that life as we know it has developed only from pre-existing life, may still no doubt hold good. If these artificial forms are alive it is not life as we know it in nature. It is not life which can claim descent from the remote past, and it is not life which will hand on its own type to the distant future. The idea that we should ever produce such living protoplasm as we see to-day in nature, that the 


\section{I88 THE ORIGIN OF LIFE}

protoplasm should be evolved from inactive matter in the laboratory, seems extremely improbable. There is but one step from the artificial to the natural, and it is a step that by artificial means we do not think we shall ever be able to take. The gap is insurmountable, and the most we can hope to accomplish is to fill in a few of those gaps in the chain of evolution. That is what we have been endeavouring to do. We do not think that science for many days to come will be successful in filling all the gaps. But it may continue day by day to furnish a new link, philosophically speaking, between living and so-called dead matter.

If these experiments, then, do not bear directly on the problem of the origin of life, they at any rate do bear indirectly upon it.

In this way too the question of that origin seems to us to be involved with many other questions, such as the origin of mind, the origin of consciousness, and perhaps even the origin of conscience too, as the direct outcome of natural development of a struggle between the individual and its surroundings, by promoting such as are often merely accidental variations, but which happen to be most adapted to them. We may regard in a certain sense a certain amount of psychical as well as vital, chemical, and physical phenomena of the most elementary type to be inherent in all matter. Ours is merely a middle nature, between the infinitely great and the infinitely small, between the infinitely complex and the absolutely simple. 


\section{THE DESCENT OF PROTOPLASM $\quad$ I 89}

And it is possible to regard the atoms of which matter is composed as bearing the same relation to the cells of the physiologists that these cells do to still more complex living organisms. In the sense in which we have used the words we do not see any reason to look beyond the material basis of the inquiry. There are material aggregations as permanent as any of us would wish them to be, and our expectation of the existence of a soul which survives what we ordinarily call death is quite consistent with the monistic view of Nature. It all depends upon what we mean by matter. The fear that human life would lose its sweetness and its strength if this doctrine of monism were true should scarcely apply, for are we not such stuff as ideas are made of and our little selves mere groups of stable or unstable aggregations of units of that stuff? And is it not possible that the most stable of these may persist when we have shuffled off the more unstable portions of this mortal coil ?

To those who understand the problem it does appear that, whatever atoms may really be, we certainly are merely spirits, units that react and commune with one another. Here, of course, we reach the limits of natural knowledge: the reader who wishes to go beyond the question of our descent from the primordial substance will take counsel of the metaphysician. Length of life is only relative, and even such stable aggregations as the chemical atoms finally break up and go 
to bits. But it is possible that mind may be associated with some types that will persist beyond the dissolution of our mortal frame. It may be that that unity of consciousness has its physical analogue in some phenomenon in the rther which can no more be created than it can be destroyed, like a vortex ring or filament in a frictionless and perfect fluid, which the rether is supposed to be. These points are mentioned merely to remind ourselves that our descent from protoplasm and its descent from simpler matter need raise no fears as to our future state.

For our own part, although such coherency on the part of Nature has, as we think, been the result of her natural course, there does not appear to be anything in this conception, strictly speaking, antagonistic either to theism in its highest sense. Why should we not regard the play of physical forces as the mode of action of the Divine Mind? The purely scientific aspect of things admits of being interpreted in either way. And it is beyond the purely scientific that we must look for the solution of this question. This remark is made to clear the atmosphere of fears or misapprehensions that the strictly dynamical and consistent view of things involves any real antagonism to the theistic view of Nature. 


\title{
CHAPTER XI
}

\author{
SPONTANEOUS GENERATION
}

Three states of electronic aggregation-Spontaneous generation a problem like that of perpetual motioncannot be demonstrated-Views of Pasteur and Weismann-Objections to Pasteur's results-Views of Bastian-J. Arthur Thomson - Haeckel-Bastian's heterogenesis-Method of filtration - Japp's views on asymmetric structures-Asymmetric structure of biogen-Origin of asymmetric structure as profound as that of life-Karl Pearson and FitzGerald on climate as a factor in producing asymmetry.

From what has been said the term spontaneous generation admits of more than one interpretation, and the sense in which we use it must not be understood to mean the development of life from the absolutely lifeless. On the contrary, as we have endeavoured to show, there is a continuity throughout the whole realm of Nature and the various scales or orders of magnitude of which natural phenomena take place. There is, as we say, a continuity in vital processes, and the phenomena of the building up and breaking down of integrated units take place in an ever simplifying scale throughout the Universe. In the phenomenon of life in protoplasm it manifests itself in a 


\section{THE ORIGIN OF LIFE}

most complex and most marvellous manner, though in a similar way analogous phenomena are to be found in a much simpler degree in other realms of Nature.

We have seen that the development of these organic structures admits of being illustrated by purely dynamical conceptions. By regarding biogen as the intermediate stage between matter, crystallised electricity, if we might call it so, and free electricity or electrons in the so-called gaseous state, we can arrive at a conception of a notion of a state of electricity which is neither matter nor electricity as we understand these, but an intermediate state which is or may be regarded as being the primordial substance to which life is due.

Not merely have we electrical phenomena and material phenomena, but a class of phenomena intermediate between these two as much phenomena of electricity as matter itself.

It has been said that life is as much a phenomenon of matter as electricity is. More clearly, life and matter are merely different phenomena of electricity, matter being merely the fossilised state of biogen, and life of the phenomena which take place in biogen in that stage through which electronic aggregations have to pass before they are converted into the crystalline forms of electrons which we call the chemical atoms of matter. The three states of electrons may be the purely electrical, when they are perfectly free; 


\section{SPONTANEOUS GENERATION I93}

the living state or biogenetic state when they form a highly complex aggregate, and the material state when they are finally condensed into definite forms like crystals corresponding to the free states in which the atoms of matter in a much larger scale are also to be found, namely, the gaseous, the liquid, and the crystalline or solid states.

Organic or cellular life as we see it at the present day is thus the result of the physical and chemical properties of biogen, and not of its chemical properties alone. The formation of such cells is what is generally called spontaneous generation, and the current belief of the present day is that such cells are never to be found except as the descendants of other cells.

Pasteur in his investigations on the floating matter of the air arrived at the conclusion that living organic matter is always the result of previously existing living organic matter, and Tyndall, in his similar investigations, expressed a similar belief "that it is unlikely that the notion of bacterial life developed from dead dust can ever regain currency among the members of a great scientific profession." "Omne vivum ex vivo" was their dogma. Dr. Bastian, on the other hand, has consistently maintained that life does spring from the apparently lifeless, although how he shows or can show from his experiments that invisible organic germs have been destroyed is not apparent. In fact, this is Weismann's great difficulty in accepting any proof of spon- 


\section{I94 THE ORIGIN OF LIFE}

taneous generation on such lines as Dr. Bastian and his colleagues in the past have adopted. There may be, in our opinion there most assuredly are, organic types quite invisible under the highest microscopic powers at our disposal to-day. But even if they were visible it would not get over the diffculty that the principle of metabolism is continually simplifying, and will be found to occur even when we get beyond the atomic to the electrical substance, which, as we have endeavoured to show, should, in certain states, manifest in the most elementary degree the first stages of the phenomenon of life.

Thus it seems to us that the problem of spontaneous generation resolves itself into as great an absurdity as the problem of perpetual motion; and as those who think they have arrived at a satisfactory solution of the latter problem will before very long find themselves running counter to the principle of the conservation of energy; so, on the other hand, those again who share a like enthusiasm for the notion of spontaneous generation, will doubtless find themselves encountered with somewhat similar difficulties. How can it be ascertained that all forms of life have been destroyed? Most assuredly it can be asserted that in certain circumstances organic forms can be destroyed, but it cannot be shown that ultra-microscopic or even ultra-atomic types of organic or inorganic life do not still remain.

The experiments of Pasteur, however, do not throw so much light upon the subject as might at first be 


\section{SPONTANEOUS GENERATION 195}

imagined. For, when spontaneous generation apparently takes place, it can be maintained that previously existing life still remained, when the results are negative, as in the case of Pasteur's experiments, the opposition has a stronger case because no doubt the conditions under which life could have been originated might, in the circumstances or conditions under which the experiment was made, have been sufficient to prevent the phenomenon from taking place. Furthermore, even if the conditions are not such as to prevent a reappearance of life, that reappearance may take many years or centuries or, forsooth, æons in which to assert itself. And thus such experiments cannot, strictly speaking, be regarded in either case as quite conclusive.

When, however, such forms as may reappear in experiments with positive results are totally different from anything that may have existed therein beforehand, there surely is no room for inference other than that of the transmutation of some germ or germs not totally destroyed; or, if destroyed, of course the spontaneous development of something new. Between these, it is not easy, even if it should be possible, to decide.

The subject of spontaneous generation has been perennially discussed, and by none more consistently than by Dr. Bastian since his work on the Beginnings of Life, already alluded to, was published more than thirty years ago, as well as amongst other works in his studies of heterogenesis published in 1903. He has pleaded, and pleaded strongly, in 


\section{96 THE ORIGIN OF LIFE}

favour of the doctrine of the generation of life de novo.

Professor J. Arthur Thomson has emphasised the theory that protoplasm may even at the present day be slowly forming, but in very small quantities, too small indeed to be perceived. $\mathrm{He}$ is, however, in no way dogmatic on the subject, believing, as he does, that the facts within the knowledge of the biologist are insufficient.

Haeckel is another great believer in the doctrine of spontaneous generation, chiefly on account of the bodies he has called monera, which he regards as the lowest forms of organisms although, as we have said, they are really probably far more complex in their nature than has been supposed. He bases his belief on the fact also that highly complex organic compounds can be synthesised from inorganic bodies. These bodies, to which Bathybius was said to belong, called by him the protistæ, are supposed to constitute the borderline, so to speak, between the organic and the inorganic and a kingdom in itself higher in the scale of being than the mineral kingdom and the link between it and the vegetable one.

The various types of monera, however, have been found to fit in with other groups of higher structure, and although forced, as he seems to have been, to abandon the kingdom of protistæ, he still maintains that monera correspond to the most primitive or most elementary forms of life which arose when water was condensed upon the surface of the earth. 


\section{SPONTANEOUS GENERATION 197}

Dr. Bastian, in his recent work already referred to, a note on which appeared in the Proc. Roy. Soc., 1905 , describes his observations on what he regards as the development of certain ciliated infusoria from the eggs of a rotifer. He looks upon such development as an instance, a remarkable instance, of heterogenesis. This extraordinary suggestion, strange as it may seem at first sight, would not be more amazing than that organic life in certain media should have originated from mineral or inorganic matter. $\mathrm{He}$ has found that under various conditions the egg of a rotifer can divide up into otostomata, into amœbæ, and into flagellate monads. All this is very interesting, but it has been received with scepticism by the scientific world, as original discoveries always have been and ever should be.

Dr. Bastian, objecting as he very rightly does on some of the grounds we have given to Pasteur's experiment, has adopted the course of filtering instead of that of sterilising. This method is one again which is open to similar objections, although it has the advantage that it does lead to positive results. Sterilising, if it did lead to positive results, may still be open to the objection that some germs totally different from those which have been eliminated have survived. The method of filtration does not give us that satisfaction, because in this case germs of the same kind as the larger ones that are eliminated may still get through. It is by no means certain that the method of filtration will eliminate even those forms of life 


\section{I98 THE ORIGIN OF LIFE}

which we already know, as sterilisation would, since it is merely a question of size, and those germs which have not yet grown to a sufficient size may not be eliminated.

He has answered his critics, who have repeated these filtration experiments with negative results, by pointing out that bacteriological filters do produce in organic liquids which have passed through them chemical changes of a similar nature to those produced by heat, so much so that with one filtration, it is said, positive results may be obtained which are rendered impossible by two or three filtrations. This seems to us to leave the subject very much where it was so far as the appearance of life de novo is concerned. But where heterogenesis has actually been seen, if these ciliated infusoria are really infusoria and not merely artificial bodies which resemble them, the phenomenon must be admitted to be most remarkable. Dr. Bastian, in his more recent work, would no doubt be able to throw more light upon the subject. ${ }^{1}$

To turn to the opposite school, Professor Japp, in his famous British Association Address, has emphasised that Pasteur was led to entertain his predilection for biogenesis chiefly on account of the difficulty which he experienced in explaining the origin of the behaviour of the tartrates.

1 Dr. C. W. Saleeby's book on this subject is expected in the course of the next twelve months or so: it will doubtless contain valuable contributions to the discussion of the subject, 


\section{SPONTANEOUS GENERATION I 99}

Japp remarks that physiologists are naturally more attracted to Pasteur's subsequent work, in which the biological element predominates; in fact, he doubts whether many of them have given much attention to the earlier work. And yet it ought to be of interest to physiologists, not merely because it is the root from which the later work springs, but because it furnishes, he is convinced, a reply to the most fundamental question that physiology can propose to itself, namely, whether the phenomena of life are explicable in terms of chemistry and physics; in other words, whether they are reducible to problems of the kinetics of atoms or whether, on the contrary, there are certain residual phenomena, inexplicable by such means, pointing to the existence of the directive force which enters upon the scene with life itself and which, whilst in no way violating the laws of the kinetics of atoms-though indeed acting through these laws-determines the course of their operation within the living organism.

This latter aspect of the question is what is generally understood by vitalism.

Pasteur's view was that compounds which are optically active, that is, have the power of rotating the plane of polarisation of light right-handedly or left-handedly as the case may be, were never obtained except by the intervention of living substance, and, as Japp remarks, hardly any experimental method of fundamental importance for the separation and transformation of optically active 
compounds has been added to those described in "Pasteur's Classical Researches." Pasteur was in advance of his time, and his theory of molecular asymmetry was a seed that lay for many years in the ground without germinating. The theory of the asymmetric carbon atom has been before the scientific world for a long time. Viewing the matter from a purely physical standpoint, it does not appear that the explanations so far offered, from a physical point of view, are really altogether satisfactory. It has been suggested repeatedly that the carbon atom has a twisted structure, but from a purely physical point of view it may be said once more that the statement is scarcely satisfactory; something further is required to put the matter on a dynamical basis.

In view of the theory which we have put forward the elements which constitute biogen bear the same relation to the more stable chemical elements, their mode of aggregation, their systems of electrons, that nebular condensations do to solar systems. The former should admit of spiral forms and those substances in which the atoms have a spiral structure, as little spiral nebulæ of electrons whose period of existence is very long and stable would no doubt be optically active. It thus appears that it is amongst such biogenetic substances that the optically active atoms or those having a distinct twisted structure are to be found, though the atoms of the ordinary elements appear to be symmetrical. 


\section{SPONTANEOUS GENERATION 2OI}

The connection which Pasteur has emphasised between living and optically active substances is thus one which has a physical signification. The atoms of living substance or biogen are, as we have said, those which have not yet condensed or been transformed into actual elements. Their form should appear, from their astronomical analogy, spiral, or more accurately, corkscrew shape. An atom composed of electrons which assume this corkscrew configuration would no doubt rotate the plane of polarisation of light which was transmitted through it; the reason being that since plane polarised light is made up of two circular vibrations in opposite directions, the effect of increasing or diminishing the rotation of one relatively to the other is equivalent to rotating the plane of vibration of the total effect (see Preston's Theory of Light or any other similar work). Therefore, if the atom has a corkscrew structure, let us suppose a right-handed one, the effect will be to retard the right-handed vibrations and let the left-handed ones pass unaffected: the effect will be a rotation of the plane of polarisation of the resultant vibration.

This conception helps to give us a clue as to the dynamical connection between the phenomena of vitality and those of optical activity.

Japp regards the chance synthesis of the simplest optically active compound as absolutely inconceivable. $\mathrm{He}$ arrives at the conclusion of the production of single asymmetric compounds or their isolation from the mixture of their enantio- 


\section{THE ORIGIN OF LIFE}

morphs-an enantiomorph being a right-handed or a left-handed atom-is, as Pasteur firmly held, the prerogative of life. Only the living organism, with its asymmetric tissues, or the asymmetric products of the living organism, or the living intelligence, with its conception of asymmetry, can produce this result, and only asymmetry can beget asymmetry. And again, he asks, "Is the failure to synchronise single asymmetric compounds without the intervention direct or indirect of life due to a permanent inability or merely to a temporary disability which the progress of science may remove?" Pasteur took the latter view and suggested that the formation of chemical compounds in the magnetic field or under the influence of circularly polarised light would furnish a means of solving the problem; van't Hoff also thinks the latter method feasible. "As regards magnetism Pasteur's suggestion was undoubtedly based on a misconception; the magnetic field has not an asymmetric structure, it is merely polar, since the rotation which it produces in the plane of polarisation of a ray of light changes sign in the direction of the field." As regards circularly polarised light, he is forced to confess to having doubts as to whether it can be regarded as an asymmetric phenomenon, the motion of the æther above the axis of the ray being circular, not spiral, but it is only by considering the difference of phase from point to point along the ray that the idea of the spiral can be evolved from it. In fact, are there such forces asymmetric 


\section{SPONTANEOUS GENERATION 203}

in themselves in the geometrical conception of asymmetry applicable to dynamical phenomena at all except in so far as these deal with asymmetric material structures such as quartz, crystals, or organic molecules containing asymmetric carbon atoms? He thus recapitulates the conclusions at which he arrived that "non-living asymmetrical matter-the matter of which the inorganic world is composed-interacting under the influence of symmetric forces to form asymmetric compounds always yields either pairs of enantiomorphous molecules or pairs of enantiomorphous groups united within the molecule, the result being in either case mutual compensation and consequent optical inactivity. The same will hold good of symmetric matter interacting under the influence of asymmetric forces, supposing that such forces exist, provided that the latter are left to produce their effect under conditions of pure chance." If these conclusions be correct, as he believes they are, "then the absolute origin of the compounds of onesided asymmetry to be found in the living world is a mystery as profound as the absolute origin of life itself. The two phenomena are intimately connected, for, as we have seen, these asymmetric compounds make their appearance with life and are inseparable from it."

Pasteur, for similar reasons, held the belief that asymmetric compounds could not arise except under the influence of life.

Karl Pearson and FitzGerald, on the other hand, 


\section{THE ORIGIN OF LIFE}

have discussed the weakness of Professor Japp's argument. The chances are that living matter, if it started from some few centres, would not be equally divided between right-handed and left-handed forms, but that one or other of these forms preponderated, and if it started from one source alone it must have been either right-handed or left-handed. Hence, as FitzGerald remarks, the facts adduced only show that life, or rather what we understand here as organic life, originated from a small number of centres, and possibly only one.

All these considerations are, we think, surmounted by attributing to that substance which we call biogen a particular twisted structure. The probability is that of these asymmetric twisted atoms of biogen, the numbers of those which are right-handed and left-handed would not be exactly equal, and one or the other would preponderate.

Whatever aspect we may take of the problem of the origin of life, it seems to us that that problem does resolve itself, not merely into that of the origin of asymmetric atoms, but also of the origin of that substance which in the course of time has assumed a simple and symmetric form.

\section{On Structural Organic Synthesis.}

The synthesis of natural life, of that phenomenon which we see taking place around us in the form of living proteid, has, as we find, hitherto eluded our grasp. We may say this with all due deference to 


\section{SPONTANEOUS GENERATION 205}

Dr. Bastian. His results are most remarkable, and deserve to be studied with the greatest care. As a veteran and experienced worker, and a thinker, too, he commands that consideration which is his due, whatever our opinions may be as to the inferences which he has drawn from his observations, or even as to the precise nature of those observations themselves. They are, as most people would admit, most careful and most detailed descriptions of what he has himself observed, and though difficult to account for, our preconceived notions must give way if the logic of his facts can supplant them. There remains much room for the discussion of his observations before the doctrine of spontaneous generation can be accepted as a fact. As we have said, the line of argument as well as the method of experiment we have ventured to pursue are quite different, and our experiments have not led us to suppose that life de novo is a phenomenon which it is our privilege to see to-day. Those forms we have obtained cannot be identified with any types of living things we see around us, using the word life for that phenomenon of metabolic change in protoplasm which can give rise to assimilation, growth, perfect reproduction and decay. But if the word life be extended, as we have tried to extend it, to the phenomena of metabolism generally; and if it is admitted that in those forms, those purely artificial forms, which we have obtained in the laboratory, and which in a similar manner can perform, in the 


\section{THE ORIGIN OF LIFE}

outline at least, those processes which in a higher and more complicated degree are also performed by that which in a more restricted sense is called living protoplasm, we see not why, although spontaneous generation of living protoplasm may not occur at the present day, it should not have occurred in the remote past and under similar though somewhat different conditions from those in the laboratory; in a word, that this method of approaching the problem affords a means of synthesising life like that in living proteid though it differs from it widely.

The artificial synthesis of cells that can in a like manner assimilate from their surroundings, or perform the function of nutrition, which can grow, reproduce themselves and then decay or die, is, strictly speaking, artificial life. This may or may not be the same as natural life, but still there is no reason why it should not be regarded as a mode of life, and in view of the widespread nature of metabolism there is no reason why these cells should not be regarded as corresponding in the scale of being to forms of life which serve to bridge the gap between the animate and the inanimate. In fact why they should not be types which have thus served in the remote past to fill those gaps that have once existed and have long since ceased to be. Of the indefinite varieties thus formed few, very few indeed, could have had the power and the properties to resist all the opposing circumstances of nature; and it will therefore be 


\section{SPONTANEOUS GENERATION 207}

clear that the proposal to fill or to replace those gaps which we now see no more is the course which men of science at the present day would find most fruitful to adopt.

It is therefore by the artificial synthesis of highly complex compounds, and the artificial production of cells from them, that progress seems to us to lie most hopefully in view. And apart altogether from the artificial synthesis of these compounds, given the substances, provided they have been properly sterilised, the artificial synthesis or construction of cells from them is a step onward in the right direction.

We have shown how it is that the action of certain salts under certain conditions on gelatinous substances can give rise to the formation of such cells-of cells which have all, or at any rate most, of the properties which are associated with vital processes. We see how it is that by the action of radio-active bodies the effects if carefully attended to can show a still more approximate imitation of the vital processes which of their own accord present themselves in nature. We see that the process of metabolism, not confined to living protoplasm alone, is a phenomenon of as wide an application as it is of wide significance, and that it can take place in certain circumstances under the action of radio-active bodies.

The formation of such cells by the action of salts on gelatinous media is the result of a highly complex molecular process. These cells are produced, 


\section{8}

\section{THE ORIGIN OF LIFE}

as we have described in much simpler instances, as in the case of foam cells, by mixing two salt solutions of different strengths; they are also produced by the action of potassium ferrocyanide on gelatin, and even by the action of common salt upon certain kinds of ink, notably China ink, as Luduc has shown, and, again, liquid crystals, as Lehmann has found, which can be formed in certain organic bodies of complicated organic structure. The liquid bodies shown in the figures prepared for the most part from $p$-azoxyphenetol under various conditions exhibit the effects of crystals on polarised light. They have the power of sub-dividing and of influencing foreign bodies. The appearance of these bodies is most striking and beautiful, as the photographs distinctly show.

On the other hand, the bodies produced by the action of radium resemble not merely in their appearance, but also in their behaviour, the types of bodies which protoplasm can give rise to. And if the substances which we have postulated in a similar manner constitute biogen, by their interactions with protoplasm it should form still more complex aggregations approximating more closely to cellular and proteid life.

It is often stated that chance will account for the production of the necessary asymmetry, but as a matter of fact it seems more probable that a directive action, subject however to the dynamical laws of nature, has played a part even in this. If one tosses a penny a number of times over, 


\section{SPONTANEOUS GENERATION 209}

provided the number of times be sufficiently large, the probability is that the number of heads will be the same as the number of tails. If, however, there is some other force operating, the element of chance may be greater for one than for the other, as, for instance, if a piece of wax or crumb adheres accidentally to one side of the coin; and this apparently directive tendency would of course be consistent with the forces of nature. The tendency for one rather than the other to occur is merely the result of some accident, and we do not know all the conditions in the remote past under which right-handed and left-handed atoms have been produced. There remains the possibility, therefore, not to say the probability, that some such directive force, as natural as any other force we have to deal with, took part in producing one effect rather than the other. And we have no reason to suppose that the mode of production of right-handed and left-handed enantiomorphs was, strictly speaking, the result of mere chance, but that there was some accidental force which tended to produce one instead of the other.

Now, guidance frequently attributed to ultramaterialistic or spiritualistic sources seems to us to be based somewhat on a misapprehension. These directive phenomena, whatever they may be, if they can exert force upon matter, do concern us so long as in the study of nature they form part of the dynamical connections of the Universe. If it is stated or implied that they can exert some action 


\section{THE ORIGIN OF LIFE}

on matter, without matter reacting upon something, then of course we go beyond the limits of a dynamical theory. There is no reason to suppose, however, that any such phenomenon occurs and we should prefer, in fact we see no reason for refusing to do so, to regard the so-called spiritual world as a part of the dynamical system of the Universe. Sir Oliver Lodge would no doubt give his assent to this, and in that spiritual world we should expect to find new forms, new manifestations of energy.

We do not think that Haeckel, on the other hand, if cross-examined, would limit his monistic views to matter of the kind the physicist and chemist till recently understood by that word, but rather, we feel confident, that he would be willing to extend his views, not merely to the material atoms and molecules, but to the immaterial, ultra-material, ethereal, spiritual or anything else we may wish to call it, so long as the connections between these things were admitted throughout to rest upon a dynamical foundation. By that we mean that they follow the relation of cause and effect, the cause being the invariable and unconditional antecedent of the effect, so that relatious exist which admit of being ultimately expressed by means of equations of motion. To go beyond that seems to us to be equivalent to replacing the scientific aspect of the Universe by something mystical and unintelligible, not to say unknowable.

It must be admitted, however, that this craving 


\section{SPONTANEOUS GENERATION 2II}

for a unity and relation of a permanent character in all things may have no philosophical foundation other than that of being an instinct which forms the basis of our comprehension of things generally. And the notion that all things should be intelligible if we only knew enough to understand them, is a perfectly reasonable frame of mind. To deny this would be equivalent to assuming, as Herbert Spencer did, the existence of an unknowable. In his Presidential Address to the British Association at Cambridge, 1904, Mr. Balfour emphasised the fact that this craving for unity in all things may be none other than the result of natural selection. And that the "intense intellectual gratification" which we derive from the perception of that unity and relationship in Nature, owes its origin to the fact that healthy minds, that is minds suited to their present environment, happen to possess that quality. The philosophic attitude of mind does not appear, directly at least, to be most useful to our ordinary environment, and why it should have survived is not apparent unless it be a necessary correlative of that faculty or faculties which enables us to adjust ourselves to it, that is the faculty of common sense.

It is therefore admissible that this unity and relationship, which we regard as the basis, not merely of science, but of all knowledge, may have no basis other than our frame of mind demands. If so, then the expectation that the so-called material and the so-called spiritual or ultra-material 


\section{I2 THE ORIGIN OF LIFE}

phenomena are connected by links of cause and effect: in a word, that the Universe, known and unknown, to us forms one consistent and harmonious whole, is only a faculty of our nature, like that of fellow feeling or the love of truth, though it should admit of a passion equally intense. Else it should be a system which admits of no interpretation whatsoever and have no rational foundation.

The problem of the origin of life, even if it should imply directive forces, would therefore not on that account lie beyond the limits of the knowable, or, in other words, of the intelligible world. 


\section{CHAPTER XII}

THE MECHANISM OF LIFE

Two opposing principles in vital processes; the constructive and the destructive-Mode in which metabolism is kept up in the cell in consequence of the electrical and radioactive properties of the nucleus-Artificial cells merely models, but yet give a clue to the nature of the mechanism in natural ones-Biogen hereditary substance-Nature of this substance.-Biogen the transition stage between free electricity and condensed electricity or atomic matterAstronomical analogue-Constituents of protoplasm the lightest elements-Bearing of this on the origin of protoplasm-Two kinds of biogens.

IN the remotest times vitality was looked upon as the result of opposite contending principles of strength and of weakness, of growth and of decay, of life and death. Like the two ppinciples of good and evil, they were supposed to be continually contending with each other. The deity was supposed to be continually struggling with the devil. In more modern conceptions an analogy still exists, for vitality, which has been described as a series of fermentations in catalytic actions, is ultimately found to be a metabolism, the building up and breaking down of molecules. So that it is also 


\section{I 4 THE ORIGIN OF LIFE}

the result of two opposing principles, the constructive and the destructive.

In organic life this metabolism is always accompanied by the cellular structure. There are cellular structures without metabolism, and there are metabolic actions without cellular structure; organic life is the unique combination of these two.

On the other hand, our idea of the cell admits of considerable modification, and, as has been said, the molecules themselves may be regarded as such elementary bodies. With this extension the atoms and molecules can be regarded also as the seats of a certain amount of metabolic change. For even the atoms themselves may be looked upon as minute organisms of other and far smaller units. In this way the continuity in the process is found to exist, and many phenomena, strictly speaking physical, would come under the realm of biology by the striking resemblances which they thus exhibit between physical and biological effects: as links which serve to connect the organic with the inorganic or living with apparently dead matter. As we have said, the luminosity of flames, as well as that of phosphorescent and fluorescent bodies, appears to be due to the building up and breaking down of highly complex molecular aggregations, so that these too, it would appear, come under the class of metabolic actions, although, of course, of a far simpler kind than any which take part in living processes as familiarly understood. This idea of the mechanism of vitality 


\section{THE MECHANISM OF LIFE 2 I 5}

presents a more intimate relationship between biology and physics-if it does not actually suggest the possibility of a new branch of science such as bio-physics. Whilst it helps to modify our idea of life in its most elementary sense, it helps also to place it upon a more physical and dynamical basis.

We have defined life as a specialised mode of motion, the specialised mode of motion being that of a complex system of molecules in a dynamically unstable state, so that there is a continuous or continual change or flux in its substance between the individual aggregates and their surroundings.

It has been shown that the structure of the cell, its growth and subdivision, can be explained on the supposition that within the nucleus there is a substance whose properties are somewhat similar to those of the emanation from radium. That, of course, would not explain the metabolism of the cell. The metabolism, however, might be explained, as a cell has itself a minute structure and becomes manifested when the metabolism is a molecular phenomenon. The swift passage of numerous electro-magnetic pulses from the nucleus outwards may be sufficient to produce a series of molecular interchanges equivalent to those which take place in phosphorescent and fluorescent bodies, whilst there would also be lines of flow relatively to the structure of the cell in which the metabolism would take place. The radiation from the nucleus would be radial, and the intensity of 


\section{I6 THE ORIGIN OF LIFE}

its effects would depend upon the quality and the nature of the matter traversed. Thus the amount of metabolism could be mapped out relatively to the centre or nucleus. The assimilation would no doubt depend largely upon the nature of the cell walls, and where there is absorption of certain substances in preference to others it is the result of electrification of the nucleus which would thus attract to itself those ions which carried the opposite charge.

It thus seems that the flow and flux in cellular bodies can ultimately be traced to the electrical properties of the substance in the $n$th or ultimate nucleus. The cell should be regarded as made up of smaller and smaller structures until we get to the molecules and the atoms themselves, and even these would seem, in the light of recent investigations, to be structural bodies too. Thus a comprehension of the nature of the whole process really resolves itself into a complete understanding of the mechanism which goes on, not merely in the cell itself as a whole, but also in its constituent parts. This understanding, however, we cannot hope to arrive at, and we can only endeavour to picture to ourselves roughly at least an idea of what that mechanism may be.

In the limit-using the word in its mathematical sense-we find that the phenomena of metabolism ultimately resolve themselves into the phenomena of purely physical metabolic interactions. The evidence for this will become more 
and more distinct as we come to see that in many substances such types of physical metabolism are slowly but continuously taking place.

We shall see that by the action of cathode rays on fluorescent bodies a kind of metabolism takes place, and that the effect of glycerine and gelatin on solutions of these bodies is to lengthen or increase the period of duration of the individual molecules produced by the electro-magnetic pulses or waves set up by the bombardment.

Now a cell with a radio-active nucleus would have such disturbances taking place in it. And as electrons are continually shot out from the nucleus, such disturbances as accompany them should give rise to the kind of physical metabolism we have described. The cell would be the seat of a continual process of building up and breaking down of molecular groups, and this process would be more or less symmetrical relatively to the nucleus.

The metabolism is not merely a make-believe in the shuffling of molecules; for the strong electrification of the nucleus and the ionisation which accompanies the radiation from it will tend to draw towards it matter from the surrounding medium, and thus assimilation and growth will ensue. The flow of matter being radial too, there will be a certain amount of exchange or give and take between the cell and its environment; but just as some ions are drawn in, others are driven out. Those taken in will exceed those 


\section{I8 THE ORIGIN OF LIFE}

given out in the earlier stages of the cell's career. In the course of time, however, there will be a balance, and the growth of the cell will cease. The substance in the nucleus will go on increasing assuming that it is like an emanation, so that the nucleus will in the course of time reproduce, and this in turn will increase in size and produce a strain within the cell of the kind it observed in the phenomena of karyokinesis. It will thus force the sub-division of the cell, the newly formed nucleus being the nucleus of the newly formed cell. And this in turn can again repeat the same process.

If the charge of the nucleus changes sign, as might easily happen if an excess of ions of the charge opposite to that which it originally had gathered round it, then the cell should begin to part with some of the substance which it had absorbed. Nay, more, if the radiation from the nucleus ceases, metabolism of the cell will in the course of time cease too, as in the case of phosphorescent bodies and the flow of matter stopping, the cell would degenerate and ultimately die. In other words, we should observe a complete cyclic process with reproduction in such artificial cells. Such metabolism with nutritive properties is what cells possess.

Still, such artificial cells would be merely models of the natural ones. We should not have sufficient reason to suppose that the actual metabolism or chemical changes which take place within them are 


\section{THE MECHANISM OF LIFE 2 I 9}

the same. The artificial cell, however, would possess the properties, though merely physical ones, which would entitle us to attribute some form of life to it. Once more, then, we see how near we may approximate to the natural phenomena and yet how far we remain from the actual thing; perhaps, indeed, as far as ever. Still, it is something to approximate even if we do not reach the end. "To travel hopefully is better than to arrive, and the true success is to labour." Those artificial cells may never, and we think will never, bring us to the goal; but in thus travelling, in thought at least, with the progress of these ideas we may arrive at a clearer comprehension as to what the nature of that goal shall be.

The element which we suppose to constitute the material of the ultimate nucleus is thus the hereditary substance. It is generally held that protoplasm does not contain the necessary hereditary material. Reference has already been made to the experiments of Boveri. Amongst others who would agree with this view are Weismann and Hertwig, who postulated such an hereditary substance. The point that it has been our object to explain is that such substance, if it possessed properties akin to those of the unstable elements, would also account for the formation of the properties of the cell. No doubt there would be a great variety of such substances, particularly on account of their unstable nature. We have seen that other elements than radium can produce 
artificial cells in gelatin media. But as the element is more unstable, the analogy to living forms becomes more marked. So that by the method of extrapolation we may reasonably hope to reach ultimately those substances which in a similar manner produce cells which might very appropriately be said to be alive.

We have seen that by the presence of such substance or substances in the nucleus the process of metabolism can be maintained. In such instances as have been mentioned the metabolism is purely artificial, and it does not seem as if it were much more than a secondary effect. But this is not so, since the assimilation would depend upon the separate molecular aggregations formed, which would influence the catalytic interactions in the cell itself. Living proteid is protoplasm under the influence of these disturbances, which keep the molecular and atomic interactions, that constitute metabolism, going.

The question then arises, and very naturally so, as to whether these metabolisms are of the same nature as the metabolisms which living proteid actually undergoes. The answer is that the cells in one case, namely the artificial ones, can be regarded as nothing more than models of the original in nature. The labile constitution of living proteid, as distinct from the state of stable equilibrium of dead proteid, may be accounted for in some such way, but whether the actual chemical changes are the same it cannot, of course, be said; 
although it is probable that they should be different if the metabolism is merely due to the radiation from the electrical properties of the nucleus. But this will also have, in addition to its electrical and radio-active or electro-magnetic effects, its chemical effects too. And if its chemical properties resemble those of cyanogen, then we should have, as Pfluger has pointed out, many, if not all, the chemical properties of living proteid as distinct from dead proteid.

It is therefore on a combination of these causes, of the radio-activity of electrical and electro-magnetic effects, of the diffusion of electrified particles or ions and the chemical properties of the nuclei, together with the metabolic and catalytic actions which are thus set up in the cell in.virtue of those other actions, that the vitality of the total mass depends.

With cyanogen-like molecules in the living cell, proteids, carbohydrates and fats, as also the products of their decomposition, would be formed, so that all the principal or necessary products formed in dead protoplasm would be found.

Physiological chemists have long since maintained that the reactions of living and dead substances are different, such reactions being in the former case almost invariably alkaline or neutral and in the latter case usually acid. And, moreover, there is a tendency for substances which are liquid in living cell-substance to coagulate and become solid when life ceases. The inference has been drawn that there should exist, that in fact there do exist, 
certain compounds in living substances which are not to be found in dead cell-substance. The fact that the biogens must contain a large quantity of energy and be extremely labile has long been admitted, and the analogy between them and explosive bodies has more than once been pointed out. Pflüger, as has already been mentioned, pointed out that the radical (CN) most probably exists in living substance and that it is absent in dead proteids, and it is more probable, therefore, that the cyanogen radical which is thus wanting in dead proteid is present in the biogen molecule.

Any labile and unstable compound of which dynamite is composed is decomposed by electrical means or by shocks into water, carbonic acid, nitrogen, and oxygen. The biogen substance doubtless also contains a vast store of energy, but relatively to this is far more nearly stable, though really unstable.

The question then remains, Is the biogen a compound or an element? If it is a compound it must at the same time be like the perpetually self-producing substances which we call emanation, and if it is an element it must at the same time be highly unstable.

On the whole, we have been led to think that the biogen or substance that constitutes the ultimate nucleus is something of the nature of a highly unstable element which has many of the chemical properties of the cyanogen radical; that, in fact, it is so very ill-defined as an element that the 
chemist would scarcely regard it as such, whilst its manifold potentiality and possibilities lead us to regard it as something more than a radical and therefore as an aggregation, ill-defined though it should be, of electrons constituting not so much a little solar system as the stable elements may be said to do, but a miniature sun, so to speak, wherein a vast complexity of motion is taking place: that vital substance or biogen we regard as neither molecular nor atomic, strictly speaking, but the substance from which molecules and atoms by condensation are evolved. In a word, we regard the biogens as a sort of nebula of electrons in the process of formation into atoms or elements, and we have therefore called them bio-elements; systems, however, which have already reached a state of motion which may be regarded as giving them a character of their own as their life period is very great. If the analogy between the formation of solar systems and that of atoms holds, there is obviously room for such a state of things, and as the elements would correspond to the stable solar systems, so, too, the bio-elements would correspond to the more or less unstable states of aggregation-such as molecular. Like a great nebula, the bio-element from which the human race has sprung presents a similar complexity in its structure as well as in its form of motion.

By regarding, therefore, the biogen, not as a compound radical essentially, but rather as such a complex system of electrons, we surmount the 


\section{THE ORIGIN OF LIFE}

difficulty which seemed to weigh so heavily upon Clerk Maxwell's mind. Such systems, on account of their ultra-atomic nature, like the radio-active elements, may withstand a considerable temperature. So that the sun itself should contain such bioelements as our planet doubtless did in the remote past, the almost dead elements or chemical atoms being the last remnants of such magnificent systems of aggregation and of motion.

This theory, which is probably quite new, is the inference which analogy, extrapolation, and experimental results have led us to draw.

We thus regard the ultimate vital substance which seems to play so mysterious a part in the phenomena of nature as corresponding to a state of matter which should be described as neither molecular nor atomic, but of matter in the process of being; a state of electronic aggregation from which matter in the course of time has been evolved, the hiatus, the borderland or critical state between disintegrated and integrated electricity. In fact, if we regard electrons in the free state as gaseous electricity and electrons condensed into atoms as solid electricity, then biogens or vital substances would correspond to electricity, or electrons in the ill-defined state between them. And the varieties of motion and aggregation of which they admit have thus their counterparts in the combination of which atoms and molecules admit. Thus in the various scales of being, from solar systems to molecular and atomic ones, down 


\section{THE MECHANISM OF LIFE 225}

to similar systems in the electronic or electrical, we see the same or similar modes of stable as well as unstable aggregation and of motion, which shows us that as in our middle nature similar systems are to be found in the infinitely great and infinitely small. It is only a question of the order of magnitude relatively to our own, and once more we may perceive that there is surely nothing either great or small but thinking makes it so.

Biogen may be regarded as the intermediate state between free electricity and condensed electricity which we call matter-the hiatus between electricity as we know it and matter as we know it; the missing link that bears

"The heavy and the dreary weight

Of all this unintelligible world."

In this way we may look upon the nuclear substance in its ultimate form as the material from which the energy and potentialities of the cell are stored and afterwards emanate. It possesses those properties which enable it in suitable environments to produce cells like the artificial ones we have demonstrated, but possesses also the power of exciting vigorous metabolism and of developing into more divers forms.

This nuclear substance, consisting of biogens or more accurately described as bio-elements is thus the basis from which the manifold properties of living things we see around us are ultimately due.

It is obvious that such a type of electronic aggregation should exist, that between the states of gaseous or free electricity, and solid or con- 


\section{THE ORIGIN OF LIFE}

densed electricity, which we call matter, there is the unsteady and unstable state which, corresponding as it would to the liquid state of electricity, and admitting as it would of various states of motion, enables it to give rise to the vast complexity of types of which such biogens seem possible.

The analogy with the liquid state of matter is scarcely adequate, and that of the nebular as compared with solar systems is probably a more happy one. It is evident that just as a solar system is the more stable product of aggregations, which once constituted a solar system, so also biogen corresponds to the substance which in the course of time becomes condensed into atoms, the order of magnitude in time for the electronic aggregations is not of days nor years but probably thousands of years.

It is curious that the four elements hydrogen, oxygen, nitrogen, and carbon, which are the principal elements in living substance, are also the simplest or rather the lightest elements of each group. And according to modern theories, these elements should be the final products of other and less stable groups of electrons.

Thus thorium, which is unstable, would become converted into another and lighter element. As uranium becomes converted into radium, so also thorium will become converted into lead and perhaps also into carbon.

It is noteworthy, however, that sulphur and phosphorus, which come next to oxygen and 



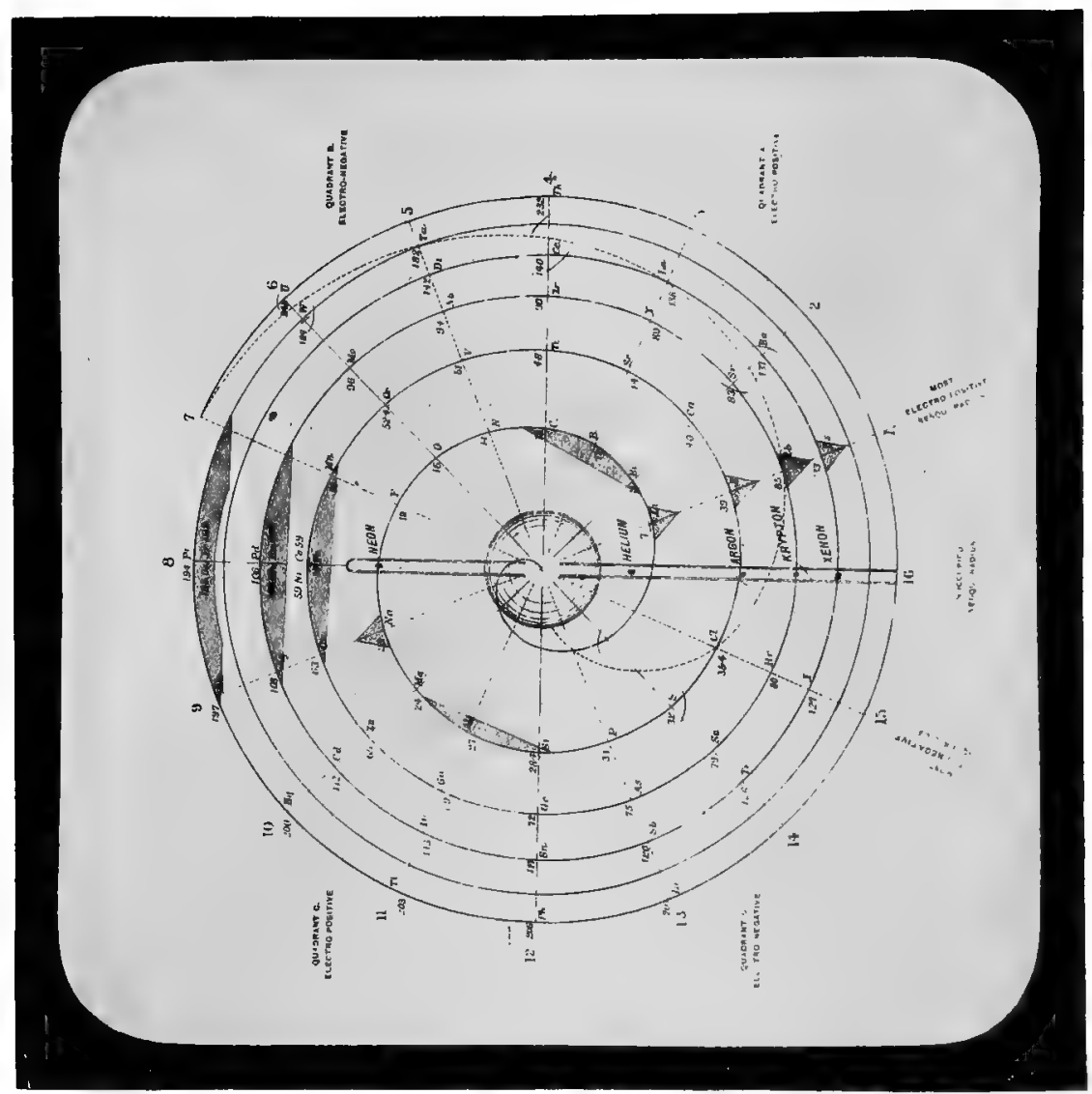

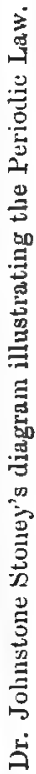




\section{THE MECHANISM OF LIFE}

nitrogen, also occur, though in very much smaller proportions, as also sodium and aluminium. There is also some iron, this being the lightest in its own particular group, and magnesium and sodium are not wanting. The group to which iron belongs, although consisting of tetrads, has many peculiarities which distinguish it from the carbon group. Iron is at any rate the lightest amongst the group of nickel, cobalt, ruthenium, rhodium, osmium, iridium, palladium, and platinum.

The rate of transformation of the elements downwards in atomic rate may depend, and most probably does depend, upon the temperature when the temperature is very high; experiments on radium emanation up to a temperature of about $1000^{\circ}$ have not revealed so far any such increase in rate of change. Nevertheless, since the constituents of protoplasm, as we have shown, most probably came together at a very high temperature, the fact that it was only the lightest elements of the groups that apparently took part in it seems to indicate that transformation took place more rapidly at that high temperature than it does at comparatively low ones. It stands to reason, in fact, that although all ordinary collisions between radio-active atoms may not be sufficient to increase their rate of disintegration, yet it should be possible by making those collisions sufficiently violent to affect that rate. In other words, by raising the temperature to a sufficiently high degree it should be possible to increase the rate of transformation.

It is curious to note that those lighter elements, 
and doubtless the most stable ones which constitute protoplasm, are also the ones which are to be found in the largest quantity. This points to the fact that protoplasm is of very ancient origin and must have been formed of at any rate that substance of which it is but the direct descendant; as radium is the descendant of uranium and probably of less stable elements, the ancestors of protoplasm must have been formed at a very early date in the history of the earth.

Cellular protoplasm, however, is doubtless of much later origin because the cells are destroyed by heat; nevertheless, it seems highly probable that the lightest elements of each group, such as carbon, nitrogen, oxygen, and hydrogen, are the products of disintegration of other highly unstable elements not yet discovered, as also iron, phosphorus, sulphur, and helium. In fact, helium we know is the final product of disintegration of radium. Those heavier elements do not necessarily, in their transformation downwards, have to pass for any length of time through each of the intermediate stages; they are most probably transformed into their more stable groups almost directly. The constituents of biogen, therefore, would seem to be, from our reflections on the subject, the unstable ancestors of these more permanent elements. Biogen, therefore, is once more either an element or a combination of elements in a highly unstable state and capable of giving rise to extremely complex organisations.

Many ingenious speculations may be framed on the 
Periodic Law in this matter. First, the table shows one arrangement in which the transformation probably takes place, commencing, as we should, with highly complex, almost nebulous, aggregations of electrons. Thus we should get the transformations of uranium in column 2, to radium, zinc, oxygen, and finally helium, and again when we get others polonium seems to disintegrate into bismuth, copper, and nitrogen, and again thorium into lead, tin, iron, and carbon, all these being corresponding series in the Periodic Law differing alternately in their electro-positive and electro-negative properties. But as regards the hydrogen series it is rather difficult; there is probably some electro-positive element to start with whose atomic weight is about 220 ; this would probably degenerate into gold, cæsium, silver, rubidium, copper, potassium, sodium, lithium, and finally hydrogen; however, we have not sufficient evidence to go upon; all that can be said is that some of the heavier elements do change into lighter ones and that the lightest of each group which form the constituents of protoplasm are most probably also the descendants of highly complex elements in highly unstable states.

The stable elements stand as the solar systems, ${ }^{1}$ the unstable elements, and notably those which we associate with biogen, being like the nebulæ in the larger scale of being.

Nay, more, we should expect at least two kinds of nuclear substance, one corresponding strictly to the gaseous, the other more condensed and capable

1 Many fluorescent bodies contain helium. 


\section{THE ORIGIN OF LIFE}

of acting as a nucleus. When these two unite the tendency will be for particles of the nebular type or negative electrons to begin to arrange themselves in a more or less regular fashion; the second, or nucleus, would be positive ions. The union of these two would constitute the birth or formation of nuclear substance with a definite character. The cells in which nebulous biogen forms the nuclear substance, or characterless nebulous biogen, would correspond to the ova, and those with the concentrated nuclear substance corresponding to the positive nuclei of atoms would correspond to spermatozoa. Now when these two cells unite and the nuclear substances also unite, that substance will acquire a more or less stable configuration depending upon the nature of both nuclear substances; as if two systems were to come into collision and rotate round each other we should then get a new type of nuclear substance, and this would be the guiding principle in the development of the newly combined cell. In a word, the union of biogen consisting of positive and negative electricity may be regarded as that which gives rise to a new system which begins to assume some stability of form. The new system thus begins a new career of its own; and once more the analogy, based upon astronomical considerations of the birth of nuclear substance to which the development of cells is due, is extensible: that nuclear substance no doubt in the course of time, most probably in the course of ages, being in turn converted into mere chemical atoms. Roughly at least, then, there 


\section{THE MECHANISM OF LIFE 23I}

is a possibility of seeing a connection between the development or mechanism to which vital phenomena are due from the mere mechanical processes which take place on a much larger scale throughout the universe.

There will no doubt be countless and innumerable such aggregates formed at a time, their nature being dependent upon the constituent biogens which have thus come together. We see a clue here to the possibility of such a phenomenon as that of heredity of the transmission of the characteristics of the two parents being reproduced in the newly formed cell. This, however, is not a question which we can attempt to enter into; at the most what we can hope to do is to propose a dynamical theory upon which the simpler phenomena may be based, or, indeed, to indicate merely how it should be possible for the phenomena to occur that would in any way resemble the phenomena of life around us. More than that, if that indeed is not too much, it would be beyond our scope to endeavour to unravel. Yet these are not idle thoughts, and heterodox or orthodox they may give a clue as to the beginning and the end of life. The point to bear in mind is that in the indefinitely small we should expect to find phenomena like those which occur in the indefinitely large, and that our own scale of being should not prejudice our minds, as if it were the dividing line between them. 


\section{CHAP'TER XIII}

\section{PHYSICAL METABOLISM}

The phenomenon of fluorescence-Discovered by HerschelChange of refrangibility discovered by Stokes-Work of Lommel-Change of absorption-Description of experiments on this-Views of C. E. Guillaume and A. CottonNegative results - The experiments of Nicholls and Merritt-Relation between absorption and the intensity of fluorescence-Inference to be drawn from these observations and the change of refrangibility, the fluorescence being independent of the presence of the exciting lightFluorescence a building up and breaking down of molecules-Physical metabolism.

Sir William Herschel first observed the effect of light upon certain substances such as sulphate of quinine, paraffin oil, \&c., which shine on the surface when exposed to ordinary daylight and give out what he called epipolised light: whilst Sir George Stokes investigated the matter more fully and discovered the law of change of refrangibility of light known as Stokes' Law: the change of frequency of light from higher to lower. This he called Fluorescence. As far back as 1852 he was led by his experiments to remark that it is possible to conceive and at the time it seemed probable to him that there 


\section{PHYSICAL METABOLISM}

existed various degrees of molecular connection from mere casual juxtaposition to the closest chemical union.

Thus a compound molecule may vibrate as a whole, or by virtue of its connections with adjacent molecules, or it may vibrate by itself in the manner of an isolated vibrating plate or rod, and between these extreme limits we may conceive various intermediate modes of vibration. The resultant effect would naturally be of the most irregular type, and the spectrum appear to be continuous, as is found to be the case with all fluorescent and phosphorescent substances, except with chlorophyll, when the spectrum is homogeneous and no actual change of refrangibility occurs.

Indeed, it may be shown experimentally by the method of crossed prisms, originally used by Newton and employed by Stokes in his experiments, that when the illumination is feeble the fluorescent light never seems to be homogeneous. By this we should now understand that it never appeared to be homogeneous, on account of the feebleness of the illumination; our own opinion being that a continuous spectrum is not an essential part of the phenomenon of fluorescence, because when the light is sufficiently intense we have seen what appeared to be a continuous spectrum at lower intensities become resolved into a line or fine band spectrum, but this only in the case of gases; still, the line spectrum, as the brightness diminished, likewise assumed the 
apparently continuous form. Thus, from these considerations and from others based upon the change of absorption, it will appear that the apparently continuous spectrum of fluorescent and phosphorescent substances is made up of a series of fine bands or lines. This discontinuity, however, does not alter the fact that the spectra of such bodies do on the whole seem to be continuous, in other words, that they range round frequencies for each substance; as for instance in the bands of maximum and minimum in the fluorescent spectrum of uranium glass.

\section{Independence of Exciting and Excited Rays.}

It is most remarkable that there does not seem to be any connection between the emitted and the exciting light. ${ }^{1}$ By the method of crossed prisms it may be shown without difficulty that the period of the fluorescent light is entirely independent of that of the exciting light or even of its nature; so much so that the incident rays may be those which are very high up in the ultra-violet, and the spectrum of the fluorescent light be the same as if the exciting light were in the blue or violet.

This is a most noteworthy fact, as it indicates that the luminous vibrations are not forced.

The experiment is as follows:-

When the solar spectrum is thrown upon a 1 British Assoc. Report, Belfast, 1902. 



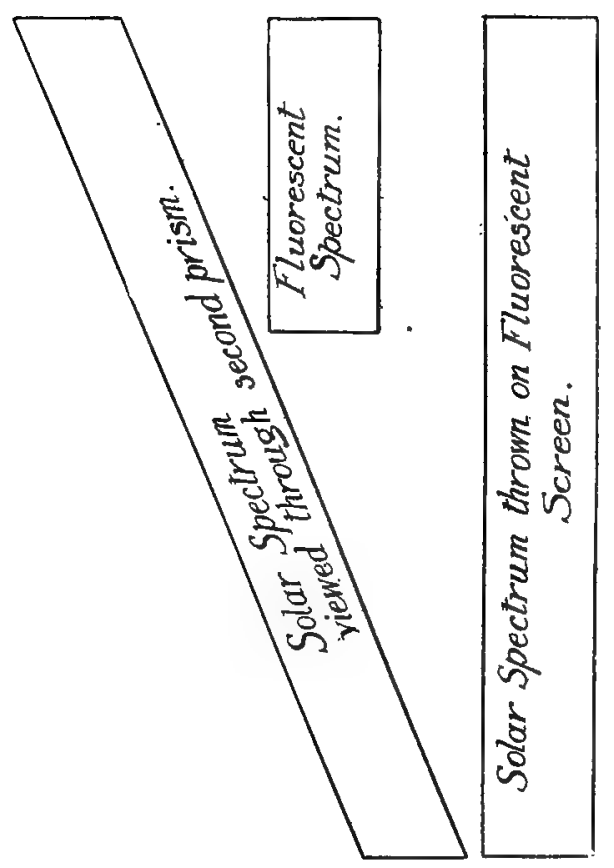

To fuce page 235 
screen painted with some fluorescent substance, the colour of the fluorescent light is the same throughout the whole length of the visible spectrum which excites the fluorescence, and is found in some cases with quartz prisms to extend as far into the ultraviolet as ten times the length of the visible spectrum. By examining the light thus obtained with a crossed prism whose edges are parallel to the original spectrum two spectra are obtained; one, the fluorescent spectrum, which is merely shifted some distance parallel to itself, and wider than the original spectrum; the other, the visible solar spectrum, which now appears distorted in a straight line at an angle to the original spectrum. The fluorescent spectrum, which is parallel to the latter, lies well within the space between the original spectrum and its shifted image; so that every ray in it is less refracted than the corresponding ray in the visible spectrum, at least as regards those solar rays which are of greater refrangibility, and to which the fluorescence owes its origin.

A glance at the accompanying figure will make the effect quite clear.

By this means it is found that the fluorescent spectrum is always not merely of less refrangibility than the exciting light, but also that its period is independent of part of the spectrum which gives rise to it. ${ }^{1}$ Thus, as Stokes first observed, the homogeneous light of high refrangi-

1 That is, speaking generally. See Moore, Astrophysical Journal, March, 1905. 


\section{THE ORIGIN OF LIFE}

bility gives rise to fluorescence with the same periods as if the body were exposed simultaneously to the whole radiation of the solar spectrum: which indicates that the spectrum of the emitted rays does not depend upon that of the exciting ones. This point has, as we think, hitherto not been sufficiently emphasised, considering the importance of its bearing on the theory of fluorescence.

Again, there are many examples in which the spectrum of the fluorescent light of a substance is very similar, if not precisely the same, whether it is excited by light, or by some other means. For instance the spectrum of ruby, amongst a number of other substances, was observed by Sir William Crookes to be the same, whether it is produced by sunlight or by cathode rays. ${ }^{1}$ These facts indicate that the fluorescent molecules are, for the time being at least, independent vibrating systems; whilst the effect of ultra-violet light, as we shall see, is to bring about the conditions which make it possible for these systems to be formed and then to radiate.

Since the spectrum of the emitted light is always the same, whatever that of the exciting cause, we have strong evidence in support of the hypothesis that the fluorescence is a secondary phenomenon brought about by the action of the incident light.

When fluorescence is excited by cathode rays,

${ }^{1}$ Crookes, "Discontinuous Phosphorescent Spectra," Proceedings of the Royal Society, May, 1881, p. 205. 


\section{PHYSICAL METABOLISM}

the new connections may be brought about by the electro-magnetic "pulses" or ultra-violet disturbances resulting from the impacts, or rather from the sudden stoppage, of the cathode rays on the surface of the body-for this complex of thin pulses, resolvable as they are into waves of very short wave-lengths, corresponding to periods much higher than those of the ultra-violet in the solar spectrum, may set up chemical action, as is well known from the effect of Röntgen rays on photographic plates; whilst the actual emission of light can be attributed to the breaking down of the molecules thus formed, which is greatly increased, as we shall see, by the presence of free corpuscles, that increase the rate of disintegration. In passing, then, from this to other but allied points, it may be remarked that if the phosphorescent light were due to forced disturbance, its spectrum in the afterglow would differ from that during the time of excitation; in one case the vibrations being free and in the other forced. Such a difference has never been observed, and the spectrum remains roughly the same under various modes of excitation.

The Change of Absorption during Fluorescence.

The independence of the fluorescent periods, however, does not prove that these are due to new atomic connections, or that there are new periods which do not exist when the body is inactive. These modes of vibration may be per- 


\section{${ }_{23}^{8}$ THE ORIGIN OF LIFE}

manent ones in the substance, which are merely roused up by the more refrangible rays, that agitate the molecules and thus give rise to their natural modes of internal vibration. This in fact is what Stokes believed fluorescence to be due to.

To illustrate our purpose, we may imagine the molecule to be a hollow sphere and a particle near its centre to be connected with the surface by elastic springs. Such a molecule, if violently shaken, will in addition to the period of this vibration radiate light of another period, namely, that of the internal particle, which will simply be roused up by the general disturbance.

Thus a phenomenon very similar to fluorescence should result. But, however, as the period of vibrations of the internal particle is a natural full period of the molecule, and thereupon always one of its permanent and possible modes of vibration, it will respond to vibrations of the same period when a wave of that frequency passes through it. Thus the body, although not fluorescing, will absorb the fluorescent light from another similar body of the same substance. Fluorescent bodies, however, when inactive, are generally transparent to the light of the wave-lengths they emit, which disproves the idea that the fluorescence is due merely to the excitation of previously existing periods; whilst, on the other hand, we have seen that it cannot be a forced vibration, as its period is independent of that of the exciting light.

How then are we to reconcile these apparently 



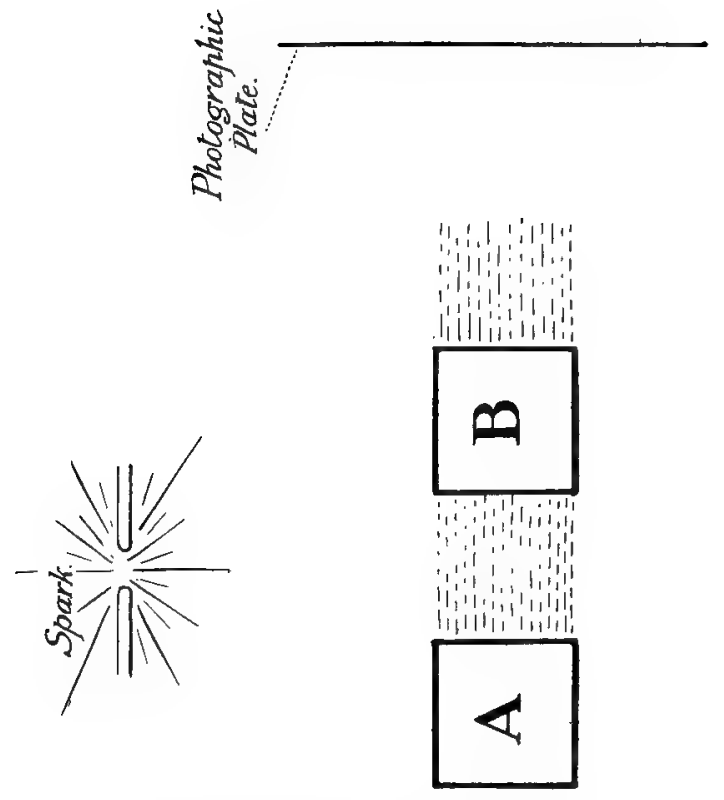

[A and $B$ should be transposed in the text.] 
contradictory facts? Of their truth there cannot be any question. Their contradiction therefore must only be apparent. The answer is to be found in the fact that the absorption of the fluorescent light takes place only during the period of fluorescence, and the transparency can be observed only when the body is inactive. In other words, the absorption spectrum of the body undergoes a change whilst it is fluorescing, and this I have attributed to a temporary change in the body during the action of the exciting light.

The phenomenon of the change of absorption produced by fluorescence was observed by the author some years ago, notably in the case of uranium glass, and has led up to the theory of fluorescence herein put forward.

The experiment is as follows:-1

Two cubes of uranium glass, $A$ and $B$ (as in the figure), are illuminated as in the drawing by the light from a spark of a Leyden jar between cadmium electrodes (the jar is not shown).

$A$ is first made to fluoresce, whilst $B$ is screened from the radiation; the light from $A$ in the direction $B A$ being photographed on the plate $P$. Then $A$ is screened whilst $B$ is illuminated, and the light from $B$ transmitted by $A$ is superposed on the previous effect, the exposures being of equal duration. The plate $P$ is then slightly displaced in a vertical direction and the effect of the two cubes taken when illuminated simultaneously, the 1 See Philosophical Transactions, Vol. 191 (A). 


\section{THE ORIGIN OF LIFE}

exposure being equal to that of each of the others separately.

In every instance the resultant effect in the former was greater than in the latter case. And this is due to the fact that the cube $A$ is more transparent to the light from $B$-that is the light which it can itself radiate-when it is screened from the spark than when it is itself fluorescing. This result has been tested in many ways, which it would take too much space to describe here. It may, however, be pointed out that this experiment alone can be explained on the supposition that the fluorescent rays have the power of diminishing the intensity of the fluorescence just as Becquerel and Stokes found that the less refrangible rays have the property, when acting simultaneously with the more refrangible rays, of diminishing the intensity of the phosphorescence in a previously excited screen. It seemed, therefore, that the fluorescent light might thus help to extinguish itself. But this is not so.

Thus if the two cubes $A$ and $B$ be illuminated by rays perpendicular to the plane of the paper, and the fluorescent light in the direction $A s$ be observed, according as the cube $A$ is screened from its neighbour, or exposed to its illumination, there is found to be no appreciable difference in the brightness of $A$, and if anything there is an increase rather than a diminution, and this slight increase would appear to be merely due to the scattered light from $B$, as may easily be verified 
by noting the light in the direction $A s$, when $A$ is screened from the illumination of the spark, but exposed to that from $B$.

This effect is of the same order in both cases. The point in this last experiment may not be very clearly understood without a few remarks about the experiments of Becquerel and Stokes upon this property which the less refrangible rays of the spectrum possess of discharging the phosphorescence when acting in consort with the exciting rays. Becquerel ${ }^{1}$ found this in a very remarkable degree, so much so that he has succeeded by this means in studying the infra-red spectrum by the action of the rays upon a phosphorescent screen. These rays appear to have a neutralising action on the effect produced by the more refrangible ones of the spectrum, an effect somewhat similar to the reversal in photography: but the heat due to their absorption may be sufficient to increase the brightness of the phosphorescent screen and thus diminish the duration, in the affected part, relatively to the other parts of the screen. Thus in the regions of maxima intensity in the spectrum there would be correspondingly dark bands in the phosphorescent screen. This may simply be a case of thermoluminescence. Many substances, when warmed, possess the power of radiating energy which they had previously stored up in some other way: a phenomenon which is known as Thermoluminescence. It is by

1 Comptes Rendus, 1882. 
no means clear, however, that the phenomenon we are now dealing with is really a case of thermoluminescence, in so far as the effect is said to be produced only under the combined action of the exciting more refrangible, and the destructive less refrangible ones, and not by the former alone. Stokes in his paper (Proc. Roy. Soc., 1882, p. 65) emphasises this point. He found that the colour of the phosphorescence changes under the influence of the less refrangible rays, and in his opinion the destructive effect is due to the combined influence of both. He describes an interesting experiment upon this point: "a phosphorescent tablet was laid horizontally on a lawn on a bright day towards evening when the sun was moderately low, and a pole was struck in the grass in front of it, so as to cast a shadow on the tablet. After a brief exposure the tablet was covered with a dark cloth and carried into a dark room for examination.

"It was found that the place of the shadow was brighter than the general ground, and also a deeper blue. For a short distance on both sides of the shadow the phosphorescence was a little feebler than at a greater distance.

"This shows that, though the direct rays of the sun by themselves alone would have strongly excited the phosphorescence, yet acting along with the diffused light from all parts of the sky they did more harm than good.

"The slightly inferior luminosity of the parts, to some little distance on both sides of that on which 
the shadow fell, shows that the loss of the diffused light corresponding to the portion of the sky cut off by the pole was quite sensible when that portion lay very near the sun."

"It is known that, with certain preparations, if a plate be exposed for a very short time to diffuse daylight, and be then exposed to a pure spectrum in a dark room, on subsequently developing the image it is found that while the more refrangible rays have acted positively, that is, in the manner of light in general, a certain portion of the less refrangible have acted in an opposite way, having undone the action of the diffused daylight to which the plate was exposed in the first instance. It appears then that in photography, as in phosphorescence, there may in certain cases be an antagonistic action between the more and the less refrangible rays, so that it stands to reason that the withdrawal of the latter might promote the effect of the former."

All this seems to show not merely that there is a striking resemblance between photographs and phosphorescence on the one hand, which we shall have occasion to discourse upon, but also on the other that the less refrangible rays have undoubtedly the power of destroying the phosphorescence as well as of preventing the phosphorescence from taking place under the action of the more refrangible rays.

In the case of photography, however, Sir William Abney, one of the highest authorities in scientific 


\section{THE ORIGIN OF LIFE}

photography, believes the effect is due, not to the influence of the red rays in undoing what the blue and violet rays have done, but to a further chemical action.

This is the case of bromide of silver, the effect of the more refrangible rays is to convert the undevelopable bromide into sub-bromide, which is developable: and the action of the less refrangible rays is to convert this again into oxybromide, which is once more undevelopable.

In the case of phosphorescence, the effect would appear to be somewhat similar, although the obstacles in the way of ascertaining this point are, on the whole, more difficult and complicated.

According to Stokes the effect of the less refrangible rays is not due to heating and therefore is not a case of thermoluminescence, because these rays alter the colour of the phosphorescence, rendering its light less refrangible, and he maintained that merely heating a phosphorescent substance does not alter its spectrum.

It would therefore appear that, as in the case of photography, the destructive effect of the red and infra-red rays is likewise chemical.

In studying the absorption of a fluorescent body when fluorescing, it is a matter of importance that the effect of the less refrangible rays should not be overlooked, as if the saurce is a flame, these may exercise a considerable influence in diminishing the brightness of the fluorescent light and thus apparently increasing the absorption of the transmitted light. 


\section{PHYSICAL METABOLISM}

The experiment I have described, however, sufficiently proves that the fluorescent light itself has not this action upon its own radiation, and therefore when the light absorbed is the same as the fluorescent light itself, the effect observed is really a case of a change of absorption and not merely of a diminution in the brightness of the fluorescent light.

In endeavouring to repeat my experiments on the change of absorption produced by fluorescence of uranium glass, M. Camichael ${ }^{1}$ adopted a method which from its nature was rather too loose to enable one to detect the effect sought; but his negative result is of interest in so far as it gives an indirect confirmation of my previous work on the subject. He appears to have been much impressed by the circumstance that when the source of the transmitted light is a flame, as in his experiments, of a petroleum lamp, the more refrangible rays increase the fluorescence and thus the coefficient of transmission is diminished, and he has since then taken precautions to prevent this. As, however, it is a matter of differences, there is no need to lay much emphasis upon this point, and the results obtained by Messrs. Nichols and Merritt ${ }^{2}$ very satisfactorily prove that the increased fluorescence does not prevent the effect of the change of absorption from being observed. In my own experiments, it was the absorption of the fluorescent

1 Comptes Rendus, Jan. 16th, 1905.

2 Physical Review, Dec., 1904. 


\section{THE ORIGIN OF LIFE}

light itself that was measured, and the objection does not apply.

M. Camichael uses a thick screen of uranium glass $7 \mathrm{~cm}$. in thickness to cut out the more refrangible rays, and in so doing the light from the lamp corresponding to the fluorescent periods is considerably cut down, so that that transmitted by the screen would undergo much variation of absorption in passing through another such piece of uranium glass, as the transmitted light has already been filtered of the particular rays whose absorption it is proposed to measure, and a negative result is therefore to be expected. But this negative result indirectly confirms the fact that the fluorescent spectrum is probably made up of fine lines or bands, as the effect of sifting or filtering of rays would thus still become more marked. It is difficult to judge by merely looking at the transmitted spectrum what actually takes place. The phenomenon of the change of absorption produced by fluorescence has since been investigated more fully from a spectroscopic point of view by Nichols and Merritt. ${ }^{1}$ The difficulty which I encountered when studying this subject was the uncertainty of photometric measurements, and my experiments were primarily directed to affording a satisfactory proof of the existence of the phenomenon, and I did not regard my results as conclusive till they were tested by totally distinct and independent methods as well as photographed. Nichols and 1 loc. cit. 


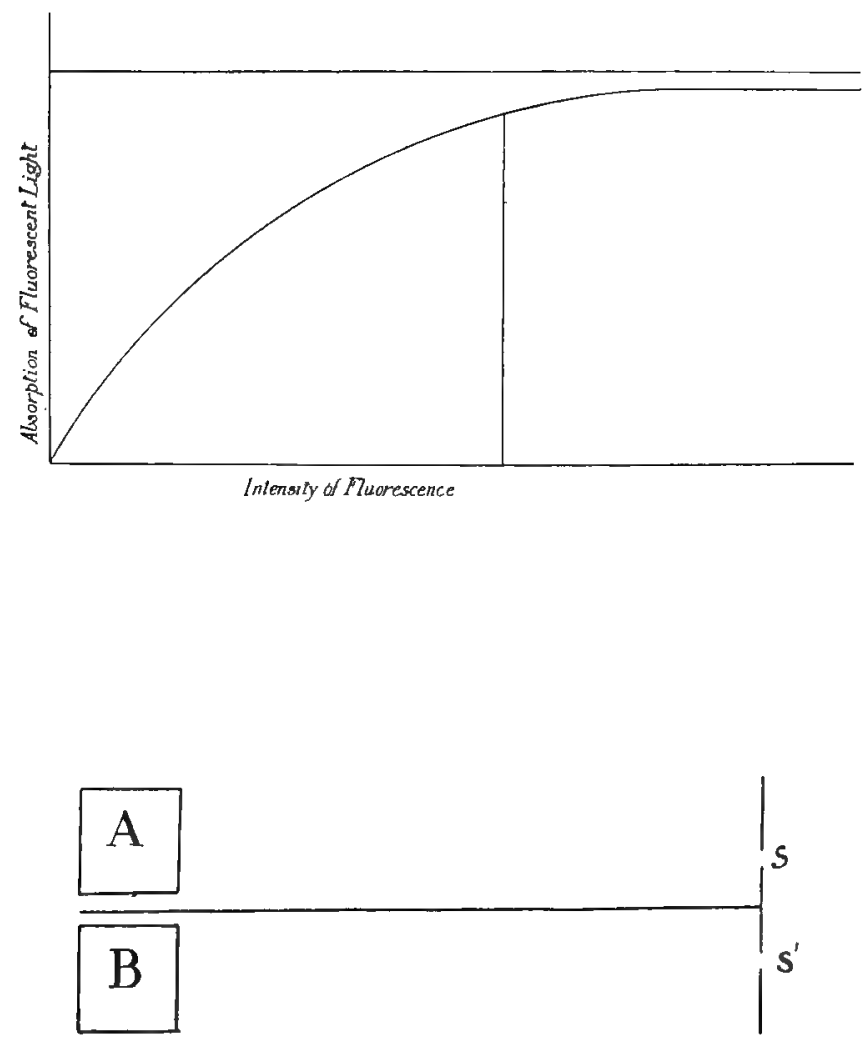

[To face page 247. 
Merritt have studied the absorption in different parts of the spectrum and have found that it corresponds, as we should expect, to the fluorescent spectrum, being a maximum when the intensity of the fluorescence is also a maximum. Nay, more, the absorption and fluorescence on the whole run parallel, so much so that the one increases with the other, until a maximum is reached, when a saturation effect occurs, after which the absorption remains constant with further increase in the fluorescence.

The accompanying figure will make this quite clear.

The intensity of the fluorescent light would be proportional to the illumination after the absorption has reached a maximum.

The substances which they worked with were dilute solutions of fluorescein in water, of eosin in alcohol, and resorcin in alcohol, and in every case the change of absorption was most marked. There can be no question but that the change of absorption throws much light upon, and gives us an insight into, the molecular processes which underlie the phenomenon of fluorescence.

It is not thus, as Stokes supposed, a rousing up of pre-existing modes of vibration, but an actual change in the structure of the body, with new atomic connections, which in being resolved into their original condition radiate intensely, and thus give rise to the luminosity which is observed. 'I'hus the difference in the absorption of the fluorescent light is itself due to the temporary change 


\section{THE ORIGIN OF LIFE}

in the structure or chemical composition of the body when exposed to the influence of the exciting light, the new luminosity and the new absorption being due to these new free periods.

The more refrangible or exciting rays form unstable molecular aggregates, and it is in the breaking down of these unstable and probably large molecular groups that the luminosity occurs. Thus, as we have said, as in the case of photography a chemical change appears to be produced by the blue and violet and ultra-violet rays, but one that differs from this from the physical point of view in so far as the molecular aggregations, instead of remaining fixed, rapidly disintegrate, radiating intensely all the while the energy which was stored up in their formation. And the luminosity itself is thus but the visible manifestation of the process of building up and breaking down of complicated molecular aggregations: a process analogous to metabolism, however much it may in reality differ from it. Our anticipation of the previous chapters is thus beginning to unfold itself.

On my other hypothesis the vibrations which give rise to the fluorescent light would not be harmonic ones if the absorption were to depend upon the intensity of the fluorescent light.

An elementary knowledge of the subject will enable us to comprehend that the absorption in such a vibration must be independent of the amplitudes. But if new periods are excited as I 
have ventured to describe, the intensity and the absorption would depend upon both the number and the duration of the periods thus produced; and it is this which I think the change of absorption in fluorescence most distinctly proves.

We may now perhaps turn our attention to the obvious bearing of this phenomenon on Balfour Stewart and Kirchoff's law.

M. Ch. Ed. Guillaume ${ }^{1}$ and M. A. Cotton ${ }^{2}$ have given much attention to this subject. At first sight, indeed, it may seem as though the change of absorption during fluorescence is a direct consequence of this law, another instance merely of the general rule that all bodies absorb the radiations which they can emit. But this phenomenon, however, on closer examination is not really one of the direct consequences of the law.

In general, at a given temperature, there are in a given body, for a particular kind of radiation, an emissive power and an absorptive power which are equal.

But in the case of fluorescence, the absorptive power is changed like the emissive power without any appreciable change in the temperature of the body; and this is due to the fact that under the influence of the external source the fluorescent body emits a new kind of radiation, which is extinguished in the course of time when the exciting source is removed and the molecular structure of

1 Nature, March 3rd, 1898.

2 Astrophysical Journal, April, 1899. 


\section{THE ORIGIN OF LIFE}

the body, as we have seen, appears to be changed. When the fluorescent body is not under the influence of the external source which can excite luminosity in it, the radiation which it can emit in such circumstances is not absorbed.

The conception of a fictitious temperature or temperature of luminescence has been suggested by E. Wiedermann. But Guillaume (loc. cit.), in discussing the change of absorption, has pointed out that such an extension of the notion of temperature only leads to the heaping up of difficulties instead of arriving at something definite, so much so that it would seem far simpler to evade the notion of temperature altogether in the discussion, as it thus appears to be far too general to be limited by conceptions which ought to have a precise and definite signification.

A. Cotton has entered into a criticism of many important points, in connection with the application of Balfour Stewart and Kirchoff's law with special reference to the change of absorption in fluorescent bodies when fluorescing, and concludes that the rule connecting absorption and emission for the same body applies in a great number of cases, particularly of luminescent bodies, which are not governed by the law properly so called.

How the aspect of the question taken in this chapter bears upon physical metabolism in its most general form receives further confirmation in the sequel. 


\section{CHAPTER XIV}

\section{RADIATION AND MOLECULAR AGGREGATION}

Summarily the result of association and dissociation-Or more or less complex molecular groups-Radiation from flames -Tyndall's experiments on the emissive and absorptive powers of gases-Spectra of oxygen-Repulsion between spheres of molecular dimensions whilst radiating intensely - How aggregates may preserve their identity-Catalytic action-Effect of glycerine and gelatin on aggregation in fluorescent bodies.

THE results we have arrived at lead us to a matter of great importance on account of its intimate bearing upon the problem of the radiation from hot bodies, whether the radiation is due to the increased amplitudes of the vibrations or to new vibrations that result from molecular metabolic interactions. For as the temperature is raised the collisions become more frequent and more violent, so that when any pre-existing vibrations are roused up, their amplitudes are increased, and the energy radiated thus intensified.

The question is whether, as the temperature is raised, the luminosity results from their increased vibration, or from vibrations set up by molecular dissociation or association, or from both.

It is our endeavour to show that the luminosity 


\section{THE ORIGIN OF LIFE}

results from the intramolecular vibrations resulting from partial chemical combination in two stages, of association first and then of dissociation, during which, as in the case of fluorescence, new molecular aggregations and new free periods are found to exist, the constants in the equations of motion of the vibrating systems being thus altered.

The radiation from an incandescent body would appear to be due to two more or less independent processes. That resulting from the vibrations roused up by the increased frequency and violence of the molecular collisions on the one hand, and that, on the other, which is due to intramolecular vibrations not directly connected with the translational motion of the molecules themselves. One, as we shall see, seldom or never acquires sufficient intensity to become luminous, the other is the immediate source of radiation in all luminous bodies, whether excited by heat or any other means.

It is undoubtedly possible to decide experimentally how far the radiation from a body is due to one cause or the other.

We have seen that the rate of absorption for harmonic vibrations, since it depends solely upon the constants in the equation of motion, is unaffected by the amplitudes of the vibrations, whilst that due to new free periods undergoes a great change. ${ }^{1}$

1 Thus in the vibrating system

$$
m \ddot{u}+K \ddot{u}+n^{2} u=f(t)=E(p t-\delta) .
$$

The rate of absorption is $=-\frac{K \cdot E^{2} \cdot p^{2}}{\left[K p+\left(n^{2}-m p^{2}\right)^{2}\right]}$. 
Hence, if the number into molecules with a particular free period is increased, the absorption is increased, and if the number is diminished the absorption for this particular period is also diminished, whereas if the number of molecules executing vibrations of a particular period remains constant, the absorption for that particular period likewise remains constant at all temperatures, irrespective of the intensity of the radiation.

The problem, however, is not quite so simple as this; at first sight the number of molecules executing a particular vibration does not remain constant, as the temperature rises even if there be no association or dissociation; for as the temperature rises and the translational velocity increases, as in the case of billiard balls, the vibrations become converted into shriller and shriller ones. And this would increase according to some definite law connecting the frequency with the temperature. Various attempts have been made to determine the law connecting the radiation in any particular part of the spectrum with the temperature. The assumptions, however, which must be made to get the right result are not altogether satisfactory; and it is desirable that the relation between emission and absorption should be more clearly understood. Thus, for any particular molecule as the temperature is raised, if the frequency of its vibration is also increased, the energy of translation must ultimately be frittered away in the conversion of these 


\section{THE ORIGIN OF LIFE}

vibrations into higher and higher nodal sub-divisions. And this, it has been calculated, should take place very rapidly. But we know that if it takes place at all it must take place to a very small extent, the energy from radio-active bodies being the nearest approach we have to any such continuous loss of energy. The answer, which therefore seems obvious, is that the assumption-that by repeated collisions the frequencies are altered without an accompanying change in the structure of the molecule -is unsound, and that the increase in the energy of higher vibrations as the temperature is raised must be sought for in the increased number of molecules so changed as to radiate in this particular manner. Thus no amount of heating will cause a gas to give out a continuous spectrum, and new frequencies must be accompanied by new atoms or molecular connections.

In the case of solids and liquids all sorts of molecular connections may be produced, from the casual juxtaposition to the closest chemical union; and therefore a continuous spectrum may be expected. But the continuous transformation of vibrations from high to higher, as in the case of billiard balls, is not to be expected, and, in fact, such a transformation would lead to wrong expectations, by a false analogy, with the processes which actually take place.

It may therefore be said with safety that if a vibration becomes intense in any part of the spectrum without any change of a molecular or 


\section{MOLECULAR AGGREGATION 255}

atomic nature, such modes of vibrations must have existed in the body at a lower temperature and at all temperatures so long as its composition remains precisely the same. The coefficient of absorption will, however, be constant, as this does not depend upon the amplitudes of the vibrations.

Thus a change in absorptive spectrum means a change in the molecular structure of the body. And this is the point it is our endeavour to bring out.

As in the case of fluorescence so also here with incandescent bodies, flames, and other high temperature sources of light, the change of absorption is the test of change of molecular or chemical composition.

Therefore, a comparison of the curves of intensity and absorption will enable us to judge how far the radiation is due to intramolecular and how far to isolated molecular or atomic motions.

This test, and the hypothesis of which it is but the test, form the basis of our conceptions, as well as of our experiments on the theory of luminosity.

A body will always absorb the radiation it emits; but if the simpler process without change of molecular composition takes place, variation in the amount of the absorption for any particular wave-length will not correspond to variations in the intensity of emission for the same wave-length. Thus Balfour Stewart and Kirchoffis law applies, strictly speaking, more accurately to the phenomenon of luminosity of a chemical nature than other of the 


\section{THE ORIGIN OF LIFE}

purely molecular type, such as are contemplated in the kinetic theory of gases, whilst the almost universal acceptance now of this law is the strongest argument for the chemical theory of radiation for which we plead. Whilst there may be a small fraction of the emissive power due to newly rousedup latent modes of oscillation, the correct meaning of the law is that at any given temperature a body absorbs the rays which it actually emits at that particular temperature, but that the relative values of its emissive and absorptive powers may change with the temperature. This, indeed, is the correct interpretation of the law, in its most general form, in which it can at once embrace all forms of luminosity. Thus once more the absorption in all cases remains constant when the temperature rises, so long as dissociation or association or any other molecular change does not set in, but when this happens the absorption increases rapidly, the rate of increase being proportional to that of the molecules of the particular period.

It is, therefore, or ought to be, possible from what has been said to separate or rather to distinguish between the energy due to one cause and that due to the other; in the case of a gas-burner, for instance, we may suppose the radiation to be due partly to the one cause and partly to the other; the luminosity resulting in the one case from previously existing free periods which have merely been roused up and in the other to entirely new free periods resulting from new molecular and atomic connections. 
Hence, if there is any change in the absorptive coefficient of radiation of any particular wavelength, that change would be due not to any preexisting periods in the gas, but to others brought into being by new molecules or atomic groupings, due, most probably, to chemical or unstable semichemical interactions.

Thus it is by no means true that a body when cold absorbs the radiation which it emits when hot and it is only for the same temperature that the absorptive and emissive spectra correspond.

M. Gouy has made a very interesting and important experiment on the spectra of coloured flames, to determine their transparency to the rays which they emit.

He found by a very simple method doubling the the thickness of the flame and measuring the brightness of the line with a spectral photometer, that the brightness is not doubled, from which it may be inferred that there is an appreciable $a b-$ sorption accompanying the emission.

He found also that absorption set in as soon as the line had attained a certain brightness, and was careful to note that it was only those parts of the flame which emit the light whose absorption was studied.

- Iodine vapour heated to redness in a tube becomes luminous. The spectrum appears at first sight continuous, but on close examination is found to consist of diffuse bands and flutings which correspond to those of the absorption observed at the 


\section{THE ORIGIN OF LIFE}

same temperature. It is therefore a case of change of molecular structure.

On the other hand, he records a number of cases of coloured flames which give emission bands and are yet quite transparent to their own radiations. It is true for several bands of calcium, strontium, barium, copper, and carbon, and, within the errors of observation, the brightness of these bands has been found to double with the thickness of the flame. The same result has been found in the case of the luminosity produced by the electric discharge in hydrogen in high vacua, but these may all be due to the fact that the coefficient of absorption is in these cases small, thus requiring a great thickness of gas to produce a sensible effect, whilst it indicates that the number of luminous molecules is small relatively to that in substances in which the absorption during luminosity is great.

Tyndall found that many gases have emissive and absorptive powers in the infra-red which are proportional, in which case the radiation must be due to molecular aggregations, according to the theory we have put forward.

He also found that these powers of radiation and absorption are very different for different gases, that gases formed of complicated molecules give far higher values than simple gases.

Ethylene, for instance, emits and absorbs much more strongly than air, and the emission from a polished plate of metal can be considerably increased by coating it with a film of this gas. 


\section{MOLECULAR AGGREGATION 259}

Hydrogen and nitrogen, on the other hand, do not show any perceptible absorption; this may be due, as we have said, to the small number of luminous molecules, but if combined with ammonia gas, their absorption and emission become considerable.

All these facts, therefore, are in agreement, that luminosity results from the formation of more or less complex molecular groups.

The absorption and phosphorescent spectra of oxygen are worthy of special consideration in their intimate bearing upon the question at issue with reference to the formation of molecular groups.

The absorption spectrum of oxygen has been attributed by Angström to ozone or to oxygen in the state in which it becomes phosphorescent, as he failed to discover any other emission spectrum resembling these absorption bands. They appear to be identical with the bands which Schuster has observed in the negative glow of oxygen which have been identified by Newall with those of the phosphorescent glow in certain circumstances.

The absorption bands exhibit a most remarkable property observed by Jansen.

The absorption for the A and B lines varies as the thickness and as the density; but for the rest of the spectrum as the thickness and the square of the density; so that it is also proportional to the number of molecular collisions, these being proportional to the square of the density.

Ordinary collisions between molecules, however, 
do not last long enough to enable the absorption which takes place during these intervals to be appreciable. The collisions, therefore, in the present instance probably last for a considerable time, so long that during these intervals the molecules in collision may be regarded as distinct but unstable molecular groups or aggregates, which, as we have endeavoured to show, ought to occur in fluorescent and other luminous bodies.

There can therefore be little doubt, from these results also, that the formation of unstable groups is one of the conditions of luminosity.

From consideration as to the specific inductive capacity of gases, it can be deduced from a formula of Lorenz ${ }^{1}$ that in a luminous gas the spectral lines are not given out by every molecule, but only by a comparatively small number of molecules, and that the systems which give out one line may be different from those which give out the others.

These points are in strict agreement with our views on the subject which were arrived at independently in other ways, chiefly from considerations bearing upon the phenomena of the change of absorption during fluorescence, which involve the temporary formation of new molecular aggregations to which the new emission and absorption spectra of fluorescent substances are due. ${ }^{2}$ The

1 J. J. Thomson, Archives Nierlandaises, 1902.

2 British Association, Bradford, 1900, and Belfast, 1902. Phil. Mag., 1901. 


\section{MOLECULAR AGGREGATION 26I}

hypothesis we put forward in this book that luminosity is thus merely the high frequency radiation resulting from a catalytic process is thus greatly strengthened by its bearing the formation of large groups, even consisting of chains of molecules which should by no means be broken up as quickly as might at first be imagined, when chemical interactions take place within the groups themselves, and the linkage in such cases would thus be sufficiently great to enable them to hold together for a considerable time, the radiation also being sufficient by its presence to mitigate very greatly the effects of molecular collisions. For it may be inferred from Professor Poynting's results ${ }^{1}$ that spheres of molecular dimensions, by radiating intensely, can so exert a repulsion on each other so as to prevent themselves from doing much damage by mutual collisions.

These systems, however, may exist even when such molecules are not actively radiating: but the duration of their existence would doubtless be much shorter. Such encounters as may last so long that the colliding molecules can be looked upon as systems differing from the separate or isolated molecules are no obstacles in the way of the dynamical theory of gases, although they are extremely few and far between. They may be regarded as the chosen few amongst the masses.

It will be remembered that the results of Clerk

1 "Radiation in the Solar System," Philosophical Transactions, 1903. 
Maxwell's investigation ${ }^{1}$ on the subject of the kinetic theory are independent of the duration of an encounter and also of the law of force (which in a previous paper was assumed to be the inverse fifth for convenience) provided the law of force is consistent with the conservation of energy. Maxwell's theory will apply to bodies composed of the system of molecules we have described.

$\mathrm{He}$ admits, it is true, that in following the steps. of the investigation, as given by Boltzmann or by Watson, it is difficult, if not impossible, to see when the stipulation about the shortness and the isolation of encounters is made use of. "We may almost say that it is introduced rather for the sake of enabling the reader to form a more definite mental image of the material system than as a condition of the demonstration."

It will be seen that the formation of these molecular groups is greatly facilitated by the presence of a third substance of high specific inductive capacity. This may frequently be water vapour, or some other vapour, or when the luminosity is due to a discharge of electricity in vacuo, the walls containing the gas through which the discharge is sent.

The number of these colliding systems is increased when the gas becomes luminous, and this can doubt-

1 “On Boltzmann's Theory on the Average Distribution of Energy in a System of Material Points." Collected Works Vol. II. 
less be produced by chemical, or what may appear to be semi-chemical, catalytic processes.

In fact, molecular theory in its relation to that of luminosity must be looked at from a more detailed point of view than that in which it is generally regarded.

Thus, again, the behaviour of a luminous gas or other substance in the formation of large molecules "is analogous" to that of a vapour condensing into a liquid, to the freezing of a liquid, or to the formation of crystals from a saturated solution, and the passage of a discharge through a gas at certain pressures. For in the absence of any foreign substance the temperature and pressure at which these occur are very indefinite; but when a foreign substance the molecules of which can act as nuclei are present, these effects take place under perfectly definite conditions and at perfectly definite "temperatures and pressures." 1

The influence of nuclei in producing these effects will be considered in the sequel.

The author ${ }^{2}$ has found that the after-glow in gases is influenced by the presence of impurities, so that the formation of groups in some cases, perhaps of polymeric forms, is greatly facilitated by the presence of traces of foreign bodies, just as it is influenced by the presence of nuclei and negative ions.

Sir James Dewar has inferred from his experiments at low temperatures that the more complicated the molecular structure of a body, the more likely

1 J. J. Thomson, Phil. Mag., 1894.

${ }^{2}$ Loc. cit. 


\section{THE ORIGIN OF LIFE}

it is to phosphoresce, and organic compounds like albumin become very phosphorescent if first exposed to the temperature of liquid air.

He found also that water is slightly phosphorescent, even if pure, at low temperature; but that when slightly impure it is very phosphorescent, and as we have concluded in the case of gases, foreign bodies as slight impurities play a most important part in the interactions giving light. These effects of impurities in their relation to catalytic actions will be considered later on.

Experiments such as those of Lippmann on colour photography show that it is actually possible to obtain layers of such large molecules as we have contemplated by stationary waves, and of the dimensions of the wave-length, since the distances apart of the layers depends upon the wave-length of the impinging light. The use of the word molecules for the matter which contributes these layers can of course be made use of only in an extended sense, and for that reason we call them aggregates of molecules, which is doubtless what they are, although it may be permissible to call them "large molecules."

In the photographic plate they remain fixed, whilst in a phosphorescent substance their presence would be only more or less permanent.

However, as the addition of glycerine or gelatin to solutions of phosphorescent substances causes a considerable increase in the duration of the phosphorescent light, this thickening of the solution 


\section{MOLECULAR AGGREGATION 265}

enables the phosphorescent molecule to remain intact for a much longer time.

We may regard, therefore, in the light of these facts, the effect of glycerine or gelatin on such liquids, as a confirmation of the hypothesis that the luminosity is stored up in newly formed molecules produced by the action of the more refrangible rays.

A cell with a radio-active nucleus would, it appears, be the seat of such molecular aggregations and disintegrations, and in a certain sense of metabolism too; since such molecular metabolism to which luminosity is akin must result in a medium in which a radio-active particle is immersed. 


\section{CHAPTER XV}

ON THE FORMATION OF AGgREgATES OF LARGE MOLECULES

The effect of infra-red rays-Stokes' law reversed, or calorescence-The function of a nucleus in phosphorescent bodies-The effect of surface tension on aggregation-Influence of films-Chemical reaction in high vacua.

\section{Effect of Infro-red Rays, Etc.}

THE effect of infra-red rays in general is to destroy or discharge phosphorescence, see p. 234. This phenomenon was discovered by Becquerel, ${ }^{1}$ and investigated by Stokes. ${ }^{2}$ By its means, as we have seen, Becquerel and others have investigated the solar spectrum in the infra-red.

The cause of this phenomenon is not very clearly understood, but it seems not improbable that the explanation lies in the fact that, under the influence of heat, phosphorescent bodies give out their energy much more intensely, and therefore in a much shorter time, as in the case of thermoluminescence, so that when a phosphorescent screen is exposed to the infra-red part of the Comptes Rendus, 1882.

2 Loc. cit. 


\section{FORMATION OF AGGREGATES 267}

spectrum, the radiation is rendered so intense that in a very short while the parts upon which the rays fall cease to be luminous, and the screen becomes marked with a number of dark bands corresponding to the luminous ones in the spectrum.

According to Stokes, the combined action of the more refrangible and less refrangible rays is necessary. He also believed that it was not a case of thermoluminescence, because during the phenomenon the refrangibility of the phosphorescent light undergoes a further change from higher to lower.

There is a chemical change of some sort accompanying this phenomenon, as well as that of ordinary fluorescence and phosphorescence.

This appears at first sight to be a contradiction of Stokes' law that a transformation when it does occur is from higher to lower, whereas here there seems to be a change from slower waves to more rapid ones. There appears, however, to be a change in this direction, although the excited luminosity is of higher frequency than that in the infra-red that excites it to so great an extent.

Some instances are to be found in which this effect is even more marked. For example, a ray of deep red light will cause a solution of naphthalenered to emit an orange-yellow light. This is an illustration of Tyndall's so-called fluoreseence reversed, or calorescence. But it seems not at all improbable that the fluorescence in this case, as in that of chlorophyll, is due to the emission of energy, which the substance received by exposure 


\section{THE ORIGIN OF LIFE}

to light at some previous time and has remained. stored up in it. The infra-red rays are well known to possess the power of destroying chlorophyll. They also have a reversing action in photography.

Now if the phenomenon of phosphorescence is due, as we have tried to show, to the disintegration of large molecular groups in the manner described, it is evident that when disturbed their size will depend upon the wave-length of the disturbances, and that the agglomeration thus formed will be larger when the disturbances in the rether correspond to the infra-red, than when they correspond to the ultra-violet rays in the spectrum. But there obviously will be a limit to the dimensions which these molecules will attain, for by collision and so forth they are bound to break up when they get beyond a certain size.

The influence of the infra-red rays would appear to be to increase the size of the aggregates to such an extent that they become so large as to exceed the size at which they are able to hold together, and thus break up as they should if the temperature in the first instance was increased to a sufficient extent.

\section{The Function of a Nucleus.}

Now the existence of these molecules seems to depend upon the presence of nuclei, and it is a matter to be borne in mind that all the phenomena in the rether which give rise to fluorescence also 


\section{FORMATION OF AGGREGATES 269}

produce nuclei in the substances through which they pass, and vice versâ. Thus the cathode rays, the radiation from radio-active substances, Becquerel rays, Röntgen rays and ultra-violet rays all produce nuclei by their passage through gases and give rise in suitable circumstances to phosphorescence.

Now cathode rays have precisely the same effect as infra-red rays. ${ }^{1}$ They increase the brightness, and thereby diminish the duration of the phosphorescence.

The infra-red rays alter the molecular structure of a body as in the case of chlorophyll, and it is to their power of effecting this change that their destructive influence on phosphorescence should be attributed. The effect of these rays like that of negative ions is to facilitate the growth, as it were, of the molecular groups and thus cause them to be subsequently broken up.

The question is how this is accomplished, and whether it is a necessary consequence of the phenomena which have previously been considered.

By far the most conclusive and also remarkable results I have obtained in the endeavour to establish this point have been with radio-active bodies. Before entering into the subject, however, it would be of interest to consider the effect of surface-tension in producing aggregation.

I Philosophical Magazine, March, 1901. 


\section{THE ORIGIN OF LIFE}

Effect of Surface Tension on Aggregates.

By the experiments upon the effects of various substances upon the afterglow in gases, it is found that ether and other organic substances, such as scents which destroy the surface-tension between a liquid and a gas, also spoil the glow and render it difficult, if not impossible, to reproduce the phosphorescence in the same apparatus.

It thus looks as if the existence of the luminous molecules depends somehow upon surface tension effects, and it is of interest to consider the manner in which these two may be related. The existence of the glow depends, as I have said, upon the presence of nuclei, so that the molecular agglomerations evidently tend to accumulate round these.

In such an event, if the surface-tension by which the molecules are kept together were diminished, it would result in an increase in the size of these molecular groups, since the surface tension varies inversely as the radius of curvature, the condensation on the nuclei will be greatly increased.

Many observers-Richards, R. von Helmholtz, Shelford Bidwell, Aitken, C. T. R. Wilson-have found that condensation in gases is greatly facilitated by the presence of ions, and that negative ions produce a greater condensation than positive ones.

The tendency of the electrified nucleus, therefore, 


\section{FORMATION OF AGGREGATES}

is to increase the number of molecules that cluster round it, and therefore the size of the group. The ion tends to become larger and larger unless there is some counteracting process at work to check its growth. Now the surface-tension would tend to do this, so that the maximum size of the aggregate is that which would be obtained when equilibrium is arrived at between the contending forces.

A stage would thus be reached at which the presence of ions will overpower that of surfacetension.

The electrification which promotes condensation is bound at a certain point to overpower the surfacetension which tends to prevent this, at any rate for very small drops, because the effect due to surface-tension varies inversely as the radius of curvature, whilst that due to electrification varies inversely as the square of the radius of curvature. Hence, when the surface-tension is destroyed the aggregates of molecules will fly to bits by the disintegration of the constituent parts, the luminosity being a consequence of the energy thus radiated.

The ratio of the energy given out by a molecule or particle, or group of molecules of molecular dimension, by condensation, to the potential energy varies directly as the radius of curvature, so that more energy will be given out by the negative ions on which its condensation takes place than by the positive ones, as the condensation on these is much larger. 


\section{THE ORIGIN OF LIFE}

If the surface-tension is diminished by not more than one per cent., enough energy is liberated to raise the temperature of the film of oxygen $10^{-8} \mathrm{cms}$. in thickness, through several degrees centigrade.

The luminosity produced by the motion of mercury on glass appears to be produced in a similar manner by this breakdown of surface tension on the film of oxide, whilst the extraordinary brightness and efficiency of the discharge through mercury vapour presents a problem of intense interest, and in fact of great practical importance with which we hope to deal presently.

The author has found that the negative ions tend to extinguish the glow, whereas, on the other hand, the positive discharge can be sent through the gas with facility, without affecting its duration, as the cathode rays spoil the phosphorescence in a very short time, by producing further condensation.

\section{Chemical Reaction in High Vacua.}

The chemical changes which go on at the surface layers, of molecules as well as of larger bodies, which we have been considering, may be such as we have no experience of at ordinary temperatures, from experiments with large masses of the substances.

Thus the combinations which go on more freely between gases condensed on the surfaces than 


\section{FORMATION OF AGGREGATES 273}

between the same gases when free, may also occur by the condensation of the molecules into complex groups or systems of aggregation in the gas itself, round nuclei, or foreign substances, which by their presence facilitate the formation of these aggregates alone.

Hence the passage of a discharge of electricity through a gas can be said in certain circumstances to produce not merely ionisation but large groups of molecules possessing a large store of potential energy that may be radiated away, partly in the form of light. The life period, if we might so call it, of these molecules is greatly increased, as will be shown, by removing them from the presence of the ionised gas.

It is conceivable, and it seems quite probable, that by the passage of a discharge, a mixture of gases can at certain pressures enter into chemical combination of a somewhat unstable kind; although they may not be known to form such combinations at ordinary pressures, so that reactions analogous to chemical combination, but unknown at ordinary pressures, are facilitated by the passage of the discharge in high vacua and manifested by the phenomenon of phosphorescence. ${ }^{1}$

We have said that, speaking generally, radiations which excite phosphorescence also produce ionisation. It is, therefore, a matter of very great

1 Philosophical Magazine, 1901, p. 352. 


\section{THE ORIGIN OF LIFE}

importance to decide whether the ionisation in these bodies is the cause or the consequence of the luminosity, or whether they are merely concomitant phenomena.

If it is merely a concomitant, we should expect that the phosphorescence results from the rapid electromagnetic disturbances, which in other cases are found to give rise to ionisation; whilst if it is the cause, the phosphorescence must result from collision between ions as they recombine. If it is the effect, the phosphorescence may be regarded as the disintegration of molecules, thus giving rise to ionisation, which seems more probable, since the collisions would require to be very violent in order that the radiations should be so intense, and this in turn would imply molecular forces of extraordinary magnitude.

The ionisation is probably the result of the molecular radiation, in which case it would come under the heading of concomitant effects, or secondary effects, according to the way we choose to look upon it.

All that has been said has led us to the result that the spontaneous emission of light is dependent upon the formation of new, and more or less complex, groups of molecules, which for the want of a better name we may call megamolecules.

We have seen that a careful study of the question shows that separate or distinct free 


\section{FORMATION OF AGGREGATES}

periods exist during phosphorescence-that is, new molecules.

In the case of gases there is direct evidence of the existence of such large molecular groups, which may be made to diffuse from one tube to another, through narrow metal tubing earthed; thus showing that the molecules do not carry a free charge of electricity. Electrical forces, therefore, cannot be expected to enter, otherwise they would, if the charge on the particles be sufficiently large, influence molecular forces to a very great extent.

The influence of intra-molecular forces is doubtless of importance in the phenomenon of phosphorescence, since solids are so much more phosphorescent than liquids, and these far more so than gases, in which an afterglow is of rather rare occurrence; and then it is characteristic chiefly of the gases which polymerise, such as oxygen, cyanogen, acetylene, etc.

These facts indicate that the influence of molecular forces is, however, of importance ; moreover, since the light emitted by fluorescent crystals is polarised, it shows that the emission of light depends upon vibrations in groups of molecules, rather than in the individual molecules themselves. From which it may be inferred that the emission of light depends largely upon the nature of the molecules and their environment.

The first point we have endeavoured to prove, 


\section{THE ORIGIN OF LIFE}

then, is that during the period of fluorescence separate molecules are formed which are gradually or quickly broken up, according as the body is phosphorescent or fluorescent.

There is reason to think that these molecules are very much larger than ordinary molecules, and may be made to diffuse through narrow metal tubing in the case of phosphorescent gases; that in the case of phosphorescent liquids they may be fixed by the addition of glycerine or gelatin; at any rate, that by increasing the viscosity and diminishing the frequency of collisions between the molecules, their life-period and the duration of the phosphorescence are greatly increased; whilst the optical experiments on solids and liquids show distinctly that the existence of altered periods is the cause of the change of refrangibility.

Phosphorescent gases also present a semiopacity, but as no measurements have ever been made on this point, nor, indeed, is it easy to make them, and as the possibility of optical illusion in such matters is great, in judging contrasts the matter may be said to be an open question at present. But although the quantity of matter in a vacuum tube is very small, such opacity is nevertheless possible if the number of luminous molecules is proportionally very great.

If the gas can radiate there is no reason why it should not also, at the same time, absorb; 


\section{FORMATION OF AGGREGATES 277}

but absorption only during phosphorescence would imply a change in the molecular structure of the gas.

In the case of fluorescent bodies they undoubtedly are formed, whilst the destructive action of infra-red rays shows that they can also be made to break down more easily when the aggregation exceeds a certain size. 


\section{CHAPTER XVI}

PHOSPHORESCENCE AND MOLECULAR AGGREGATION

Phosphorescence and catalytic action-Effect of molecular concentrations on freedom of corpuscles-Dependence of phosphorescence upon free-paths and velocity of corpuscles-Existence of separate phosphorescent molecules in liquids, and of separate active molecules in luminous gases -That separate large molecules exist in flames-The process of catalysis and metabolism once more.

A CONNECTION between phosphorescence and radio-activity undoubtedly exists. Many phosphorescent substances are radio-active, and all radioactive substances produce phosphorescence. Although radio-activity, so far as our knowledge goes, is not dependent upon combustion, nor accompanied by any permanent chemical or molecular change in the structure of the body, it may yet be associated with some temporary molecular or pseudo-chemical interactions; whilst the study of phosphorescence indicates that molecular interactions appear to underlie the most simple, as well as the most complicated, facts of observation. There is, however, no permanent change in the chemical composition of the body, even when the luminosity which results 
from a slow process of combustion, as in the case of phosphorus, and in that of the luminosity of glow-worms and photogenic bacteria which are catalytic in their nature. The process may be compared to a form of catalysis, when molecular and even chemical interactions take place without any permanent chemical or physical change in the constitution of the body: a catalyst in this sense being a substance which, by its mere presence, effects chemical reaction without entering into the final product. First of all there is the formation of an unstable compound, the action is set going by the presence of a small quantity of the impurity until stable equilibrium is reached, and a series of chemical changes in which the final product and the active impurity are the same as at the beginning is the final result.

An agglomeration of molecules takes place, and by it an internal rearrangement of atoms in the production of light, with the separation of atomic groups of the same nature as those before the process, whilst the fact that phosphorescence depends so much upon the presence of impurities strongly supports this view of the cause of luminosity.

On the Effect of Molecular Concentrations on the Freedom of Corpuscles

Those large molecular agglomerations or centres of force so formed appear to be positively charged molecules, so that the corresponding negative cor- 
puscles are scattered freely within the substance when the large aggregates are brought about. The number of molecules is diminished and the freepaths of the corpuscles correspondingly increased. If the molecular concentrations be very great, as also the charges on them, the effect on the free-paths will be very considerable, and then by some means, such as by the action of violet or ultra-violet light, large molecular condensations are brought about and their charges neutralised. Any free negative corpuscles that remain will have a great opportunity of escaping from the body. Their velocities will not merely be increased by the more intense molecular attraction during the change in the molecular structure of the body, but they will also have greater freedom to diffuse out of the substance in virtue of the increased length of the free-path. Consequently a phosphorescent body, when exposed to the more refrangible rays of the spectrum, will lose negative electricity and emit a swarm of negative ions or corpuscles. This phenomenon has been observed by Lenard and Wolf (Wied. Ann., xxxvii. p. 443, 1889), and is of the same nature as the well-known discharge of negative electricity from a polished metal surface.

Whether the action of light is to produce similar molecular agglomerations in metals so as to give the corpuscles greater freedom, it is difficult to say; but the action of light on a metal, according to this view, should be to diminish its resistance, and 


\section{PHOSPHORESCENT MOLECULES $28 \mathrm{I}$}

this has been found to be the case with selenium. The substance would acquire something of the nature of a spongy structure, and the corpuscles would diffuse through it as hydrogen does through platinum. Similar effects are, as we know, produced, though in a smaller degree, in carbon and tellurium. A substance will emit these corpuscles in a greater or less degree according to the freedom with which the molecular agglomerations are formed in it and the size which they assume. Thus those substances ought to be most radio-active in the slow or easily absorbed $(\beta)$ rays whose molecules have the greatest tendency to concentrate round nuclei and to form into groups. Thin films of metals ought to be more transparent to cathode rays when they are exposed to light than when not, but this I have not been able so far to detect.

\section{Dependence of Phosphorescence upon the Free-poths and Velocity of the Corpuscles}

When it is borne in mind that the phosphorescence in gases takes place only at low pressures, when collisions seldom occur in comparison with those at higher pressures, we have a strong argument in favour of the existence of large aggregates of numerous atoms or molecules closely packed together in a single group. The charge of electricity carried by such molecules can, on account of their size, be likewise greater than the unit charge, so much so that they would, if they carried their maximum 


\section{THE ORIGIN OF LIFE}

charge, act as highly electrified particles. The corpuscles or electrons will be attracted towards them and towards the walls of the tube with great acceleration and attain great velocity if the freepath be sufficiently long; the free-path affects the nature of the collisions, if the approach with the molecules be sufficiently near, and then produces light. Those luminous molecules should be very large aggregates like clouds which are produced by ultra-violet light.

The phenomenon of the spontaneous discharge in high vacua illustrates this fact; for if the ionisation is first produced, phosphorescence is manifested when the free path reaches a certain amount. Thus when a discharge is sent through oxygen at pressures of about 2 or $3 \mathrm{~cm}$, and this pressure is reduced, no effect is observed until the pressure is below $0.7 \mathrm{~mm}$. The spectrum of this glow, observed by Schuster, which is the same as that of the negative glow in oxygen at the boundary of the dark space and beyond it, results doubtless from the collisions of the corpuscles with the molecules of the gas in moving through the dark space when the former have acquired a sufficient velocity under the electromotive force. The gas then begins to phosphoresce. There does not seem to be any reason to suppose that the diminution of pressure gives rise to any change in the gas, other than that of increasing the free-path of the molecules; unless an electric discharge is sent through it, so that when the free-path is of suffi- 


\section{PHOSPHORESCENT MOLECULES 283}

cient length the violence of the collisions becomes correspondingly increased. At first sight, indeed, it does not appear that the molecular attractions can give rise to such marked effects when the corpuscles collide with the aggregates, but we know that if large molecules exist and are highly charged, the molecular attraction would be considerable in deviating the path and attracting corpuscles towards the molecular groups. The effect of a collision is thus a function of the free-path of the corpuscles, and luminosity takes place when this reaches a certain length. The point is whether molecular forces very much larger than those contemplated in the ordinary kinetic theory can ever exist, and our endeavour is to prove, or at any rate to show, that there is considerable evidence for supposing that luminosity results from the existence of such forces.

On the Existence of Separate Phosphorescent Molecules in Liquids

When violet or ultra-violet light falls on a fluorescent substance such as a solution of sulphate of quinine, or glass coloured with oxide of uranium, a violent agitation of the molecules or atoms is set up, analogous to that which occurs when chemical action suddenly takes place, or on crystallisation, concussion, or some other exciting cause. So long as the exciting light falls on a fluorescent substance, the agitation of the 


\section{THE ORIGIN OF LIFE}

molecules is maintained, and during this state of things their structure is altered, but as the effect is only pro tempore, chemical change is not manifested and all is reduced to its initial state shortly after the incident light is removed, except in the case of phosphorescent bodies, when the return to the initial state is not rapid, but takes many minutes, or hours, or perhaps days. The molecules are thus during the period of excitation thrown into a new state of molecular grouping or aggregation, from which they gradually recover, when the light is shut off, slowly in the case of phosphorescent bodies, almost instantaneously in the case of fluorescent bodies, although here also it lasts for a fraction of a second. The agglomeration of molecules is of greater or less stability according as the body is phosphorescent or fluorescent, and this period can be increased by fixing the molecules in the case of liquids by means of glycerine or gelatin.

The addition of glycerine or gelatin to solutions of fluorescent liquids, as we have seen, produces a considerable increase in the intensity of the fluorescent light and also in its duration. This thickening of the solutions diminishes the loss of energy by collisions between the fuorescent molecules themselves, since in consequence of the lesser mobility and greater viscosity, the molecules of the same kind impinge much less frequently and therefore exist for a longer time. This concentration, how- 


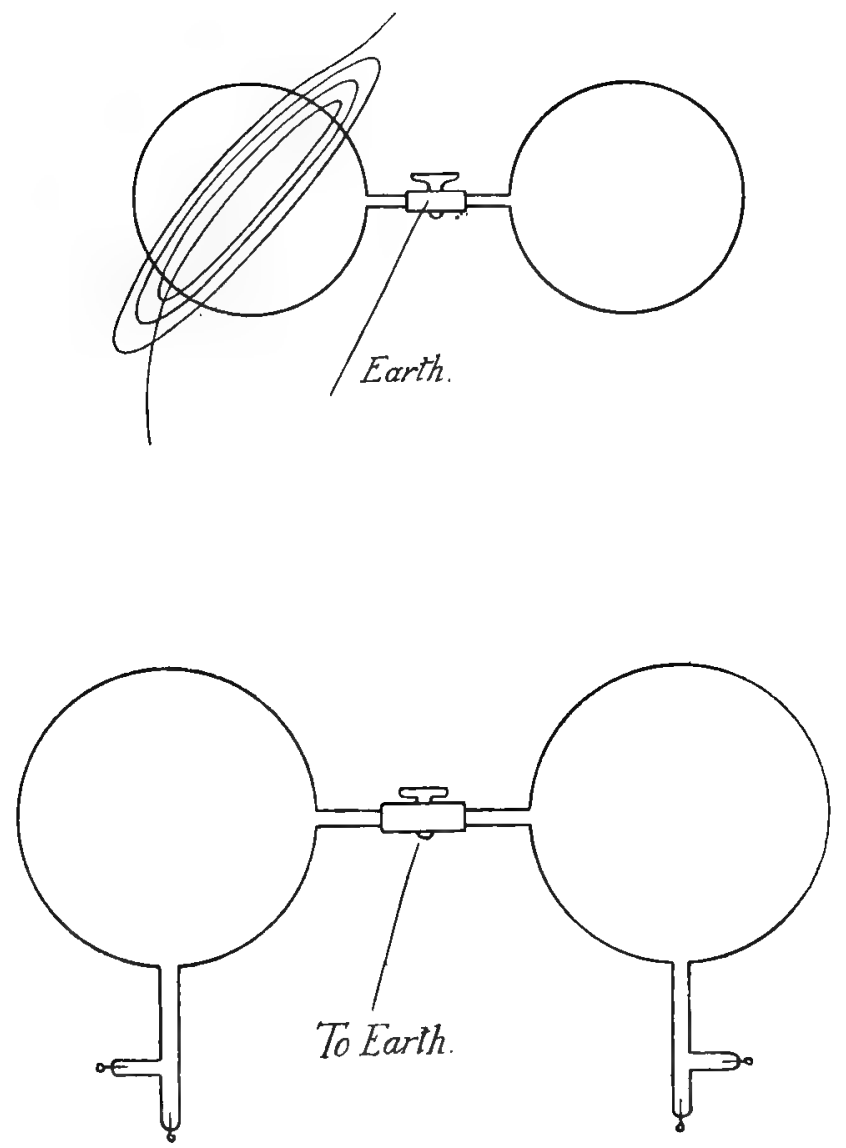

Apparatus for demonstrating the separate existence and nature of phosphorescent nolecules. 


\section{PHOSPHORESCENT MOLECULES 285}

ever, does not affect the freedom of the negative corpuscles to the same extent.

We may gather from these facts once more that the phenomenon of fluorescence is dependent upon the formation of distinct molecules, and that the fixing of these molecules by gelatin appears to be of a similar nature to that with which we are already familiar in' a photographic plate: with this exception, that the change in the latter case is more permanent.

Again, it is indeed remarkable with what pertinacity a particular mode of fluorescence attaches itself to a particular substance. The fluorescence of uranium nitrate, for instance, is the same in crystals which are doubly refracting, as in solution, and Stokes was led long ago to believe that in all probability the vibrations by which the fluorescent light is produced are vibrations of the constituent parts of the molecules themselves, and not vibrations in which the molecules more about amongst one another. It is the constituent parts that move about amongst one another, and it is the large positive aggregate that seems to be the chief factor in the performance of the process by which the luminosity is produced.

Existence of Separote Luminous Molecules in Gases

Under the influence of the exciting cause a certain amount of energy is stored up in a phosphorescent body and subsequently radiated in the form of light. 


\section{THE ORIGIN OF LIFE}

When a discharge is sent through a vacuum tube without electrodes, by the discharge of a Leyden jar through a few turns of wire wound round the tube, the effect produced inside the tube is due to the induced alternating current in the gas, and consists of a luminous ring discharge which gives rise to ionisation of the gas and to molecules, or groups of ions such that, if they carry a free charge of electricity, their size must be, for molecules, very large. They have a certain amount of energy stored up in them which is radiated away in the form of light. The duration of these more or less unstable molecules is greatly increased by removing them from the presence of the gas in which the discharge is produced (Burke, Philosophical Magazine, March, 1901). Thus if the phosphorescent gas is made to diffuse through narrow metal tubing from the bulb in which it is produced into another exhausted to the same degree, the metal tubing being at zero potential with the earth so that ordinary ions in the first bulb cannot diffuse into those in the second, the phosphorescence in the second bulb is greatly increased in brightness as well as in duration, from which we may gather that the presence of ions diminishes the duration of the glow and also that separate phosphorescent molecules exist and that if they carry a charge, they must be very large. ${ }^{1}$

I See J. S. Townsend on "Diffusion of Ions," Philosophical Magazine, 1898. 


\section{PHOSPHORESCENT MOLECULES 287}

The phosphorescent molecules produce ionisation in the gas as they pass through it, probably by the radiation they emit, which at molecular distances should exercise a sufficient influence upon neighbouring molecules so as to break them up into ions. The subsequent collisions between these and the glowing molecules would keep up the phosphorescence, although, if the number of such collisions is too numerous, the molecules would be completely broken up and the glow destroyed. The radiation from the glowing molecules would, however, be sufficient to mitigate the effects of ordinary collisions.

\section{That Separate Large Luminous Molecules Exist in Flames}

We have seen that from considerations as to the specific inductive capacity of gases, Thomson has deduced by means of a formula of Lorenz that in a luminous gas the spectral lines are not given out by every molecule, but only by a comparatively small number of systems formed in some way out of the molecules, perhaps by aggregations of greater complexity than the molecules. He considers that the systems which give out one line may be different from those which give out the others. These points, quite independently, support the theory of molecular aggregates in luminosity worked out in this book, some of the experimental evidence for which has already been described. Since his ob- 
servations on the change of absorption during fluorescence (Burke, Philosophical Transactions, 1898), it has appeared to the author that the phenomenon of fluorescence necessarily involves the temporary formation of new molecular aggregations to which the new emission and absorption spectra of fluorescent substances are due.

Thomson (Phil. Mag., December, 1895) has indicated the importance, from a physical point, of molecular aggregates in chemical theory, and his idea of chains of molecules in carrying the discharge in his "Recent Researches" is, we venture to think, one of the most useful conceptions in the theory of luminosity. The view put forward here that luminosity is a visible manifestation of a kind of catalytic action would be greatly strengthened if chains of molecules could be formed. The one strong objection, that such chains of molecules if they existed would very quickly be broken up by the bombardment of other molecules, does not appear to be sound, since the linkage between the molecules may be sufficiently great to enable them to hold together for some time, and this would be much longer in phosphorescent substances than in non-phosphorescent ones. Furthermore, Poynting has shown (loc. cit.) that spheres the size of molecules, if they radiate intensely, would exert considerable repulsive force on each other.

The small fall of potential in the positive column is a matter to which much attention has been given recently. There can be no doubt that 


\section{PHOSPHORESCENT MOLECULES 289}

the presence of such large luminous molecules will greatly facilitate the passage of the discharge. There is very strong evidence that luminous molecules in a gas do produce ionisation, and speaking generally, in the positive column in an ordinary electric discharge through a rarefied gas, namely, the part of the discharge extending from the positive electrode to close upon the negative electrode where a dark space exists, the electromotive force is comparatively small, the greater part of the force needed to produce the discharge being required in the neighbourhood of the negative electrode. Throughout the positive column the force is much too small to produce ionisation by collisions between ions and molecules, when the former are acted upon by the electric field. The fall of potential, that is, the electric force in the positive column, is from 5 to 30 volts per centimetre, whereas a force of between 200 and 300 volts per centimetre is usually the minimum to produce a discharge. It is thus probable that the ionisation in the positive column results from some kind of radiation from the molecules themselves. It is likewise not improbable that the ionisation which accompanies the phosphorescent after-glow is due to the radiation from the glowing molecules when they come very close to other molecules, that is, when they collide with them. It is therefore not merely the collision between ions, but those between luminous molecules that should be taken into account.

In fact, molecular theory in its relation to the 


\section{THE ORIGIN OF LIFE}

theory of luminosity must be looked at from a more detailed point of view than that in which the kinetic theory is generally regarded, which has no special reference to physical foundations and the conceptions involved therein. Stoney's paper "On the Kinetic Theory of Gases, as illustrating Nature" (Proc. Roy. Dubl. Soc., 1895), is of great critical value and importance in its bearing upon some of these questions.

The energy which we know is stored up in a gas and may be given out in certain circumstances is that to which chemical combinations and explosions can be attributed. An enormous amount of energy may be stored up in the atom without any account being taken of it in the kinetic theory. The rotations too rapid to be radiated, assuming the æther to have a molecular structure, must be the sources of several phenomena when those rotations are slowed down by the approach of a corpuscle to the molecular system.

When the rotations exceed a certain limit, the body becomes radio-active and shoots off an electron or a corpuscle. And this would be accompanied in some cases with a non-deflectable but highly penetrating radiation, namely the ultraultra-violet, very rapid vibrations which may approach the limit of the frequencies that the æther can transmit.

The phosphorescence then results from the collision of the corpuscles with the concentrated groups or aggregates of molecules. The a rays are shot 


\section{PHOSPHORESCENT MOLECULES 29I}

off at the same time, much more easily than a corpuscle, as it is of the same sign as the aggregate. The $\beta$ rays are the corpuscles which are either shot out with a great velocity or on account of the molecular concentration and increased free-path acquire greater freedom and diffuse out of the body. 


\section{CHAPTER XVII}

\section{RADIO-ACTIVITY AND PHOSPHORESCENCE}

Molecular theory of phosphorescence and of radio-activityAnalogy between phosphorescent molecules and those of radio-active emanation from thorium and radium compounds-Model of radio-active and phosphorescent molecules-Model of positive ion-The electric theory of matter.

Molecular Theory of Phosphorescence and of Radio-Activity

LoRD KeLvin has shown that the result of repeated collisions between molecules will be to transform their translational energy into energy of higher and higher nodal sub-divisions, and if the molecules, like billiard balls, have a sufficient and almost indefinite number of degrees of freedom, all the energy of translation will become transformed into these higher and higher vibrations, so that ultimately in the case of such molecules their energy will be radiated away. Fitzgerald calculated that the air in a room 5 metres cube should lose all its energy in about fifteen 


\section{PHOSPHORESCENT ACTIVITY 293}

minutes, if this process actually takes place. It is a matter of experience that the internal energy is not thus dissipated away. Why, then, does it not take place? The Boltzmann-Maxwell Law, which states that the partition of energy is equally divided between various degrees of freedom in the molecule, does not permit us to assume that a molecule has more than a very small number of degrees of freedom. If very complex aggregates of molecules exist, as in the case of phosphorescence, this transference of energy may to some extent take place until the aggregates are broken up. In the case of non-phosphorescent but luminous gases these may, and probably do, nevertheless exist, but only for a brief period, during which they radiate some of their energy to the æther. In this manner a number of degrees of freedom of luminous molecules would be very different from those of non-luminous molecules, and if there are a large number of luminous molecules in a gas, the ratio of the specific heats in a luminous gas would be quite different from that in a gas in a non-luminous state.

The existence of such large, more or less permanent, molecular groups, as in the case of phosphorescent bodies, will enable them to transform their energy of translation to the æther, whilst their small number prevents their temperature from falling below that of surrounding objects.

If, then, the duration of the phosphorescence is very great, it would result from the fact that such 


\section{THE ORIGIN OF LIFE}

molecules or molecular groups are more or less stable. The higher and higher vibrations-within these molecular groups - set up by collision with other molecules must ultimately reach a limit when they cannot be given up to the æther; for if the æether has a molecular structure, there must be a limit to the frequency of vibrations which it will transmit. Thus the energy of the high frequency vibrations will accumulate in the immediate neighbourhood of the source of vibration. When the amplitude becomes very great as the energy is not radiated away, the corpuscle is shot off and we have $\boldsymbol{a}$ or $\beta$ rays according as the corpuscle is positive or negative; whilst the $\gamma$ rays are merely ultra-ultra-violet vibrations which are not too rapid to be refused transmission by the rether. The wave-length of vibrations which are just taken up by the æther must be of the order of magnitude of the distance between its consecutive particles. This theory, which I have been working at for some time past, has the advantage of fitting in with the facts of radio-activity, of phosphorescence and of bridging over the serious difficulty between the facts of Iuminosity as revealed by the spectroscope and the number of degrees of freedom, according to the kinetic theory, in a luminous gas. 


\section{PHOSPHORESCENT ACTIVITY 295}

Analogy between Phosphorescent Molecules and Radio-active Emanation from Thorium Oxide and Radium Bromide

In the Phil. Mag. (loc. cit.), the author described some experiments which indicated that when a discharge is sent through a gas which gives an after-glow, molecules are formed that apparently do not carry a free charge of electricity, unless the molecules are very large, and they produce conductivity in the gas as they pass through it. These phosphorescent molecules can be made to diffuse through narrow metal tubing well earthed; but their rate of diffusion is rather small, and the ionisation to which they give rise is doubtless due to the radiation they emit, which at a collision, as will be shown, is sufficient to produce ionisation. There is a striking resemblance between the behaviour of these phosphorescent molecules and that of the emanation from thorium oxide, as was then pointed out, since the latter also appear not to carry a free charge of electricity, but to produce ionisation in a gas through which it passes. This emanation is a gas which disintegrates into helium. The phosphorescent glow was found to penetrate thin sheets of aluminium, but on careful examination it was discovered that this effect was of a secondary nature.

If the emanation really gets through aluminium the phenomenon must be one of singular importance, since the molecules diffuse as do the 


\section{THE ORIGIN OF LIFE}

ordinary molecules of a gas. Their size and velocity are those of the molecules of a gas with the atomic weight lying between the above limits.

These molecules, although they do not appear to carry a free charge of electricity, are nevertheless always attracted towards an electrode which is negatively charged. They also give out a radiation which is very penetrating and not deflected by a magnet.

\section{Model of Radio-active and Phosphorescent} Molecules

If a charged sphere is oscillating round a fixed centre, in such a manner that the period of vibration of the sphere is less than that of the electricity over the surface, ${ }^{1}$ the electromotive intensity and the magnetic force diminish very rapidly as we recede from the sphere, the magnetic field being practically confined to the inside of the sphere; so that in this case the energy of the moving sphere remains in its immediate neighbourhood. Hence if we imagine a molecule like this it is only at a collision that a molecule which behaves in this fashion will exercise its influence on surrounding molecules.

We are familiar with vibrations of electrons which give rise to undulations in the rther, whose refrangibility can give spectra many times the length of the visible spectrum, but there does not

1 See J. J. Thomson, Phil. Mag., 1881; also "Recent Researches." 


\section{PHOSPHORESCENT ACTIVITY 297}

appear to be any reason to suppose that there should not be vibrations of a much more rapid period than those which have yet been observed, and to ignore this fact is to obscure our minds to the possibilities of discovering phenomena which undoubtedly exist and which we may be sure perform an important part in the phenomena of Nature.

Thus the well-known model of fluorescence suggested by Stokes can be applied in another way than that proposed by him to the rether so as to show that if the vibrations of the electrons on the atoms are more rapid than a certain period, the minimum period which the æther-as a solid or fluid with ultimate molecular structure-can transmit, the energy of the vibrations, instead of being radiated away, becomes confined to the neighbourhood of the atom and its interior. The solution of one of the great difficulties in the kinetic theory pointed out by Lord Kelvin and FitzGerald is greatly facilitated by this conception. "The average effect of repeated mutual collisions must be to convert all the energy of translation into shriller and shriller vibrations of the molecules, and when each molecule is a continuous elastic solid it is rigorously demonstrable that the whole translational energy must ultimately be transformed into vibrational energy of higher and higher nodal sub-divisions." This seems to be correct, for instance, in the case of billiard balls, since they have an infinite number of degrees of freedom. Hence the energy of the vibrations when the frequency becomes too rapid to be 


\section{THE ORIGIN OF LIFE}

radiated is simply stored up in the atom, and it therefore becomes, as it were, a storehouse of energy in the æether.

We know that an electron cannot move faster than the velocity of light. Hence if $n$ be the frequency of a vibration and $r=$ radius of the orbit of the electron as a limit, $n=\frac{3 \times 10^{10}}{2 \pi r}$.

If $n$ becomes greater than this value-r being the minimum radius of the orbit-the electron will necessarily fly off. If $r$ be equal to $10^{-8}$, then the frequency of vibration at which the electron is shot off is equal to $10^{18}$. But we have reason to think that the value of $r$ is very much less than that which corresponds to the radius of the sphere of action of a molecule; consequently $n$ is greater than $10^{18}$. The energy of the corpuscles thus shot off will by their collisions increase the energy of translation of the molecules with which they may collide, and as their velocity is diminished they will ultimately be caught by a molecule and absorbed by it; then this whole process is repeated again. The energy which is dissipated is only that which the æther takes up before the vibrations are rapid enough not to affect it.

If $\alpha=$ distance between two consecutive particles in the æether, then $n=\frac{3 \times 10^{10}}{\pi \alpha}$ if the analogy of a stretched cord with pellets is to hold, $\alpha$ being the distance between two consecutive particles in the æther. The condition, therefore, that energy should be stored up in the atoms is that the distance 
between two consecutive particles in the æther should be greater than the minimum diameter of the orbit of an electron.

\section{Model of the Positive Ion}

It is a question worth considering whether a system vibrating in such a manner as not to lose its energy by radiation will exert a repulsive or an attractive force upon neighbouring objects, and it seems probable that a negative corpuscle will be attracted rather than repelled by an atom, the vibrational energy in which is not dissipated, but assumes the form of potential energy in the atom.

The force acting on a corpuscle, instead of acting outwards as a repulsion, becomes converted into an attraction. The energy of the vibrations, instead of flowing outwards, flows inwards towards the molecule, and the pressure acting on a neighbouring electron will be reversed, the distribution of force being turned inside out. The atom or molecule will thus be attracted towards a negatively electrified body, and behave as a positive ion. Is a positive ion, then, nothing more than a regative ion consisting of a large system of corpuscles in a most violent state of agitation? It is most likely.

An electron rotating in such a manner as not to radiate will act just as a gyrostat. The connection between the electron and the æther will 
produce a drag on the latter in the nature of a permanent rotational strain; but if by some means the frequency of rotation of the rotating electron, constituting the gyrostatic system, can be diminished, the atomic system will radiate energy to the æther when the period is sufficiently diminished. This can be accomplished by the approach of a negative corpuscle which will take up some of the energy of the system and slow down the motion. Hence, when a collision takes place between a corpuscle and the positive ion or atom, which we have devised, radiation occurs. While it is radiating the ion behaves as if it were not charged. When the corpuscle and the rotating electron come very close together, it is easy to see that the average effect of the latter on the former is a repulsive one. The corpuscle and so-called positive atom will move about together and rotate, but never ultimately unite till, by the influence of collisions, the vibrations which the corpuscle controls cause this to fly off, and the internal vibrations of the electron are again increased by subsequent molecular collisions. There will be again radiations before reaching the nonradiative periods of oscillation, whilst potential energy is again stored up in the æther. Thus radiation occurs whenever association or dissociation takes place.

The effect of molecular agglomerations, then, is to attract negative corpuscles to set free the potential energy which is stored up in the atom 


\section{MODEL OF POSITIVE ION 301}

in the form of very rapid vibration. If there are certain free periods in the atom, then in the transformation downwards of the rotations of the electron the radiation will become intense as it passes through these periods. Thus we arrive at an explanation of the results of experiments that, speaking generally, the spectrum of the fluorescent light is independent of that of the exciting cause, so that when ultra-violet light falls upon a fluorescent body the association or dissociation produced is accompanied by radiation in the same part of the spectrum, whatever the wave-length of the exciting light.

This model will lead us in search of forms of radiation of a very penetrating kind from the positive ion, as doubtless free periods of very high frequency exist in the molecule to which the intrinsic energy of a positive ion will most effectively yield, as in the emanation from thorium oxide and radium bromide.

The phosphorescent molecules in a phosphorescent gas will not carry a free charge so long as they are radiating, and will radiate in virtue of the close proximity of the negative corpuscles. The molecular agglomerations are an indispensable part of the process in attracting the corpuscles so as to liberate the potential energy of the atoms composing them, which if scattered at comparatively great distances do not accomplish the associations with the same facility. 


\section{The Electric Theory of Matter}

An "analogy is often a deceitful guide," yet even in its most dangerous and adventurous pursuits it may sometimes prove to be a helper and friend of the pioneer worker and the guide that arouses some of his loftiest thoughts and inspirations.

Memorable epigrams are after all only epigrams, even if they have originated from the pens of great masters. They seldom convey more than one aspect of the truth, and analogy may, no doubt, be followed with advantage, when due caution is exercised, and it is not too much to say that some of the great strides which science, and in particularly physical science, has made in recent years have been due, to no small extent, to the help which has been derived from the use of mechanical contrivances and dynamical analogies that represent the processes underlying the actions of Nature.

More particularly has this method been fruitful in attacking the problems presented by electricity and matter and their relation to the æther.

The theory of matter, which is now engaging so much attention, may be said to be the direct outcome of the earlier studies of the present occupant of the Chair of Newton at Cambridge, embodied in two voluminous memoirs on "The Dynamical Theory of the Laminiferous Ætther" and on "The Theory of Electrons," published in the Philosophical Transactions some ten years ago. 


\section{ELECTRIC THEORY OF MATTER $3 \circ 3$}

Fifteen years ago the theory of matter as we find it to-day might have been ruled out of court. But the work of Professor Larmor at Cambridge and of Lorenz at Leyden made it quite clear that the radiation from the atom could be accounted for by the rotation of negative electrons round the atom and that the atom itself is made up of electrons; whilst that of Zeeman tended to confirm the view that the mass of these electrons is much smaller than that of the atom. There were many reasons as well for supposing that cathode rays are also of this nature, since it was known from the researches of Lenard that they could penetrate thin sheets of metal, and that their magnetic deflection is independent of the gas in the tube which they traversed; whilst their absorption by matter is directly proportional to the density. The more acute thinkers already perceived that electrons were on the horizon. Some workers were already engaged in determining the ratio of the charge carried by the cathode ray to its mass. Almost simultaneously J. J. Thomson in England and Kauffmann in Germany published independently within a few days similar results, which seemed to identify the cathode rays with electrons. The latter, indeed, has since shown that the mass depends upon the velocity and is thus a variable quantity. Thomson, on the other hand, has identified the charge on the cathode rays with that of the electron, or unit charge of electricity. His determinations were those of the charge carried by the 


\section{THE ORIGIN OF LIFE}

ions when produced in a gas by Röntgen or Becquerel rays, and these are doubtless slow-moving cathode rays. It is a matter of induction that the cathode rays also carry this charge, and there can be little doubt that these also are negative electrons, disembodied atomic charges of electricity of much smaller mass than the atom.

But of electrons there are two kinds, positive and negative. The word "corpuscle" has been suggested for the smaller or negative electron, as the positive electron is supposed to be made up of the others and to be merely an atom from which a corpuscle has been removed.

A difficulty, however, remains for which no satisfactory solution has been offered. We are given a number of mutually repelling particles, units of negative electricity-and it is said that they can so form themselves into a community-which as a whole can act as a unit of positive electricity; and this group of mutually repelling units of negative electricity, it is supposed, will, when acting in concert, attract another similar unit of the same kind, which they all separately and individually repel.

Still, notwithstanding all this, there are reasons for supposing that the atom is built up of the corpuscles, and that the positive ion is the atom deprived of a corpuscle; so that the second is merely an aggregate of the first.

How and in what manner the properties of electrons are to be accounted for in this way is a problem which awaits solution. 


\section{ELECTRIC THEORY OF MATTER 305}

Thus the theory of positive and negative electricity still eludes our grasp as much, if not more so, than the theory of gravitation; but although a satisfactory clue has not yet been given, it is probable that matter is made up of one kind of electricity only, and that the originality and ingenuity of the Cavendish professor may find a way of explaining it.

These difficulties, however, should not be so emphasised as to stand in the way of the earnest worker, in search beyond these strange enigmas for an answer to the riddle they present. Questions at one time apparently as difficult have now yielded, though reluctantly, their solutions, which even the most critical have accepted. May it not be hoped that the problem of matter and of electricity too will be solved by such piercing methods of scientific investigation? The lessons of the past may in their turn help to lighten the views we may take of the future; for is it not persistency and resource that pave the way for that success which is not ephemeral, but lasting?

With all its faults, it is to the scientific imagination, once more, with its flights of fancy into unknown realms of speculative thought, that even the most sceptical must look to seek salvation. It is to the experienced guide who can let his fancy go, when on safe ground, but knows when to pull up, that we have to entrust ourselves. Such investigators as Tyndall, Maxwell, and Faraday did not content themselves to work like bees or bricklayers, adding in their own dull way to the 


\section{THE ORIGIN OF LIFE}

vast edifice which they laboured to erect. New observations are made only by those who are on the alert. It was Pasteur, if we remember rightly, who said that "in the great field of observation chance only favours those who are prepared." There is a tendency amongst would-be crities to distrust, and even to discourage, these natural flights of the speculative mind, quite forgetting that in science creative and destructive thought are partners, allies in the same field.

The idea, however inconclusive in its present form, that the chemical atoms of which matter is composed are built up of electrons of one type, that matter is electricity, is, notwithstanding many diffculties, slowly but surely gaining ground. Beautiful models have been devised by Thomson to illustrate the structure of the atom and the way in which it may be supposed to be built up of electrons. The agreement, on the whole, with the periodic law, notwithstanding some exceptions, is certainly remarkable. There are some gaps which still remain to be bridged over. The models are confined to two dimensions, and may be supposed to lose much of their value on that account; but the analogy is so striking that, approximately at least, it seems possible, if not also probable, that the atom is itself flat and two-dimensional! Like little solar systems the rotations of each group would be merely in one plane, and, like a top, spin with rigidity and stability. Those critics whose knowledge is but second-hand, not being actively engaged 


\section{ELECTRIC THEORY OF MATTER 307}

in science, may endeavour to throw dust in the eyes of earnest workers, but the progress of the world will continue to be made, not by those who destroy and pull to bits, but by those who create and put together. In Science, as in Letters, we may say with Matthew Arnold that, "To have the sense of creative activity is the great happiness and proof of being alive, and it is not denied to criticism to have it; there is the promised land towards which we can only beckon. That promised land it may not be our lot to enter, and we may die in the wilderness; but to have desired to enter it, to have saluted it from afar, is already the best distinction amongst contemporaries: it will certainly be the best title to esteem with posterity." 


\section{CHAPTER XVIII}

MODELS OF POSITIVE ION OR ATOMIC NUCLEUS

Fluorescence of monatomic gases-Effect of specific inductive capacity on molecular aggregation-Difficulties in the kinetic theory-Nature of positive nucleus-Effect of approach of corpuscles on motion in nucleus-Balmer's law -Ramage's observations-Transmutation of the elements of same series-Aggregations produced by pressureModels of molecules in phosphorescent gases and in emanations.

THE fluorescence of the monatomic gases presents a striking anomaly in many respects, and opens up many new lines of thought and investigation. It was hoped that experiments upon this phenomenon would help to elucidate, in some degree further, some of the problems which bear so closely upon these questions, but still remain unsolved.

In dealing with them it is worthy of note that helium is found in small quantities in many fluorescent substances, such as compounds of uranium, yttrium, tungsten, zirconium, thorium, etc., and it seemed quite possible that the gas might exhibit phosphorescence when subjected to the influence of ultra-violet light. Helium is one of the most phosphorescent of all gases under the influence of the electric spark. 


\section{MODELS OF POSITIVE ION}

About three years ago some experiments were carried out by the author on the fluorescence of the metallic vapours of sodium and potassium. They were undertaken with the view of determining whether the Zeeman effect exists in the case of gases in a state of fluorescence or to determine whether the fluorescent light is polarised in a magnetic field, even in the continuous part of the spectrum. Sodium gives the $D_{1}$ and $D_{2}$ lines when fluorescent, as discovered by Wiedemann and Schmidt, as also the continuous or fluted bands corresponding to the absorption spectrum of the gas, when cold. Similarly with the fluorescence spectrum of potassium vapour it was again the absorption spectrum that was visible whilst the bright $\mathrm{K}$ lines were invisible. The experiments were entireiy negative as regards the effect of a magnetic field on the polarisation, and, moreover, the effects which it was hoped would be detected at the borders of the bands could not be found.

The condensation of the metallic vapour on the walls of the tube was a source of very great trouble in the above experiments; but the condensed vapour on the glass showed also a distinct change of refrangibility, and the fluorescence was much greater.

It is interesting to note that the $\mathrm{Hg}$ vapour also shows a very marked tendency, under very slight provocation, such as the falling of mercury drops in a mercury still, to luminesce when it condenses on the glass. The light is green and characteristic 


\section{I0 THE ORIGIN OF LIFE}

of mercury, and quite distinct from that which is observed by the friction of mercury on glass. The great luminous efficiency of the discharge in mercury vapour may be attributed to the readiness with which the mercury molecule or aggregate of molecules breaks up.

It is therefore worthy of note that so many of the monatomic gases phosphoresce; the ordinary gases do not show this property except when, as we have seen, condensation takes place on the walls of the tube: in which case even the fluorescence of the metallic vapours is greatly increased.

We attribute this to the influence of a substance of high specific inductive capacity in enabling the electrons to interchange, according to the theory put forward.

The monatomic gases, and other fluorescent gases, have a high specific inductive capacity, oxygen and air being exceptions. Thus the refractive indices of

$\begin{array}{ll}\text { Cyanogen } & =1 \cdot 000834 \\ \text { Nitrous oxide } & =1.000503 \\ \text { Phosphorous vapour } & =1 \cdot 001364 \\ \text { Arsenic } & =1.001114\end{array}$

The phosphorescence of oxygen does not need a substance of high specific inductive capacity to bring about the molecular aggregates.

The motion of mercury on glass is well known to give rise to luminosity. I have found it does not take place in a Torricellian vacuum, but depends upon the presence of air, and then spreads 


\section{MODELS OF POSITIVE ION 3 II}

gradually, as the air is rarefied, into the volume of the gas. It also occurs only at pressures about which the other phenomena of phosphorescence in gases take place, the limits, however, being somewhat wider.

If the thickness of the layer is comparable with the sphere of molecular forces, the amount of chemical decomposition will also be very small, as the quantity of matter will be equally so. R. Threlfall and Miss Martin (Proc. Camb. Phil. Soc., 1877) endeavoured to detect the presence of ozone at the pressures at which a variation from Boyle's law had been found to exist by Bohr, Baly and Ramsay, and others, but they failed to detect any traces of it by chemical means.

The chemical changes which take place at the surface layers, which we have been considering, may be such as we have no experience of at the ordinary temperature from experiments with large masses.

\section{Chemical Combinations in High Vacua}

We have put forward the hypothesis, which, as we have seen, has found support in the results of numerous experiments described in this and in previous works, and also in those by various other investigators, that the phosphorescence in gases is started by the interchange of carriers between atoms that do not carry the charges that correspond to them, such, for instance, as a positively charged oxygen 


\section{THE ORIGIN OF LIFE}

atom and a negatively charged hydrogen one, as the passage of a discharge through the gas ought to produce an equal number of positively and negatively charged atoms of both substances.

It has been shown that when condensation of the gas takes place on the walls of the vacuum tube the interchange of carriers is facilitated, as also when a foreign substance is present in the gas, the molecules of which would act as nuclei, and again enhance the possibility of the interchange of charges to take place.

We have, in fact, a certain amount of energy stored up in a gas by the passage of a discharge through it, and in solids and liquids by the other sources that give rise to phosphorescence: by Entladungstrahlen, ultra-violet light, Becquerel rays, Röntgen rays, cathode rays, or by the radiation from radio-active substances similar to cathode rays.

Professor J. J. Thomson has illustrated by a gyrostatic model (loc. cit.) the behaviour of an atom, according as the charge which it carries is or is not the one for which it has a specific attraction. He has shown that the internal potential energy of a hydrogen atom is greater when it has a negative charge than when it has a positive one; and conversely that that of an oxygen atom will be greater when it carries a positive than when it carries a negative charge. $\mathrm{He}$ also deduces from this that forces will be brought into play between charged atoms placed very close together, in addi- 
tion to those given by the ordinary laws of electrostatics. It would make the attraction between a positively charged oxygen atom and a negatively charged hydrogen atom less than that between a negatively charged oxygen atom and a positively charged hydrogen one. It is to these unstable or nascent ions that we may once more attribute the stored-up energy which in suitable conditions can be given up as phosphorescent light.

If the energy stored up be great there is very little chance of these ions recombining, and the two forces, those brought into play by the conditions of the wrong charges and the electrostatic ones, may neutralise each other, or perhaps actually be repelled.

This would enable them to maintain their separate existence for a very long time, until the conditions are such that condensation occurs on the walls of the vacuum tube, when the interchange, according to the theory, must take place, and as a consequence of which luminosity will be the visible manifestation.

The identity between the spectrum of the "pressure glow" and that of the negative glow in oxygen suggests that something similar occurs beyond the boundary of the dark space.

The passage of a discharge through a gas must give rise to both the stable and unstable ions, and when the latter come within the path of the cathode rays they will act as nuclei which will facilitate the interchange of carriers, during which new molecules 


\subsection{THE ORIGIN OF LIFE}

will be formed, which will emit light and admit of being blown about. They will last for some time unless they are exposed to the excessive influence of the cathode rays, as they would cause them to radiate too intensely and therefore give up their energy in a much shorter time.

It is not improbable that some of the cathode rays, when they have acquired a sufficient velocity under the electromotive force, produce both the stable and unstable ionisation, and that others act as nuclei round which agglomeration takes place and which thus facilitates the necessary interchange between the charges on the unstable ions.

We have already seen that in phosphorescent liquids it is probably the positive ion that plays the important part in the luminosity. It seems probable also that it is the positive oxygen atom that plays the important part in the luminosity of gases. As we have seen, oxygen behaves as if it were the carrier of electricity at the boundary of the dark space in nitrogen containing a trace of oxygen; as well as in air, nitric oxide, and oxygen. Moreover, the fact that water vapour also performs a by no means unimportant part in the passage of electricity through gases suggests the formation of the unstable compound hydrogen peroxide, $\mathrm{H}_{2} \mathrm{O}_{2}$. We shall consider this point more fully when we come to examine the conditions which give rise to the glow of the vapour of phosphorus.

Thomson (Proc. Roy. Soc., vol. i., viii., p. 244) has inferred from experiments on the spectrum of 


\section{MODELS OF POSITIVE ION 3I5}

carbon, that the spectrum depends upon whether the ion or atom that is radiating carries a positive or a negative charge.

In the present case, we think it is the positive unstable atom of oxygen that is the chief factor in the production of the continuous or band spectrum of the negative glow.

We know, as Schuster has observed, that the spectrum of the negative glow is made up of three parts, namely, the high temperature spectrum of oxygen, the spectrum of the positive pole, and the continuous or band spectrum. The spectrum of the positive pole would seem to be that of the negative atoms of oxygen, and the band spectrum of the negative glow that of the positive.

\section{Models of the Atomic Nuclei}

It was with the endeavour to arrive at a comprehensive hypothesis which should form the basis of a mechanical model, by analogies, and by the sifting of facts already within our knowledge, as well as by the results of experiments suggested by these analogies, that this work was undertaken. But it was not, as might indeed have been anticipated, without successive failures that the theory which forms the substance of this book has been found to be, so far, the fittest to survive, and been adapted, but only after a direct appeal to Nature in many instances had been satisfied.

It will help to clear the ideas if we were to 


\section{$3^{16}$ THE ORIGIN OF LIFE}

indicate the problem proposed in the case of luminosity in terms such as these. When billiard balls knock about, their translational energy is quickly turned into more and more rapid internal motions until it all gradually gets degraded into heat. The question is why the same does not go on in molecules.

It is generally assumed that there exists some mechanism, in all bodies, by which rapid vibrations, when absorbed, become gradually changed into the slow kind of vibrations that correspond to the average temperature of the body. In most bodies this action is supposed to take place pretty rapidly and continuously. In all probability, in solids and in liquids vibrations of intermediate rates are about equally excited, and are similarly affected; while in fluorescent and phosphorescent bodies these vibrations, on their way down from the rapid to the slow periods, corresponding to the temperature of the body, excite the fluorescent and phosphorescent rates of vibration intensely; and these vibrations, being only very slowly turned into the slower rates, as well as pretty intensely radiated, we see them as fluorescent and phosphorescent light.

The question is why all the vibrations do not get converted into more and more rapid ones instead of vice versâ. The answer is that they do get so converted into shriller and shriller vibrations, but that the energy of these vibrations, when their frequency exceeds a certain limit, is 
not radiated away, and accumulates in the atom when the energy of vibration becomes so great that the atom shoots off an electron, and thus converting its energy of translation to the molecules with which it collides, so that the original energy of translation of the molecules, which was converted into more and more rapid vibrations in the atom, is again returned into translational energy, minus, of course, the small amount of energy which was radiated by the atoms in the conversion of the vibrations into shriller and shriller ones.

We have an illustration of the very rapid vibrations in the radiations from uranium, which are non-deflectable by a magnet and not absorbed, also the highly penetrating and likewise nondeflectable rays from thorium. They resemble the "soft" and "hard" Röntgen rays, except in so far that they probably are trains of rapid oscillation, whereas the latter are admitted to be thin pulses in the æther. The corpuscles which also accompany these are a necessary consequence of the process.

As we have said that the action of violet or ultra-violet light is to produce in some cases a permanent and in others a temporary chemical change, by giving rise to molecular agglomerations; so that the phenomenon of fluorescence or phosphorescence is of secondary nature, resulting from the approach towards those molecules of the negative corpuscles, by which means the stored-up 


\section{THE ORIGIN OF LIFE}

energy of the molecular aggregates is lowered in frequency and delivered up to the æther. The extent to which this is accomplished depends upon the proximity of the corpuscles, and that again will depend upon their velocity, so that the greater its velocity, the more closely will it approach the rotating gyrostatic system of electrons in the atom, and cause them to give up some of their energy to the æther. We presuppose, therefore, the existence of these free corpuscles in a substance, and it is implied they must be made to approach a molecule with some considerable violence before the internal energy can be transformed down and the molecule become luminous. This is accomplished by the aid of great aggregates of molecules. The change of refrangibility of light and the change of absorption are once more the necessary consequences of the approach of a corpuscle to the gyrostatic system of electrons. If the absorption spectrum is in the ultra-violet it is lowered in a particular molecule, while fluorescing, to the visible part of the spectrum. This spectrum of the emitted light will be the same whether the fluorescence is excited by ultra-violet light or by cathode rays, since in every case it is the approach of the corpuscle to its partner that causes the luminosity.

The internal motions in the atom are brought within the reach of our visible spectrum under the influence of neighbouring corpuscles, by whose presence it is enabled to rid itself of some of its internal energy. The periods corresponding to 


\section{MODELS OF POSITIVE ION}

the radiation therefrom necessarily exist only during the period of radiation. ${ }^{1}$

It is generally admitted, although disputed by some eminent authorities, that a gas cannot be rendered luminous by the mere process of heating until chemical action, in some form or another, takes place; for instance, the presence of a salt in such cases, in which it may act chemically, is indispensable to the production of a spectrum. The free periods would, therefore, depend upon the presence of a foreign substance. The same atom will always give out the same spectrum, but the free periods will exist only when the corpuscle and the atom are within each other's reach. Thus the actual number of degrees of freedom in an atom will depend upon the arrangement of corpuscles around it, so that the Boltzmann-Maxwell law is not interfered with as long as the gas is not radiating, the number of degrees of freedom in an atom, as indicated by its spectrum, in no way corresponding with its number of degrees of freedom when not radiating. The actual number of internal degrees of freedom in an atom will depend upon the number of corpuscles that it carries, and these need not be more than one or two or three as indicated by the ratio of the specific heats.

The great complex of lines in the spectrum of an element will depend upon the closeness of the

1 This appears to be a most important point in the kinetic theory. 


\section{THE ORIGIN OF LIFE}

corpuscle to the gyrostatic system, and in all probability different lines in the spectrum are due to different atoms, as the experiments of Schuster and Hemsalech on the mechanism of the spark seem to show (Philosophical Transactions, A, 1899). ${ }^{1}$

They found that when photographs of the spectrum of a spark between metal electrodes were taken upon a rapidly moving film, the lines in the spectrum are not all curved to the same extent, but that some of the short lines in the spectra of the metal electrodes are very much curved whilst others are not so, these lines forming the spectra of the same element. It seems justifiable to infer from this that the various lines in the spectrum of an element are not given out by a single atom, but by different atoms moving with different velocities, the faster ones, and presumably also the smaller ones, giving the more refrangible rays. The atoms of an element need not be all of the same size, but more probably range themselves round a certain average value. The period of the vibration which the atom will communicate to the æther will depend only upon the distance of the corpuscle from the gyrostatic system, so that if the corpuscle always fixes itself at the same distance, the new period of the gyrostat will always be the same. The atom and the

1 The doublets are more displaced than the triplets; yet the displacements of corresponding lines in zine and cadmium are the same. 


\section{MODELS OF POSITIVE ION $32 \mathrm{I}$}

corpuscle will for the same element be related to each other according to a definite law, and the period by which the gyrostat is affected will depend upon the relationship of corpuscles with the atom, so that the various periods of the gyrostats in different atoms will follow a corresponding law.

\section{Balmer's Law}

We have endeavoured to arrive at a general law connecting the frequencies of these various vibrations communicated to the æther by the atoms of an element.

Thus if $n_{0}$ be the fundamental frequency of an electron and $n$ its period when it radiates under the influence of the corpuscle, then supposing we regard a Faraday tube extending between the corpuscle and the atom as a bundle of vortex filaments, as Thomson has shown, the effective inertia of the tube would involve a term proportional to the square of the polarisation. Now the ratio of the change in the moment of momentum of the radiating system to that in its original state is equal to the ratio of the difference between the original inertia and the inertia of the Faraday tube to the original inertia, so that

$$
\begin{aligned}
\frac{n_{0}-n}{n_{0}}=\frac{i}{i_{0}} \text { when } i & =\text { inertia of Faraday tube, } \\
i_{0} & =\text { total inertia of field. }
\end{aligned}
$$




\section{THE ORIGIN OF LIFE}

Then

$\frac{n_{0}-n}{n_{0}}=\frac{K P^{2}}{8 \pi}$ when $P$ is the polarisation and $K=$ constant.

Hence

$$
1-\frac{n}{n_{0}}=\frac{K P^{2}}{44} \text { and } n=n_{0}\left(1-\frac{4}{K P^{2}}\right),
$$

which agrees with the known relation between the frequencies discovered by Balmer.

$P$ is proportional to the number of corpuscles in the neighbourhood of the nucleus.

The value of $n_{0}$ depends upon the mass of the atom or nucleus. The researches of Ramage (Proc. Roy. Soc., vol. Ixx.) show that when comparing the spectra of each group, the positions of the strongest lines, and of the others in order, change regularly with the increase in the atomic mass of the metals, the lines being towards the less refrangible end of the spectrum.

It has already been pointed out that the change of refrangibility of light in any given substance may be attributed to a difference in the mass of the molecular agglomerations when actually radiating, and those that absorb the ultra-violet rays which give rise to the molecular complexities.

An effect similar to that of the change of refrangibility, according to Stokes' Law, from higher to lower frequency is known to take place in the spectrum of a gas by increase of pressure (Humphrey and Mohler, Astro-physical Journal, 1896). This phenomenon admits of an explanation 
in the same manner by the formation of large molecules.

The effect is proportional to

$\sqrt[3]{\text { atomic volume } \times}$ (linear expansion), when the (atomic volume) $=\frac{\text { atomic weight }}{\text { density }}$.

Further, from a consideration of the spectra of impurities, the amount of material present does not appear to be the important factor in producing the shift in the spectral lines, but rather the total pressure on the size of the molecular groups and not on the actual density of the vapour under consideration. An explanation of this nature has been offered by FitzGerald (see Larmor, Physical Review, May, 1901, p. 311). The inevitable outcome of this theory is that with sufficient pressure the spectrum of one substance may be so displaced as to correspond approximately with that of another, that is, the next in the series of elements to which it belongs, if the discharge could be taken at a sufficiently high pressure. ${ }^{1}$ Thus the spectrum of mercury may be converted into that of cadmium, that of cadmium into zinc, zine into magnesium, and so on. The obstacles, however, in the way of accomplishing this would be very great. The effect is one which the acute observer

1 With our present appliances it does not seem to be possible to accomplish this; but it is conceivable that such events may have taken place in Nature when the earth's crust was in a semi-molten státe. 


\section{THE ORIGIN OF LIFE}

will not pass over without due consideration. For most of the elements the displacement of the lines is about the same for all the lines. The elements copper, silver, and gold, however, behave in a very anomalous fashion, so that the change of the spectrum of gold to that of silver is by no means, in the present state of our knowledge, to be looked for as the result of these facts, but to be more akin to that of the transformation of uranium into helium.

The effect of these large molecular groups is to load, as it were, the electrons and thereby alter their free periods, but, as a matter of fact, what would really occur is that the period of rotation of the rotating electrons is lowered or increased by the approach of a corpuscle to it. The distance at which the corpuscles will remain attached to the atom is that which will determine the period of the internal rotating system.

Consequently, the increase of pressure in a gas favours the formation of these centres of attraction, and thereby a lowering of the frequency of the internal rotation in the atom.

In the case of phosphorus in gases at low pressure, however, the large molecules are formed by the discharge of electricity through the gas, whilst in order that the phosphorescence should be produced, the corpuscles must be made to pass through a certain distance under the attraction of the molecules before they can acquire the necessary velocity to do the work required.

If the gas in a vacuum tube be exposed to the 


\section{MODELS OF POSITIVE ION 325}

action of Becquerel rays, the pressure at which the ordinary after-glow appears may be much greater than in ordinary circumstances, that is, it may be produced at a pressure of $2 \mathrm{~mm}$. instead of $0.5 \mathrm{~mm}$. Here, of course, there is greater ionisation, and, as we shall show, the large molecules are much more easily formed; for the forms of radiation which excite phosphorescence in every case produce ionisation. The emanation from radium bromides glows more intensely when the gas in a vacuum is compressed (see Ramsay, Nature, August 13, 1903).

When a spark is taken in a dense liquid medium there is again a displacement of the spectrum, which, as Wisling and others have shown, is extensive and indefinable.

The model of fluorescence, consisting of a system of pellets, attached to a weightless string at equal intervals, suggested by Stokes, illustrates the change of refrangibility, but does not explain the fact that the fluorescent light is independent of the exciting light, and that fluorescence does not always occur at the border of an absorption band, as the model would require. ${ }^{1}$

${ }^{1}$ If we have a number of particles attached along a string and let them assume a form as in this figure,

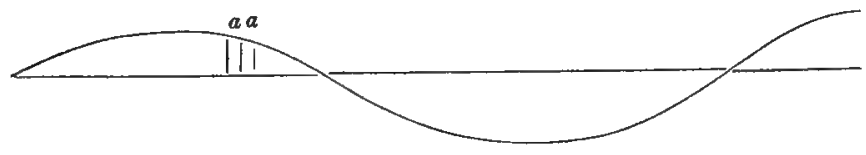

$m=$ mass of each particle. 
This analogy may be applied to the case of an electron which executes its rotations so rapidly Suppose $a=$ distance between two consecutive particles and $T$ the tension of the string. Then we have for the $n$th particle (see Preston's Theory of Light)

$$
m \frac{d \cdot r n}{d t^{2}}=T \cdot\left[\frac{y_{n+1}-y n}{a}\right]-T \cdot\left[\frac{y_{n}-y_{n}-1}{a}\right],
$$

adapting the notation of Preston, Theory of Light, p. 49.

Let $y_{n}=A \cos (w t-K x)$

$$
\begin{aligned}
-m w^{2} & \cos (w t-K x)=\frac{T}{a}\{\cos (w t-K(x+u))-2 \cos (w t-K n) \\
& +\cos (w t-K(n-u)) \\
= & \frac{2 T}{a}[\cos (w t-K n) \cos K a-\cos (w t-K n)] \\
= & \frac{-4 T}{a} \cos (w t-K n) \sin ^{2} \frac{K a}{2} .
\end{aligned}
$$

Hence $w^{2}=\frac{4 T}{m a} \sin ^{2} \frac{K a}{2}$.

Now if $v$ be the velocity of propagation of the wave,

$$
\frac{2 \pi v}{\lambda}=\frac{2 \pi}{T}=w=2 \sqrt{\frac{T}{m a}} \cdot \sin \left[\frac{K a}{2}\right]=\frac{2 v}{a} \sin \left(\frac{K a}{2}\right)
$$

when $v_{1}=$ velocity of propagation in a wire of the same density per unit length.

Hence if $=v=v_{1} \frac{\pi a}{\lambda}=\sin \left(\frac{K a}{2}\right)$,

we may write $y=\cos 2 \pi\left(\frac{t}{r}-\frac{x}{\lambda}\right) K=\frac{2 \pi}{\lambda}$.

$\therefore \frac{\pi a}{\lambda}=\sin \left(\frac{\pi a}{\lambda}\right)$, which means that $\left[\begin{array}{l}a \\ \lambda\end{array}\right]$ must be very small. Also

$$
\frac{v}{v_{1}}=\frac{\sin \left(\frac{\pi a}{\lambda}\right)}{\left(\frac{\pi a}{\lambda}\right)}=\frac{\sin \theta}{\theta} \text { when } \theta=\frac{\pi a}{\lambda} .
$$

If $\lambda=a$, then $v=0$. 
that it cannot communicate its energy to the æther--assuming that the æther has a molecular structure of great density, which is probably the case.

In such circumstances the energy of the electron will remain stored up in the part of the æther occupied by the atom and an envelope surrounding it.

At a collision, when another atom or molecule comes within the region of the envelope it will be We may write

$$
\begin{gathered}
v=v_{1}\left[1_{i}-\frac{1}{[3} \cdot\left(\frac{\pi a}{\lambda}\right)^{2}+\frac{1}{\left[\frac{5}{5}\right.}\left(\frac{\pi a}{\lambda}\right)^{4} \ldots .\right] \\
\therefore v=v_{1}+\frac{A}{\lambda^{2}}+\frac{B}{\lambda^{4}}+\frac{C}{\lambda^{6}}
\end{gathered}
$$

If $a$ is small compared to $\lambda$, all terms higher than the first must be negligible.

Sin $\cdot\left[\frac{\pi a}{\lambda}\right]$ is small; so that $\lambda$ is never equal to $\sqrt{\frac{\tau}{m a}}$, but must be a small fraction of this. Therefore it is only when $\lambda$ is large compared with $a$ that a wave is freely propagated.

If we write $\cos (w t-K x)$ in the form

$K=\frac{2 \pi}{\lambda}$.

$$
\cos \frac{2 \pi}{t}\left(\frac{t}{r}-\frac{x}{\lambda}\right)
$$

But the very highest value of $\omega$ requires that

$$
\begin{gathered}
\frac{K a}{2}=\frac{\pi}{2}, \text { hence } \\
\frac{\pi}{a}=\frac{2 \pi}{\lambda} \text { or } \lambda=2 a .
\end{gathered}
$$

Now for a wave in a uniform wire of the same tension

and

$$
\omega<\sqrt[2]{\frac{\bar{\tau}}{m a}}<\frac{2}{a} \sqrt{\frac{\tau}{a}}<\frac{2 v}{a}
$$

Hence $\lambda>\pi a$.

$$
\omega=\frac{2 \pi}{r}=\frac{2 \pi r}{\lambda} \text {. }
$$


affected in the same manner as if very rapid light waves were falling upon it, the result of which would be ionisation.

The glowing particles in a phosphorescent gas, and the emanation from thorium oxide, are instances of this state of things.

The ionisation caused by the phosphorescent molecules is due to collision, notwithstanding that these molecules move with a small velocity; but the manner in which the radiation occurs is of a different nature. The rotations of the electrons of the phosphorescent molecules and the thorium emanation can part with the energy, particularly at a collision.

This is just the phenomenon we have been in search of to account for the energy which ought to be frittered away by collisions. The energy accumulates in the atom, by repeated collisions, on the supposition that the vibrations are converted into higher and higher rotations of the electrons, till the amount of energy stored up is very great, when the atom then also parts with the energy by collision in the form of radiation.

If a corpuscle approaches an atom such as this, a Faraday tube extends between the two, regarding the tube as possessing the properties of a bundle of vortex flaments in an irrotationally moving liquid. When the rotating electrons, forming, as it were, a gyrostatic system in the atom, rotate with this immense velocity, the concentration of the vortex filaments along the axis of 
the tube is increased as the moment of momentum of the tube is increased, and therefore the pull between the atom and the corpuscle is also increased. Hence an atom with this great amount of internal rotational energy will be attracted towards a negatively electrified body, and behave, as it were, as a positive ion. If the corpuscle approaches very closely to the atom, it will disturb the motion of the electron and tend to slow down its motion.

The molecule, therefore, when it does not carry a free charge will merely radiate extremely penetrating waves of very high frequency. These, in fact, are the properties of the emanation.

As we have seen, the positive oxygen atom is one of the chief factors in the phenomena of phosphorescence. And the fact is also another instance of stored-up energy, except that here the corpuscle approaches much more closely to the rotating system of electrons in the atom.

The apparent paradox that the radiation is due, as the Zeeman effect requires, to motion of a negative charge on the electron, but that it is from the positive ion that radiation comes, is a point of no small importance in the theory of luminosity.

The argument for the existence of aggregates of molecules has thus been pursued and subjected to the test of experiment. Notable amongst these is the change of absorption in the fluorescent light during fluorescence. This phenomenon, which has 


\section{0 THE ORIGIN OF LIFE}

been described as the result of careful quantitative experiments, has led up to the theory of fluorescence herein put forward. The question has been discussed as to whether the change of absorption can be the result of the increased amplitudes of the vibrations of the fluorescent light, or whether it is due to the formation of free periods-not previously existing in the molecules which give rise to the absorption, but brought about by the conditions which excite fluorescence. The conclusion the author has arrived at is that the results of observation can only be explained by the formation of new molecules under the action of the violet or ultra-violet rays.

Investigations in various fields of research likewise show that a lowering in the refrangibility of the spectrum of a body is accompanied by the existence of heavier molecules.

The problem also presents itself to account for the growth of these molecular aggregates under the influence of light and other sources of fluorescence.

The experiments of Stokes and Becquerel on the destructive influence of the infra-red and less refrangible rays of the visible spectrum on phosphorescence indicate that the formation of the molecular aggregates depends somehow upon the wave-length of the exciting light. It also appears that the formation of these molecules depends upon the presence of nuclei; and it is suggested that their size would depend upon surface tension which keeps the group together, as substances which 


\section{MODELS OF POSITIVE ION $33^{\mathrm{I}}$}

destroy surface tension also destroy phosphorescence in a gas, whilst their size will depend upon the wave-length of the disturbance. An estimate can be made upon this supposition of the size of these molecules, and their diameter is calculated to be of the same order of magnitude as the wavelengths of light in the visible spectrum, whilst the building up and breaking down of these molecules is nothing else than a phenomenon of physical metabolism. 


\title{
CHAPTER XIX
}

\author{
MATTER AND "MIND-STUFF"
}

Conclusions-Résumé of what has been said-Biogen is matter in process of becoming or being transformed from free electricity into condensed electricity, called atoms-Universal nature of physical metabolism-Matter a mode of motionMotion a complex perception or mode of thought-Two modes of thought, our own minds and matter are concomitant-Difficulty solved by Idealism-Berkeley and Hume Their respective positions-Mind-stuff, how reconciled with Idealism-The permanent source of possible sensation.

THIs chapter closes for the present what we have to say upon this subject. As the development of the living organism we see to-day is but a part of that grand series of developments that Nature presents to us, in many degrees of time, of magnitude and of complexity, the evolution of biogen or lifestuff from the primordial substance we call electricity, whatever that may be, is but a part also of the process of evolution in the totality of things: organic and inorganic, physical and mental.

There is first of all the continuity of vital processes, extending from the most complex organisms 
to the simplest atoms and electrons. Simple, no doubt, only relatively to our own scale of being; for these in their turn may be highly complicated too. In this way, however, we have perceived the correlation of vital phenomena from the complex to the simple and from the simple to the complex.

The physical basis of life is in truth the necessary foundation of this correlation, or, at any rate, the principle which enables us to view it as a consistent and philosophic whole. By the artificial production of cells in protoplasmic substances we have been enabled to imitate some of the phenomena of nature, however different, however totally distinct the two may be. These types of artificial life with their metabolisms, their interactions with their surroundings; their growth, reproduction, decay and death, all point to the conclusion that by similar though more complex conditions the organisms which have survived in Nature through the most opposing circumstances were, in a like manner, also similarly formed.

The minute structure of these cells, and of cells generally, is the circumstance upon which subsequent development largely depends. On the function of the nucleus in its ultimate form, with its great potentialities, the development really rests. The monera must have a structure relatively simpler than that of other cells, and this most probably accounts for the fact that they have never properly developed.

This theory of the nucleus doubtless plays a 


\section{THE ORIGIN OF LIFE}

most important part in directing the development and subsequent history of the cell. If the nucleus has little potentiality of energy, or is lacking in marked characteristics, the cell makes little progress in development and, as in the case of the monera, remains inactive and unformed. Its simple nature therefore would be no indication whatsoever that such forms correspond in any way to the more primitive forms of life, any more than that such inferior types as still survive are necessarily in their present forms more like primitive organisms than the higher ones.

The types which are handed down to us are dependent for their properties chiefly upon those of the nucleus, and this in turn is dependent for its properties upon the peculiar type of dynamical configuration which the constituent particles of that nucleus have as in the course of ages now assumed.

Although we may agree with Weismann that acquired habits are not transmitted from one generation to another; there may be, and most probably is, a steady change slowly but surely taking place in the substances which constitute the nucleus of the cell.

It may take ages for any marked change to occur, and the evolution in biogen may be as slow as that in the elements and solar systems.

We have seen how it is that the asymmetric structure of living substance can be accounted for on the same hypothesis, of spiral configura- 


\section{MATTER AND “MIND-STUFF” 335}

tions of millions of electrons, somewhat in the manner of spiral nebulæ.

Pasteur's conclusion that living matter is invariably associated with an asymmetric structure is undoubted, and lends further support to the views herein expressed. But it gives us very little help towards the question of spontaneous generation at the present day.

Upon the point of physical metabolism and molecular aggregation the facts show how widespread the phenomena are, and indicate how it is only a question of degree, as the phenomena vary from the simplest to the most complex types.

Hence the mechanism of life is a process which in its nature resembles that of the artificial forms or cells we have described, and affords a sufficiently close analogy with which we may frame hypotheses as to the actual dynamical systems involved. The metabolisms, as it is shown, are a necessary consequence of the properties of the nuclear substance, this substance being the seat and the source of complex disturbances. The question as to how the metabolism is started and kept up is thus equivalent to the great question as to how the nuclear substance or biogen can afford the directing power and internal energy which we know it to possess. We have shown from the analogous cases of artificial forms that the continuous process of change, the catalytic and metabolic actions of the 


\section{THE ORIGIN OF LIFE}

cell, its structure, the apparently directive force, the enormous store of energy which it contains, all result from the peculiar constitution and nature of the nucleus, and that the biogen or nuclear substance is as distinct in its constitution as inert matter and nothing more or less than matter in the process of becoming.

This theory of biogen forms a link between purely electrical and purely material phenomena. It is an attempt to attribute the properties of biogen to a purely dynamical or electrodynamical source, and to show that these phenomena are as much a part of the great system of the Universe as the simplest of physical effects.

The analogous phenomena of physical metabolism in the case of radio-active, phosphorescent and Iuminous bodies generally broadens the field of vision from which the subject of life should be viewed.

In every part of Nature that same process of building up and breaking down of molecules occurs, and, reasoning from analogy once more, it would appear that the phenomena which we witness in this our miniature planet take place also in somewhat similar ways in other and remote worlds where like forces play their part.

It is not to be expected that in those other planets and other worlds precisely the same types of life are to be found as we see around us here to-day. The conditions cannot have been or be the same, and therefore variations of other 
types have doubtless become adapted to them. In all these various types, however, we should expect to find the operation of like forces; the production of such organic forms as we are familiar with being, there as well as here, the products of forces which are equally subservient to the same laws.

But now, granting all this; assuming as we have assumed, and think we have had a right to assume, that all the phenomena of organic as well as of inorganic nature are alike the manifestations of the great principles of action and reaction; of conservation of energy and possibly of substance too, how much farther do we thus get towards the comprehension of the great system itself?

So much have we said of molecules, of atoms, and of electrons; but what then are these?

If matter and life can be reduced to the configurations and motions of electrons, what then is the electron?

If we regard it as a rotational strain in the æther, that all-pervading medium we have alluded to so often, that may account for its physical properties; but surely not for all of them.

We can reduce matter to motion, and what do we know of motion save that it is a complex perception or a mode of thought? The student of science finds that the phenomena of mind are largely, if not altogether, dependent upon the phenomena of matter; or, more accurately, upon the phenomena of electrons or of æther, and these 


\section{$33^{8}$ THE ORIGIN OF LIFE}

in time are nothing more than modes of motion and therefore nothing more than perceptions. For of motion we know nothing except that it represents a continuous change of certain perceptions in their relations with those of space and time.

Hence one form of thought-our own mindsruns parallel to and is concomitant with another form of thought, perhaps more permanent-though that we cannot say-which we call matter, electricity or æther. And it all resolves itself into mind perceiving mind.

Esse est percipi. We know nothing of the world, any more than of ourselves, except as perceptions in our own minds.

We know there are other minds, but only as perceptions in our own. We know that by complex, extremely complex, aggregations of these perceptions or ideas we call atoms of matter selfconscious units like ourselves arise. To us they seem to share like properties, but they are mere spirits like ourselves.

That such self-conscious units can so result from the combination of the perceptions we call atoms, leads us to suppose that these too in a sense possess a consciousness in some dim remote degree. For that reason we regard matter, or the electrons of which matter is composed, as mindstuff. The atoms are nothing more than ideas: and the higher forms of mind which we generally call by that name are merely aggregations of ideas, and in the limit, of ideas such as these. 
Such conscious units or ideas aggregate and disintegrate: they are of necessity ideas in some mind or else we should find ourselves landed in mere negation as Hume did. To him the Universe was merely an idea in his own mind, and perhaps also in the minds of all normally constituted beings. But that permanency which we attribute to the perception which we call the Universe, as distinct from the perception which we call ourselves, would have no basis. The difference between Hume and the founder of Modern Idealism then is that whereas Berkeley regarded the Universe as a system of ideas in the Divine, the all-pervading Mind, ${ }^{1}$ Hume regarded it merely as a series of perceptions in his own mind, and perhaps in the minds of others similarly disposed: like so many copies of the same book. But if all these minds ceased to be, the Universe likewise would cease with it. In a sense this is quite true, because the Universe, as they perceived it, would cease to be. But students of physics at the present day would scarcely deny that those ideas which we do not see, or hear, or feel, but think about and reason about, namely, molecules, atoms and electrons, will continue to occupy those relations amongst themselves which we now attribute to them quite independently of

1 Strictly speaking Berkeley did not regard us and our perceptions as falling within the Divine mind, though be regarded us as created by God and our perceptions as directly caused by His volition. 


\section{$34^{\circ}$ THE ORIGIN OF LIFE}

ourselves. There is the innate feeling, not to say conviction, that something takes place, which, acting in concert with ourselves, produces the sensations we perceive, and that that something will go on independently of mankind for all ages to come. We will not call that something " a permanent possibility of sensation," as John Stuart Mill did, we should prefer to call it "a permanent source of possible sensation." That permanent source may be a system of ideas or perceptions, as no doubt they must be perceptions in some mind other than our own if they are entities at all. That permanent source of possible sensation is no doubt a perception in some mind, and that mind is the permanent reality. That permanent source is therefore, although unknowable to us, knowable as perception in some mind.

This was the aspect of the question taken up by Berkeley or, in the form in which we have presented it, more clearly by Lotze. This absolute mind is no doubt self-conscious, and we are encountered with the serious difficulty that selfconscious units like ourselves should form part of this self-conscious whole; that is, that there would be apparently selves within selves. Certain schools of metaphysicians would maintain this to be an impossibility, and Dr. McTaggart, who represents this school in England, would deny self-consciousness to the whole, and grant it only to the parts; for this reason, that there cannot be selves within selves, and that as we know some of the parts to be self-conscious, the whole cannot be. We should 


\section{MATTER AND “MIND-STUFF” 34I}

hold, on the other hand, that the separate selfconscious units are merely particular modes of thought in the Divine mind and that this selfconsciousness is different from that of its constituents. ${ }^{1}$ But the reader had better consult Dr. McTaggart himself upon this point (Studies in Hegelian Cosmology, by J. Ellis McTaggart).

The questions thus raised as to the possibility of one self being within another, or of one mind being within another mind, is no doubt a difficult one. Yet what do we mean by "within"? The idea of space must not delude us. Two material bodies cannot occupy the same space; although two atoms might occupy the same space (see Clerk Maxwell, Collected Works, "Atom") just as two wave disturbances can pass through the same space without affecting each other.

Space, however, must not enter into the question, for the possibility of selves within selves does not really involve the idea of selves in space. There does not appear to be any reason why if the universe or totality of things be self-conscious the constituent units, which are also self-conscious like ourselves, should be regarded as "within" and not merely as related to or influenced by it.

Dr. McTaggart, however, regards the totality of

1 This view, though it appears to us to be the most consistent, is not, strictly speaking, Berkeley's view nor Lotze's ; the latter did hold that we are parts of the Absolute, but he would not have reduced us and the whole Universe as we have done to a system of ideas in the Divine mind. 


\section{THE ORIGIN OF LIFE}

things as a community of selves, as, for instance, a college or other similar society. To him the unity is merely in the conception or idea of the society. It seems quite conceivable to us somehow that there should be one self as a nucleus amongst the many selves and one that would act and react on them, so that if almost infinitely superior to the rest it should act as the unifying principle between them. This, we think, is possible without having recourse to the apparently self-contradictory notion of selves within selves.

On this view the constituent selves are merely "reflections," so to speak, of the original; like so many images of the same man in a number of mirrors; or of the multiple images in any one of them. It cannot be said that one is within the other, although they all reflect and are dependent on the central figure, which constitutes the unifying principle between them all.

So also is it with the world of mind. Those dim self-conscious units, ourselves, can scarcely be units of very much importance to the universe as a whole. The conviction is deeply rooted in our minds that such units are insignificant compared with that greater and far more important unit which unites the whole. Nay, the very existence of that permanent source of possible sensation which we call the universe on idealistic principles thus involves a universal mind.

If we denied the reality of that permanent source of possibility of sensation then as idealists, 


\section{MATTER AND “MIND-STUFF" 343}

once more we should have to accept Dr. McTaggart's conclusion, and perhaps also regard this unity which binds the units as fictitious as "the empty shadow of our own mind's throwing," although in the importance which it attaches to the self it stands as the Ptolemaic conception of the Universe.

There is a unity and plurality in all things, and as we come to consider the nature of consciousness we find that whatever plurality-our personality-may involve, unity is the striking feature of the phenomenon. However much we may try to localise it, it is found to elude the attempt; and for that reason it has been regarded by so many of the greatest thinkers as something which transcends both space and time, and will outlive them.

We are not in a position to say that this view is not correct, that such self-conscious units should not outlive "the wreck of matter and the crush of worlds." This is quite possible whether the totality has also a self-conscious unifying principle or not.

In the earlier portion of this work, however, we adduced physical reasons for the possibility that some stable configuration of units of mind-stuff with which consciousness seems to be associated may survive our ordinary mortal coil. But these too in time, however long that time may be, will most probably become disintegrated, and it is possible that consciousness would become gradually dimmed and in turn cease to be. 


\section{THE ORIGIN OF LIFE}

That unity of consciousness when viewed from a psychological standpoint may be found to be a mere delusion, owing to the limitations of our faculties and to the fact that its unity is merely apparent, that it is only a number of effects superposed, the apparent unity being the result.

Many metaphysicians will not admit this, because of the nature which they suppose selfconsciousness itself to be. All science can do is to suggest that certain types of aggregation with which consciousness is particularly associated may survive the bodily organism, but from a physical point of view such aggregation will in the course of time, however long that time may be, in turn break up, with the result that we shall find that

"These our actors,

As I foretold you, were all spirits and

Are melted into air, into thin air :

And, like the baseless fabric of this vision, The cloud-capp'd towers, the gorgeous palaces,

The solemn temples, the great globe itself,

Yea all which it inherit, shall dissolve

And, like this insubstantial pageant faded,

Leave not a rack behind."

"The great globe itself, and all which it inherit, shall dissolve ... and leave not a rack behind." This is the body and the soul of Hume. But all "the baseless fabric of this vision" is just what we maintain is a thought, perhaps only a passing thought, in that Mind that Is. The conviction remains that there is something substantial that will outlive it all. This is the question of all 
questions, the theme of themes that the greatest of intellects have always delighted to dwell upon.

Huxley to some extent, of course, was a follower of Hume. And Tyndall, if his studies had gone far enough, would, we think, have been a Humist too. We owe much to Hume for having cleared the atmosphere. And yet "this insubstantial pageant," a series of perceptions, must be in something or some things that can perceive.

That seems to have been Hume's error. The perceptions imply something that perceives and "the baseless fabric of this vision," though baseless in so far as it is nothing more than a series of perceptions, yet bears testimony to the percipient mind.

We may regard nature as perceptions, bearing a certain and invariable relationship to each other, the mind-stuff of which it is composed being in fact perception in the universal mind which constitutes the "great ocean of thought" in which we live and move and have our being. The eternal laws which govern it, the universal rhythm which prevails throughout its ever-changing forms : the allpervading harmony that operates throughout it, from the infinitely great to the infinitely small, and in the future as well as in the past, enables us to perceive more clearly than we have ever done before the universal principles that govern, that regulate, or that constitute that intelligence, and which enables us to perceive that Nature is only a perception or a mode of mind. This was Berkeley's 


\section{THE ORIGIN OF LIFE}

philosophy throughout, and in a modified form it is the view of many modern idealists. The great universe into which we shall ultimately, consciously or unconsciously, be resolved, is mind, and nothing more nor less than mind.

Here we reach the threshold of the Temple of Knowledge, where, having offered sacrifice, if we may put it so, we may enter and kneel before the shrine of truth: where all Nature from that infinitude of :ons past ere matter knew itself, to that infinitude of æons yet to come, when it will know itself no longer, appears but as a passing thought in that Mind that Is. This is Idealism in its most comprehensive form.

As Huxley has remarked," "It is worth any amount of trouble to comprehend the exact nature of the argument by which Berkeley arrived at his results, and to know by one's own knowledge the great truth which he discovered-that the honest and rigorous following up of the argument which leads us to 'materialism' inevitably carries us beyond it." In the Dialogues between Hylas and Philonous we find this great conception of the world as a system of perceptions most charmingly and most lucidly put forward:

"See, Hylas, the water of yonder fountain," said Philonous, "how it is forced upwards in a round column to a certain height at which it breaks and then descends to the basin from which it rose, its ascent as well as its descent being governed by the 1 "Hume, with helps to the study of Berkeley." 
same law or principle of gravitation. So, also, the same reasons which lead us to scepticism, when followed up, bring us back to common sense." 1

But here we may leave the subject, where so many others, like ourselves, have done before.

To dwell upon these thoughts may give us what Mr. Balfour has described as that "intense intellectual gratification" that satisfies our highest nature. The noblest aspirations, the strongest feelings of cosmic emotion of infinitude of thought, alike suggest by the association of ideas that which is permanent and everlasting. Like the loftiest passions which are aroused in the most refined and highly-strung temperaments from the complex sensations, produced by the harmony and rhythm and the majestic combinations of tone of a great orchestra, to which the inmost depths of the soul resounds, the sentiments, passions and emotions akin to eternal love are responded to, though to a far greater degree when in the intellectually intense the unity and relationship of things is once perceived with force, with clearness, and with imagination.

But, alas! the object of philosophy after all is to construct the great edifice of human knowledge that we might view it whole. Too careful we cannot be in fixing the practical limitations of that knowledge and of distinguishing that which is unknowable to us from that which is unknown or imaginary

1 The principles are more fully worked out in the Essay on A New Theory of Vision and in a Treatise on the Principles of Human Knowledge. 


\section{$34^{8}$ THE ORIGIN OF LIFE}

or hypothetical, and these still more so from that which we already know to be. The limits must not extend too far, neither should they be too narrow. It is by observation and experiment that real progress is to be attained. Idealism does not affect the question, although Idealism be true.

Each newly acquired fact, though only an idea, must be such that it may safely be deposited in its place like a brick, to stand for all time as a part and a support of the great fabric of ideas which generations yet to come will help to build, but which it may never be our lot to accomplish. The ideal of research is to secure at each successive step that which will remain, independently of all place and time, as something permanent and something real, something for those who are to continue our work to take their stand upon, as firmly as on the solid ground of nature that we trod, though it is only an idea too, in their endeavour to reach those heights of Olympus and Parnassus from which Humanity, seeing the relations of things, may yet perceive with greater clearness the pure light of Truth. The scaffolding of our hypotheses may then be removed while the stone and marble will remain in their architectural beauty of form for all ages to behold, not merely as the symbol, but as the idea of what IS. 


\section{INDEX}

Abet Spatanzani, 5

Abiogenesis, 4

Abney, Sir Wm., 243

Absorption and fluorescence, 236

Aggregation, 251, 266, 270, 278, 283

Aitken, 270

Àngström, 259

Aristotle, 6, 9

Arnold, Matthew, 307

Artificial cells and artificial life, 113

Athenaum, 150

Aurelins, Marcus, 24

Balfour, Right Hon. A. J., 83, 211, 346

Balmer's Law, 321

Bastian, Charlton, 6, 28, 161, 163, $175,197,205$

Bathybiue, 169

Becquerel, 241, 266, 330

Berkeley, 339

Bidwell, Shelford, 270

Biogen, 155, 192, 193, 222, 223

Biogenesis, 4

Boltwood, 124

Boltzmann, 262, 293

Bon, Le, 125

Bouillon, 92

Boveri, 136

Brewster, Sir David, 43

Buffon, 4, 5

Buitschli, 106, 145, 175

Calorescence, 267

Camichael, 245, 246

Catalytic action, 6

Cavendish Laboratory, 98

Cavendish, Professor, 305

Cells, artificial, 113, 132

Cells, foam, 117

Chronicle, Daily, 113

Classification of living types, 45
Clerk Maxwell, 37, 81, 143, 163, 224, $262,293,305,341$

Clifford, 21

Consciousness, 20, 21

Continuity of vital processes, 25

Copernicus, 43

Correlation of vital phenomena, 61

Cosmoson, 169, 176

Cotton, 249

Creator, 36

Crookes, Sir Wm., 236

Crosse, 182

Crystals of glycerine, 91

Cyanogen, 14, 15, 95, 96, 181

Cyclic process, 27, 104, 105

Daily Chronicle, 113

Darwinian theory, Fechner and the, 33

Descent of living protoplasm, 172

Dewar, Sir James, 263

Dubois, R., 98, 123, 124, 175

Ellectrictan, 73

Electric theory of matter, 302

Empedocles, 9

Enzymes, 73

FARADAY, 12, 305, 328

Father Needham, 4, 5

Fechner, G. T., 33, 176

Fermentation, life a series of, 6

First cause, various meaningsiof, 36

Fisher, 144

FitzGerald, 203, 204, 297, 323

Fluorescence, 232, 237

Fluorescence and metabolism, 71

Flux, vital, 134

Foam cells, 117

Fortnightly Review, vii

Gladdstone, J. H., 91

Gouy, 257

Guillaume, 249 
HaECKeL, 54, 152, 153, 157, 184, 210

Harvey, 9

Helmholtz, 167, 270

Hemsalech, 320

Henneguy, 122

Herbert Spencer, 28, 211

Herrera, 175

Herschel, Sir Wm., 232

Hertz, 69

Hippocrates, 8, 65

Howard, Newman, 150

Hume, 339, 344

Humphrey, 322

Huxley, 4, 5, 28, 31, 77, 108, 344, 346

JANSEN, 259

Japp, 198, 199, 201

Kart Ptarson, 203

Karyokinesis, 136, 146, 218

Kauffmann, 303

Kelvin, Lord, 167, 292, 297

Kepler, 43

Kirchoff, 70, 249, 250, 255

Künstler, 175

LARMOR, 302, 323

Laveran, 122

Le Bon, 125

Leduc, 105, 175

Lee, Frederic S., 9

Lehmann, 117, 118, 145, 175

Lewis, History of Philosophy, 183

Life, a specialised mode of motion, 6

Life-activity, 166

Life, artificial, 113

Life, definition of, 48,49

Life-stuff, 53

Lippmann, 264

Living protoplasm, 172

Lodge, Sir Oliver, $147,149,153,164$,

Loeb, 127, 128

Lorenz, 260, 302

Luminosity, 65

\section{MoTaggati, 341}

Malebranche, 36

Marcus Aurelius, 24

Matthew Arnold, 307

Max Sehultze, 135

Maxwell, Clerk, 37, 81, 143, 163, 224, $262,293,305,341$

Mechanism of life, 213, 231

Merritt, Nichols and, 245, 246

Metabolism, 7, 26, 73, 139, 232, 248, 250

Micellæ, 111

Mill, John Stuart, 340

Mind-stuff, 19, 21, 23, 79, 332
Miracles, 54

Models of positive ions, 299, 308, 315

Models of radio-active and phosphorescent molecules, 296

Mohler, 322

Molecular aggregation, 251, 266, 278, 283

Molecular concentration, 279

Molecules luminous in gases, 285, 287

Monera, 152, 157, 184, 185

Monthly Review, 74

Moore, 235

Motion, life, a specialised mode of, 6

Müller, Max, 42

Müller, Johannes, 78

NAEGELI, 54, 111

Natural cells, 132

Nature, 113

Nebular theory, 48

Needham, 4, 5

Newall, 259

Newman Howard, 150

Nichols and Merritt, 245, 246

Nucleus as a source of energy, 153

Nucleus, atomic, 308, 315

Nucleus, function of, in molecular aggregation, 268

OPTICAL ACTIVITY, 200

Pasteur, 5, 108, 185, 193, 202, 305

Pearson, Karl, 203

Pflüger, 14, 15, 95, 97, 167, 184, 221, 222

Phosphorescence and molecular aggregation, 278,283

Phosphorescence and radio-activity, 292

Physical basis of life, 80

Physical metabolism, 230, 232

Plato, 24, 79

Positive ions, marvels of, 299, 308

Poynting, 69

Preston, 201, 326

Preyer, 169, 170, 175, 176, 178

Protoplasm, 26, 172

QUiNoKe, 116, 145, 173, 175

RAdration, 14, 28

Radiation and molecular aggregation, 251

Radio-activity, 292

Radium and culture media, 90

Rainey, 174

Ramage, 322 


\section{INDEX}

Ramsay, Sir William, 119, 126, 325

Ramsay and Soddy, 124

Redi, 4

Religion and morality, 26, 162

Rhythm, 151

Richards, 270

Richter, 169, 170, 176

Rudge, 128

SACHS, 102

Saleeby, C. W., 198

Schleiden, 157

Schnell, 107, 110, 175

Schrön, 114, 158, 169

Schultze, Max, 135

Schuster, 259, 320

Schwann, 157

Shelford Bidwell, 270

Soddy, 124, 162

Spallanzani, Abbé, 5

Spencer, Herbert, 28, 211

Spontaneous generation, 3, 191

Stewart, Balfour, 249, 250, 255

Stokes, 70, 232, 233, 242, 244, 247, $266,267,330$

Stoney, G. Johnstone, 290

Structural organic synthesis, 204

Structure of cells, 132

Strutt, 124

Surface tension, 270
Sûrruta, 9

Survival of living proteid, 47

Tension, sURFACP, 270

Theism, 190

Thomson, J. Arthur, 196

Thomson, J. J., 37, 260, 303

Tommasina, 88

Townsend, J. S., 286

Tyndall, $5,24,38,108,185,193,267$, 305,344

VACUOLIDES, 98

Van't Hoff, 202

Verworn, 9, 95, 137, 138, 140, 141, $155,176,184$

Virchow, 163

Vitality, processes which constitute, 26,27

WATSON, 262

Watts-Dunton, 151

Wiedemann, 249

Weismann, 56, 193

Wilson, C. T. R., 69, 270

YAJURVEDA, 9

ZmemaN, 303, 329

THE END

R. CLAY AND SONS, LTD., BREAD ST. HILL, E.C., AND BUNGAY, SUFFOLK. 




